\title{
Einfluss von Herkunft und Alter auf Schlachtkörper- und Fleischqualitätsmerkmale von Puten
}

\author{
Dissertation \\ zur Erlangung des Doktorgrades \\ der Fakultät für Agrarwissenschaften \\ der Georg-August-Universität Göttingen
}

\author{
vorgelegt von \\ Joachim Riegel \\ geboren in Bremen
}

Göttingen, 01.02.2007 
D 7

1. Referent: Prof. Dr. M. Wicke

2. Korreferent: Prof. Dr. Dr. M. Gauly

Tag der mündlichen Prüfung: 01.02.2007 


\section{Inhaltsverzeichnis}

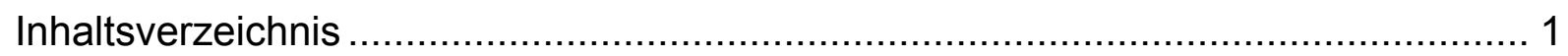

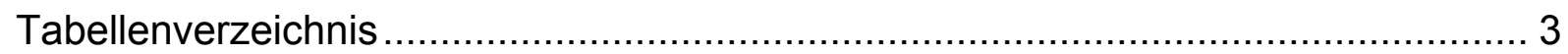

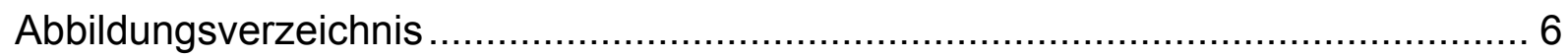

Abkürzungsverzeichnis............................................................................. 7

1 Einleitung und Zielsetzung ………................................................... 9

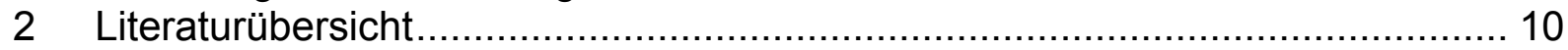

$2.1 \quad$ Allgemeines zur Putenproduktion ....................................................... 10

2.2 Struktur, Bildung und Funktion der Muskulatur ................................... 11

2.3 Postmortale Veränderungen der Muskulatur ........................................ 16

2.4 Fleischbeschaffenheitsmerkmale bei Puten ........................................ 17

2.4.1 Rohnährstoffe und Trockenmassegehalte ..................................... 17

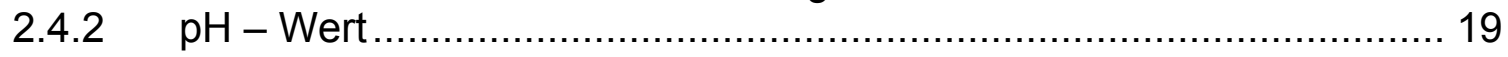

2.4.3 Leitfähigkeitswert .................................................................. 22

2.4.4 Helligkeits- und Farbwerte....................................................... 23

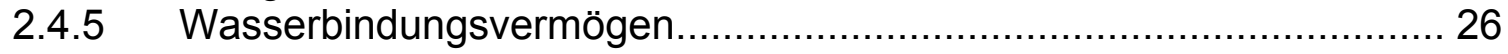

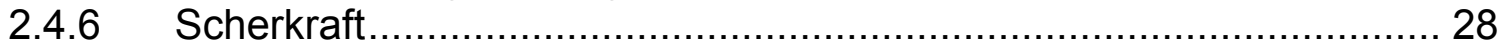

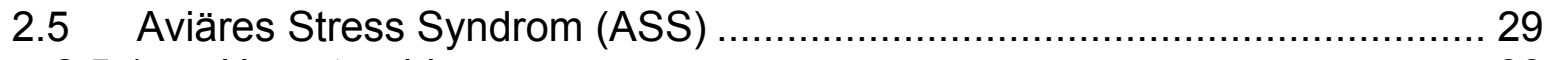

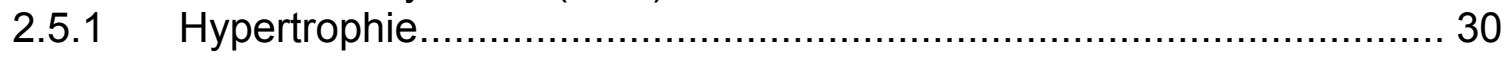

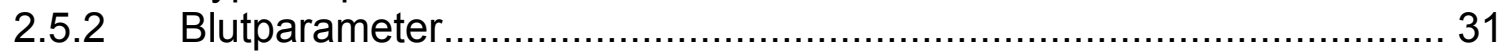

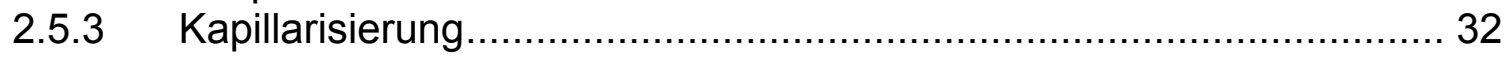

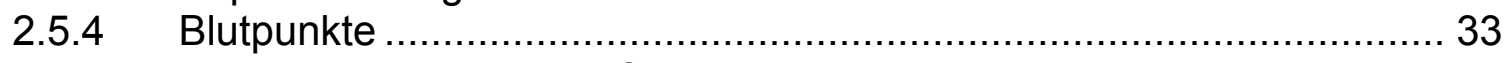

2.5.5 Myopathien und Muskelfaserdegenerationen................................... 34

2.5.6 PSE-Inzidenzen und Transportverluste........................................ 37

2.6 Schlussfolgerung aus der Literatur ................................................. 40

3 Material und Methoden ......................................................................... 41

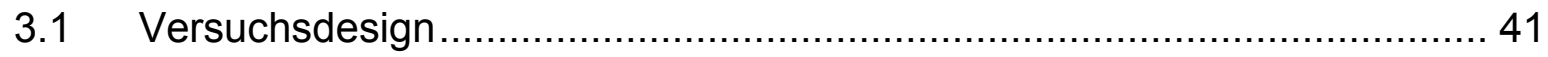

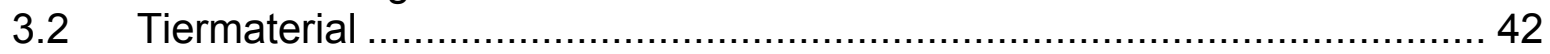

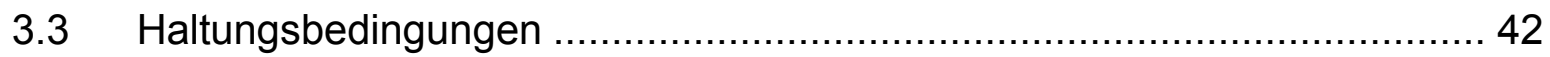

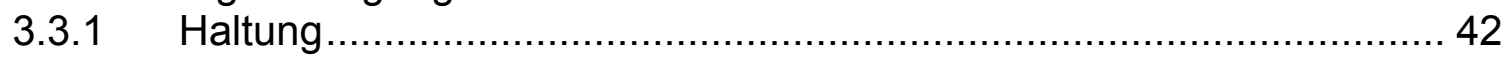

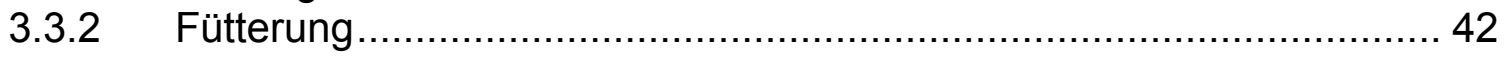

3.4 Probengewinnung und Lagerung …………................................... 43

3.5 Erhebung von Schlachtkörper- und Fleischbeschaffenheitsmerkmalen ..... 45

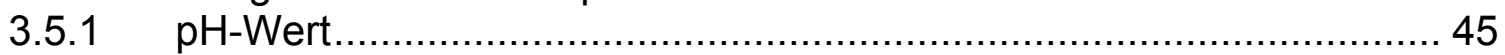

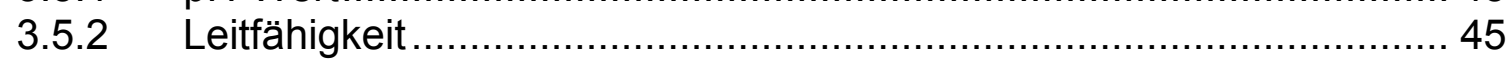

3.5.3 Helligkeits- und Farbwerte........................................................ 45

3.5.4 Rohnährstoffe und Trockenmasse ............................................. 45

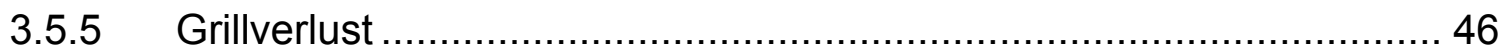

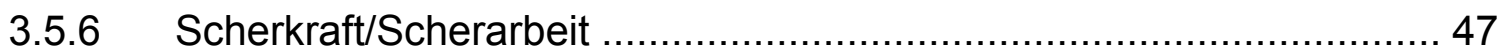

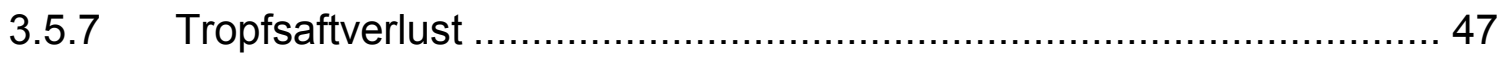

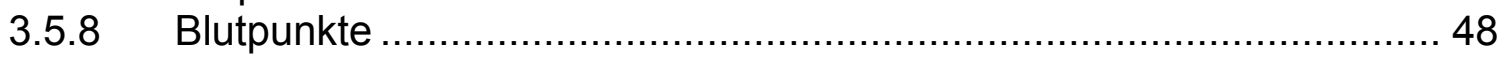

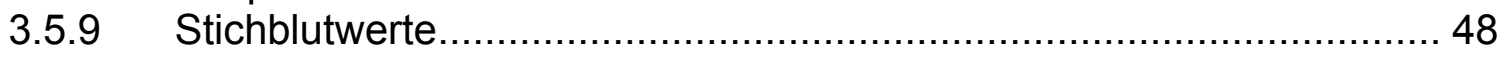

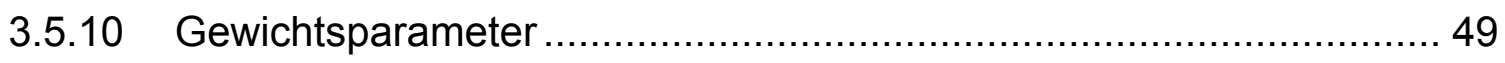

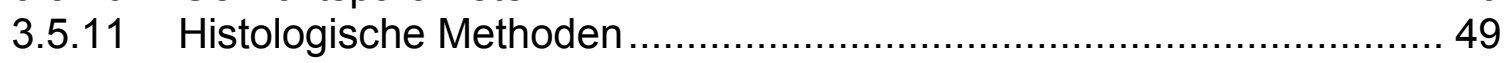

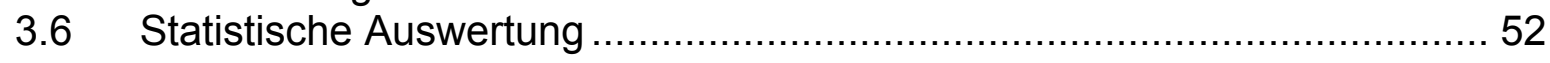

$4 \quad$ Ergebnisse .................................................................................... 53

4.1 Schlachtkörper- und Fleischbeschaffenheitsmerkmale in Abhängigkeit vom

Alter aller Versuchstiere .................................................................. 53

4.2 Schlachtkörper- und Fleischbeschaffenheitsmerkmale in Abhängigkeit vom

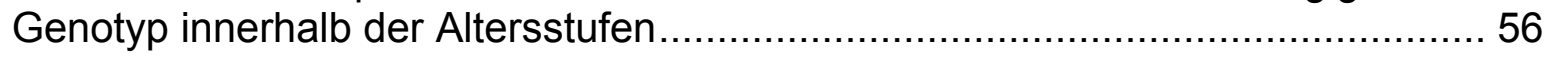




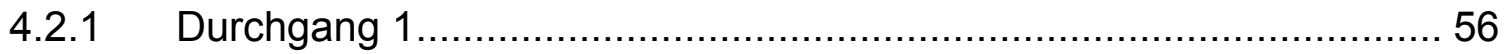

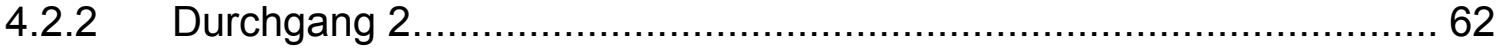

4.3 Korrelationen der Merkmale der Grundgesamtheit aller Versuchstiere ..... 70

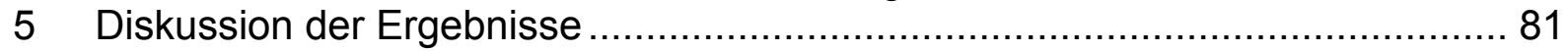

5.1 Einfluss des Alters auf Schlachtkörper- und

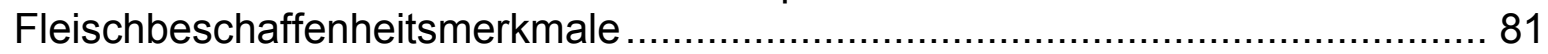

5.1.1 Gewichtsparameter und Inhaltstoffe des Brustmuskels .................... 81

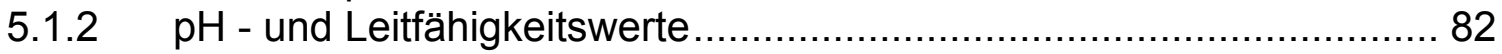

5.1.3 Helligkeits- und Farbwerte ....................................................... 83

5.1.4 Physikalische Fleischqualitätsparameter ………………............... 83

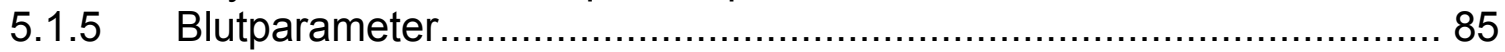

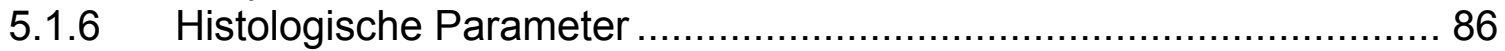

$5.2 \quad$ Einfluss des Genotyps auf Schlachtkörper- und
Fleischbeschaffenheitsmerkmale

5.2.1 Durchgang 1: B.U.T. BIG 6 vs. Kelly's BBB ................................ 91

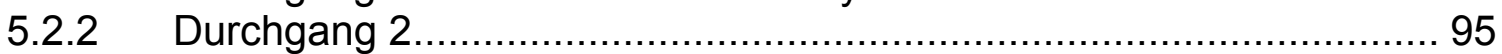

5.3 PSE - Inzidenz der untersuchten Probanden ....................................103

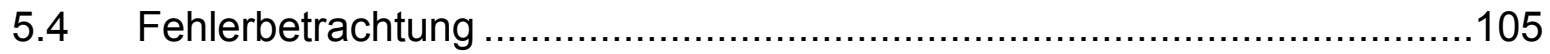

$6 \quad$ Zusammenfassung und Schlussfolgerung ..............................................107

$7 \quad$ Summary and Results .........................................................................110

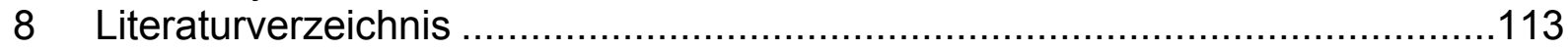




\section{Tabellenverzeichnis}

Tab. 1: Bezeichnungen und Eigenschaften der verschiedenen Muskelfasertypen ... 12 Tab. 2: Durchschnittliche Zusammensetzung des Skelettmuskels von Säugetieren (\% d. Frischmasse; SIELAFF,1996). 18

Tab. 3: Durchschnittliche chemische Zusammensetzung von Putenfleisch (SIELAFF, 1996)

Tab. 4: Durchschnittliche chemische Zusammensetzung von Putenfleisch ((1)

SLOWINSKI und STOLARSKI, 1998; (2) WERLEIN und WATKINSON, 1998) ....... 18

Tab. 5: pH - Werte von Putenbrustmuskeln zu verschiedenen postmortalen

Messzeitpunkten.

Tab. 6: Schlachtkörperzusammensetzung, CK-Aktivität und histometrische

Parameter in Abhängigkeit vom pH - Wert 20 min. p.m. bei Puten (WICKE et al. (2000a)

Tab. 7: pH-Wert und Leitfähigkeit $(\mathrm{mS} / \mathrm{cm})$ in schnell $(\mathrm{pH}<6,220 \mathrm{~min}$ p.m.) und langsam $(\mathrm{pH}>6,5)$ glycolysierender Putenbrustmuskulatur $(\mathrm{n}=80$, HAHN et al. 2001 $a, b)$

Tab. 8: Entwicklung der $L^{*}$ - Werte von PSE - freiem Putenbrustfleisch über einen Zeitraum von 9 Tagen (Mittelwert, Standardfehler, Minimum, Maximum, $n=64$;

Rammouz et al. 2004)

Tab. 9: Farbmesswerte $\left(\mathrm{L}^{*}, \mathrm{a}^{*}, \mathrm{~b}^{*}\right)$ in schnell $(\mathrm{pH}<6,2)$ und langsam $(\mathrm{pH}>6,5)$

glycolysierender Putenbrustmuskulatur ( $n=80$, HAHN et al. $2001 \mathrm{a}, \mathrm{b})$

Tab. 10: Tropfsaftverlustentwicklung (in \%) bei PSE - freien Puten über einen

Zeitraum von 9 Tagen (Mittelwert, Standardfehler, Minimum, Maximum, $n=64$;

RAMMOUZ et al. 2004)

Tab. 11 Einteilung von Hühnerbrustfleisch in PSE-, Normal-, und DFD - Fleisch 6 -

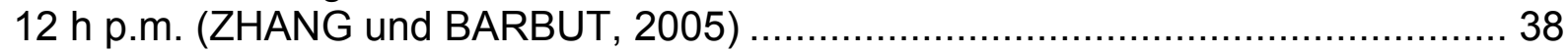

Tab. 12: Inhaltstoffe und Energiegehalte der Futtermittel des ersten Durchgangs ... 42

Tab. 13: Inhaltstoffe und Energiegehalte der Futtermittel des zweiten Durchgangs. 43

Tab. 14: Gewichtsparameter von Puten in zwei Altersstufen (LSM \pm SE) ............... 53

Tab. 15: Inhaltstoffe und Trockenmassegehalte des M.pect.superfic. von Puten in

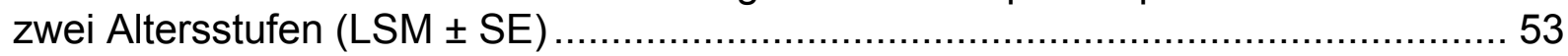

Tab. 16: pH-, Leitfähigkeits- und $L^{*}, a^{*}, b^{*}$-Werte des M.pect.superfic. von Puten in

zwei Altersstufen (LSM \pm SE)

Tab. 17: Parameter der Fleischqualität des M.pect.superfic. sowie CK - Aktivität und

Laktatgehalt im Stichblut von Puten in zwei Altersstufen (LSM \pm SE) ...................5 54

Tab. 18: Histologische Parameter des M.pect.superfic. von Puten in zwei Altersstufen $(\mathrm{LSM} \pm \mathrm{SE})$.

Tab. 19: Gewichtsparameter des M.pect.superfic. der Herkünfte B.U.T. BIG 6 und Kelly's BBB im Alter von 12 Wochen (MW \pm SE)

Tab. 20: Gewichtsparameter des M.pect.superfic. der Herkünfte B.U.T. BIG 6 und

Kelly's BBB im Alter von 22 Wochen (MW \pm SE) .

Tab. 21: Inhaltsstoffe und Trockenmassegehalte des M.pect.superfic. des ersten Durchgangs (MW $\pm \mathrm{SE})$.....

Tab. 22: Inhaltstoffe und Trockenmassegehalte des M.pect.superfic. des ersten Durchgangs (MW $\pm \mathrm{SE}$ ).

Tab. 23: pH-, LF- und L*a*b*-Werte des M.pect.superfic. der Herkünfte BIG 6 und BBB im Alter von 12 Wochen (MW \pm SE).

Tab. 24: pH-, LF- und L*a*b*-Werte des M.pect.superfic. der Herkünfte BIG 6 und BBB im Alter von 22 Wochen (MW \pm SE). 
Tab. 25: Parameter der Fleischqualität des M.pect.superfic. sowie CK - Aktivität und Laktatgehalt der Herkünfte BIG 6 und BBB im Alter von 12 Wochen (MW \pm SE) ..... 59 Tab. 26: Parameter der Fleischqualität des M.pect.superfic. sowie CK - Aktivität und Laktatgehalt im Stichblut der Herkünfte BIG 6 und BBB im Alter von 22 Wochen (MW \pm SE).

Tab. 27: Histologische Parameter des M.pect.superfic. der Herkünfte BIG 6 und BBB im Alter von 12 Wochen (MW \pm SE).

Tab. 28: Histologische Parameter des M.pect.superfic. der Herkünfte BIG 6 und BBB im Alter von 22 Wochen (MW \pm SE) .

Tab. 29: Gewichtsparameter der Brustmuskulatur und des M.pect.superfic. der

Herkünfte BIG 6, Wrolstad und Super Mini im Alter von 12 Wochen (MW \pm SE) . 62

Tab. 30: Trockenmassegehalte und Inhaltstoffe des M.pect.superfic. der Herkünfte

BIG 6, Wrolstad und Super Mini im Alter von 12 Wochen (MW \pm SE).

Tab. 31: pH-, LF- und $L^{*}, a^{*}, b^{*}$-Werte des M.pect.superfic. der Herkünfte BIG 6 ,

Wrolstad und Super Mini im Alter von 12 Wochen (MW \pm SE)

Tab. 32: Parameter der Fleischqualität des M.pect.superfic. sowie CK - Aktivität und Laktatgehalt im Stichblut der Herkünfte BIG 6, Wrolstad und Super Mini im Alter von

12 Wochen (MW $\pm \mathrm{SE}$ ).....

Tab. 33: Histologische Parameter des M.pect.superfic. der Herkünfte BIG 6, Wrolstad und Super Mini im Alter von 12 Wochen (MW \pm SE)

Tab. 34: Gewichtsparameter der Brustmuskulatur und des M.pect.superfic. der

Herkünfte BIG 6, Wrolstad und Super Mini im Alter von 22 Wochen (MW \pm SE) .... 66

Tab. 35: Trockenmassegehalte und Inhaltstoffe des M.pect.superfic. der Herkünfte

BIG 6, Wrolstad und Super Mini im Alter von 22 Wochen (MW \pm SE)

Tab. 36: pH-, LF-, und $L^{*}, a^{*}, b^{*}$ - Werte des M.pect.superfic. der Herkünfte BIG 6,

Wrolstad und Super Mini im Alter von 22 Wochen (MW \pm SE)

Tab. 37: Parameter der Fleischqualität des M.pect.superfic. sowie CK - Aktivität und Laktatgehalt im Stichblut der Herkünfte BIG 6, Wrolstad und Super Mini im Alter von

22 Wochen (MW \pm SE)

Tab. 38: Histologische Parameter des M.pect.superfic. der Herkünfte BIG 6, Wrolstad und Super Mini im Alter von 22 Wochen (MW \pm SE) .

Tab. 39: Korrelation zwischen den Gewichtsparametern und den Parametern pH, LF

und $L^{*}, a^{*}, b^{*}$ des M.pect.superfic von Puten

Tab. 40: Korrelation zwischen den Gewichtsparametern und den Muskelinhaltstoffen von Puten

Tab. 41: Korrelation zwischen den Gewichtsparametern und den physikalischen

Parametern sowie den Stichblutwerten von Puten ....

Tab. 42: Korrelationen zwischen den Gewichtsparametern und den histologischen

Parametern des M.pect.superfic. von Puten.

Tab. 43: Korrelationen zwischen den Muskelinhaltstoffen (inkl. Trockenmasse) und

den Parametern $p H$, LF und $L^{*}, a^{*}, b^{*}$ des M.pect.superfic. von Puten $(n=399) \ldots \ldots .74$

Tab. 44: Korrelationen zwischen den Muskelinhaltstoffen (inkl. Trockenmasse) und

den physikalischen Parametern sowie den Stichblutwerten von Puten $(n=399) \ldots \ldots . .74$

Tab. 45: Korrelation zwischen den Muskelinhaltstoffen (inkl. TM) und den

histologischen Parametern des M.pect.superfic. von Puten $(n=399) \ldots \ldots \ldots \ldots \ldots \ldots \ldots . \ldots \ldots$

Tab. 46: Korrelationen zwischen den physikalischen Parametern und den

Parametern $\mathrm{pH}, \mathrm{LF}, \mathrm{L}^{*}, \mathrm{a}^{*}, \mathrm{~b}^{*}$ des M.pect.superfic. bei Puten $(n=399)$...

Tab. 47: Korrelationen zwischen den Blutparametern/Blutpunktzahlen und $\mathrm{pH}$ -

Werten, Leitfähigkeitswerten sowie Helligkeits- und Farbwerten bei Puten $(n=399) .77$

Tab. 48: Korrelationen zwischen den physikalischen Parametern des M.pect.superfic. und den histologischen Parametern $(n=399)$. 
Tab. 49: Korrelationen zwischen den Blutparametern bzw. Blutpunkten und den histologischen Parametern des M.pect.superfic. bei Puten $(n=399) \ldots \ldots \ldots \ldots \ldots \ldots \ldots . . . . . .78$ Tab. 50: Korrelationen zwischen histologischen Parametern und den Parametern $\mathrm{pH}$, LF, $L^{*}, a^{*}, b^{*}$ des M.pect.superfic. bei Puten $(n=399)$. 79

Tab. 51: Korrelationen zwischen den Anteilen degenerierter Fasern sowie dem Kapillar/Zellverhältnis und den Parametern $\mathrm{pH}, \mathrm{LF}, \mathrm{L}^{*}, \mathrm{a}^{*}, \mathrm{~b}^{*}$ des M.pect.superfic. bei Puten (n=399).

Tab. 52: Lebendgewichtsentwicklung beim Herkunftsvergleich B.U.T. BIG 6 - Kellys BBB 91

Tab. 53: Lebendgewichtsentwicklung beim Herkunftsvergleich B.U.T. BIG 6 Wrolstad - Super Mini (www.kelly-turkeys.com; MEYER, 1991) 95 


\section{Abbildungsverzeichnis}

Abb. 1: Feinbau der quergestreiften Muskelfaser (SILBERNAGL und

DESPOPOULOS 1991)

Abb. 2: Schematische Darstellung eines Myosinmoleküls (VOET und VOET, 1992) 13

Abb. 3: Schematische Darstellung der Muskelkontraktion (SILBERNAGL und

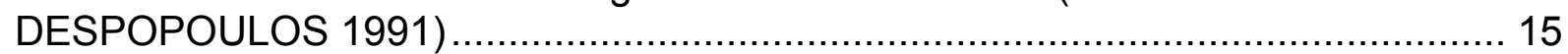

Abb. 4: pH-Wertverlauf p.m. im Schweinemuskel (BENTLER, 1972) ................... 20

Abb. 5: Einfluss von Hitzestress auf den $\mathrm{pH}$ - Wert - Verlauf im M.pect.superfic. von

Putern. ( $n=61$ pro Gruppe; $a, b=$ signifikannte Unterschiede zwischen den Gruppen, $p$

$\leq 0,05$; MC KEE und SAMS, 1997) .......................................................... 22

Abb. 6: Einfluss von Hitzestress auf denL* - Wert - Verlauf im M.pect.superfic. von

Puten. ( $n=61$ pro Gruppe; $a, b=$ signifikannte Unterschiede zwischen den Gruppen, $p$

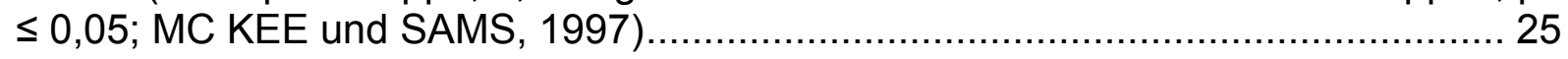

Abb. 7: Schematische Darstellung der Pathogenese der genetisch bedingten

Myopathie (MARTENS, 1998)...

Abb. 8. Schema zum Ablauf der Aktivierung des schnellen

Kohlenhydratstoffwechsels post mortem in PSE - Muskulatur (ROCK und KOZAK-

REISS, 1987).

Abb. 11: Bearbeitungs- und Zerlegemuster für den M.pect.superfic.................... 44

Abb. 12: Warner-Brazler-Scherkopf mit Stanzhülse ......................................... 47

Abb. $13 \mathrm{a}+\mathrm{b}$ : Versuchsaufbau zur Tropfsaftverlust-Ermittlung .......................... 48

Abb. 14: Schematische Darstellung von verschiedenen Muskelfaserdurchmessern

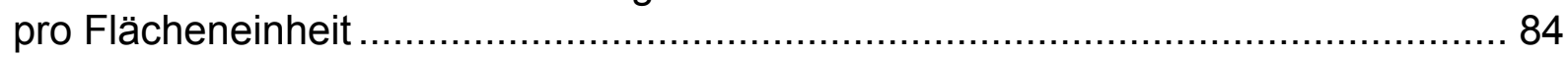

Abb. 15 : Charakteristischer Ausschnitt einer Probe des M.pect.superfic. (B.U.T. BIG

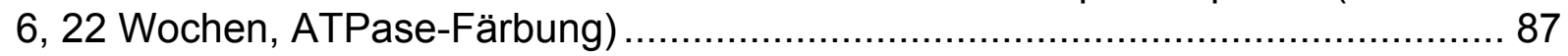

Abb. 16 a+b: Mm.pect.superfic. von B.U.T. BIG 6 - Puten im Alter von 12 Wochen

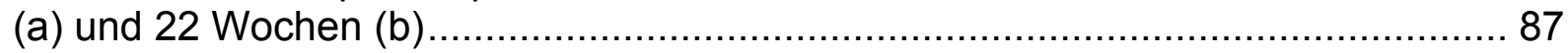

Abb. 17: Riesenfaser (Giant Fibre) umgeben von pathologisch unverändertem

Gewebe im M.pect.superfic einer 22 Wochen alten B.U.T. BIG 6 - Pute ................. 88

Abb. 18: Anguläre Faser im Verbund nicht pathologischer Muskelfasern im

M.pect.superfic. einer B.U.T. BIG 6 - Pute im Alter von 22 Wochen.

Abb. 19: Verteilung der Kapillaren im Gewebe des M.pect.superfic. von B.U.T. BIG 6

- Puten im alter von 12 (a) und 22Wochen (b) ............................................ 89

Abb. 20: Anordnung von Kapillaren im Gewebe des M.pect.superfic. von B.U.T. BIG

6 - Puten im Alter von 22 Wochen. ......................................................... 90

Abb. 21: Verteilung der $L^{*}$ - Werte der Gesamtheit aller untersuchten $\mathrm{Mm}$. pect.

superfic. von Puten $(n=399)$.

.104

Abb. 22: pH - Wertverteilung 20 min. p.m. im M. pect. superfic. von Puten $(n=399)$ 


\section{Abkürzungsverzeichnis}

${ }^{\circ} \mathrm{C}$

$\%$

$a^{*}$

a.m.

Abb.

ADP

ASS

ATP

$b^{*}$

BMA

B.U.T.

BSE

bzw.

$\mathrm{Ca}$

ca.

CAF

CK

$\mathrm{Cl}$

$\mathrm{cm}$

$\mathrm{CO}_{2}$

dest

DFD

d.h.

dl

et al.

FOSVWE

FTG

FTO

$\mathrm{g}$

$\mathrm{h}$

K

Kap.

$\mathrm{kD}$

$\mathrm{kg}$

I

$L^{*}$

LF

LKW

Lsg.

LSQ

Max.

Min.

$\min$.

$\mathrm{m}$

$\mathrm{ml}$

$\mathrm{mmol}$
Grad Celsius

Prozent

Rot-/Grünwert

ante mortem

Abbildung

Adenosindiphosphat

Aviäres Stress Syndrom

Adenosintriphosphat

Blau-/Gelbwert

Brustmuskelanteil

British United Turkey

Bovine Spongioforme Enzephalopathie

beziehungsweise

Calcium

Circa

Calciumaktivierender Faktor

Creatinkinase

Chlor

Zentimeter

Kohlendioxid

destilliert

Dark, firm, dry

das heißt

Deziliter

et alii (und andere)

Forschungs- und Studienzentrum für

Veredelungswirtschaft Weser/Ems

fast twitch glycolytic

fast twitch oxidative

Gramm

Stunde

Kalium

Kapillare

Kilodalton

Kilogramm

Liter

Helligkeitswert

Leitfähigkeit

Lastkraftwagen

Lösung

Least square means

Maximum

Minimum

Minute

Meter

Milliliter

Millimol 


\begin{tabular}{|c|c|}
\hline M. & Musculus \\
\hline ME & umsetzbare Energie \\
\hline $\mathrm{Mg}$ & Magnesium \\
\hline mg & Milligramm \\
\hline mio. & Million \\
\hline MJ & Megajoule \\
\hline Mm. & Musculi \\
\hline $\mathrm{mS}$ & Millisiemens \\
\hline MW & Mittelwert \\
\hline MyHC & Myosin heavy chain \\
\hline $\mathrm{N}$ & Newton \\
\hline$n$ & Anzahl \\
\hline $\mathrm{Nm}$ & Newtonmeter \\
\hline o.g. & oben genannt \\
\hline $\mathrm{p}$ & Irrtumswahrscheinlichkeit \\
\hline pect. & pectoralis \\
\hline $\mathrm{pH}$ & Pondus hydrogenii \\
\hline$P$ & Phosphor \\
\hline$P_{1}$ & Phosphatrest \\
\hline PE & Polyethylen \\
\hline p.m. & post mortem \\
\hline PSE & Pale, soft, exudative \\
\hline PSS & Porcines Stress Syndrom \\
\hline$\mu \mathrm{m}$ & Mikrometer \\
\hline umol & Mikromol \\
\hline RyR & Ryanodin Rezeptor \\
\hline r & Korrelationskoeffizient \\
\hline SE & Standardfehler \\
\hline sek. & Sekunde \\
\hline SKG & Schlachtkörpergewicht \\
\hline STO & slow twitch oxidative \\
\hline superfic. & superficialis \\
\hline $\mathrm{t}$ & Tonne $(1000 \mathrm{~kg})$ \\
\hline Tab. & Tabelle \\
\hline U & units \\
\hline u. & und \\
\hline V. & Vene \\
\hline Vv. & Venen \\
\hline Wo. & Wochen \\
\hline ZMP & $\begin{array}{l}\text { Zentrale Markt- und Preisberichtstelle für } \\
\text { Erzeugnisse der Land-, Forst- und }\end{array}$ \\
\hline
\end{tabular}




\section{Einleitung und Zielsetzung}

Der Verbrauch von Putenfleisch ist in den letzten Jahren stetig gestiegen. Grund dafür ist neben der BSE - Krise der relativ niedrige Fettgehalt des weißen Fleisches und dessen Zartheit.

Das erzeugte Putenfleisch wird dem Verbraucher sowohl als Frischware, als auch als verarbeitetes Produkt angeboten. Vor allem Convenience-Produkte, d. h. Produkte mit einem höheren Verarbeitungsgrad sind in den letzten Jahren deutlich in der Verbrauchergunst gestiegen. Vor dem Hintergrund der genannten Verwendungsmöglichkeiten für das Ausgangsprodukt Putenfleisch ist die Erhebung von Qualitätsfaktoren dahingehend von großer Bedeutung, als dass sie die Grundvoraussetzung für die besondere Eignung der Rohware zum verarbeiteten Produkt darstellen.

Um der gesteigerten Nachfrage nach Putenfleisch entsprechend begegnen zu können, wurden bei der Selektion der Puten die Futterverwertung, das Mastendgewicht sowie der Brustmuskelanteil als primäre Selektionsziele angesehen. Noch 1980 beschrieben PINGEL und JEROCH ein Lebendgewicht von $6 \mathrm{~kg}$ von Puten bei einem Schlachtalter von 16 Wochen.

Heute werden die männlichen Puten nach Herkunft auf Mastendgewichte zwischen 18 und $25 \mathrm{~kg}$ nach ca. 22 Wochen selektiert. DRANSFIELD und SOSNICKI (1999) beschrieben sogar Gewichte von $25 \mathrm{~kg}$ nach 20 Wochen Mast. WICKE et al. (2001) gab an, dass etwa $90 \%$ der Putenfleischproduktion in Deutschland über schwere Verarbeitungsputen realisiert werden. HAHN et al. (1998) konnten nachweisen, dass die Handelswertbestimmung bei Mastputen in den meisten Fällen über eine Videobildauswertung erfolgt, deren Angaben auf Volumenberechnungen beruhen. Diese liefert jedoch keine hinreichend sichere Aussagen über die gewebliche Schlachtkörperzusammensetzung, Qualitätseigenschaften werden nicht berücksichtigt.

VELLEMAN und NESTOR (2003) erklärten, dass die Selektion auf höhere Wachstumsrate, bessere Futterverwertung sowie auf hohen Muskelfleischanteil zu einer Verminderung der Fleischqualität bei Mastputen führte. YOST et al. (2002) bemerkten hinsichtlich der o.g. Selektionsziele ebenfalls eine Begünstigung der Myopathienhäufigkeit im Pectoralismuskel sowie eine Anhäufung von PSE Eigenschaften im Fleisch entsprechend selektierter Puten beiderlei Geschlechts.

WICKE et al. (2000b, 2001) konnten bei Mastputen mit gleichen Selektionszielen bereits Parallelen zu Symptomen des Stress-Syndroms bei Schweinen (Porcines Stress-Syndrom - PSS) aufzeigen, welche von Ihnen unter dem Begriff Aviäres Stress Syndrom (ASS) zusammengefasst wurden.

Ziel dieser Untersuchung ist die Betrachtung ausgewählter Fleischqualitätsparameter an vier Putengenotypen in zwei Altersgruppen (12 Wo./22 Wo.). Dabei sollte die in Deutschland typische Verarbeitungspute B.U.T. Big 6 in zwei Durchgängen mit drei Genotypen (Kelly's BBB, Kelly's Super Mini, Kelly's Wrolstad) verglichen werden. 


\section{Literaturübersicht}

\subsection{Allgemeines zur Putenproduktion}

Im Jahr 2000 belegte Deutschland unter den 10 führenden Staaten in der Produktion von Putenfleisch mit einer Jahresproduktion von ca. 255.000 t Putenfleisch Rang fünf (WINDHORST, 2001). Die ZMP gab für dasselbe Jahr $292.000 \mathrm{t}$ produziertes Putenfleisch in Deutschland an. Weltweit nimmt die USA mit 2,4 mio. t Putenfleisch im Jahr 2000 marktführende Position ein. Im Jahr 2005 sank laut ZMP die Putenproduktion in Deutschland im Vergleich zum Jahr 2004 um 0,8 \%. Dieser Trend war noch deutlicher bei der französischen Putenproduktion zu beobachten, welche in dem gleichen Zeitrahmen um 9,8 \% sank. Diese rückläufige Tendenz scheint anzuhalten, denn auch im Jahr 2006 wurde in Deutschland zwischen den Monaten Januar und September mit 279.971 t 2,7 \% weniger Putenfleisch produziert, als im vergleichbaren Vorjahreszeitraum.

Nach Aussagen der ZMP (2002) betrug der Pro-Kopf-Verbrauch an Putenfleisch in Deutschland im Jahre $20005,6 \mathrm{~kg}$. BÖTTCHER und SCHMIDT (2002) gaben für dasselbe Jahr einen Pro Kopf Verbrauch von 5,3 kg an. WINDHORST (2001) nennt für dasselbe Jahr hinsichtlich des Gesamtverbrauchs an Geflügelfleisch einen Selbstversorgungsgrad von 71,1\%. Neben den USA hat auch Brasilien als Exporteur von Putenfleisch zunehmend Einfluss auf den Weltmarkt genommen (BECK, 2002).

Die konventionelle Mastputenhaltung erfolgt in Tageslichtställen mit seitlichen Öffnungen für eine natürliche Windlüftung, welche mit luftdurchlässigen Jalousien oder mit Lüftungsklappen ausgestattet sind. Die typischen Offenställe sind in der Regel zwischen 12 und 20 m breit und bis zu 120 m lang, die Einstreu besteht aus Stroh oder Sägespänen, seltener aus Sand (BERK, 1999). Abgesehen von Fütterungs- und Tränkeeinrichtungen sind die Haltungsflächen unstrukturiert. Da männliche und weibliche Puten unterschiedliche Mastleistung zeigen, werden sie voneinander getrennt gemästet (FELDHAUS und SIEVERDING, 2001). Generell werden die Puten im Rein - Raus - Verfahren je nach Geschlecht und Stallkapazität im 13 Wochen - Rhythmus, 19 Wochen - Rhythmus oder 22 - 24 Wochen Rhythmus gemästet (BERK, 1999). Die Ad Libitum - Fütterung erfolgt nach Alter der Tiere gestaffelt.

Nach Ablauf der Mastdauer werden die Puten in Lkws zum Schlachthof transportiert. Die Lkws sind in der Regel an den Seiten luftdurchlässig gestaltet.

Am Schlachthof werden die Tiere betäubt. Die beiden gängigsten Methoden sind die elektrische Betäubung und die Betäubung mit Gas. Die elektrische Betäubung variiert hinsichtlich der Parameter Spannung, Stromstärke und Frequenz derart zwischen den Geräten und Methoden, so dass eine konkrete Angabe an dieser Stelle unterbleibt. Die Betäubung mit Gas erfolgt mit $\mathrm{CO}_{2}$ oder Argon. Nach der Betäubung werden die Puten durch öffnen der Vv. jugularis entblutet. Es folgt das Brühen der Schlachtkörper bei 50 - $60{ }^{\circ} \mathrm{C}$ mit anschließender automatischer Rupfung. Nach der Entfernung der Innereien wird der Schlachtkörper begutachtet, die Ständer werden entfernt und der Schlachtkörper zur Reifung auf $4-5^{\circ} \mathrm{C}$ heruntergekühlt. Die Zerlegung der Puten erfolgt bei Puten in der Regel manuell, es gibt jedoch auch automatische Wege der Zerlegung bzw. des Entbeinens (BARBUT, 2002). 


\subsection{Struktur, Bildung und Funktion der Muskulatur}

In der Literatur wird die Muskulatur in drei Arten unterteilt. Zunächst wird die glatte Muskulatur von der quergestreiften unterschieden. Letztere unterteilt sich ihrerseits in Skelett- und Herzmuskulatur.

Die glatte Muskulatur befindet sich in Eingeweiden sowie in einigen Blutgefäßen und ist für die weitere Betrachtung nicht von Bedeutung.

Die quergestreifte Muskulatur erhält ihren Namen durch das lichtmikroskopische Erscheinungsbild der einzelnen Muskelfasern, denn die Sarkomere sind in Form einer Querstreifung sichtbar (HUXLEY und HANSON, 1954; SCHMIDT und THEWS, 1993).

Der Grundaufbau ist bei allen Skelettmuskeln gleich (Abb.1).

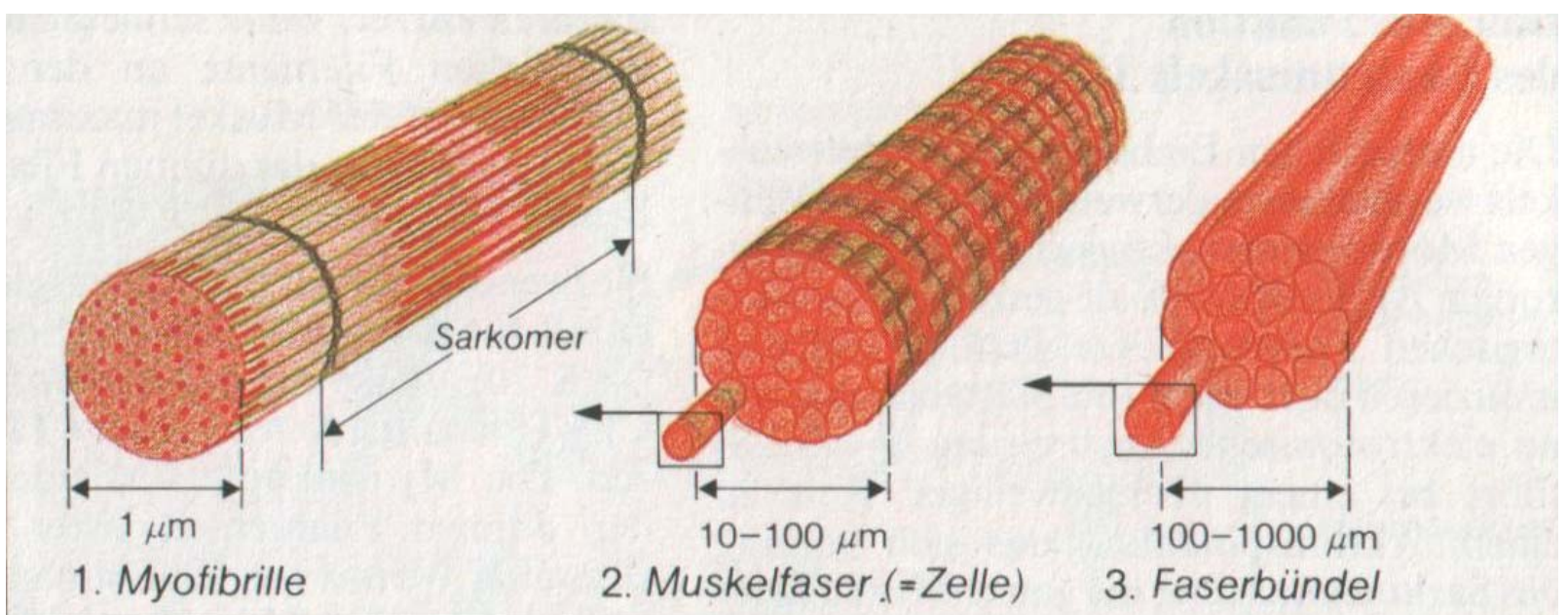

Abb. 1: Feinbau der quergestreiften Muskelfaser (SILBERNAGL und DESPOPOULOS 1991)

Die in Abb.1 dargestellten Faserbündel werden auch als Primärbündel bezeichnet. Diese bilden, vom Perimysium umschlossen, mit benachbarten Primärbündeln ein Sekundärbündel. Diese werden vom Epimysium umschlossen und von einer Faszie bedeckt.

In der Literatur werden im Wesentlichen drei Muskelfasertypen unterschieden, ein roter, ein intermediärer und ein weißer Typus. Obwohl es in der Literatur verschiedene Ansätze hinsichtlich der Fasertypisierung gibt, so ist die zurzeit gängigste die Aufteilung in drei Fasertypen. Auch wenn es über die genaue Bezeichnung der Typen noch Uneinigkeit gibt, so sind die dazu beschriebenen Eigenschaften bezüglich Erscheinungsbild, Stoffwechsel und Funktionalität weitestgehend übereinstimmend. Im Folgenden werden für die drei Muskelfasertypen die Kürzel FTG (Fast-Iwitch-Glycolytic), FTO (Fast-Iwitch-oxidative) und STO (Slow-Iwitch-oxidative) verwendet. In Tabelle (1) sind die entsprechenden Eigenschaften und weitere Bezeichnungen aufgeführt. 
Tab. 1: Bezeichnungen und Eigenschaften der verschiedenen Muskelfasertypen

\begin{tabular}{|c|c|c|c|c|}
\hline Parameter & FTG & FTO & STO & Quelle \\
\hline Myoglobingehalt & Niedrig & Hoch & Hoch & $\begin{array}{l}\text { BECHTEL } \\
1986, \\
\text { DRANSFIELD } \\
\text { u. SOSNICKI } \\
1999\end{array}$ \\
\hline Faserdurchmesser & Groß & Intermediär & Gering & $\begin{array}{l}\text { BECHTEL } \\
1986, \\
\text { DRANSFIELD } \\
\text { u. SOSNICKI } \\
1999\end{array}$ \\
\hline $\begin{array}{l}\text { Kontraktions- } \\
\text { geschwindigkeit }\end{array}$ & Schnell & Schnell & Langsam & $\begin{array}{l}\text { BECHTEL } \\
1986,\end{array}$ \\
\hline Art d. Kontraktion & Phasisch & Tonisch & Tonisch & $\begin{array}{l}\text { BECHTEL } \\
1986,\end{array}$ \\
\hline $\begin{array}{l}\text { Anzahl an } \\
\text { Mitochondrien }\end{array}$ & Niedrig & Intermediär & Hoch & $\begin{array}{l}\text { BECHTEL } \\
1986,\end{array}$ \\
\hline $\begin{array}{l}\text { Größe der } \\
\text { Mitochondrien }\end{array}$ & Klein & intermediär & Groß & $\begin{array}{l}\text { BECHTEL } \\
1986,\end{array}$ \\
\hline Blutkapillardichte & Niedrig & intermediär & Hoch & $\begin{array}{l}\text { BECHTEL } \\
1986,\end{array}$ \\
\hline $\begin{array}{l}\text { Oxidativer } \\
\text { Stoffwechsel }\end{array}$ & Niedrig & intermediär & Hoch & $\begin{array}{l}\text { BECHTEL } \\
1986, \\
\text { DRANSFIELD } \\
\text { u. SOSNICKI } \\
1999\end{array}$ \\
\hline $\begin{array}{l}\text { Glycolytischer } \\
\text { Stoffwechsel }\end{array}$ & Hoch & intermediär & Niedrig & $\begin{array}{l}\text { BECHTEL } \\
\text { 1986, } \\
\text { DRANSFIELD } \\
\text { u. SOSNICKI } \\
1999\end{array}$ \\
\hline Lipidgehalt & Niedrig & intermediär & Hoch & $\begin{array}{l}\text { BECHTEL } \\
1986\end{array}$ \\
\hline Glycogengehalt & hoch & intermediär & niedrig & $\begin{array}{l}\text { BECHTEL } \\
1986\end{array}$ \\
\hline $\begin{array}{l}\text { Weitere } \\
\text { Bezeichnungen }\end{array}$ & $\begin{array}{l}\text { Weiß, } \\
\text { MyHC2b } \\
\text { IIB } \\
\text { a } \\
\text { FG }\end{array}$ & $\begin{array}{l}\text { Intermediär, } \\
\text { MyHC2x/2a } \\
\text { IIA } \\
\alpha \beta \\
\text { FG/FOG }\end{array}$ & $\begin{array}{l}\text { Rot, } \\
\text { MyHC slow/l } \\
\text { I } \\
\text { B } \\
\text { so }\end{array}$ & $\begin{array}{l}\text { BECHTEL } \\
(1986) \\
\text { CHANG et al. } \\
\text { (2003) } \\
\text { MORITA et al. } \\
\text { (1970) } \\
\text { YELLIN, } \\
\text { GUTH, (1970) } \\
\text { PETER et al. } \\
\text { (1972) }\end{array}$ \\
\hline
\end{tabular}


CHANG et al. (2003) unterteilten die drei Muskelfasertypen nach ihren Myosinheavy-chain-Isoformen (MyHC). Das Myosin besteht aus unterschiedlichen molekularen Grundbestandteilen.

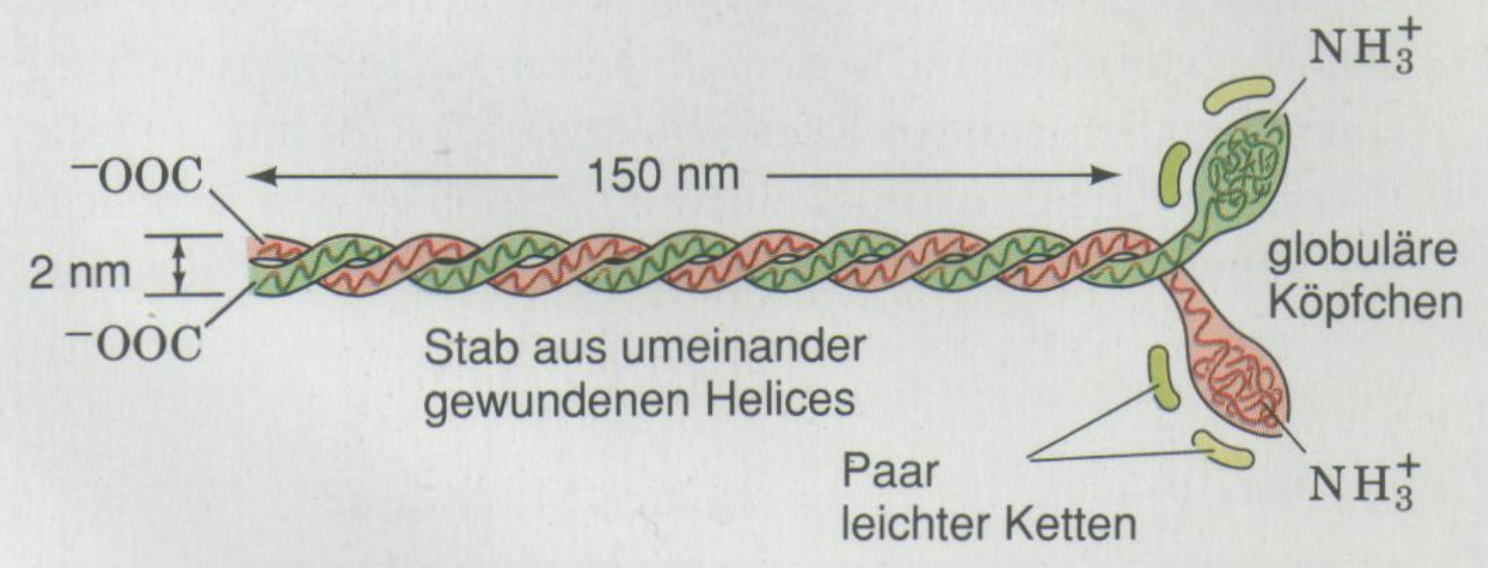

Abb. 2: Schematische Darstellung eines Myosinmoleküls (VOET und VOET, 1992)

Die schweren Myosinketten (MyHC) bilden den Stab aus umeinander gewundenen Helices (Abb.2). Von den um die Myosinköpfchen angeordneten leichten Myosinketten existieren die Isoformen LC1 und LC2, welche nicht nach einem festen Grundschema verteilt sind. Die MyHC können in vier verschiedenen Isoformen auftreten, wobei aber immer zwei gleiche Arten eine Myosinhelix bilden. Die schweren Myosinketten sind aufgrund ihrer hohen molekularen Masse (230 kD) bedeutsamer für die Gestaltung des Muskels, als die vergleichsweise unscheinbaren, leichten Myosinketten (20 kD) (VOET und VOET, 1992). CHANG et al. (2003) beschrieben, dass die vier Isoformen der MyHC den Unterschied zwischen STO, FTO und FTG ausmachen. So bestehen die STO aus MyHC slow/l, die FTG aus $\mathrm{MyHC} 2 \mathrm{~b}$. Für die intermediären Muskelfasern werden die beiden Isoformen MyHC2a und MyHC2x genannt, wobei die MyHC2a eher zu den MyHC slow/l tendieren, die MyHC2x hingegen zu dem MyHC2b.

Die Muskulatur des Geflügels ist dadurch gekennzeichnet, dass sie nur spärlich intramuskuläres Bindegewebe enthält. Die Dicke der Muskelfasern ist ein rassedeterminiertes Merkmal und ist daneben von Alter und Geschlecht abhängig (HAMM 1981). Ferner unterscheiden sich die Muskeln auch farblich. Die Flugmuskeln sind beim Mastgeflügel allgemein heller, die der Brust fast weiß; die Gliedmaßenmuskulatur ist deutlich dunkler (SIELAFF,1996).

Das Muskelwachstum gestaltet sich während der embryonalen Entwicklung des Individuums anders, als in der postnatalen Phase. Während der embryonalen Phase findet in erster Linie Hyperplasie, also die Zellvermehrung statt. Die Zellvermehrung gilt mit der Geburt (Schlupf) als beendet (SMITH, 1963). Im jungen Tier liegen die Muskelfasern noch weitgehend undifferenziert in einem auf oxidativem Stoffwechsel beruhendem Stadium vor (ASHMORE und DOERR, 1972; CASSENS und COOPER, 1971). Es existieren zwei Grundformen des Muskels, Typ a (Typ II) und Typ $\beta$ (Typ I), welche nach ihrer Myosin-ATPase - Aktivität eingeteilt wurden. 
Lediglich der Typ a kann sich in eine Faser mit glycolytischem Stoffwechsel umwandeln, der Typ $\beta$ behält zeitlebens seinen oxidativen Stoffwechsel (RUUSUNEN und POULANNE, 2004). Das weitere Ansteigen der Muskelgewichte postnatal ist auf Zellwachstum (Hypertrophie) zurückzuführen. Dieses Wachstum beruht auf der Aktivierung bislang ruhender Satellitenzellen (MOSS und Le BLOND; 1971). Diese Satellitenzellen sind in der Zelle zwischen Basallamina und Plasmamembran lokalisiert (MAURO, 1961). Die Satellitenzellen vermehren sich und verschmelzen mit den bereits entwickelten Muskelzellen. Dort sorgen sie für einen erhöhten DNA - Gehalt, welcher für eine höhere Proteinsynthese, und damit für Muskelzellwachstum sorgt (YABLONKA-REUVENI, 1995).

Bezüglich der Muskelmasse, insbesondere des Brustmuskels wurden Unterschiede zwischen den Geschlechtern sowohl bei Puten, wie auch bei Hühnern und Wachteln festgestellt (BURKE und SHARP, 1989; BURKE, 1994; Riegel et al., 2004). Bei Puten war dieser Unterschied schon beim 12 Tage alten Embryonalstadium erkennbar (BURKE, 1994). LIU et al. (2004) konnte diesen Unterschied erst ab dem 16. Tag des Embryonalstadiums signifikant absichern. VELLEMAN et al. (2002) konnten hinsichtlich der Brustmuskelentwicklung festlegen, dass Unterschiede zwischen den Geschlechtern erst zwischen dem 20. und dem 25. Tag nach der Befruchtung signifikant abzusichern waren.

Der lebende Muskel ist in der Lage chemische Energie (ATP) in mechanische Energie und Wärme umzuwandeln. Die entsprechende Aktivierung des Muskels erfolgt über Motoneurone, welche an den motorischen Endplatten einen Endplattenstrom induzieren (Abb.3). Ist dieser Reiz stark genug, kommt es zu einem Aktionspotential, welches sich entlang des Sarkolemms über die gesamte Muskelfaser (Muskelzelle) ausbreitet. Die Muskelzellmembran weist an vielen Stellen senkrecht zu den Muskelfibrillen schlauchartige Einstülpungen auf, welche als transversale Tubuli oder auch T-System bezeichnet werden. Das T-System läuft in der Muskelzelle in enger Nachbarschaft zu dem in Längsrichtung zu den Myofibrillen laufenden sarkoplasmatischen Retikulum, dessen Kammern auch als longitudinale Tubuli bezeichnet werden. Diese stellen ein Reservoir für $\mathrm{Ca}^{2+}-$ Ionen dar. Neben Aktin- und Myosinfilamenten und $\mathrm{Ca}^{2+}-$ Ionen ist für die Muskelkontraktion die Anwesenheit von Magnesiumionen $\left(\mathrm{Mg}^{2+}\right)$, ATP und ATPase notwendig. Das Aktionspotential läuft über das T-System in die Muskelzelle und setzt das in den benachbarten longitudinalen Tubuli befindliche $\mathrm{Ca}^{2+}$ frei. Dieses $\mathrm{Ca}^{2+}$ verbindet sich mit Troponin, wodurch das am Troponin befindliche Tropomyosin seine hemmende Wirkung auf die Aktin-Myosin-Verbindung verliert. Es kommt zur Anlagerung der Myosinköpfe an das Aktin. Aktin aktiviert daraufhin die ATPase des Myosinköpfchens und das daran lagernde ATP wird aufgespalten. Für diesen Vorgang ist die Anwesenheit von $\mathrm{Mg}^{2+}$ erforderlich. 


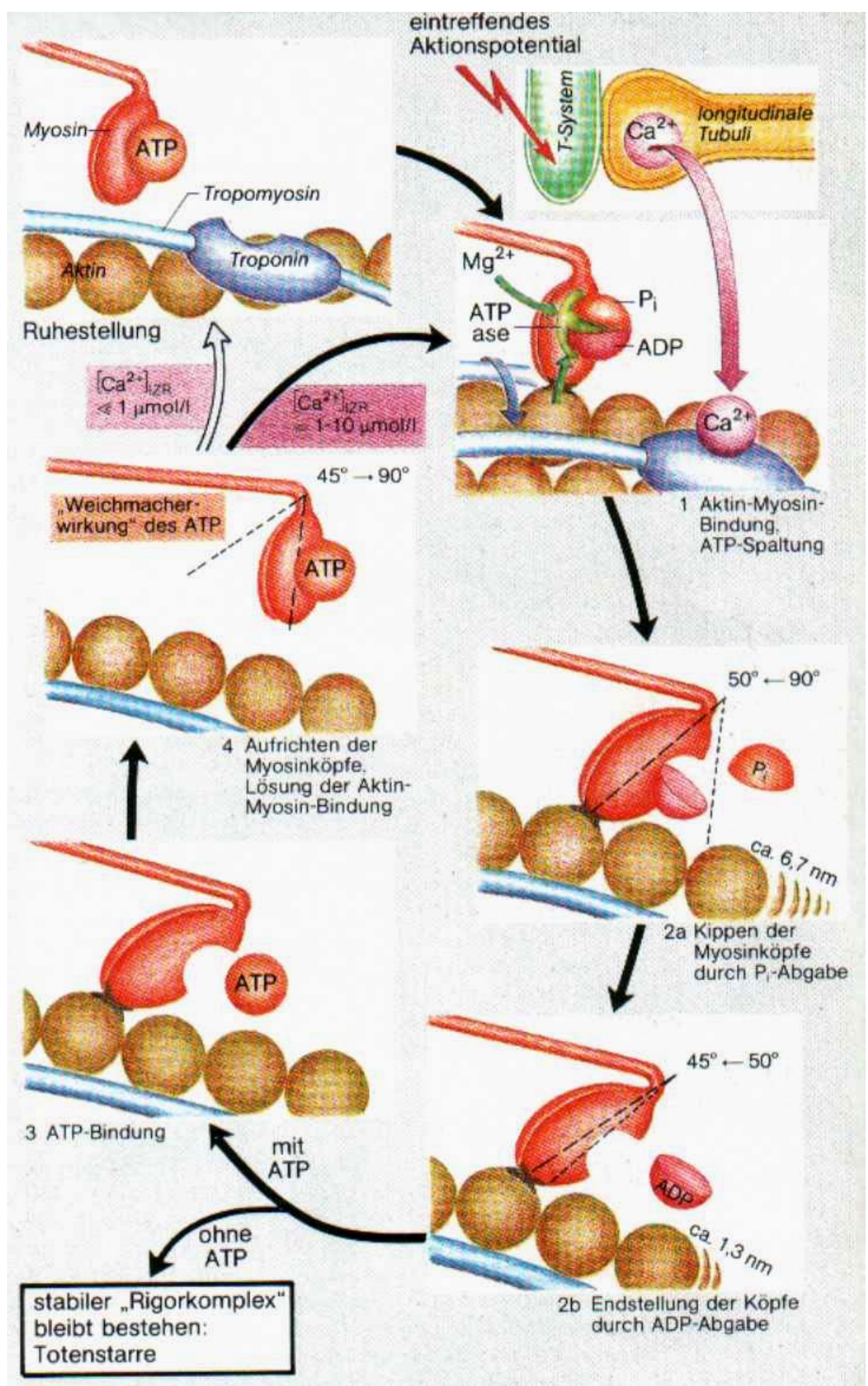

Abb. 3: Schematische Darstellung der Muskelkontraktion (SILBERNAGL und DESPOPOULOS 1991)

Das am Myosinköpfchen befindliche ATP wird in ADP $+P_{i}$ gespalten. Sobald das anorganische Phosphat den Myosinkopf verlassen hat, kippen die Myosinköpfe aus ihrer ursprünglichen $90^{\circ}$-Stellung in eine $50^{\circ}$-Stellung. Aktin- und Myosinfilamente werden dadurch gegeneinander verschoben. Die Abgabe von ADP aus dem Myosinköpfchen führt zu einem weiteren abknicken um $5^{\circ}$, was gleichzeitig das Ineinandergleiten der Filamente beendet. Der so gebildete Aktin-Myosinkomplex ist stabil (Rigorkomplex) und kann nur durch erneute Anbindung von ATP an den Myosinkopf wieder gelöst werden. Während der beschriebene Vorgang abläuft, wird das in der Muskelzelle befindliche $\mathrm{Ca}^{2+}$ zurück in die longitudinalen Tubuli gepumpt. 
Dadurch kann das Tropomyosin in seine ursprüngliche Stellung zurückgleiten und die Aktin-Myosinbindung hemmen. Durch Anwesenheit von ATP am Myosinkopf springt dieser in seine ursprüngliche $90^{\circ}$ - Stellung zurück.

Im Muskel des toten Organismus wird kein ATP mehr gebildet. Dies bedeutet zum einen, dass sich der Aktin-Myosinkomplex nicht mehr lösen kann, zum anderen findet kein Rücktransport des $\mathrm{Ca}^{2+}$ in die longitudinalen Tubuli statt, da dieser Transport ebenfalls ATP-abhängig ist. Es kommt zur Totenstarre, welche sich erst wieder bei der Zersetzung der Aktin- und Myosinmoleküle wieder löst (Abb.3, SILBERNAGL und DESPOPOULOS, 1991).

\subsection{Postmortale Veränderungen der Muskulatur}

Mit der Tötung des Tieres kommt der Blutkreislauf und damit die Sauerstoffversorgung im Muskelgewebe zum Stillstand. Der Stoffwechsel läuft zunächst jedoch anaerob weiter. Die Spaltung der Glucose verläuft bis zur Stufe des Pyruvats genau so wie die Glycolyse unter Sauerstoffbeteiligung. Das entstandene Pyruvat wird jedoch nicht mehr in Acetyl-CoA umgewandelt und in den Citratzyklus eingespeist, wodurch sich pro mol Glucose ein Nettogewinn von 38 Mol ATP ergeben würde, sondern zu Laktat abgebaut, welches sich in der Muskulatur anhäuft. Die Energieausbeute ist beim anaeroben Glucoseabbau erheblich geringer (2 Mol ATP pro Mol Glucose). Unterhalb einer ATP-Konzentration von $1 \mu \mathrm{Mol} / \mathrm{g}$ wird die AktinMyosin-Verknüpfung in den Muskelfilamenten nicht mehr gelöst: Der Muskel verharrt in seiner Position, es setzt der Rigor mortis ein. Bei einer anschließenden Lagerung des Fleisches setzt durch Proteolyse der myofibrillären Proteine die Fleischreifung ein (HONIKEL, SCHWÄGELE, 1998)

Der Rigor mortis ist primär durch die Vorgänge

- ATP-Abbau,

- Milchsäureanhäufung und damit verbundener

- pH-Wertabfall,

- Membranperforation des sarkoplasmatischen Retikulums,

- Freisetzung von Calciumionen,

- Bildung von Actomyosinkomplexen,

- Sarkomerverkürzung und

- Elastizitätsverlust

gekennzeichnet.

(BATE-SMITH und BENDALL, 1947; BRISKEY und WISMER-PEDERSEN, 1961a+b; BENDALL et al., 1963; BRISKEY et al., 1966; HONIKEL und FISCHER, 1977; FISCHER und HONIKEL, 1977).

MA und ADDIS (1973) stellten fest, dass Puten, welche unbetäubt entblutet wurden, eine Totenstarre von $143 \mathrm{~min}$ aufwiesen, die betäubten Tiere dagegen hatten eine Rigor Mortis - Dauer von 314 min. In diesem Zusammenhang ist anzumerken, dass nach Aussage anderer Autoren (ALVARADO und SAMS, 2000; PAPINAHO et al. 1995) die elektrische Betäubung keinen direkten Einfluss auf die postmortalen Vorgänge im Brustmuskel induziert. 
Für die Lösung des Rigor mortis werden verschiedene proteolytische Enzyme verantwortlich gemacht. Die myofibrilläre Proteolyse beginnt mit dem Inkrafttreten des Calciumaktivierten Faktors CAF. Darunter ist eine neutrale Protease zu verstehen, welche im Sarkoplasma lokalisiert ist und dort durch steigende Calciumkonzentrationen stimuliert wird (BUSCH et al.,1972; PENNY, 1974; DAYTON et al. 1976). Im saurem Milieu ist der CAF nicht wirksam, dort werden Kathepsine wirksam. Kathepsine sind Endopeptidasen, welche sich im lebenden Organismus in den Lysosomen befinden. Sinkt der pH - Wert ab, reißen die Organellen auf und geben zahlreiche lytische Enzyme, darunter auch die Kathepsine frei. Sowohl die Kathepsine, als auch der CAF bewirken beide eine Destrukturierung der Z-Scheiben ( OLSON und PARRISH, 1977; OLSON et al., 1977; PENNY und DRANSFIELD, 1979; KATSARAS et al, 1984). Während der Fleischreifung verliert das Fleisch an Transparenz und nimmt eine rötlich-braune Farbe an. Es wird wieder flexibel, saftiger und bildet sein Aroma aus. Die Aromastoffe bestehen sowohl aus Metaboliten der Fleischinhaltsstoffe als auch aus Reaktionsprodukten der Fleischreifung. Die Fleischreifungsgeschwindigkeit lässt sich durch die Lagertemperatur beeinflussen. Es kann zu einer abartigen Fleischreifung kommen, wenn die Körper- oder Teilstückwärme ungleichmäßig abgeführt wird und eine hohe Restwärme längere Zeit im Inneren der Muskulatur verbleibt. Die Muskulatur verfärbt sich kupferfarben, der $\mathrm{pH}$ - Wert ist niedrig, Schwefelwasserstoff und Buttersäure werden nachweisbar. Ein fauliger Geruch ist feststellbar, besonders im Inneren des frisch angeschnittenen Muskels. Ursache dafür ist keine mikrobielle Zersetzung, sondern eine saure Gärung, welche bei höheren Muskelinnentemperaturen bevorzugt abläuft. Man spricht in diesem Zusammenhang auch von „Stickiger Reifung“ (SIELAFF,1996). Neben der Kühlung gibt es eine Reihe endogener und exogener Einflüsse auf die Fleischqualität, welche im Folgenden bei den Fleischbeschaffenheitsparametern oder im Zusammenhang mit dem Aviären Stress Syndrom besprochen werden.

\subsection{Fleischbeschaffenheitsmerkmale bei Puten}

\subsubsection{Rohnährstoffe und Trockenmassegehalte}

Das Fleisch setzt sich im Wesentlichen aus Wasser, Proteinen, Lipiden und Kohlenhydraten sowie Mineralstoffen zusammen. Die mittleren Inhaltstoffe von Säugetieren sind in Tabelle 2 nach SIELAFF (1996) dargestellt. 
Tab. 2: Durchschnittliche Zusammensetzung des Skelettmuskels von Säugetieren (\% d. Frischmasse; SIELAFF, 1996)

\begin{tabular}{|l|l|l|l|}
\hline Komponente & Gehalt \% & Komponente & Gehalt \% \\
\hline Wasser & $75 \%$ & $\begin{array}{l}\text { Stickstoffhaltige } \\
\text { Nichteiweiße }\end{array}$ & 1,5 \\
\hline Protein & 18,5 & Kreatin + Kreatinphosphat & 0,5 \\
\hline Myofibr. Protein & 9,5 & Nucleotide (ATP,ADP...) & 0,3 \\
\hline Myosin & 5,0 & Freie AS & 0,3 \\
\hline Aktin & 0,2 & Peptide & 0,3 \\
\hline Tropomyosin & 0,8 & Andere Nichteiweiße & 0,1 \\
\hline M-Protein & 0,4 & $\begin{array}{l}\text { Kohlenhydrate + N-freie } \\
\text { Substanzen }\end{array}$ & 1,0 \\
\hline C-Protein & 0,2 & Glycogen & 0,8 \\
\hline a- Actinin & 0,2 & Glucose & 0,1 \\
\hline B- Actinin & 0,1 & $\begin{array}{l}\text { Produkte d. } \\
\text { Zellstoffwechsels }\end{array}$ & 0,1 \\
\hline Sarkoplasma-Pr. & 6,0 & Anorganische Bestandteile & 1,0 \\
\hline Lösl. Sarkoplasma + & 5,5 & Kalium & 0,3 \\
\hline mitochondrale Enzyme & 0,3 & Gesamtphosphor & 0,2 \\
\hline Myoglobin & 0,1 & Schwefel & 0,2 \\
\hline Hämoglobin & 0,1 & Chlor & 0,1 \\
\hline $\begin{array}{c}\text { Cytochrome }+ \\
\text { Flavoproteine }\end{array}$ & 3,0 & Natrium & 0,1 \\
\hline Stroma-proteine & 1,5 & Rest & 0,1 \\
\hline Kollagen/Reticulin & 0,1 & & \\
\hline Elastin & 1,4 & & \\
\hline Unlösl.Proteine Rest & 3,0 & & \\
\hline Lipide & 1,0 & & \\
\hline Neutralfette & 1,0 & & \\
\hline Phospholipide & 0,5 & & \\
\hline Cerebroside (Glycolip.) & & \\
\hline Cholesterol & 0,5 & & \\
\hline & & & \\
\hline
\end{tabular}

Dieselbe Quelle gibt für Putenfleisch (ein gemittelter Wert verschiedener Fleischteilstücke) folgende chemische Zusammensetzung an (Tab.3):

Tab. 3: Durchschnittliche chemische Zusammensetzung von Putenfleisch (SIELAFF, 1996)

\begin{tabular}{|l|l|l|l|l|}
\hline Gehalt & Wasser (\%) & Proteine (\%) & Fette (\%) & Mineralstoffe \\
\hline $\ln \%$ & 70,0 & 21,0 & 7,5 & 1,0 \\
\hline
\end{tabular}

Von anderen Autoren werden für Putenbrustfleisch folgende prozentuale Inhaltstoffe angegeben (Tab.4):

Tab. 4: Durchschnittliche chemische Zusammensetzung von Putenfleisch ((1) SLOWINSKI und STOLARSKI, 1998; (2) WERLEIN und WATKINSON, 1998)

\begin{tabular}{|l|l|l|l|l|}
\hline Autor & Wasser (\%) & Proteine $(\%)$ & Fette $(\%)$ & Mineralstoffe \\
\hline$(1)$ & 74,5 & 22,5 & 1,0 & Keine Angaben \\
\hline$(2)$ & 74,23 & 23,94 & 1,53 & Keine Angaben \\
\hline
\end{tabular}


Der Proteingehalt des M.pect.superfic. wurde von FERNANDEZ et al. (2001) an drei Linien zwischen 24,8 und 26,9 \% angegeben.

Putenfleisch, wie Geflügelfleisch im Allgemeinen, wird insbesondere von kalorienbewussten Verbrauchern, sowie von Personen mit erhöhten Cholesterinwerten wegen seines sehr geringen Fettgehaltes geschätzt. Dabei wird vernachlässigt, dass gerade dem intramuskulären Fettgehalt eine nicht unerhebliche Rolle hinsichtlich der sensorischen Qualität zukommt. Erste Untersuchungen bei Schweinen belegten schon vor zwanzig Jahren deutliche Einflüsse des Fettgehaltes auf die gustatorischen Eigenschaften des verzehrten Fleisches (BARTON-GARDE und BEJERHOLM, 1985; REDE et al., 1986; SCHWÖRER et al., 1987; BERGMANN et al., 1989; IANSSEN und SEHESTED, 1989; GÖTZ, 2002).

Bei Puten konnte ein intramuskulärer Fettgehalt im M.pect.superfic. von 1,51 \% ermittelt werden. Diese Ergebnisse wurden aus zwei verschiedenen Linien (einer langsam wachsenden (Company Goubin) und einer schnell wachsenden Linie (B.U.T. Linie 32)) sowie deren Kreuzungsprodukt ermittelt. Zwischen den Linien gab es keine signifikanten Unterschiede (FERNANDEZ et al., 2001). PINGEL et al. (1998) konnten belegen, dass die intensive Selektion auf schnelles Wachstum dazu führt, das die Tiere schon im frühen Alter zum Fettansatz neigen. Bei dieser Selektion haben solche Tiere einen Selektionsvorteil, die aufgrund ihres Appetits mehr Energie aufnehmen als für das Wachstum erforderlich ist. Die überschüssige Energie wird in Fett angesetzt.

Der Aschegehalt im M. pect. superfic. von Puten wurde von FERNANDEZ et al. (2001) an den schon beschriebenen drei Linien untersucht und betrug einen Anteil von $1,30-1,33 \%$. Es gab keine linienspezifischen Unterschiede.

Die Trockenmasse des M. pect. superfic. konnte von FERNANDEZ et al. (2001) zwischen Gehalten von $26 \%$ und $26,5 \%$ abgesichert werden.

\subsection{2 $\mathrm{pH}-$ Wert}

Der pH-Wert des Muskels im lebenden Organismus liegt etwa zwischen 7,0 und 7,3. Mit Beendigung des Lebens und damit auch der kreislaufabhängigen Stoffwechselvorgänge kommt es zum bereits beschriebenen $\mathrm{pH}$-Wertabfall. Dieser beruht aber nicht ausschließlich, wenngleich doch im Wesentlichen, auf einer Anhäufung von Laktat. Zum einen entsteht durch den Zerfall organischer Phosphorsäureester (ATP, ADP...) in geringen Mengen Phosphorsäure, zum anderen sorgt eine durch die zwangsläufig eingestellte Atmung bedingte Anhäufung von Kohlendioxid für eine Absenkung des pH-Wertes. Schon 1973 hat BENDALL festgestellt, dass ebenfalls die aus der ATP-Hydrolyse freiwerdenden Protonen für ein absinken des p.m. pH - Wertes verantwortlich sind.

Rote und weiße Muskelfasern prägen ebenfalls den $\mathrm{pH}$-Wertverlauf im Muskel. Rote Muskelfasern neigen nur wenig zum glycolytischen Stoffwechsel, was zur Folge hat, dass auch nur relativ wenig anaerobe Glycolyse p.m. betrieben wird.

Entsprechend anders verhalten sich die weißen Muskelfasern, welche wegen Ihrer Präferenz für glycolytische Stoffwechselwege auch als „Glycolytische Muskelfasern“ bezeichnet werden.

Die Intensität des normalen pH-Wertabfalls ist in der folgenden Grafik zusätzlich zu denen der zum Auftreten der Fleischfehler PSE und DFD führenden Abläufe aufgeführt (Abb.4). 


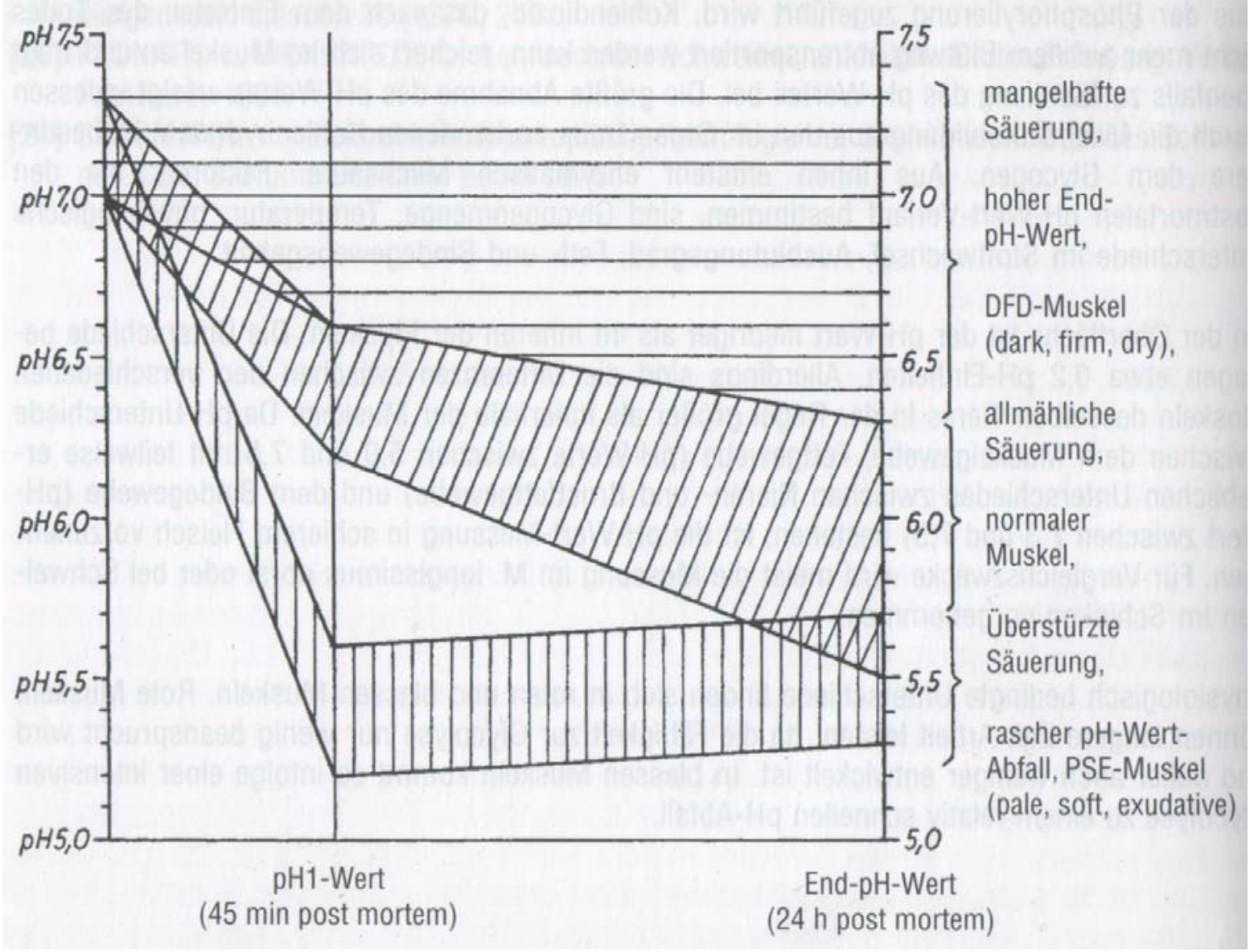

Abb. 4: pH-Wertverlauf p.m. im Schweinemuskel (BENTLER, 1972)

Im Verlauf einiger Tage kommt es wieder zu einem Anstieg des $\mathrm{pH}-$ Wertes, dieser ist jedoch auf mikrobielle Tätigkeit zurückzuführen (SIELAFF,1996).

In welchem Umfang die $\mathrm{pH}$ - Wert - Absenkung bei Puten post mortem erfolgt, zeigt Tabelle 5.

Tab. 5: pH - Werte von Putenbrustmuskeln zu verschiedenen postmortalen Messzeitpunkten

\begin{tabular}{|c|c|c|}
\hline $\begin{array}{c}\text { Messzeitpunkt } \\
\text { post mortem }\end{array}$ & $\mathrm{pH}-$ Wert & Quelle \\
\hline $15 \mathrm{~min}$. & $\approx 6,25$ & WOJCIK et al., 2004 \\
\hline $15 \mathrm{~min}$. & $5,71-7,0$ & FRAQUEZA et al., 2001 \\
\hline $20 \mathrm{~min}$. & $6,8-6,2$ & DRANSFIELD und SOSNICKI 1999 \\
\hline $30 \mathrm{~min}$. & $6,69 \pm 0,13$ & OBANOR et al., 2005 \\
\hline $4 \mathrm{~h}$. & 5,94 & MC KEE et al., 1998 \\
\hline $24 \mathrm{~h}$. & $5,93 \pm 0,09$ & OBANOR et al., 2005 \\
\hline
\end{tabular}


WICKE et al. (2000a) konnten in Ihren Untersuchungen an der Putenbrustmuskulatur feststellen, dass jene mit niedrigen $\mathrm{pH}$ - Werten ebenfalls auch eine niedrige mitochondrale Atmungsrate von Pyruvat aufweisen. Als Ursache hierfür wurde eine verminderte Aktivität der Pyruvatdehydrogenase, eine reduzierte oxidative Nutzung des Pyruvats und eine vermehrte Laktatbildung vermutet. Des Weiteren konnten WICKE et al. (2000a) folgende Beziehungen (Tab.6) zwischen dem pH - Wert 20 min p.m. und schlachtkörperrelevanten Parametern aufzeigen und damit direkt auf den Einfluss der Selektion auf hohes Schlachtkörpergewicht / Brustmuskelanteil und dem $\mathrm{pH}-$ Wert als Fleischqualitätskriterium hinweisen.

Tab. 6: Schlachtkörperzusammensetzung, CK-Aktivität und histometrische Parameter in Abhängigkeit vom pH - Wert 20 min. p.m. bei Puten (WICKE et al. (2000a)

\begin{tabular}{|l|l|l|l|l|l|}
\hline Parameter & $\begin{array}{l}\text { Schlachtkörper- } \\
\text { gewicht }(\mathrm{kg})\end{array}$ & $\begin{array}{l}\text { Brustmuskel- } \\
\text { anteil (\%) }\end{array}$ & $\begin{array}{l}\text { CK- } \\
\text { Aktivität } \\
\mathrm{Mmol}^{*} \mathrm{~s}^{-} \\
\left.{ }^{-1}\right|^{-1}\end{array}$ & $\begin{array}{l}\text { Faserfläche } \\
10 \text { Wo. } \\
\left(\mu \mathrm{m}^{2}\right)\end{array}$ & $\begin{array}{l}\text { Faserfläche } \\
20 \mathrm{Wo}^{2} \\
\left(\mu \mathrm{m}^{2}\right)\end{array}$ \\
\hline $\begin{array}{l}\mathrm{pH}_{20 \text { min p.m. }} \\
\geq 5,7\end{array}$ & $13,30^{\mathrm{b}}$ & $31,85^{\mathrm{b}}$ & $413^{\mathrm{b}}$ & $3222^{\mathrm{a}}$ & $5651^{\mathrm{b}}$ \\
\hline $\begin{array}{l}\mathrm{pH} \\
\leq 5,7\end{array}$ & $16,03^{\mathrm{a}}$ & $34,90^{\mathrm{a}}$ & $1011^{\mathrm{a}}$ & $3278_{\mathrm{a}}$ & $7081^{\mathrm{a}}$ \\
\hline
\end{tabular}

Unterschiedliche Buchstaben (a; b) kennzeichnen signifikante Mittelwertdifferenzen $(p \leq 0,05)$

RAMMOUZ et al. (2004) konnte zudem signifikante Korrelationen zwischen dem End - pH - Wert und dem Tropfsaftverlust an einem Versuch mit 64 PSE - freien B.U.T. 9 Hähnen nachweisen. Das die Höhe des End - $\mathrm{pH}$ - Wertes auch durch Selektion beeinflusst werden kann, zeigten LE BIHAN-DUVAL et al. (1999), welche für den End - $\mathrm{pH}-$ Wert bei Broilern eine Heritabilität von 0,49 $\pm 0,11$ ermittelten.

Der $\mathrm{pH}-$ Wert bzw. dessen Absenkung p.m. ist ebenfalls durch äußere Faktoren beeinflussbar. So konnten MC KEE und SAMS 1997 nachweisen, dass männliche Nicholas-Puter, welche vor dem Schlachten einem definierten Hitzestress ausgesetzt wurden, einen schnelleren pH - Wert - Abfall p.m. im Brustmuskel zeigten, als die ungestresste Vergleichsgruppe. Der Verlauf der $\mathrm{pH}$ - Wert - Entwicklung ist in Abbildung 5 dargestellt.

NIEWIAROWICZ und PIKUL (1979) unterteilten die $\mathrm{pH}-$ Werte von Hühnern (Broilern) hinsichtlich ihrer möglichen Fleischfehler in drei pH-Wert-Gruppen, gemessen 15 min p.m.: Normales Fleisch zeigte Werte zwischen 5,9 und 6,2. Das Fleisch von PSE-Tieren lag zwischen 5,6 und 5,7. Die pH-Werte der DFD - Tiere lag zwischen 6,4 und 6,7. 


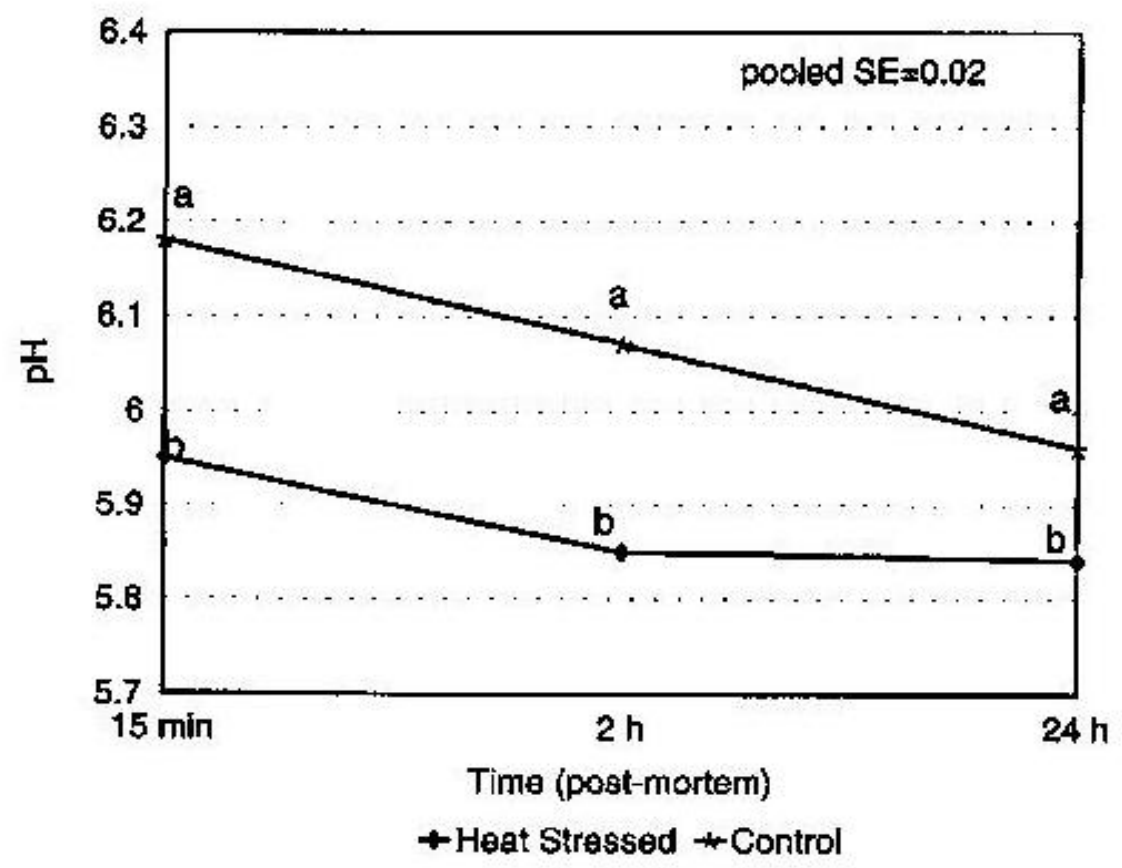

Abb. 5: Einfluss von Hitzestress auf den pH - Wert - Verlauf im M.pect.superfic. von Putern. ( $n=61$ pro Gruppe; $a, b=$ signifikannte Unterschiede zwischen den Gruppen, $p \leq 0,05$; MC KEE und SAMS, 1997).

\subsubsection{Leitfähigkeitswert}

Fleisch ist in der Lage wegen seines hohen Anteils an elektrisch leitender Gewebsflüssigkeit (Elektrolyt) und seiner Struktur als Leiter elektrischen Stroms zu fungieren. Diese Leitfähigkeit beruht auf der Bewegung der lonen im Gewebswasser. Von ausschlaggebender Bedeutung für die lonenbewegung ist zum einen die strukturelle Verteilung der fleischeigenen Elektrolyte innerhalb und außerhalb der Muskelfasern, zum anderen das Wasserbindungsvermögen der intrazellulären Eiweißkörper. Des Weiteren ist der strukturelle Zustand des Sarkolemms sowie die Temperatur des Fleisches Einfluss nehmend auf das Leitfähigkeitsvermögen (SIELAFF,1996).

Als physikalische Messmethode für die Läsionen der Zellmembranen und demnach für den lonenaustausch zwischen den Muskelzellen kann die elektrische Leitfähigkeit (LF) herangezogen werden. Aufgrund des zeitlichen Ablaufs der Strukturveränderungen in den Zellmembranen ist die Leitfähigkeit im Gegensatz zum $\mathrm{pH}$ - Wert als sekundäres Merkmal einzustufen und nach MEIERING (1995) ist mit aussagekräftigen Ergebnissen frühestens 60 min p.m. zu rechnen.

HAHN et al. (2001a,b) konnten einen signifikanten Einfluss des pH - Wertes 20 min p.m. auf die Leitfähigkeitswerte sowohl 20 min p.m., als auch 24 h p.m. nachweisen (Tab.7). 
Tab. 7: pH-Wert und Leitfähigkeit ( $\mathrm{mS} / \mathrm{cm})$ in schnell (pH < 6,2 20 min p.m.) und langsam (pH > $6,5)$ glycolysierender Putenbrustmuskulatur ( $n=80$, HAHN et al. 2001 a,b)

\begin{tabular}{|l|l|l|}
\hline Parameter & LF $(\mathrm{mS} / \mathrm{cm}) 20 \mathrm{~min}$ & $\mathrm{LF}(\mathrm{mS} / \mathrm{cm}) 24 \mathrm{~h}$ \\
\hline $\mathrm{pH}$ niedrig & 7,6 & 10,0 \\
\hline $\mathrm{pH}$ hoch & 4,4 & 3,3 \\
\hline Signifikanter Unterschied & $* * *$ & $* * *$ \\
\hline
\end{tabular}

(Signifikanzgrenzen: n.s.: nicht signifikant; *:p $\leq 0,05 ;{ }^{* *}: p \leq 0,01 ;{ }^{* * *}: p \leq 0,001$ )

SLOWINSKI und STOLARSKI (1998) gaben $12 \mathrm{~min}$ p.m. eine Leitfähigkeit im Brustfleisch bei Truthennen von $4,5 \mathrm{mS} / \mathrm{cm}$ an, $12 \mathrm{~h}$ p.m. betrug die Leitfähigkeit schon 5,4 mS/cm. Bei Hähnen lag der mittlere Leitfähigkeitswert 12 min. p.m. bei 4,9 $\mathrm{mS} / \mathrm{cm}$, nach 12 h p.m. bei 8,4 mS/cm. Der Unterschied zwischen den Geschlechtern wird mit dem ebenfalls signifikant unterschiedlichen Körpergewicht erklärt, welches bei den Hähnen deutlich größer war. Die Autoren geben an, dass der weite Streubereich der ermittelten Leitfähigkeitswerte bei einzelnen Schlachtkörpern darauf hinweist, dass es eine Reihe von Faktoren gibt, die diesen Parameter beeinflussen und somit Einfluss auf die technologische Qualität von Putenfleisch haben können. Des weiteren konnte gezeigt werden, dass sowohl zwischen den $\mathrm{pH}$ - Werten 12 min. p.m. und 12 h p.m. sowie den Leitfähigkeitswerten 12 h p.m. ein reziprokproportionales Verhältnis besteht. Die Autoren räumen jedoch ein, dass der ermittelte Korrelationskoeffizient relativ niedrig ausfiel, was auf einen nur schwachen Zusammenhang der Parameter hinweist. Abschließend wurde belegt, dass der $\mathrm{pH}-$ Wert als messbarer Parameter bessere Vorhersagen zur technologischen Qualität (Wasserbindungsvermögen, Kochverlust,...) von Putenfleisch liefert, als eine Leitfähigkeitsmessung. In diesem Zusammenhang merkten SLOWINSKI und STOLARSKI (1998) entgegen allgemeiner Meinung an, dass die Messstelle für die Einstichelektroden im Brustmuskel keinen Einfluss auf die Messergebnisse erkennen ließ.

\subsubsection{Helligkeits- und Farbwerte}

Das äußere Erscheinungsbild des Produktes Fleisch ist ausschlaggebend für die Kaufentscheidung des Konsumenten. Dazu zählen im Wesentlichen die Fleischhelligkeit, die Fleischfarbe sowie visuell erkennbare Fleischfehler (z.B. Einblutungen im Gewebe) (FLETCHER, 2002). SEBASTIÁN et al. (2003) konnten durch Befragung französischer Geflügelfleischkonsumenten herausfinden, dass diese dem helleren Brustfleisch deutlich zugeneigter waren.

Die für den Farbeindruck hauptverantwortlichen Farbstoffe sind das Myoglobin und das Hämoglobin. Das wasserlösliche Myoglobin ist mit über $90 \%$ des Gesamtpigmentgehaltes das mengenmäßig dominierende Farbpigment. Der Gehalt des Muskels am Blutfarbstoff Hämoglobin hängt von der Menge des nach dem Ausbluten des Schlachtkörpers noch im Muskel verbleibenden Restblutes ab. Bei normal ausgebluteten Tieren macht das Hämoglobin nur wenige Prozent am Gesamtpigmentgehalt aus.

Die Fleischfarbe wird neben der Myoglobinkonzentration ebenfalls von der Wertigkeit des Zentralatoms des Myoglobins bestimmt. Ist das Eisenatom zweiwertig, ist das Myoglobin und das Oxymyoglobin rot bis hellrot, es ist hingegen braun bei dem dreiwertigen Zentralatoms des Metmyoglobins. Ebenfalls ist von entscheidender Bedeutung für die Farbgebung, in welchem Zustand sich das Protein befindet. 
Natives Protein hat eine andere Erscheinung, als denaturiertes, wobei dem $\mathrm{pH}$-Wert und der Temperatur ebenfalls eine Beteiligung an der Farbgebung zugesprochen werden kann (SIELAFF,1996). Bei niedrigem $\mathrm{pH}$-Wert ist das Fleisch in der Regel heller, als bei höherem pH-Wert (WYNVEEN et al. 1999). Extreme Unterschiede werden beim Auftreten von PSE- bzw. DFD-Fleisch deutlich sichtbar (SIELAFF,1996). So ermittelten BARBUT et al. (2005) L* - Werte von 57,7 für PSE Hühnerbrüste und nur L* Werte von 44,8 für DFD - Hühnerbrüste. Diese Einteilung deckt sich im Wesentlichen mit den Vorgaben von PETRACCl et al. (2004), welcher hinsichtlich der Helligkeitswerte für Hühnerbrustfilets folgende Gruppeneinteilung vornahm: Dunkel: $L^{*}<50$; Normal: $50<L^{*}<56$; Blass: $L^{*}>56$. PETRACCl et al. (2004) fanden bei den von innen untersuchten Broilern hinsichtlich der $L^{*}$ - Werte eine Variationsbreite zwischen 40 und 66. Ferner stellte er fest, dass die Broiler im Sommer um etwa 1,7 höhere $L^{*}$ - Werte aufwiesen, als die Vergleichsgruppe im Winter. Auch konnten sie zeigen, dass bei den als blass klassifizierten Broilern ein niedrigerer End - $\mathrm{pH}$ - Wert und ein geringeres Wasserbindungsvermögen zu verzeichnen war, als bei den Vergleichsgruppen. Diese Aussage wurde von WOELFEL und SAMS (2001) durch eigene Untersuchungen untermauert. Zudem belegten die Autoren, dass verschiedene Formen des Marinierens sowie die Konsistenz der Marinade keinen Einfluss auf den Zusammenhang zwischen den $L^{*}$ Werten und den Wasserbindungsparametern nehmen konnten.

RAMMOUZ et al. (2004) belegten, dass sich die $L^{*}$ - Werte im Laufe der Lagerungszeit teilweise erheblich verändern können (Tab.8).

ALVARADO und SAMS (2004) konnten hinsichtlich der Kühlungstemperatur (4 Versuchsgruppen zwischen 0 und $30{ }^{\circ} \mathrm{C}$ ) keine signifikanten Unterschiede hinsichtlich der $L^{*}$ - Werte feststellen. Die gemessenen Werte wurden sowohl an 60 min, wie auch an 105 min p.m. ausgebeinten Putenbrüsten 24 h p.m. ermittelt.

Tab. 8: Entwicklung der L* - Werte von PSE - freiem Putenbrustfleisch über einen Zeitraum von 9 Tagen (Mittelwert, Standardfehler, Minimum, Maximum, $n=64$; Rammouz et al. 2004)

\begin{tabular}{|l|l|l|l|}
\hline Parameter & MW \pm SE & Min & Max \\
\hline$L^{*} 24 h$ p.m. & $48,29 \pm 0,38$ & 40,60 & 57,60 \\
\hline$L^{*} 3$ d p.m. & $52,42 \pm 0,36$ & 46,87 & 58,57 \\
\hline$L^{*}$ 6 d p.m. & $53,16 \pm 0,34$ & 46,10 & 58,69 \\
\hline$L^{*}$ 9 d p.m. & $50,43 \pm 0,29$ & 44,28 & 56,49 \\
\hline
\end{tabular}

Von diversen Autoren ( BARBUT, 1993, 1997 a,b; LAAK et al. 2000; OWENS et al., 2000; WILKINS et al., 2000; WOELFEL et al., 2002; GALOBART und MORAN, 2004) wird der $L^{*}$ - Wert als Beurteilungskriterium für PSE - Fleisch betrachtet. Von anderen Autoren hingegen (SANTÉ et al. 1991;BERRI et al. 2001) wird die Fleischhelligkeit nicht zwingend mit dem PSE - Syndrom in Verbindung gebracht, wohl aber mit intensiver Selektion auf die Parameter Wachstum und Fleischanteil sowie dem genetisch festgelegten Anteil an Häm-Farbstoffen. OWENS und SAMS (2000) erstellten die These, dass der $L^{*}$ - Wert des Fleisches direkt mit dem $\mathrm{pH}-$ Wert zusammenhängt und begründen dies mit dem Umstand, dass niedrige $\mathrm{pH}-$ Werte zur Proteindenaturierung führen, welche das Fleisch blasser werden lassen. Sie fanden bei männlichen Puten, welche unter Standardbedingungen aufgezogen, transportiert und geschlachtet wurden, einen mittleren $L^{*}$ - Wert von 49,35. Auch MC KEE et al. (1998) fanden mittlere $L^{*}$ - Werten von 50,61 im Brustmuskel in einem Versuch an 44 männlichen Puten der Linie Nicholas. 
Einen direkten Zusammenhang zwischen den $\mathrm{L}^{*}$ - Werten und den postmortalen $\mathrm{pH}$ - Werten konnten LAAK et al. (2000) mit einem Korrelationskoeffizienten von -0,76 statistisch absichern und auch FLETCHER (2002) spricht von hohen Korrelationen zwischen pH - Wert und Fleischhelligkeit beim Geflügel. HAHN (2001b) beschrieb ebenfalls eine relativ enge kurvilineare Beziehung $(r=0,7)$ zwischen den Parametern $L^{*}$ und $\mathrm{pH}_{1,5 \mathrm{~h}}$ - Wert. Interessant ist, dass bei demselben Probenmaterial die Korrelation $24 \mathrm{~h}$ p.m. geringer ausfiel $(r=0,64)$.

MC KEE und SAMS (1997) fanden bei hitzegestressten männlichen Mastputen höhere $L^{*}$ - Werte, als bei den unter normalen Temperaturen gehaltenen Vergleichstieren (Abb.6). HAHN et al. (2001a,b) konnten dagegen keine signifikanten Korrelationen zwischen den $\mathrm{pH}$ - Werten 20 min p.m. und den $\mathrm{L}^{*}$ und $\mathrm{b}^{*}$ - Werten absichern, wohl aber zwischen den pH - Werten 20 min p.m. und den $a^{*}-$ Werten (Tab.9).

Tab. 9: Farbmesswerte $\left(L^{*}, a^{*}, b^{*}\right)$ in schnell $(\mathrm{pH}<6,2)$ und langsam $(\mathrm{pH}>6,5)$ glycolysierender Putenbrustmuskulatur ( $n=80$, HAHN et al. $2001 \mathrm{a}, \mathrm{b}$ )

\begin{tabular}{|l|l|l|l|}
\hline Parameter & $\mathrm{L}^{*}$ & $\mathrm{a}^{*}$ & $\mathrm{~b}^{*}$ \\
\hline $\mathrm{pH}$ niedrig & 51,6 & 5,8 & 2,0 \\
\hline $\mathrm{pH}$ hoch & 51,1 & 4,6 & 1,8 \\
\hline Signifikanter Unterschied & n.s. & $* \star *$ & n.s. \\
\hline
\end{tabular}

(Signifikanzgrenzen: n.s.: nicht signifikant; ${ }^{*}: p \leq 0,05 ;{ }^{* *}: p \leq 0,01 ;{ }^{* *}: p \leq 0,001$ )

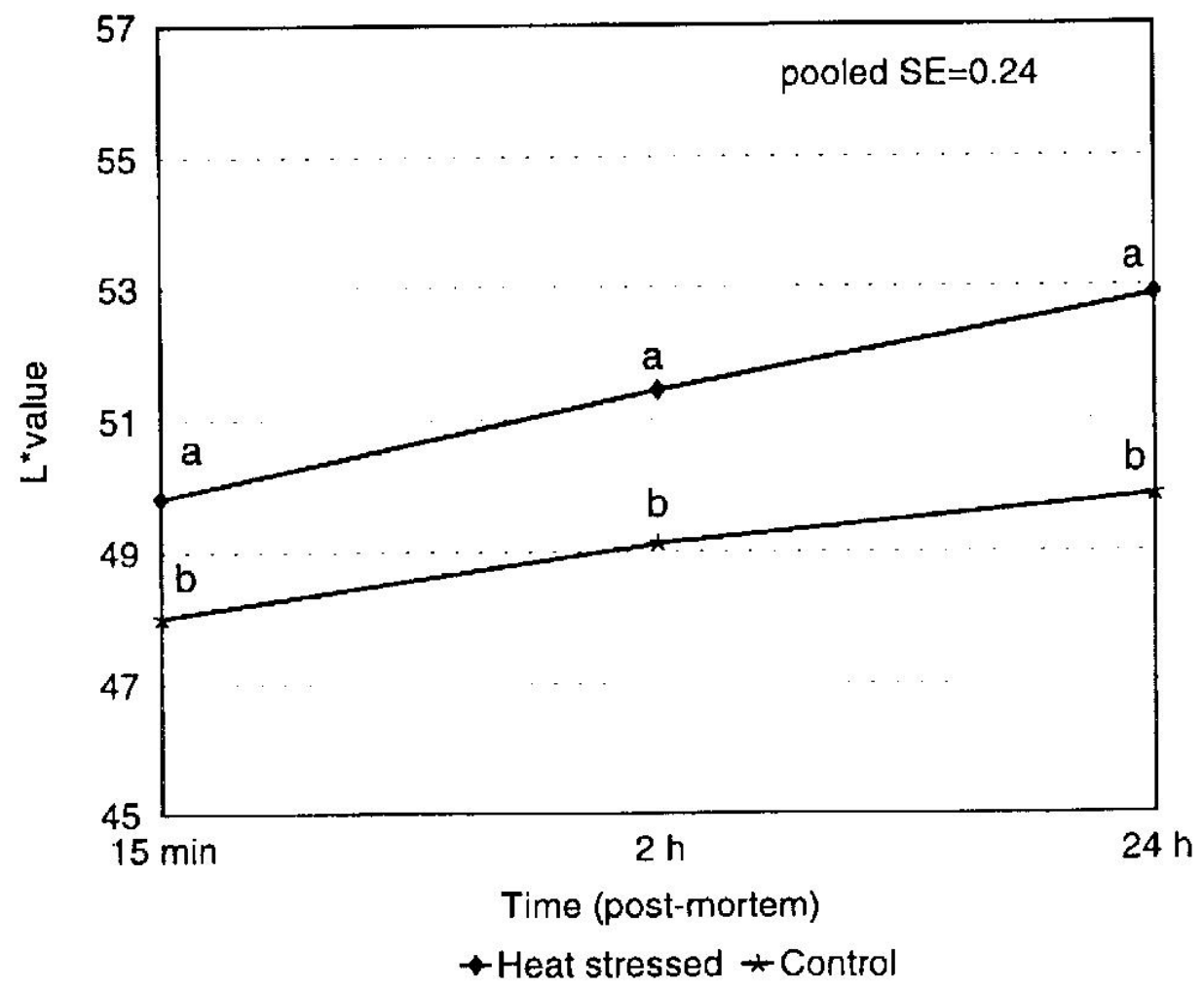

Abb. 6: Einfluss von Hitzestress auf denL* - Wert - Verlauf im M.pect.superfic. von Puten. ( $n=61$ pro Gruppe; $a, b=$ signifikannte Unterschiede zwischen den Gruppen, $p \leq 0,05$; MC KEE und SAMS, 1997) 
OWENS et al. (2000) beschrieben höchstsignifikante Korrelationen zwischen dem $L^{*}$ - Wert und dem prozentualen Tropfsaftverlust sowohl 1,5 als auch 24 h p. m. $(r$ $0,50 / 0,54)$.

LE BIHAN-DUVAL et al. (1999) konnten für den $L^{*}$ - Wert bei Broilern eine Heritabilität von $0,75 \pm 0,08$, für den $a^{*}$ - Wert von $0,81 \pm 0,04$ und für den $b^{*}-$ Wert von $0,64 \pm 0,06$ bestimmen.

Von verschiedenen Autoren (NAM und AHN, 2002; NANKE et al., 1998) wurde beschrieben, dass Bestrahlung, welche ursprünglich zur Absenkung der Mikrobentätigkeit angewendet wurde, zu einer Erhöhung der $a^{*}$ - Werte führt. In welchem Umfang diese $a^{*}$ - Wert - Anhebung stattfindet, richtet sich nach Spezies, Muskeltypus, Dosierung der Bestrahlung sowie der anschließenden Lagerung bzw. Verpackung (AHN et al., 1998). BOJARSKA et al. (2003) konnten an Putenbrüsten von Mastputern Unterschiede in Helligkeit und Farbe zwischen unterschiedlichen Messpunkten darstellen.

\subsubsection{Wasserbindungsvermögen}

Die Muskulatur besteht zu $70-76 \%$ aus Wasser. Dieses Wasser kann unterschiedlich stark an die Muskelproteine gebunden sein. Ein sehr kleiner Teil ( ca. $0,1 \%)$ ist innerhalb der Proteinmoleküle zu finden und wird als konstitutionelles Wasser bezeichnet. Weitere $4 \%$ des Fleischwassers bilden einen Wassermantel um die Proteine (sog. Hydratationswasser), welche ebenfalls relativ fest an das Protein gebunden sind. Die restlichen $95 \%$ betreffen jenes Wasser, welches durch bestimmte Einwirkungen mobilisiert werden kann. Die Aufnahme bzw. Abgabe des Wassers beruht dabei im Wesentlichen auf der Quellung bzw. Schrumpfung der Myofibrillen (OFFER und TRINICK, 1983).

Unter dem Wasserbindungsvermögen versteht HAMM (1972) das Festhalten von eigenem oder zugesetztem Wasser bei Einwirkung äußerer Einflüsse ( Druck, Temperatur).

In der Literatur werden zahlreiche Faktoren genannt, welche das Wasserbindungsvermögen beeinflussen. Diese können in innere und äußere Faktoren unterschieden werden.

Zu den inneren Faktoren zählen Alter und Geschlecht des Tieres, Species, Muskeltyp sowie der Anteil des intramuskulären Fettes.

Ferner spielt die Wasserstoffionenkonzentration im Muskel eine relativ große Rolle, da das Actomyosin bei einem pH-Wert von 5,0 hinsichtlich des Wasserbindungsvermögens ein Minimum aufweist (dieser $\mathrm{pH}-$ Wert ist zugleich der isoelektrische Punkt des Actomyosins). HAMM (1996) beschrieb, dass sich der Einfluss des $\mathrm{pH}$ - Wertes auf das Wasserbindungs- und Quellungsvermögen des Fleisches mit der elektrostatischen Theorie der Quellung erklären lässt, die auf der Wechselwirkung zwischen positiv und negativ geladenen Gruppen des Muskelproteins beruht. Die Ergebnisse seiner Untersuchungen sprachen zugunsten dieser Theorie und vieles deutet darauf hin, dass für das Wasserbindungsvermögen des Fleisches der Ladungszustand des Histidins im myofibrillären Eiweiß von besonderer Bedeutung ist.

Letztendlich ist der postmortale, physiologische Status des Muskels bedeutsam, da der Abbau von ATP einen nachteiligen Einfluss auf das Wasserbindungsvermögen hat. Generell ist das Wasserbindungsvermögen vor dem Rigor mortis höher, als danach (SIELAFF,1996). 
Zu den äußeren Faktoren zählen zunächst die Vorgänge vor dem Tod des Individuums (Fütterung, Bewegung, Erregungszustand, Betäubungsmethode...).

Auch der Schlachtmethode selbst wird ein Einfluss auf das Wasserbindungsvermögen unterstellt. Nach dem Schlachten sind die Vorgänge des Kühlens, der Fleischverarbeitung, der Elektrostimulation und der Fleischreifung Einfluss nehmend. Die Größe und die Form des Fleischstückes sowie Größe und Anzahl der Schnittflächen spielen hinsichtlich des Wasserbindungsvermögens eine Rolle (OFFER und TRINIK, 1983; HAMM, 1986; FENNEMA, 1990).

Auch unerwünschte Fleischveränderungen können das Wasserbindungsvermögen beeinflussen. So ist von diversen Autoren festgestellt worden, dass das Wasserbindungsvermögen bei PSE - Fleisch (Schwein und Geflügel) gering ist. Dieser Umstand bezieht sich auch auf die Kochverlustrate von PSE - Putenfleisch (MC KEE and SAMS, 1998; FRONING 1978). MOLETTE et al. (2005) bestätigen diese Aussage und nennen als Ursache einen schnellen, postmortalen $\mathrm{pH}-$ Wertabfall im Putenfleisch. Von OFFER (1991) wird neben dem $\mathrm{pH}$ - Wert noch eine hohe Temperatur des Fleisches für ein geringes Wasserbindungsvermögen verantwortlich gemacht. Er führt an, dass sich die Größe der Myosinköpfchen im PSE - Muskel/Fleisch von $19 \mathrm{~nm}$ auf $17 \mathrm{~nm}$ reduziert. Dadurch werden Aktin - und Myosinfilamente enger aneinander gezogen und so mehr Wasser aus dem Muskel gepresst, als dieses bei normalem Fleisch der Fall ist.

Das Wasserbindungsvermögen lässt sich zum einen über die Bestimmung des Tropfsaftverlustes, zum anderen über die Grillverlustbestimmung beschreiben.

\subsubsection{Tropfsaftverlust}

Unter dem Tropfsaftverlust (auch als Dripverlust bezeichnet) versteht man die Bildung eines Exsudats ohne direkte Einwirkung äußerer Kräfte unter spezifizierten Bedingungen (SIELAFF,1996). RAMMOUZ et al. (2004) konnten nachweisen, dass die Bestimmung des Tropfsaftverlustes bei Putenfleisch über einen längeren Zeitraum veränderte Werte erzeugt (Tab.10).

Tab. 10: Tropfsaftverlustentwicklung (in \%) bei PSE - freien Puten über einen Zeitraum von 9 Tagen (Mittelwert, Standardfehler, Minimum, Maximum, $n=64$; RAMMOUZ et al. 2004)

\begin{tabular}{|l|l|l|l|}
\hline Parameter & MW \pm SE & Min & Max \\
\hline Tropf.-verl. nach 3 d & $0,57 \pm 0,02$ & 0,14 & 1,43 \\
\hline Tropf.-verl. nach 6 d & $1,22 \pm 0,04$ & 0,82 & Ohne Angabe \\
\hline Tropf.-verl. nach 9 d & $1,90 \pm 0,05$ & 1,38 & 3,51 \\
\hline
\end{tabular}

WYNVEEN et al. (1999) belegten, dass ein direkter Zusammenhang zwischen dem Tropfsaftverlust und dem $\mathrm{pH}-$ Wert 14 min p.m. besteht. So hatten Puten mit einem $\mathrm{pH}$ - wert $\leq 5,70$ einen um $1 \%$ höheren Tropfsaftverlust $(1,75 \%)$ als Puten mit hohem pH - Wert $\geq 6,18(0,75 \%)$.

FERNANDEZ et al. (2002) konnten in Versuchen an drei Putengenotypen zeigen, dass der schnell wachsende Putengenotyp einen signifikant geringeren Tropfsaftverlust aufwies, als der langsam wachsende Vergleichstyp, bzw. deren Kreuzungsprodukt. Ferner konnten sie in Folgeversuchen (FERNANDEZ et al. 2002) absichern, dass ein niedriger $\mathrm{pH}$ - Wert 20 min p.m. einhergeht mit vergleichsweise hohen Tropfsaftverlusten im M.pect. superfic.. Diese Aussage konnte von MOLETTE et al. (2003a) bestätigt werden. 


\subsubsection{Grillverlust}

Die thermische Einwirkung auf Fleisch kann Schätzungen darüber ermöglichen, wie hoch die Verluste von Flüssigkeit, bzw. das Wasserhaltevermögen bei der Zubereitung des Fleisches geartet sind. Dieses wird in der Literatur in den meisten Fällen über die Ermittlung des Kochverlustes getan (OWENS und SAMS, 2000).

Geflügelfleisch wird aber in der Regel vom Verbraucher nicht gekocht, sondern gebraten, bzw. gegrillt, weshalb in der nachfolgenden Untersuchung mit der Grillverlustbestimmung gearbeitet wurde. Da sowohl beim Kochverlust, wie auch beim Grillverlust eine thermische Einwirkung auf das Fleisch stattfindet, lassen sich die Ergebnisse aus beiden Versuchsanordnungen zumindest tendenziell miteinander vergleichen. OWENS und SAMS (2000) konnten bei 21 Wochen alten männlichen Puten einen Kochverlust von 22,40 \% nachweisen.

\subsubsection{Scherkraft}

Es gibt verschieden Möglichkeiten, Fleisch hinsichtlich seines Verhaltens beim Verzehr zu charakterisieren. Die Begriffe reichen von plastisch $\leftrightarrow$ elastisch über zart und zäh zu weich und mürbe. Um allen genannten Formulierungen gerecht zu werden, werden sie unter dem Begriff „TEXTUR“ zusammengefasst (SZCZENIAK, 1963; KLETTNER, 1976; LEE und SCHÖN, 1985).

Die Einflüsse auf die Textur des Fleisches sind im Wesentlichen:

- Biologische Einflüsse,

- Zusammensetzung und Struktur des Fleisches,

- Haltung, Transport und Schlachtung der Individuen,

- Chemische und physikalische Veränderungen post mortem sowie

- Weitere Behandlungen zur Konservierung bzw. Weiterverarbeitung.

Als biologische Parameter sind Tierart, Alter, Geschlecht sowie die unterschiedlichen Fleischteile des Schlachtkörpers zu nennen.

Die Zusammensetzung des Fleisches, also im Wesentlichen der Gehalt an Fett, Wasser und Protein, ist bedeutsam für die Textur des Fleisches. So wird mit der Marmorierung (Fetteinlagerung) ein positiver Einfluss auf die Textur des Fleisches verknüpft. Der Proteingehalt des Fleisches, insbesondere des darin enthaltenen Bindegewebes, nimmt deutlichen Einfluss auf die Textur. Dabei kommt es allerdings weniger auf die Quantität, sondern eher auf die Struktur des Proteins an. Mit zunehmendem Alter des Tieres bilden sich zwischen den Strukturproteinen Quervernetzungen, welche die Festigkeit des Fleisches erhöhen. SIELAFF(1996) erklärt deshalb, dass jüngere Tiere durchweg ein zarteres Fleisch liefern müssten, als ältere Tiere. Er führt des weiteren an, dass auch die Muskelfaserdicke eine entscheidende Rolle für die Zartheit des Fleisches spielt.

OBANOR et al. (2005) machten den Grad der Verkürzung der Sarkomere während des Rigor Mortis sowie das fortschreiten der postmortalen Proteolyse verantwortlich für die spätere Textur des Fleisches. Sie belegten dieses mit der Tatsache, dass im Brustmuskel, welcher 3 h p.m. vom Schlachtkörper entfernt wird, signifikant kürzere Sarkomere und damit höhere Scherwerte aufwies, als die $24 \mathrm{~h}$ - Vergleichsgruppe.

WAKEFIELD et al. (1989) fanden heraus, dass schnelles Herunterkühlen des Schlachtkörpers bei Puten zu verkürzten Sarkomeren und damit zu zäherem Fleisch führt. 
Hinsichtlich des Haltungseinflusses fand WABECK (1974) heraus, dass Tiere aus Käfighaltung im Vergleich zu jenen aus Bodenhaltung ein zarteres Brustfleisch aufwiesen. Somit scheint sich ein höheres Bewegungspensum negativ auf die Textur auszuwirken.

Generell gilt, dass Haltung und Transport so zu erfolgen haben, damit eine möglichst geringe Aufregung/Belastung der Tiere eintritt. Bei ordnungsgemäß vorgenommenem Transport ist Geflügel allerdings recht unempfindlich. RISTIC (1978), EHINGER und GSCHWINDT (1981) sowie HOOF (1979) stellten keinen negativen Einfluss der Transportzeit bis zu $6 \mathrm{~h}$ auf die Fleischqualität fest. FRONING et al. (1978) geben jedoch zu bedenken, dass hohe Außentemperaturen während des Transports sowie lange Wartezeiten vor dem Schlachten die Zähigkeit des Brustfleisches erhöhen.

Im Schlachthof haben die Vorgänge des Betäubens, Rupfens und des Kühlens bzw. Gefrierens sowie des Zerlegens unterschiedlichen Einfluss auf die Fleischqualität.

OBANOR et al. (2005) stellten fest, dass frühes Zerlegen bzw. Ausbeinen (3 h p.m.) zäheres Fleisch hervorbringt, als spät zerlegtes. Die Verwendung eines Gefriergebläses erhöhte bei dem gleichen Versuch, unabhängig vom Zerlegezeitpunkt, die Scherkraftwerte um 20 - $40 \%$.

Die Untersuchungen von ALVARADO und SAMS (2000) stimmen nur zum Teil mit den Aussagen von OBANOR et al. (2005) überein, da Sie im Versuch belegten, dass Putenbrustfleisch, welches 2 h p.m. oder später zerlegt wird, keinen nennenswerten Unterschied zueinander hinsichtlich der Zartheit aufweist.

Es wurde von mehreren Autoren ( FRONING et al. 1978; BARBUT,1993; MC KEE und SAMS, 1998) belegt, dass rohes PSE - Fleisch zarter ist, als thermisch behandeltes Fleisch (kochen, grillen,...). MOLETTE et al. (2003a, 2005) untermauern diese Aussagen und belegen zudem, dass Fleisch mit rapidem $\mathrm{pH}$ - Wertabfall sowohl im rohen, als auch im gekochten Zustand höhere Scherkraftwerte aufweist, als das bei Putenfleisch mit normalem pH - Wertverlauf p.m. der Fall ist. Bei gekochtem Fleisch lagen die Scherkraftwerte bei Fleisch mit schnellem $\mathrm{pH}-$ Wertabfall sogar um 50 \% über jenen der Vergleichsgruppe mit normalem $\mathrm{pH}-$ Wertverlauf. Ferner wurde beschrieben, dass Fleisch mit geringer Zartheit unter erhöhten Temperaturen während des Rigor mortis hohe Flüssigkeitsverluste zeigt. HAHN et al. (2001a,b) konnten keinen signifikanten Zusammenhang zwischen dem $\mathrm{pH}$ - Wert und der Scherkraft absichern.

RAMMOUZ et al. (2004) ermittelte an 64 B.U.T. 9 Hähnen $\left(\mathrm{pH}_{20 \text { min }}\right.$ zwischen 6,0 und 6,1 ) eine mittlere Scherkraft von $34,20 \mathrm{~N} / \mathrm{cm}$, der kleinste Wert lag bei $15,67 \mathrm{~N} / \mathrm{cm}$, der höchste Wert bei $90,10 \mathrm{~N} / \mathrm{cm}$.

\subsection{Aviäres Stress Syndrom (ASS)}

Die extreme Wachstumskapazität der Brustmuskulatur bei Puten hat gravierende Folgen. MAHON (1999) belegte, dass mit höheren Brustmuskelgewichten größere Muskelfaserdurchmesser gekoppelt sind. Auch weisen Puten neben vergleichbaren Tierarten die bei weitem größten Muskelfaserdurchmesser auf. Des Weiteren war auffällig, dass Puten in der Brustmuskulatur fast ausschließlich Muskelfasern vom schnell kontrahierenden, glycolysierenden Typus zeigten. Fasertyp und Faserdicke verwiesen darauf, dass die Brustmuskulatur der Pute prädisponiert war, hinsichtlich des Stoffwechsels unangemessen auf verschiedene Einflussfaktoren zu reagieren. Daraus lassen sich sowohl Myopathien, als auch Muskelfaserdegenerationen im Brustmuskel ableiten. 
Diese Merkmalskombinationen weisen bemerkenswerte Parallelen zum StressSyndrom des Schweins auf (Porcines-Stress-Syndrom), so dass analog dazu von einem Aviären-Stress-Syndrom (ASS) gesprochen werden darf. Zu diesem Syndrom gehören neben den genannten Myopathien auch Fleischqualitätsmängel im Sinne von PSE- und DFD- ähnlichem Fleisch sowie der plötzliche Herztod bei Handling und Transport der Tiere (BRANSCHEID et al. 2004b). Als weiteres Charakteristikum weisen Puten derzeitiger Hybridlinien zu einem gewissen Anteil halothansensitive (3,5\%) Individuen auf (OWENS et al. 2000b).

\subsubsection{Hypertrophie}

Schon 1976 konnten WISKUS et al. nachweisen, dass der Brustmuskel bei Mastputen zu nahezu $100 \%$ aus weißen Muskelfasern (FTG) besteht. Dieser Fasertyp wies im Vergleich zu den intermediären und weißen Muskelfasern die größten Durchmesser auf. Auch WICKE et al. (2001) und LENGERKEN et al. (2002) zeigten bei Puten und Hühnern ein fast ausschließlich aus weißen Muskelfasern bestehendes Brustfleisch. WICKE et al. (2001) formulierte in diesem Zusammenhang weiter, dass zum Vergleich das Wassergeflügel nur etwa $10-20 \%$ weiße Muskelfasern im Brustmuskel besitzt. Er führt diesen Umstand darauf zurück, dass Enten und Gänse als ursprüngliche Zugvögel ein ausdauernderes Flugvermögen haben, als die Hühnervögel, deren Hauptfortbewegungsart das Laufen darstellt. ELMINOWSKA-WENDA et al. (2005) fanden bei B.U.T. Big 6 Hähnen im M. pect. superfic. 91,6\% weiße Muskelfasern, dagegen nur 8,4\% oxidative Fasern.

KLOSOWSKA et al. (1985) konnten an Schweinen aufzeigen, dass mit zunehmendem Alter die Zahl der roten und intermediären Fasern sinkt, die Zahl der weißen Fasern dagegen steigt. Somit scheinen die Anteile der unterschiedlichen Muskelfasertypen am Gesamtgewebe Altersabhängig zu sein.

DRANSFIELD und SOSNICKI (1999) beschrieben, dass mit zunehmendem Alter (postnatal) auch der Durchmesser der Muskelfasern ansteigt. Ferner zeigten sie für glycolytische Muskelfasern einen schnelleren Rigor mortis - Verlauf.

SAMS und JANKY (1991) wiesen dagegen in eigenen Versuchen an Geflügel (Broiler) nach, dass die Entwicklung des Rigor mortis bei roten Muskelfasern signifikant schneller abläuft, als bei den anaeroben weißen Fasern.

SALOMON et al. (1990) bewiesen nach eingehenden Untersuchungen an weiblichen Puten, dass das Muskelfaserwachstum (als Parameter wurde der Durchmesser verwendet) zu $99 \%$ am 166. Lebenstag des Tieres abgeschlossen ist.

MICHEL und SALOMON konnten 1977 aufzeigen, dass bei trainierten Tieren

(Schweinen) die beanspruchten Muskelfasern größere Durchmesser aufwiesen, als jene der untrainierten Vergleichsgruppe. Somit ist der Muskelfaserdurchmesser auch abhängig von seinem Trainingszustand.

BENTLEY (1999) konnte an Versuchen belegen, dass eine intensive Selektion auf hohe Körpergewichte den Muskelzelldurchmesser deutlich erhöht, nicht aber die Zellzahl. Ferner konnte er nachweisen, dass der Muskelzelldurchmesser enger mit dem Brustmuskelgewicht, als mit dem Körpergewicht korrelliert. Bei weiteren histologischen Untersuchungen des Einflusses einer intensiven Selektion auf die Parameter Wachstum, Futterverwertung und Muskelfleischanteil konnte festgestellt werden, dass eine züchterische Erhöhung des Körpergewichts zu einer Zunahme des Muskelfaserdurchmessers führt (OTTO und WEGNER 1976; VELLEMAN et al., 2003 a, 2003 b). 
In derselben Untersuchung wurde beobachtet, dass sich bei älteren Masttieren der extrazelluläre Raum im Muskelgewebe deutlich verringert. LENGERKEN et al. (2002) stellten fest, dass die weißen Muskelfasern im Brustmuskel von Puten signifikant größer waren, als die weißen Muskelfasern des M. longissimus dorsi beim Schwein. Bezüglich der Putengenotypen Big6 (B.U.T.) und BBB (Kelly) konnten OPALKA et al. (2004) keine nennenswerten histologischen Unterschiede absichern.

\subsubsection{Blutparameter}

Im Rahmen der klinischen Diagnostik existiert eine ganze Reihe verschiedener Blutparameter, welche Rückschlüsse auf die Kondition bzw. Konstitution des zu untersuchenden Individuums zulassen. In der Literatur über den postmortalen Muskelstoffwechsel ist die Creatinkinaseaktivität im Blutserum ein häufig bestimmter Parameter. Auch der Laktatgehalt im Blutserum findet Erwähnung, jedoch in erster Linie in der Herzdiagnostik. Ein hoher Laktatgehalt findet sich regelmäßig bei Herzinfarktpatienten und ist eng mit der Sauerstoffversorgung des Myokards gekoppelt (SEVEN et al., 1998). Beide Parameter liefern möglicherweise Anhaltspunkte zum ASS und werden im Rahmen der eigenen Untersuchungen bestimmt.

\subsubsection{Creatinkinaseaktivität}

Muskeln mit hohem ATP - Umsatz haben einen Speicher für freie Enthalpie, welche für eine rasche Regeneration von ATP sorgt. Bei Wirbeltieren ist dies das Phosphocreatin, welches durch reversible Phosphorylierung von Creatin durch ATP synthetisiert wird.

\section{ATP + Creatin $\longleftrightarrow$ Phosphocreatin + ADP}

Katalysiert wird diese Reaktion durch das Enzym Creatinkinase (VOET und VOET, 1992). WILSON et al. (1990) stellten nach eigenen Untersuchungen fest, dass Puten, welche intensiv auf schnelles Wachstum selektiert wurden, neben zahlreichen Muskeldegenerationen auch höhere Creatin-Kinase - Werte im Stichblut aufwiesen. Gestützt werden diese Ergebnisse durch neuere Untersuchungen von VELLEMAN und NESTOR (2004), sowie VELLEMAN et al., (2003a, 2003 b), welche zeigten, dass intensiv auf schnelles Wachstum selektierte Puten mit $12956 \mathrm{U} / \mathrm{l}$ im Vergleich zur unselektierten Ausgangslinie (6634 U/L) einen etwa doppelt so hohen CK - Level aufwiesen. Auch HOCKING et al. (1998) konnten bei Mastputen (Large White) höhere CK - Werte als bei einer traditionellen Linie auffinden. Der Unterschied wurde allerdings erst ab der zwölften Lebenswoche deutlich, denn von diesem Zeitpunkt an stiegen die CK - Werte der Mastputen im Vergleich zur Kontrolllinie extrem stark an. HOCKING et al. (1998) konnten ferner nachweisen, dass sich die CK - Werte bei männlichen und weiblichen Tieren nicht voneinander unterschieden und dass sie sich durch die Fütterung beeinflussen lassen; ad libitum - Fütterung begünstigt hohe CK - Werte.

MITCHEL und SANDERCOCK (1995) definieren den CK - Level im Plasma als Marker zur Quantifizierung von Muskelschädigungen. Auch HAHN (2000) beschrieb den CK-Level als gewebsspezifischen Indikator für Skelettmuskelschäden. Ferner führte sie aus, dass die CK - Freisetzung im Muskel durch eine gestörte intrazelluläre Kalziumregulation bestimmt wird. 


\subsubsection{Laktatgehalt}

Die Entstehung und Bedeutung des Laktats im Muskel ist bereits in den Kapiteln postmortale Veränderungen im Muskel und $\mathrm{pH}$ - Wert dargestellt. Der Laktatgehalt im Stichblut lässt Rückschlüsse auf die Sauerstoffversorgung der Muskulatur im Allgemeinen aber der Herzmuskulatur im Besonderen zu. (HAAS, 2005) beschreibt bei unzureichender Sauerstoffversorgung von Schweineherzen einen Anstieg des Laktatgehaltes im Stichblut von Schweinen. APPLE et al. (1995) konnte an Schafen nachweisen, dass die gestressten Tiere signifikant höhere Laktatwerte im Blut zeigten, als die ungestressten Vergleichstiere. Für Mastputen konnten für diesen Parameter keine Referenzdaten in der Literatur gefunden werden.

\subsubsection{Kapillarisierung}

BRANSCHEID et al. $(2004 a, b)$ zeigten bei Mastputen mit den primären Selektionszielen Mastendgewicht und Brustmuskelanteil eine geringe Kapillarisierung und damit erschwerte Sauerstoff- und Nährstoffzufuhr sowie gestörte Vorgänge beim Abtransport von Stoffwechselprodukten, insbesondere $\mathrm{CO}_{2}$ und Laktat. Auch WICKE et al. (2001) konnten aufzeigen, dass rote Muskelfasern mit geringem Durchmesser eine bessere Kapillarisierung aufwiesen, als die weißen Fasern mit vergleichsweise großem Durchmesser. Dies wurde von ASHMORE et al. (1972) und KLOSOWSKA et al. (2000) sowie von COOPER et al. (1996) ebenso dargestellt.

In $88 \%$ aller Fälle verliefen die Kapillaren parallel zur Längsachse der Muskelfasern (KROMPECHNER et al., 1970; HOPPELER und HUDLICKA; 1984).

Während des intensiven Wachstums der Putenbrustmuskulatur erhöht sich die Anzahl der Kapillaren begleitend zur Hypertrophie nicht. Dieser Umstand kann laut ELMINOWSKA-WENDA et al. (2005) zu degenerativen Muskelveränderungen führen.

Die Kapillarverteilung hängt nach Aussagen mehrerer Autoren vorrangig vom Sauerstoffbedarf des Muskelgewebes ab. Weiße Muskelfasern mit überwiegend glykolytischem Metabolismus weisen deshalb im Vergleich zu den roten Muskelfasern mit oxidativem Stoffwechsel eine deutlich geringere Kapillarisierung auf (HOPPELER et al., 1981; HOPPELER und HUDLICKA, 1984; HUDLICKA, 1985). ELMINOWSKA-WENDA et al. (2005) konnten im M. pectoralis superficialis, einem Muskel mit fast vollständig glykolytischen Muskelfasern, eine Kapillarisierung von 4,15 Kapillaren pro Muskelfaser nachweisen. Der M. biceps femoris, ein Muskel mit erheblich höherem Anteil an roten Muskelfasern, wies pro Muskelfaser 5,61 Kapillaren auf. Untersucht wurde die Muskulatur von 70 B.U.T. Big 6-Hähnen.

MICHEL und SALOMON (1977) konnten nachweisen, dass die Muskeln trainierter Tiere ein signifikant höheres Kapillar-/Zellverhältnis aufwiesen, als jene von untrainierten Tieren. Somit wurde gezeigt, dass sich die Kapillarisierung durch konditionelles Training beeinflussen lässt. SOSNICKI und WILSON (1991) konnten in eigenen Untersuchungen nachweisen, dass Puten mit Myopathien ein signifikant geringeres Kapillar/Faserverhältnis aufwiesen (3,01Kap./Faser) als jene Tiere ohne Myopathien (3,43 Kap./Faser). 


\subsubsection{Blutpunkte}

Einblutungen in das Muskelgewebe vermindert die Verbraucherakzeptanz erheblich (FLETCHER, 2002). Beim Geflügel wird dieser Fleischfehler aufgrund der vergleichsweise hellen Fleischfarbe optisch besonders hervorgehoben. Für die Einblutungen gibt es eine Vielzahl von Ursachen. Man muss zunächst in Betracht ziehen, dass das Geflügel vor dem Schlachten gefangen, verladen, transportiert, wieder abgeladen und in das Schlachtband eingehängt wird. Spitze wie stumpfe Verletzungen können auftreten. Wesentlich wichtiger ist allerdings der Umstand, dass die Tiere durch die genannte Behandlung gestresst werden. Dieser Stress fällt umso stärker aus, je extremer die Umweltbedingungen sind. Durch Stress wird der Kreislauf extrem belastet, das Kreislaufsystem wird stark beansprucht und es kann zu Rupturen der Blutgefäße (insbesondere der Kapillaren) kommen. Zudem werden Kapillaren bei der elektrischen Betäubung und dem Tötungsvorgang belastet. Der im Moment der Betäubung ausgeübte Muskelreiz erhöht den intramuskulären Druck auf die größeren Gefäße. Diese werden dadurch verkleinert, was zu einer Druckerhöhung in den peripheren Venen führt (KRANEN et al., 2000). Die Autoren unterteilten die Hämorrhagien anhand ihrer Morphologie in folgende Gruppen:

1) Petechien

Kleine, punktförmige Blutungen (in Fett und Bindegewebe „speckles“ genannt);

2) Striae

Längliche Blutungen, folgen im Muskelgewebe dem Faserverlauf;

3) Ekchymosen

Größere, flächige Blutungen (mehrere $\mathrm{mm}^{2}$ );

4) Suggilationen

Deutlich begrenzte, flächige Blutungen (mehrere $\mathrm{cm}^{2}$ ).

In der Untersuchung von KRANEN et al. (2000) entstanden die Hämorrhagien aus zerrissenen Venen im interzellulären Gewebe. Zerrissene Blutgefäße arterieller Herkunft konnten nicht nachgewiesen werden. Blutungen in der Muskulatur konnten oft mit Rupturen der Muskelfasern in Zusammenhang gebracht werden.

Auch von anderen Autoren (SOKOLOVA et al. 1988) wird die elektrische Betäubung für Schädigungen an Muskulatur und Blutgefäßsystem verantwortlich gemacht.

Die Intensität der Einblutung hängt vom Grad der Blutgefäßschädigung, dem Blutfluss, der Blutkonsistenz sowie dem Koagulationsstadium ab (KRANEN et al. 2000). Schon 1998 hatten KRANEN et al. an Broilern belegt, dass Einblutungen in die Muskulatur von mehreren Faktoren abhingen. Zu diesen gehörte jedoch nicht die Umgebungstemperatur der Tiere kurz vor dem Schlachten und ein hohes Endgewicht. Die genauen Ursachen wurden nicht dargestellt.

HAHN (2000) spricht zunächst globaler von Hämorrhagien (Blutungen und Blutpunkte). Grundsätzlich sind darunter alle rötlichen Verfärbungen zu verstehen, die durch extravaskuläres Hämoglobin in Fleisch-, Fett- und Bindegewebe hervorgerufen werden. Ursache ist der Austritt von Hämoglobin aus Blutgefäßen, deren Wände Läsionen aufweisen. Als Einflussfaktoren auf das Ausmaß von Hämorrhagien werden unter anderem die Fließeigenschaften des Blutes, Blutdruck und Blutstillung sowie postmortal vorhandene Restblutgehalte im Schlachtkörper, Blutabbau und Blutgerinnung genannt. 
Als auslösende Faktoren für Hämorrhagien im Geflügelfleisch kommen zunächst Verletzungen, Frakturen und Gewebeschäden in Frage. Besonders bei Elektrobetäubung im Wasserbad mit Ganzkörperdurchströmung treten abhängig von den elektrotechnischen Parametern vermehrt Hämorrhagien auf. Prämortaler Stress, der allgemeine Zustand der Tiere sowie deren Aufhängung werden von der Autorin als weitere Einflussfaktoren genannt.

\subsubsection{Myopathien und Muskelfaserdegenerationen}

Unter Myopathien werden Schädigungen des Muskelgewebes verstanden. Dazu schreibt MAHON (1999), dass mit Zunahme der Muskelfaserdurchmesser die Diffusionsstrecken innerhalb der Faser erheblich verschlechtert werden und leitet zwei pathologische Phänomene daraus ab:

1.) Die „Deep pectoral-Myopathie“ als charakteristische Muskelerkrankung älterer Tiere

2.) Die „Fokale Myopathie“ als Erkrankung der Masttiere

Beide gingen mit Nekrosen des Muskelgewebes, mit Infiltrationen von Ersatzgeweben (Fett, Bindegewebe) und mit einer Entwertung des Endproduktes einher. Als Ursache wurde eine mangelnde Blutversorgung genannt. Bei der Fokalen Myopathie weist die Muskulatur insgesamt Struktur- und Farbveränderungen im Sinne beeinträchtigter Fleischqualität auf. Zudem konnte im Blutserum eine erhöhte Creatinkinaseaktivität, die als das im Blut nachweisbare diagnostische Kriterium für Membranläsionen und schwere belastungsabhängige Funktionsstörungen in den Muskelfibrillen zu werten ist, bestimmt werden.

Als Grundursache beider Phänomene ist die Selektion auf hohe Mastendgewichte bzw. Brustmuskelanteile und - in genetischer Kopplung - auf großen Durchmesser der Fasern des großen Brustmuskels anzusehen. Daraus ergibt sich folgende Pathogenese:

- Genetisch fixierter Proteinansatz überwiegend durch Dickenwachstum der Muskelfasern (Muskelhypertrophie)

- Geringe Kapillarisierung, erschwerte Sauerstoffzufuhr in die Fasern, gestörter Abtransport von Stoffwechselprodukten $\left(\mathrm{CO}_{2}\right.$, Laktat)

- Gestörte $\mathrm{Ca}^{2+}$ - Regulation an den Membranen der Muskelfibrillen bei der Energieumsetzung unter Beteiligung von Ryanodinrezeptoren (SANTE et al., 1995; CHIANG und STRASBURG, 2003)

- Auftreten pathologischer Muskelfasern.

In der Literatur wird eine ganze Reihe an histologisch nachweisbaren Muskelfaserdegenerationen aufgeführt. In der vorliegenden Untersuchung wurden die beiden Formen der progressiven Muskeldystrophie histologisch ermittelt. Sie beinhaltet zum einen atrophische Muskelfasern, welche auch als anguläre Fasern bezeichnet werden und zum anderen hypertrophische Muskelfasern, welche im Folgenden als Riesenfasern (Giant fibres) genannt werden (SANDRITTER 1971). Beide Degenerationstypen sind nicht nach einem bestimmten Verteilungsmuster angeordnet und betreffen nur Einzelfasern, also weder Fasern im Gruppenverband, noch inselartige Ansammlungen. 
DRANSFIELD und SOSNICKI konnten 1999 nachweisen, dass schnell wachsende männliche Hühner eine höhere Anzahl an Riesenfasern aufweisen, als die langsamer wachsenden Vergleichstiere. In diesem Zusammenhang stellten sie fest, dass kleinere Faserdurchmesser eine größere Muskelfaserdichte erlauben, was wiederum mit einer Zunahme der Zähigkeit des Fleisches einhergeht. WILSON et al. (1990) fand bei schnellwüchsigen Putenlinien mehr geschädigte Muskelfasern, als bei den langsamer wachsenden Vergleichstieren. Dem stellten REMIGNON et al. (2000) entgegen, dass Riesenfasern unabhängig von Genotyp, Fasertyp und Muskel auftreten können. Ferner konnte er in Versuchen belegen, dass die Riesenfasern erst während des Rigor mortis auftreten bzw. entstehen und folgerte daraus, dass Riesenfasern keine pathologische Muskelveränderung im herkömmlichen Sinne darstellen. Vielmehr liegt bei ihnen ein Unvermögen der Sarkomere vor, sich wieder zu entspannen, was einen Defekt der Mitochondrien oder des Sarkoplasmatischen Retikulums nahe legt. CASSENS et al. (1969) fand bei Untersuchungen an Transportstress verendeten Schweinen, dass diese verglichen mit den zunächst überlebenden Tieren einen auffällig höheren Anteil an Riesenfasern aufwiesen. Deshalb wurde ein Zusammenhang zwischen dem Auftreten von Riesenfasern und der Stressanfälligkeit unterstellt. Bei Untersuchungen von Riesenfasern mit dem Elektronenmikroskop (DUTSON et al. 1978) konnten keine bemerkenswerten Unterschiede hinsichtlich des Gehaltes an Mitochondrien und Sarkoplasmatischen Retikulen zu benachbarten Muskelfasern verzeichnet werden. Es wurden jedoch vakuolenartige Strukturen in den Riesenfasern beobachtet.

Hinsichtlich der angulären Muskelfasern unterstellt BENTLEY (1999), dass sie möglicherweise der Rest einer früheren Muskelfaserreparatur sein könnten.

Hinsichtlich des ATP-Stoffwechsels p.m. konnten BOWKER et al. (2004) nachweisen, dass Muskelfasern mit der schnellen MyHC (Myosin-Heavy-Chain) Isoform eine höhere, aktinaktivierte Myosin-ATPaseaktivität aufwiesen, als jene der langsamen MyHC Isoformen. Dieser Sachverhalt würde eine Erklärung für die Neigung zur vergleichsweise schnellen Glycolyse bei weißen Muskelfasern darstellen.

MARTENS untersuchte 1998 die genetischen Ursachen für mögliche Muskelschädigungen. Als mikrostrukturelle Ursache nannte er für pathologische Erscheinungen das vermehrte Auftreten von weißen Muskelfasern, welche aufgrund ihres glykolytischen Stoffwechsels eine überstürzte Glykolyse begünstigen. Des Weiteren sind die weißen Muskelfasern mit ihren vergleichsweise hohen Durchmessern prädestiniert für Schädigungen, da der Weg zu den ver- und entsorgenden Kapillaren deutlich länger ist. Auch wird mit den weißen Muskelfasern oft eine unzureichende Kapillarisierung in Verbindung gebracht. Als physiologische Ursache für Muskelschädigungen beschrieb MARTENS (1998) die Mutation des Ryanodin-Rezeptors, welche eine elektrophysiologische Sensibilität und damit die Aktivierbarkeit desselben erhöht, die Inaktivierbarkeit jedoch deutlich verringert.

Der Autor erstellte anhand seiner Untersuchungen ein Regelkreismodell (Abb.7), in welchem die Abläufe im Muskel veranschaulicht werden. 


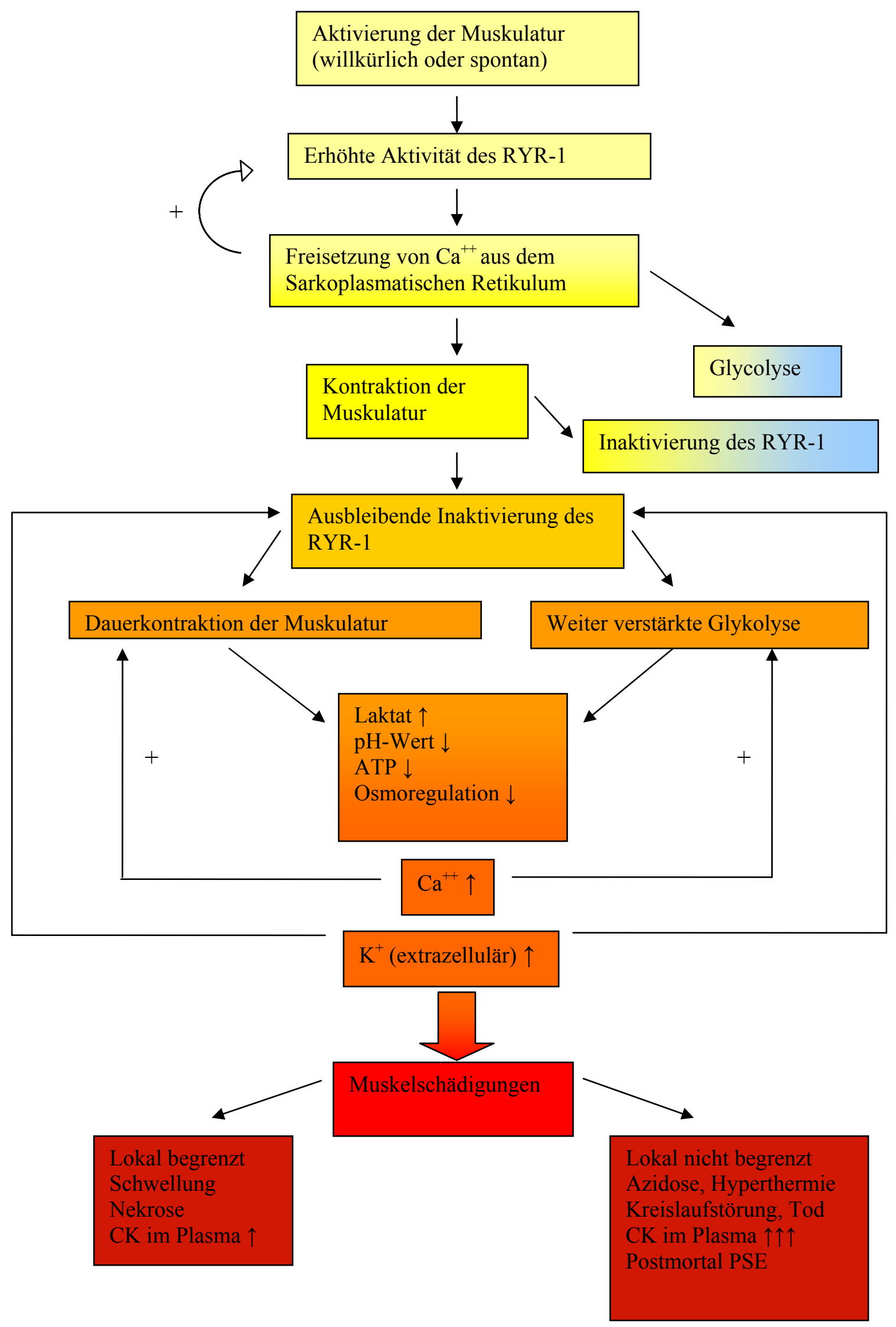

Abb. 7: Schematische Darstellung der Pathogenese der genetisch bedingten Myopathie (MARTENS, 1998) 


\subsubsection{PSE-Inzidenzen und Transportverluste}

Das Kürzel PSE hat seinen Ursprung in den englischen Worten pale, soft, exudative, was im Deutschen blass, weich und wässrig bedeutet und eine unerwünschte Veränderung des Fleisches darstellt (SOSNICKI et al. 1998; SOLOMON et al. 1998). Diese Eigenschaften sind auf partielle Denaturierungen von Muskelproteinen zurückzuführen. Sie beruhen primär auf der deutlich höheren Laktatanhäufung, als es bei normalem Fleisch der Fall ist, sowie auf einer vergleichsweise hohen Gewebetemperatur.

Folgen der Denaturierungsvorgänge sind erhöhte Farbhelligkeit und Gewebswasserverlust des Fleisches.

In der Literatur werden folgende Ursachen für das Auftreten von PSE-Fleisch genannt:

- Züchterisch bedingte Zunahme an weißen Muskelfasern über das physiologische Maß hinaus,

- dauerhafte, unzureichende Sauerstoffversorgung der Mitochondrien in Folge zu großer Faserdurchmesser der weißen Muskelfasern sowie eine geringe

Kapillardichte,

- Unzureichender oxidativer Stoffwechsel in von weißen Muskelfasern geprägten Muskeln,

- Energiedefizit, verursacht durch Belastung kurz vor dem Schlachten, welche durch erhöhte anaerobe Glycolyse nur unvollständig kompensiert wird,

- dadurch erfolgt eine erhöhte Laktatanhäufung,

- Erhöhte Schlachtkörpertemperatur durch Belastung,

- Muskeleiweißdenaturierung infolge des $\mathrm{pH}$-Wertabfalls unter 5,8 bei Fleischtemperaturen um $40^{\circ} \mathrm{C}$ innerhalb $1 \mathrm{~h}$ p.m.(SIELAFF,1996).

Das Auftreten von PSE - Fleisch ist schon vor längerer Zeit beim Schwein beschrieben worden. Beim Geflügel hingegen sind erst seit 1993 (BARBUT) zuverlässige Untersuchungen zum Auftreten von PSE veröffentlicht. OWENS et al. (2000) berichtet von 40 \% PSE - Puten in üblichen Herden. Wahrscheinlicher sind da eher die Zahlen von MCCURDY et al. (1996), der in amerikanischen Putenherden von einem PSE - Anteil zwischen 5 und $30 \%$ spricht. Diese Angaben decken sich auch mit denen BARBUTs (1997b), welcher in seinen Untersuchungen $5 \%$ bis zu 40 $\%$ PSE - Tiere in kommerziellen Putenherden fand. FRAQUEZA et al. (2001) beschrieben einen PSE - Anteil von 11,2 \% bei 223 Putern, gemessen an einem portugiesischen Schlachthof.

ZHANG und BARBUT (2005) legten 6-12 h p.m. hinsichtlich der L* - und pH - Werte Gruppeneinteilungen für PSE - , Normal - und DFD - Fleisch (Hühnerbrust) fest (Tab.11). 
Tab. 11 Einteilung von Hühnerbrustfleisch in PSE-, Normal-, und DFD - Fleisch 6 - 12 h p.m. (ZHANG und BARBUT, 2005)

\begin{tabular}{|l|l|l|}
\hline Fleisch & $\mathrm{L}^{*}$ & $\mathrm{pH}$ \\
\hline PSE - Fleisch & $\mathrm{L}^{*}>53,0$ & $\mathrm{pH}<5,7$ \\
\hline Normal - Fleisch & $46<\mathrm{L}^{*}<53$ & $5,9<\mathrm{pH}<6,1$ \\
\hline DFD - Fleisch & $\mathrm{L}^{*}<46$ & $\mathrm{pH}>6,1$ \\
\hline
\end{tabular}

MOLETTE et al. (2005) belegten in einem Versuch an 34 B.U.T. 9 Hähnen, dass es viele Faktoren beim Putenfleisch gibt, welche das Auftreten des PSE - Syndroms begünstigen. Am aussagekräftigsten hinsichtlich der PSE - Beurteilung sei aber die Stärke des $\mathrm{pH}$ - Wertabfalls 20 min p.m. zu nennen. Dieser Umstand wird damit begründet, dass 20 min p.m. zwischen den zwei aufgeführten Versuchsgruppen ein $\mathrm{pH}$ - Wertunterschied von 0,43 bestand, welcher in dieser Intensität 24 h p.m., also dem End - pH - Wert, nicht mehr nachweisbar war. Für diesen Versuch hatten MOLETTE et al. (2005) 34 B.U.T. 9 Hähne in zwei Gruppen aufgeteilt. Die 17 Tiere mit dem höchsten pH Wert 20 min. p.m. kamen in die „Normal glycolysierende Gruppe" (NG, pH 6,47 $\pm 0,01$ ), jene mit dem niedrigsten pH Wert 20 min p.m. in die „schnell glycolysierende Gruppe“ (FG, pH 6,04 \pm 0,09).

Hinsichtlich der $\mathrm{L}^{*}$ - Werte konnte bei den über den $\mathrm{pH}$ - Wertabfall bestimmten PSE - Tieren im Vergleich zu Normaltieren von verschiedenen Autoren (MOLETTE et al. 2002, MOLETTE et al. 2005; HAHN et al., 2002; RATHGEBER et al., 1999; PIETRZAK et al., 1997) kein signifikanter Unterschied abgesichert werden. Generell formulierten MOLETTE et al. (2005) aufgrund ihrer Untersuchungen, dass sämtliche Helligkeits- und Farbwerte keine Rückschlüsse auf einen raschen $\mathrm{pH}$ - Wertabfall zulassen.

Damit unterstützten Sie die Aussagen von BERRI et al. (2001), welche ebenfalls an eigenen Untersuchungen bei Broilern belegen konnte, dass es keinen zwingenden Zusammenhang zwischen blassem Fleisch und dem PSE - Syndrom gibt. Sie begründeten die Ergebnisse mit der Tatsache, dass die blasseren Fleischtypen einen geringeren Blutpigment Anteil aufwiesen, als das bei den unselektierten Kontrollgruppen der Fall war. Ferner wiesen die blassen Tiere in den untersuchten Teilen keine auffälligen Tropfsaftverluste auf.

Die Entwicklung von PSE - Fleisch kann durch postmortale Faktoren, wie Beispielsweise das Vorgehen bei der Kühlung beeinflusst werden (HONIKEL und FISCHER, 1977; OFFER, 1991). ALVARADO und SAMS (2002) belegten, dass Putenschlachtkörper, welche nach dem Schlachten langsam heruntergekühlt wurden, eher zu PSE-Erscheinungen neigten, als bei schnell gekühlten. MOLETTE et al. (2003b) konnten durch thermischen Einfluss $\left(40^{\circ} \mathrm{C}\right.$ für $\left.6 \mathrm{~h}\right) \mathrm{PSE}$ - ähnliches Putenbrustfleisch generieren. Schon 1994 hatten FERNANDEZ et al. auf die PSEfördernde Wirkung hoher postmortaler Temperatur bei Schweinefleisch hingewiesen. Der bei Schweinen zur Identifizierung von stressanfälligen Tieren (aus denen PSE Fleisch zu erwarten ist) verwendete Halothantest ist bei Puten nicht anwendbar (OWENS et al., 2000; WHEELER et al., 1999). Es gibt allerdings Hinweise dahingehend, dass das Auftreten von PSE nicht ausschließlich von externen Faktoren induziert wird, sondern auch von der Genetik der Tiere abhängt. CHIANG et al. 2002 konnten eine Mutation im Genom des Ryanodine Rezeptors a (a RyR) nachweisen. Bei Schweinen sorgt eine Mutation im vergleichbaren Rezeptorgen für eine hohe Calciumfreisetzung, was eine schnelle Glycolyse und damit einen schnellen $\mathrm{pH}$ - Wertabfall zur Folge hat. 
Schon 1987 hatten ROCK und KOZAK-REISS eine genetisch bedingte Unzulänglichkeit im Aufbau des Sarkolemms vermutet, dessen Beziehung zum pH Wert er an folgendem Schaubild verdeutlicht (Abb.8):

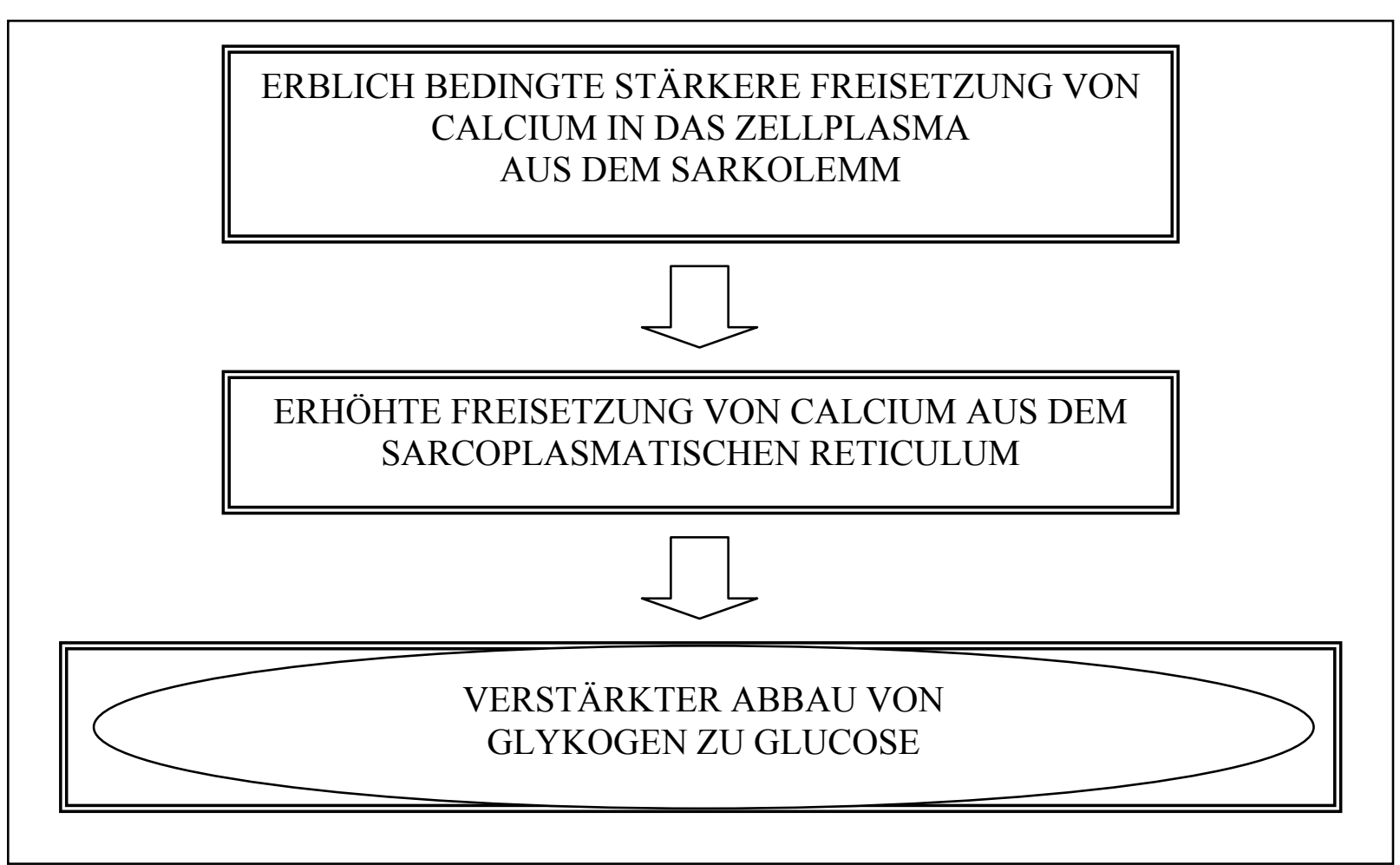

Abb. 8. Schema zum Ablauf der Aktivierung des schnellen Kohlenhydratstoffwechsels post mortem in PSE - Muskulatur (ROCK und KOZAK-REISS, 1987)

Genaue Kenntnisse über Ursache und Wirkung von PSE sind deshalb von Bedeutung, da PSE - Fleisch weder vom Endverbraucher, noch von der weiterverarbeitenden Industrie geschätzt wird. Insbesondere der Endverbraucher nimmt Anstoß an blassem Fleisch, welches in der Verpackung im eigenen Saft (bedingt durch hohe Tropfsaftverluste) schwimmt (FERKET und FOEGEDING, 1994; DRANSFIELD und SOSNICKI, 1999). HAHN (2001) gab hinsichtlich der PSE Problematik zu bedenken, dass der Zusammenhang zwischen den Parametern Wasserbindungsvermögen, Textur und Fleischfarbe/-helligkeit, welche beim Schwein als PSE - Qualitätsabweichung gelten, nicht ohne Weiteres mit denen der Pute gleichgesetzt werden können. Gründe dafür wurden nicht genannt.

Schon 1945 wiesen MC SHERRY et al. bei intensiver Selektion auf Wachstumsleistung auf die steigende Gefahr von Aortenrupturen hin, welche zu plötzlichen Todesfällen bei Stress, ja sogar schon bei Beunruhigung der Tiere führen kann. Das Verladen und der Transport der Puten bedeutet erheblichen Stress für die Tiere und es muss mit Transportverlusten gerechnet werden. 


\subsection{Schlussfolgerung aus der Literatur}

Wie im Literaturteil festgestellt wurde, existieren bereits Untersuchungsergebnisse zu folgenden Themenbereichen im Sektor der Putenfleischerzeugung:

- Struktur und Funktion der Brustmuskulatur

- Postmortale Veränderungen im Muskel

- Rohnährstoffgehalte des M. pect. superfic.

- $\quad \mathrm{pH}$ - und Leitfähigkeitswerte im M. pect. superfic.

- Helligkeits- und Farbwerte $\left(L^{*}, a^{*}, b^{*}\right)$

- Wasserbindungsvermögen

- Scherkraft / Scherarbeit

- Aviäres Stress Syndrom

Alle genannten Punkte dienen zur Beschreibung von Fehlern in Muskulatur und Fleisch. Insbesondere auf den Zusammenhang zwischen intensiver Selektion auf mastrelevante Parameter und Mängel in der Fleischqualität und Stressanfälligkeit wird häufig hingewiesen. In den seltensten Fällen werden Ansätze zur Lösung dieses Problems genannt. Dabei wären folgende Fragestellungen von Interesse:

- Existieren Putenherkünfte, auf welche gegebenenfalls zurückgegriffen werden kann, um Fleischqualitätsmängel und hohe Stressanfälligkeit bei Mastputen zu reduzieren oder gar zu vermeiden?

- Welche Wechselwirkungen bestehen zwischen den verschiedenen Parametern der Fleischqualität bzw. Stressanfälligkeit?

- Nimmt ein früherer Schlachtzeitpunkt Einfluss auf die Parameter Fleischqualität und Stressanfälligkeit?

Die vorhandenen Ergebnisse sind aufgrund unterschiedlicher Haltungs- und Schlachtbedingungen, anderen klimatischen Verhältnissen sowie verschiedener Genetiken anderer Länder nur eingeschränkt auf deutsche Verhältnisse übertragbar. Vor diesem Hintergrund soll in der vorliegenden Arbeit versucht werden, die aufgeführten offenen Fragen zu klären und sich dabei möglichst eng an den in Deutschland üblichen Haltungs- und Schlachtverfahren zu orientieren. 


\section{Material und Methoden}

\subsection{Versuchsdesign}

Entsprechend der Zielsetzung sollten verschiedene Putenherkünfte hinsichtlich ihrer Schlachtkörper- und Fleischqualität miteinander verglichen werden. Aufgrund begrenzter Labor- und Stallkapazität wurde der Versuchsaufbau in zwei Durchgänge unterteilt.

Im ersten Durchgang wurden zwei schwere Putenherkünfte miteinander verglichen. Je 100 Hähne der Linien Big 6 (B.U.T., Abb.9 a) und BBB (Kelly's, Abb. 9 b) wurden als Eintagsküken aufgestallt. Nach 12 Wochen wurde die erste Hälfte (je $n=50$ ) der Tiere unter Standardbedingungen geschlachtet und entsprechend beprobt. Mit der zweiten Hälfte der Tiere wurde nach 22 Wochen ebenso verfahren.

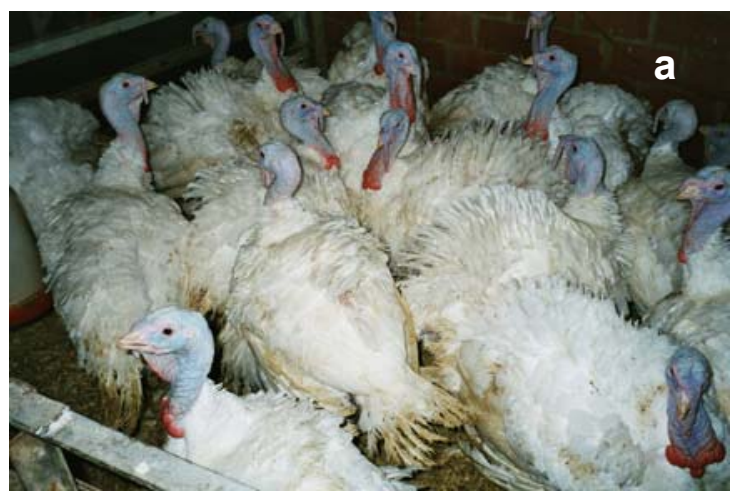

Abb. 9 a + b: a) B.U.T. BIG 6,

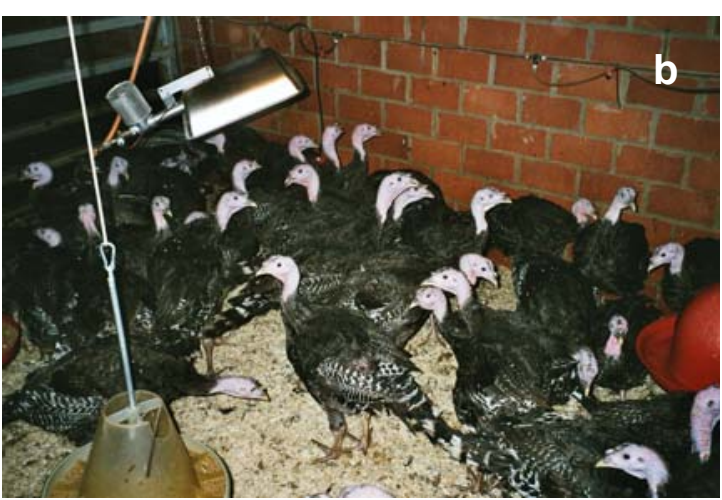

b) Kelly's BBB

Im zweiten Durchgang wurde die schwere Linie BIG 6 (B.U.T.) mit der mittelschweren Linie Wrolstad (Abb. 10 a) und der leichten Linie Super Mini (Abb. 10 b) (beide vom Züchter Kelly) verglichen. Je 70 Tiere jeder Linie wurden als Eintagsküken aufgestallt. Nach 12 Wochen wurde von jedem Genotyp je die Hälfte unter denselben Bedingungen wie bei Durchgang 1 geschlachtet und beprobt, ebenso die zweite Hälfte nach 22 Wochen.

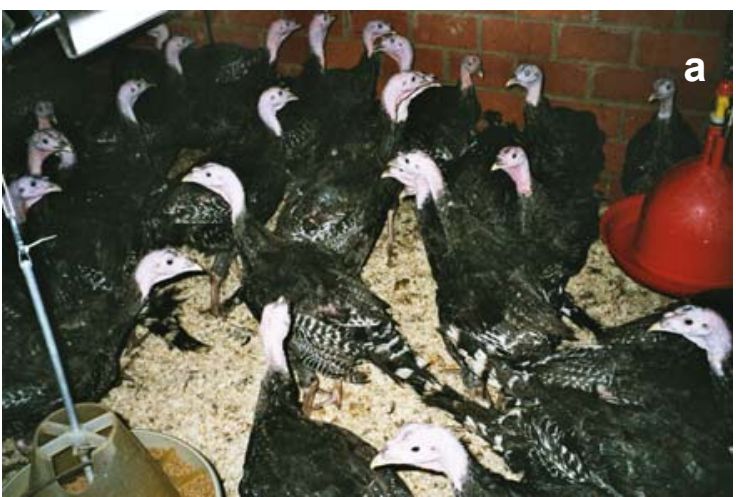

Abb. 10 a + b: a) Kelly's Wrolstad,

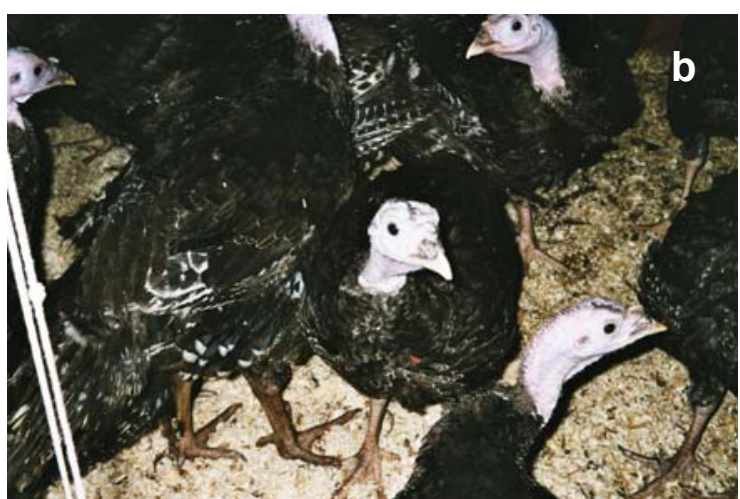

b) Kelly's Super Mini 


\subsection{Tiermaterial}

In dem Versuch wurden Genotypen von zwei verschiedenen Züchtern verglichen.

Als eine der am häufigsten in Deutschland verwendeten schweren Hochleistungsputen wurden Hähne der Linie Big 6 der Zuchtfirma British United Turkey (B.U.T.) aufgestallt. Dieser Genotyp wird in der Regel in Intensivmast (Produktionsrichtung: Mast schwerer Verarbeitungsputen) aufgezogen.

Für die extensive Mastputenhaltung (auch Freilandhaltung) bietet der Züchter Kelly mehrere Genotypen an. Für den Versuch wurden Hähne der Linien BBB (schwerer Typ), Wrolstad (mittelschwere Typ) und Super Mini (leichter Typ) gewählt.

Alle Versuchstiere wurden als Eintagsküken aufgestallt.

\subsection{Haltungsbedingungen}

\subsubsection{Haltung}

Die Puten wurden alle im selben Versuchsstall aufgezogen.

Der Stall wurde zunächst mit einer Helligkeit von 22 Lux in $10 \mathrm{~cm}$ Bodenhöhe beleuchtet. Mit zunehmendem Alter der Hähne wurde das Licht auf 4 Lux gedimmt. Die Einstalltemperatur betrug durchschnittlich $24^{\circ} \mathrm{C}$. Da die Temperatur über GasHeizstrahler geregelt wurde, war die Temperatur direkt unter dem Strahler höher, als in der Peripherie. Die Puten konnten so ihre eigene Wohlfühltemperatur durch Ortswechsel bestimmen. Mit zunehmendem Alter wurde die Stalltemperatur auf $18^{\circ} \mathrm{C}$ abgesenkt. Als Einstreu dienten Holzspäne, die immer dann nachgestreut wurden, wenn die Tiere begannen, leichte Verschmutzungen zu zeigen.

Alle Puten wurden in der dritten Lebenswoche mit dem Präparat Dindoral@ gegen blutige Darmentzündung geimpft. In der 4., 8. und 12. Lebenswoche erhielten die Tiere eine Impfung gegen Newcastle Desease mit dem Präparat ND Lasota@.

\subsubsection{Fütterung}

Die Ernährung der Tiere wurde, den Bedürfnissen des Wachstums entsprechend, mit sechs verschiedenen Putenmastfuttermitteln (PM 1-6) vorgenommen. Futter wie Wasser standen ad libitum zur Verfügung. Die verwendeten Futtermittel bewegen sich hinsichtlich der Rationsgestaltung im praxisüblichen Rahmen. Die Futtermittel wurden nach folgenden Altersstufen gestaffelt eingesetzt (Tab. $12+13$ ):

$\begin{array}{lllllll}\text { Putenmastfutter } & \text { PM 1 } & \text { PM 2 } & \text { PM 3 } & \text { PM 4 } & \text { PM 5 } & \text { PM6 } \\ \text { Alter in Wochen } & 1 & 3-5 & 6-9 & 10-12 & 13-17 & \text { ab 18 }\end{array}$

Tab. 12: Inhaltstoffe und Energiegehalte der Futtermittel des ersten Durchgangs

\begin{tabular}{|l|l|l|l|l|l|l|}
\hline & PM 1 & PM 2 & PM 3 & PM 4 & PM 5 & PM 6 \\
\hline MJ ME/kg & 11,4 & 11,6 & 11,8 & 12,2 & 12,6 & 13,0 \\
\hline Rohprotein \% & 27,0 & 26,5 & 23,5 & 20,5 & 18,0 & 16,0 \\
\hline Ca \% & 1,40 & 1,40 & 1,10 & 1,00 & 0,85 & 0,75 \\
\hline P \% & 1,00 & 1,00 & 0,75 & 0,65 & 0,55 & 0,45 \\
\hline Phytase (FYT/kg) & & & 750 & 750 & 750 & 750 \\
\hline
\end{tabular}


Tab. 13: Inhaltstoffe und Energiegehalte der Futtermittel des zweiten Durchgangs

\begin{tabular}{|l|l|l|l|l|l|l|}
\hline & PM 1 & PM 2 & PM 3 & PM 4 & PM 5 & PM 6 \\
\hline MJ ME/kg & 11,4 & 11,6 & 11,8 & 12,2 & 12,6 & 13,0 \\
\hline $\begin{array}{l}\text { Rohprotein } \\
\%\end{array}$ & 27,0 & 26,3 & 23,5 & 20,9 & 18,1 & 16,4 \\
\hline Ca \% & 1,40 & 1,40 & 1,10 & 1,00 & 0,85 & 0,75 \\
\hline P \% & 1,00 & 1,00 & 0,75 & 0,65 & 0,55 & 0,45 \\
\hline $\begin{array}{l}\text { Phytase } \\
\text { (FYT/kg) }\end{array}$ & & & 750 & 750 & 750 & 750 \\
\hline
\end{tabular}

Als Hauptproteinträger wurde Sojaschrot und ein geringer Anteil Fischmehl verwendet. Das Basisfutter bestand im Wesentlichen aus Weizenmehl und Mais.

\subsection{Probengewinnung und Lagerung}

Die Versuchstiere wurden an den jeweiligen Schlachtterminen mit einem für Putentransport üblichen LKW in entsprechenden Transportboxen aus ihrem Versuchsstall (Emstek/Höltinghausen) zum betriebseigenen Putenschlachthof der Firma Heidemark (Garrel) gebracht. Dort wurden die Puten nach dem Einhängen in die Laufbänder mit Kabelbindern an den Putenständern markiert. Nach der Betäubung im Elektrobad wurden die Tiere von Hand entblutet und das Stichblut aufgefangen. Sofort danach wurden die Blutproben auf Heparinröhrchen aufgezogen und bis zur weiteren Verarbeitung im Labor kühl gelagert. Die ausgebluteten Hähne wurden maschinell gerupft und der Kopf entfernt. Die Ermittlung der Gewichte und Fleischanteile erfolgten automatisch am Schlachtband durch Wiegung und Videobildauswertung. Im weiteren Verlauf wurden anschließend Eingeweide und Ständer entfernt. Die für die Untersuchung erforderliche linke Brusthälfte wurde von einem Zerleger der Firma Heidemark von der restlichen Karkasse standardisiert abgesetzt. Noch am Schlachthof wurden 20 min p.m. pH- und LF-Werte ermittelt. Nach der Messung wurden die Brusthälften gekühlt in thermostabilen Boxen zum Labor des FOSVWE transportiert. $4 \mathrm{~h}$ post mortem wurden nochmals $\mathrm{pH}$ - Wert und Leitfähigkeit im M. pect. superfic. gemessen. Dem folgte nach der Wiegung auf einer Laborwaage das Ablösen des M.pect.superfic. von der darunter liegenden Muskulatur. Dieser wurde ebenfalls gewogen und nach dem Schema in Abb.11 weiter bearbeitet. 


\section{Bearbeitungs- und Zerlegemuster}

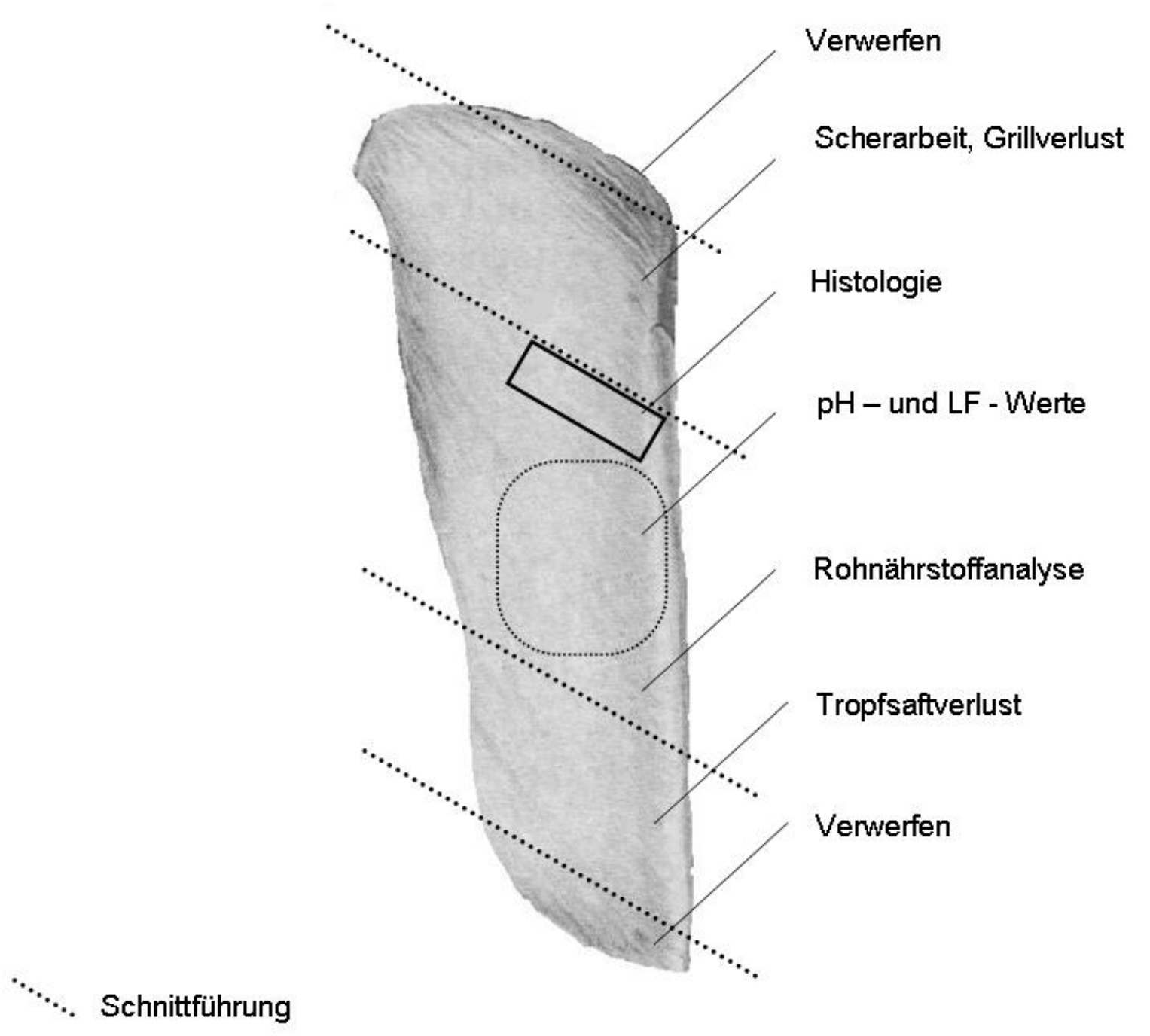

Abb. 11: Bearbeitungs- und Zerlegemuster für den M.pect.superfic.

Zunächst wurde die Autopsieprobe zur weiteren histologischen Bearbeitung entnommen und mit Talkum bepudert. Dies ermöglicht einen gleichmäßigen und schnellen Gefriervorgang im flüssigen Stickstoff. Bis zur histologischen Bearbeitung wurde die Probe im flüssigen Stickstoff $\left(-192^{\circ} \mathrm{C}\right)$ gelagert. Nach SANTE und FERNANDEZ (2000) sind damit sämtliche Stoffwechselvorgänge bis zum Auftauen gestoppt.

Nach der Entnahme der Autopsieprobe wurde der M.pect.superfic. entsprechend dem Zerlegemuster zerteilt. An den jeweiligen Schnittflächen wurden die Blutpunkte ausgezählt und die $L^{*}$, $a^{*}$ und $b^{*}$ - Werte gemessen. Der caudale Teil wurde für die Ermittlung des Tropfsaftverlustes verwendet, der craniale Teil zur Ermittlung von Grillverlust und Scherkraft. Letztere Probe wurde bei $-20^{\circ} \mathrm{C}$ bis zur Bearbeitung in Polyethylen (PE) -Beuteln vakuumiert eingefroren. Der mittlere Teil wurde mit dem Gerät Grindomix homogenisiert und bis zur Rohnährstoffanalyse bei $-20^{\circ} \mathrm{C}$ in PE Beuteln gelagert. 


\subsection{Erhebung von Schlachtkörper- und Fleischbeschaffenheitsmerkmalen}

\subsection{1 pH-Wert}

Der pH-Wert wurde 20 min p.m auf dem Schlachthof und 4 h p.m. im Labor gemessen. Dazu wurde zum einen das PH-Star der Firma Matthäus verwendet, zum anderen das PH-Meter „K 21“ der Firma NWK Binär. Beide Geräte wurden vor den Messungen mit derselben Eichlösung geeicht. Die Messung erfolgte durch Einstich in eine definierte Stelle des M.pect.superfic..

\subsubsection{Leitfähigkeit}

Die Leitfähigkeitswerte wurden 20 min p.m. und 4 h p.m. mit dem Gerät LF-Star der Firma Matthäus gemessen. Die Messung erfolgte durch Einstich in eine definierte Stelle des M.pect.superfic. quer zur Faserrichtung.

\subsubsection{Helligkeits- und Farbwerte}

Die $L^{*}, a^{*}$ und $b^{*}$ - Werte wurden mit einem Gerät der Firma Minolta (CR-300) vier Stunden p.m. gemessen.

Es wurden an den Schnittflächen, wie im Zerlegemuster dargestellt, drei Messungen durchgeführt, mit deren Mittelwert im weiteren Verlauf der Untersuchungen gearbeitet wurde. Bei der Messung wurde berücksichtigt, dass weder am Rand, noch auf Blutpunkten gemessen wurde. Es wurden drei Messungen pro Brusthälfte durchgeführt, um zum einen mögliche Messfehler zu minimieren, zum anderen spielt auch die Messstelle eine erhebliche Rolle bei den Farb- und Helligkeitsmessungen.

\subsubsection{Rohnährstoffe und Trockenmasse}

\subsubsection{Protein}

Die Bestimmung des Rohproteingehaltes im $M$. pect. superfic. wurde mit dem Elementaranalysator "Vario MAX CN“ der Firma Elementar Analysensysteme Hanau durchgeführt. Dabei wurde bei einer katalytischen Rohrverbrennung $\left(900^{\circ} \mathrm{C}\right)$ unter $\mathrm{O}_{2}$ - Zugabe der Stickstoffgehalt ermittelt, welcher durch Multiplikation mit dem Faktor 6,25 den Proteingehalt ergibt.

\subsubsection{Fett}

Die Ermittlung des Gehaltes an Rohfett im Muskel erfolgte durch Extraktion mit Petroleumbenzin in einer Soxtherm-Apparatur. Der Extraktion ging eine Hydrolyse mit 4 M Salzsäure voraus. Durch Wiegung vor und nach der Analyse berechnete sich anhand der ermittelten Ergebnisse der Rohfettgehalt der Frischsubstanz.

$$
\text { Rohfettgehalt }(\%)=\frac{\text { Rückwaage }(\mathrm{g})-\text { Analysenglas }(\mathrm{g})}{\text { Einwaage }(\mathrm{g})} \times 100(\%)
$$

Die verwendeten Ergebnisse sind Mittelwerte aus den jeweiligen Doppelbestimmungen. 


\subsubsection{Asche}

Der Aschegehalt wurde durch Veraschung von 1-2 g homogenisierten Probenmaterials bei $600^{\circ} \mathrm{C}$ für $24 \mathrm{~h}$ ermittelt. Vor der Veraschung wurde der vorgetrocknete Porzellantiegel gewogen und die genannte Menge des Homogenats eingefüllt. Nach Abkühlung im Exsikator wurde die Probe erneut gewogen.

Aschegehalt $(\%)=\frac{\text { Gewicht der Rückwaage }(g)-\text { Tiegelgewicht }(g)}{\text { Tiegelgewicht mit Probe }(g)-\text { Tiegelgewicht }(g)} \times 100(\%)$

Die verwendeten Ergebnisse sind Mittelwerte aus den jeweiligen Doppelbestimmungen.

\subsubsection{Trockenmasse}

Der Trockenmassegehalt der Probe wurde durch Trocknung bei $105^{\circ} \mathrm{C}$ für $24 \mathrm{~h}$ im Trockenschrank durch Wiegung ermittelt. Dazu wurden $5 \mathrm{~g}$ der zuvor homogenisierten Probe in Aluminiumschälchen gegeben und mit einem Filterpapier abgedeckt gewogen. Über die Ermittlung der Differenz ließ sich der prozentuale TMGehalt mit folgender Formel errechnen:

Wassergehalt $(\%)=\frac{\text { Einwaage }(\mathrm{g})-(\text { Rückwaage }(\mathrm{g})-\text { Leergewicht }(\mathrm{g})}{\text { Einwaage }(\mathrm{g})} \times 100(\%)$

Die verwendeten Ergebnisse sind Mittelwerte aus den jeweiligen Doppelbestimmungen.

\subsubsection{Grillverlust}

Das aufgetaute Probenstück wurde mit saugfähigem Papier abgetupft, gewogen und anschließend in Alufolie gewickelt zwischen die Platten eines Kontaktplattengrills gelegt. Über einen Temperaturfühler wurde kontrolliert, wann die Kerntemperatur von $72{ }^{\circ} \mathrm{C}$ erreicht war. Nach erreichen der vorgegebenen Temperatur wurde das Probenstück wiederum abgetupft und gewogen.

Der prozentuale Grillverlust berechnet sich folgendermaßen:

Grillverlust $(\%)=\frac{\text { Probengewicht roh }(\mathrm{g})-\text { Probengewicht gegrillt }(\mathrm{g})}{\text { Probengewicht roh }(\mathrm{g})} \times 100(\%)$ 


\subsubsection{Scherkraft/Scherarbeit}

Die Scherkraft/Scherarbeit wurde an den Probenstücken der Grillverlustermittlung gemessen. Dazu wurden in Faserrichtung Probenstücke mit einer Stanzhülse ( Innendurchmesser von 1,27 mm, Abb. 12 ) ausgestanzt und quer zur Faserrichtung geschert. Der Schervorgang wurde mit einer Marterialprüfmaschine von Instron, Modell 4301, unter Verwendung des Warner-Bratzler-Scherkopfes (Abb. 12) durchgeführt. Die Schergeschwindigkeit betrug $200 \mathrm{~mm} / \mathrm{min}$. Es wurde die maximal aufgewendete Kraft sowie die Extension (Weg bis zum maximalen Kraftaufwand) gemessen. Aus beiden Werten wurde die Scherarbeit berechnet:

$$
\text { Scherarbeit }(\mathrm{Nm})=\text { Scherkraft }(\mathrm{N}) \times \text { Scherweg }(\mathrm{m})
$$

Da aus einem Ausgangsstück mehrere Prüfstücke gestanzt werden konnten, wurden alle Probenstücke jeweils doppelt beprobt und aus den Ergebnissen der Mittelwert gebildet, mit dem im Folgenden gearbeitet wird.

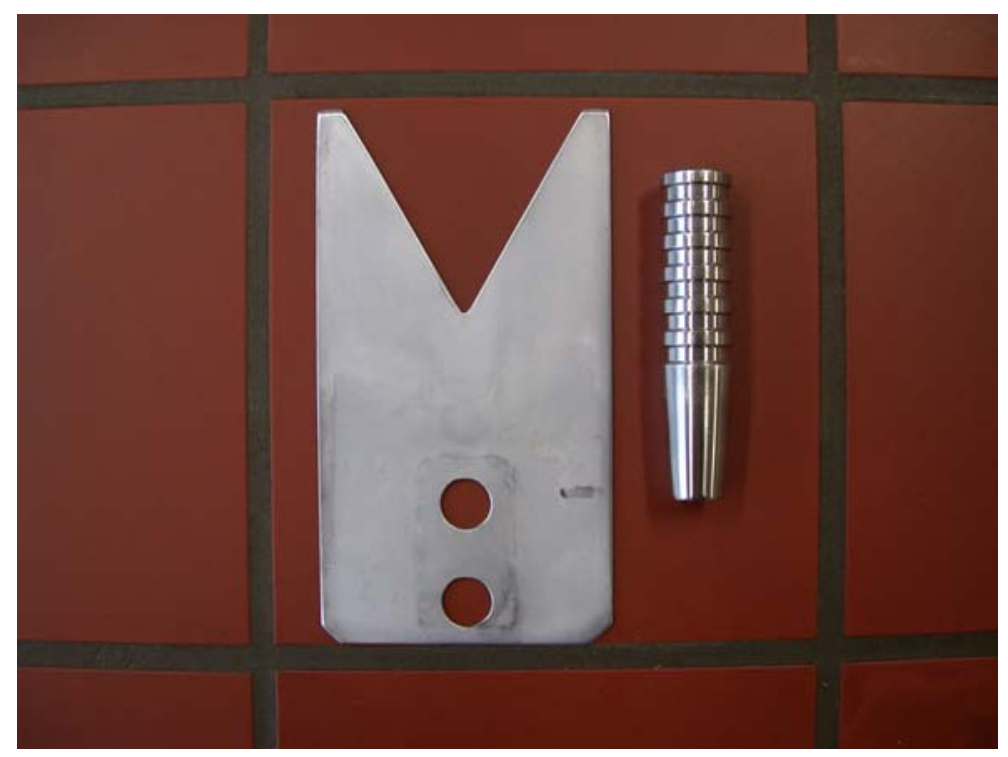

Abb. 12: Warner-Brazler-Scherkopf mit Stanzhülse

\subsubsection{Tropfsaftverlust}

Zur Bestimmung des Tropfsaftverlustes wurde ein definiertes Probenstück (ca. $50 \mathrm{~g}$ ) 4 h p.m. mit saugfähigem Papier trocken getupft und gewogen. Anschließend wurde die Probe in ein Stück Gaze gelegt und in einem PE-Beutel hängend (nicht vakuumiert) eingeschweißt (Abb. 13 a). 

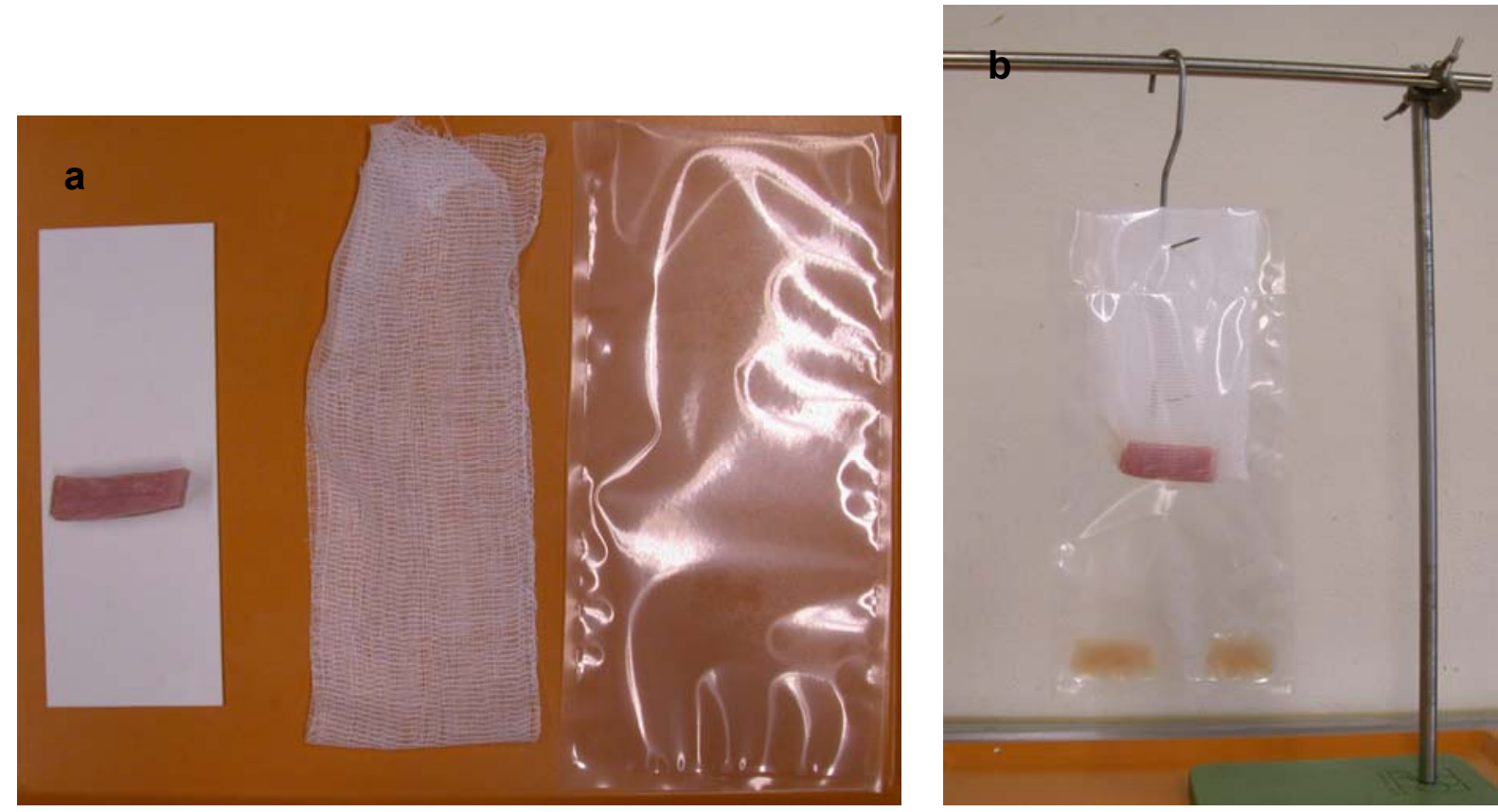

Abb. 13 a +b: Versuchsaufbau zur Tropfsaftverlust-Ermittlung

Nach einer hängenden Lagerung (Abb. $13 \mathrm{~b}$ ) in einem Kühlschrank bei $4{ }^{\circ} \mathrm{C}$ für $24 \mathrm{~h}$ wurde das Probenstück ausgepackt, erneut gewogen und aus der Differenz der Tropfsaftverlust berechnet.

\subsubsection{Blutpunkte}

Die Zahl der Blutpunkte wurde an den im Zerlegemuster dargestellten Schnittflächen ermittelt. Bei der Auszählung wurde berücksichtigt, dass jeweils nur an einer der beiden Schnittflächen gezählt wurde, um Doppelzählungen zu vermeiden.

\subsubsection{Stichblutwerte}

Das mit dem Gerinnungshemmer Heparin versehene Stichblut wurde im Labor zentrifugiert. Das abgesetzte Plasma wurde mit Einwegpipetten in Eppendorf Tubes $(1,5 \mathrm{ml})$ pipettiert und bei $-20^{\circ} \mathrm{C}$ bis zur Verarbeitung gelagert.

Im Serum wurden Creatinkinase- (CK) und Laktatgehalt photometrisch gemessen. Dazu diente das autosamplergestützte Photometer EPOS.

Zum Laktatnachweis wurde der enzymatische colorimetrische Test „Biosub® La Laktat (LOX-PAP)“ von Biocon Diagnostik verwendet.

Der quantitative CK-Nachweis erfolgte mit dem Testkit „Biozyme ${ }^{\circledR}$ CK-MB“, einem kinetischen UV-Testsatz von Biocon Diagnostik. 


\subsubsection{Gewichtsparameter}

Die Gewichtsparameter der Schlachtkörper sowie einzelner Teilstücke wurde zunächst am Schlachthof durch Wiegung und Videobildauswertung (VTS 2000) ermittelt, eine in Deutschland übliche Methode zur Ermittlung des Handelswertes von Mastputen (HAHN et al. 1998). Im Labor wurde der linke Brustmuskel (ohne Knochen) ohne Haut auf einer Laborwaage (Satorius Oberschalenwaage

E 2000 D) gewogen. Anschließend wurde der M.pect.superfic. von der darunter liegenden Muskulatur abgelöst und ebenfalls gewogen.

\subsubsection{Histologische Methoden}

\subsubsection{Herstellung der Dünnschnitte}

Die Proben wurden aus dem mit Flüssigstickstoff gefüllten Tank genommen und in flüssigem Stickstoff zum Gefriermikrotom transportiert. Dort wurden die Proben langsam (ca. $30 \mathrm{~min}$.) auf $-20^{\circ} \mathrm{C}$ bis $-25^{\circ} \mathrm{C}$ erwärmt. Entsprechend der gewünschten Lage wird die Probe nach der Temperaturangleichung mit Einbettmedium auf einem Probenhalter fixiert. Da die ersten Schnitte, bedingt durch den Gefrierprozess, stark degeneriert waren, wurden zunächst etwa 30 Schnitte durchgeführt und verworfen.

Die folgenden Schnitte wurden auf einen Adhäsions-Objektträger gezogen und unter dem Mikroskop hinsichtlich der Probenpositionierung begutachtet. Gegebenenfalls wurde die Ausrichtung der Probe zum Messer korrigiert. Für die weiteren Schnitte wurde eine Schnittdicke von $12 \mu \mathrm{m}$ gewählt. Die Mikrotomraumtemperatur betrug $20^{\circ} \mathrm{C}$, der Gefrierkopf hatte eine Temperatur von $-17^{\circ} \mathrm{C}$.

Nachdem je vier bis fünf Dünnschnitte auf einen Adhäsionsobjektträger aufgezogen wurden, folgte eine Stunde Trocknung bei Raumluft. Für jede Probe wurden je zwei Objektträger angefertigt.

\subsubsection{ATPase/Diaphorase-Färbung (in Anlehnung an HORAK 1983)}

\begin{tabular}{|c|c|c|}
\hline 1.) $\mathrm{pH} \mathrm{6,3-6,6}$ & Fixierung nach Meier & $1 \mathrm{~min}$. \\
\hline 2.) & Aqua dest. & $5 \mathrm{~min}$. \\
\hline 3.) & Aqua dest. & $5 \mathrm{~min}$ \\
\hline 4.) & Diaphoraseinkubation & $60 \mathrm{~min}$. bei $37^{\circ} \mathrm{C}$ \\
\hline 5.) & Aqua dest. & $30 \mathrm{~min}$. \\
\hline 6.) $\mathrm{pH} 4,2$ & Saure Vorinkubation & $30 \mathrm{~min}$. \\
\hline 7.) $\mathrm{pH} 7,8$ & Tris-CaCl${ }_{2}$-Lsg & $2 \mathrm{~min}$. \\
\hline 8.) $\mathrm{pH} \mathrm{9,4}$ & ATPase-Inkubationslösung & $20 \mathrm{~min}$. bei $37^{\circ} \mathrm{C}$ \\
\hline 9.) & $\mathrm{CaCl}_{2}$-Waschlösung & 30 sek. \\
\hline 10.) & $\mathrm{CaCl}_{2}$-Waschlösung & 30 sek. \\
\hline 11.) & $\mathrm{CaCl}_{2}$-Waschlösung & 30 sek. \\
\hline 12.) & Kobaltchloridlösung & $3 \mathrm{~min}$. \\
\hline 13.) & Aqua dest. & 45 sek. \\
\hline 14.) & Aqua dest. & 45 sek. \\
\hline 15.) & Aqua dest. & 45 sek. \\
\hline 16.) & Ammoniumsulfidlösung (Abzug) & $3 \mathrm{~min}$. \\
\hline 17.) & Leitungswasser (fließend) & $5 \mathrm{~min}$. \\
\hline 18.) & Aqua dest. & $5 \mathrm{~min}$. \\
\hline
\end{tabular}


Die Herstellung der angegebenen Lösungen:

1.) Fixierungslösung nach Meier:

1g Paraformaldehyd (95\%ig MERCK) Kühlschrank

$2 \mathrm{~g} \mathrm{CaCl}_{2}$ (-6-hydrat) (oder 1,47g -2-hydrat)

$6 \mathrm{~g}$ Saccharose oder Dextran

$100 \mathrm{ml}$ dest. Wasser

2.) Diaphorase-Inkubationslösung :

16 mg NADH (disodium salt, grad 2,98\% Böhringer) Kühlschrank

$3,2 \mathrm{ml}$ Phosphatpuffer $(0,1 \mathrm{M} / \mathrm{pH} 7,4)$ Kühlschrank

$4 \mathrm{ml}$ Nitro-BT Kühlschrank

$4,8 \mathrm{ml}$ dest Wasser

3.) Saure Vorinkubation:

$10 \mathrm{ml} \mathrm{CaCl} 2$-Stammlösung

$0,3 \mathrm{ml}$ konz. Essigsäure (Eisessig)

$90 \mathrm{ml}$ Aqua dest.

4.) Tris- $\mathrm{CaCl}_{2}$-Lösung:

$1,21 \mathrm{~g}$ Tris (Tris-(hydroxymethyl)-aminomethan 99,9\%, $\mathrm{M}=121,14 \mathrm{~g} / \mathrm{mol}$ )

$10 \mathrm{ml} \mathrm{CaCl}_{2}$-Stammlösung

$90 \mathrm{ml}$ Aqua dest.

5.) ATPase-Inkubationslösung:

$370 \mathrm{mg} \mathrm{KCl}(\mathrm{M}=75 \mathrm{~g} / \mathrm{mol})$

152 mg ATP (Adenosin-5'-triphosphat, $M=551,2 \mathrm{~g} / \mathrm{mol}$ ) (Gefrierschrank)

$90 \mathrm{ml}$ Glycinpuffer

$10 \mathrm{ml} \mathrm{CaCl}{ }_{2}$-Stammlösung

6.) Kobaltchlorid-Lösung:

$2 \mathrm{~g} \mathrm{Kobaltchlorit}\left(\mathrm{CoCl}_{2} \times 6 \mathrm{H}_{2} \mathrm{O}\right)$

$100 \mathrm{ml}$ Aqua dest.

7.) Ammoniumsulfid-Lösung:

$1 \mathrm{ml}$ Ammoniumsulfid

$100 \mathrm{ml}$ Aqua dest.

8.) Phosphatpuffer $(0,1-\mathrm{M}, \mathrm{pH} 7,4)$ :

Lösung 1: $\quad 0,1 \mathrm{M}$ prim. Natriumphosphat

$18,8 \mathrm{~g} \mathrm{NaH}_{2} \mathrm{PO}_{4} \times \mathrm{H}_{2} \mathrm{O}$ oder $15,6 \mathrm{~g} \mathrm{NaH}_{2} \mathrm{PO}_{4} \times 2 \mathrm{H}_{2} \mathrm{O}$ auf 1 l mit Aqua dest.

Lösung 2: $\quad 0,1 \mathrm{M}$ sek. Natriumphosphat

auffüllen.

$35,82 \mathrm{~g} \mathrm{Na}_{2} \mathrm{HPO}_{4} \times 12 \mathrm{H}_{2} \mathrm{O}$ auf 1 I mit Aqua dest. auffüllen.

Ansatz: $\quad$ 15,9ml Lösung $1+84,1 \mathrm{ml}$ Lösung $2=100 \mathrm{ml}$ Phosphatpuffer. $\mathrm{pH}$-Werteinstellung ( $\mathrm{pH} 7,4)$ erfolgt mit Lösung 1 zum sauren, mit Lösung 2 zum alkalischen Bereich.

9.) Nitro-BT :

Nitro-blaues Tetrazoliumchlorid (Firma RdH, Konz 1mg/ml)

40 mg Nitro-BT / 40 ml Aqua dest. 
10.) $\mathrm{CaCl}_{2}$-Stammlösung:

$4,99 \mathrm{~g} \mathrm{CaCl}_{2}(\mathrm{M}=111 \mathrm{~g} / \mathrm{mol})$ mit Aqua dest. im Maßkolben auf $250 \mathrm{ml}$ auffüllen.

11.) $\mathrm{CaCl}_{2}$-Waschlösung:

$7,5 \mathrm{~g} \mathrm{CaCl}_{2}(\mathrm{M}=111 \mathrm{~g} / \mathrm{mol})$ mit Aqua dest. im Maßkolben auf $1 \mathrm{l}$ auffüllen.

12.) Glycin-Stammlösung:

$7,51 \mathrm{~g}$ Glycin $(98 \%, M=75,07 / \mathrm{mol})$ mit Aqua dest. im Maßkolben auf $250 \mathrm{ml}$ auffüllen, pH-Wert auf 9,4 einstellen.

13.) Glycinpuffer:

$125 \mathrm{ml}$ Glycin-Stammlösung $+42 \mathrm{ml} 0,4 \mathrm{M} \mathrm{NaOH}(8 \mathrm{~g} / 500 \mathrm{ml})$ auf $500 \mathrm{ml}$ mit Aqua dest. im Maßkolben auffüllen und pH 9,4 einstellen.

\subsubsection{Kapillarfärbung}

Zur Färbung der Kapillaren diente die Amylase-PAS - Färbevorschrift nach Horak (1988) als Richtlinie. Die leicht modifizierte Reihenfolge der Färbe- bzw. Waschschritte ist im Folgenden numerisch aufgelistet:

- Schnitte $(12 \mu \mathrm{m})$ anfertigen und trocknen lassen

- Fixierlösung 1 Stunde im Kühlschrank

- Fixierlösung 10 min bei Raumtemperatur

- $10 \times$ mit Aqua dest spülen

- 15 min bei $37^{\circ} \mathrm{C}$ in a-Amylaselösung

- 10 x mit Aqua dest spülen

- 30 min in $1 \%$ íge Perjodsäure

- 10 x mit Aqua dest spülen

- Schiff's Reagenz 20 min

- 30 min $\mathrm{SO}_{2}$-Wasser

- 10 min Leitungswasser (fließend)

- 3 min Aqua dest

Die Herstellung der angegebenen Lösungen:

1.) Fixierungslösung:

$\begin{array}{rlll}128 & \mathrm{ml} & \text { Ethanol } & (95-100 \%) \\ 24 & \mathrm{ml} & \text { Chloroform } & \\ 8 & \mathrm{ml} & \text { Essigsäure } & (99, . . \%)\end{array}$

2.) $\alpha-A m y l a s e l o ̈ s u n g:$

$\begin{array}{lll}480 & \mathrm{mg} & \alpha-A m y l a s e \\ 160 \mathrm{ml} & \text { Aqua dest. }\end{array}$

3.) Perjodsäure:

$\begin{array}{lcl}1,5 & \mathrm{~g} & \text { Perjodsäure } \\ 150 & \mathrm{ml} & \text { Aqua dest. }\end{array}$

4.) Schiff's Reagenz:

$\begin{array}{cll}0,1 & \mathrm{~g} & \text { Fuchsin } \\ 100 & \mathrm{ml} & \text { Aqua dest. } \\ 1 & \mathrm{~g} & \text { Natriumsulfit } \\ 1 & \mathrm{ml} & \text { konzentrierte Salzsäure }\end{array}$


5.) $\mathrm{SO}_{2}$ - Wasser:

$\begin{array}{rrlr}600 & \mathrm{ml} & \text { Aqua dest } & \\ 30 & \mathrm{ml} & \text { Kaliumdisulfit-Lsg. } & \left(\mathrm{K}_{2} \mathrm{~S}_{2} \mathrm{O}_{5}-\mathrm{Lsg} \mathrm{10 \%}{ }^{\prime} \mathrm{ig}\right) \\ 30 & \mathrm{ml} & \mathrm{HCL} & (1 \mathrm{~N})\end{array}$

\subsubsection{Bildauswertung}

Die halbautomatische Bildauswertung erfolgte mit dem Softwarepaket LUCIA G der Firma Nikon, welche gleichfalls das für die Aufnahmen verwendete Mikroskop mit digitaler Kamera produzierte. Die histologischen Schnitte der 12 Wochen alten Tiere wurden mit einem 10-fach vergrößernden Objektiv bei beiden Färbemethoden digital erfasst und zur Bearbeitung gespeichert. Bei der ATPasefärbung der 22 Wochen alten Tiere wurde aufgrund der beachtlichen Größe der Muskelzellen eine geringere Vergrößerung (4-fach) gewählt. Da sich, von den degenerierten Muskelfasern abgesehen, nur ein Zelltyp im Gewebe des M. pect. superfic. vorlag, wurden für jede Probe 200 glykolytische Muskelfasern hinsichtlich Querschnittsfläche, maximaler und minimaler Durchmesser sowie mittlerer Durchmesser vermessen. Im Folgenden wird mit dem Mittelwert aus den jeweiligen 200 Messungen gerechnet.

Bei der Kapillarfärbung wurde in einem zufällig gewählten intakten Bildausschnitt Muskelzellen und Kapillaren ausgezählt und das Verhältnis beider Parameter nach folgender Formel berechnet:

Anzahl Kapillaren pro Zelle $(n)=\frac{\text { Anzahl Kapillaren }(n)}{\text { Anzahl Zellen }(n)}$

\subsection{Statistische Auswertung}

Die statistische Auswertung erfolgte mit dem Softwarepaket "STATISTICA 7.1" der Firma StatSoft Inc. 1984 - 2005.

Für die Varianzanalyse (ANOVA + Fisher - LSD - Test) wurden folgende statistische Modelle verwendet:

a.) Effekt „Alter“ zwischen allen Genotypen:

$y_{b c d}=\mu+A_{b}+B_{c}+(A B)_{b c}+e_{b c d}$

$\mathrm{y}=$ Beobachtungswert, $\mu=$ Gesamtmittel, $\mathrm{A}=$ Effekt Alter, $\mathrm{B}=$ Effekt Genotyp, $\mathrm{AB}=$ Interaktion Alter x Genotyp, e = Zufälliger Restfehler der Beobachtung

b.) Effekt „Genotyp“ innerhalb einer Altersgruppe:

$y_{i j}=\mu+G_{i}+e_{i j}$

$y=$ Beobachtungswert, $\mu=$ Gesamtmittel, $G=$ Effekt Genotyp, $e=$ Restfehler 


\section{Ergebnisse}

\subsection{Schlachtkörper- und Fleischbeschaffenheitsmerkmale in Abhängigkeit vom Alter aller Versuchstiere}

Tab. 14: Gewichtsparameter von Puten in zwei Altersstufen (LSM \pm SE)

\begin{tabular}{|l|c|c|}
\hline Alter (in Wochen) & 12 & 22 \\
\hline $\mathrm{n}$ & 150 & 184 \\
\hline Schlachtkörpergewicht (kg) & $3,66 \pm 0,08^{\mathrm{a}}$ & $11,09 \pm 0,07^{\mathrm{b}}$ \\
\hline Brustmuskelgewicht Video (kg) & $1,62 \pm 0,05^{\mathrm{a}}$ & $4,36 \pm 0,04^{\mathrm{b}}$ \\
\hline Brustmuskelanteil Video (\%) & $44,3 \pm 0,1^{\mathrm{a}}$ & $40,2 \pm 0,2^{\mathrm{b}}$ \\
\hline $1 / 2$ Brustmuskelgewicht Labor (g) & $540,6 \pm 23,0^{\mathrm{a}}$ & $2029,7 \pm 20,5^{\mathrm{b}}$ \\
\hline Gewicht des M.pect.superfic. (g) & $295,7 \pm 13,9^{\mathrm{a}}$ & $1108,2 \pm 12,4^{\mathrm{b}}$ \\
\hline
\end{tabular}

a,o: Unterschiedliche Buchstaben $=$ Unterschiede mit $p \leq 0,05$

Die erhobenen Gewichtsparameter waren zwischen den beiden Altersgruppen allesamt signifikant unterschiedlich voneinander (Tab. 14). Die Schlachtkörpergewichte der 12 Wochen alten Puten waren mit $3,66 \mathrm{~kg}$ erwartungsgemäß geringer, als die 22 Wochen alten Puten mit $11,09 \mathrm{~kg}$. Alle weiteren Gewichtsparameter waren bei den 22 Wochen alten Tieren ebenfalls deutlich höher als bei der 12 Wochen alten Vergleichsgruppe. Der über die Videobildauswertung ermittelte, prozentuale Brustmuskelanteil war bei den 12 Wochen alten Tieren mit 44,32 \% signifikant höher, als bei den 22 Wochen alten Tieren, welche einen Brustmuskelanteil von $40,2 \%$ zeigten.

Tab. 15: Inhaltstoffe und Trockenmassegehalte des M.pect.superfic. von Puten in zwei Altersstufen (LSM \pm SE)

\begin{tabular}{|l|c|c|}
\hline Alter (in Wochen) & 12 & 22 \\
\hline $\mathrm{n}$ & 198 & 201 \\
\hline Trockenmasse (\%) & $26,1 \pm 0,05^{\mathrm{a}}$ & $26,4 \pm 0,04^{\mathrm{b}}$ \\
\hline Rohprotein (\%) & $25,6 \pm 0,05^{\mathrm{a}}$ & $25,4 \pm 0,04^{\mathrm{b}}$ \\
\hline Rohfett (\%) & $0,36 \pm 0,02^{\mathrm{a}}$ & $0,93 \pm 0,02^{\mathrm{b}}$ \\
\hline Asche (\%) & $1,15 \pm 0,01^{\mathrm{a}}$ & $1,11 \pm 0,01^{\mathrm{b}}$ \\
\hline
\end{tabular}

${ }_{a, b}:$ Unterschiedliche Buchstaben $=$ Unterschiede mit $p \leq 0,05$

Der prozentuale Trockenmassegehalt konnte bei den 12 Wochen alten Putern mit $26,1 \%$ signifikant geringer nachgewiesen werden, als bei den 22 Wochen alten Tieren mit 26,4 \% (Tab.15). Hinsichtlich des Rohproteingehaltes konnte festgestellt werden, dass die 22 Wochen alten Tiere mit $25,4 \%$ einen signifikant niedrigeren prozentualen Gehalt aufwiesen, als die 12 Wochen alten, männlichen Puten mit 25,6 $\%$. Dem entgegen ergab sich beim Rohfettgehalt der 22 Wochen alten Tiere mit 0,93 $\%$ ein nahezu doppelt so hoher prozentualer Anteil, als jener der 12 Wochen alten Hähne mit 0,36 \%. Der Unterschied im Aschegehalt des M.pect.superfic. ist zwischen den beiden Altersstufen zwar nur gering, jedoch bei den 22 Wochen alten Tieren mit $1,11 \%$ signifikant geringer, als bei den 12 Wochen alten Puten mit $1,15 \%$. 


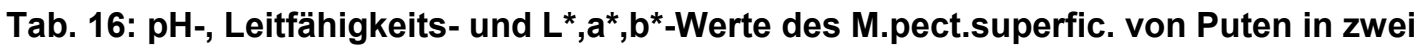
Altersstufen (LSM \pm SE)

\begin{tabular}{|l|c|c|}
\hline Alter (in Wochen) & 12 & 22 \\
\hline $\mathrm{n}$ & 198 & 201 \\
\hline $\mathrm{pH}$ 20min p.m. & $6,6 \pm 0,03^{\mathrm{a}}$ & $6,4 \pm 0,02^{\mathrm{b}}$ \\
$\mathrm{pH}$ 4h p.m. & $6,2 \pm 0,02^{\mathrm{a}}$ & $5,8 \pm 0,02^{\mathrm{b}}$ \\
\hline$\Delta \mathrm{pH}$ & $0,4 \pm 0,03^{\mathrm{a}}$ & $0,6 \pm 0,03^{\mathrm{b}}$ \\
\hline Leitfähigkeit 20min p.m.(mS/cm) & $4,4 \pm 0,16^{\mathrm{b}}$ & $4,0 \pm 0,05$ \\
\hline Leitfähigkeit 4h p.m.(mS/cm) $^{\mathrm{L}^{*}}$ & $4,2 \pm 0,2^{\mathrm{a}}$ & $5,2 \pm 0,14^{\mathrm{b}}$ \\
\hline $\mathrm{a}^{*}$ & $41,9 \pm 0,23^{\mathrm{a}}$ & $43,1 \pm 0,20^{\mathrm{b}}$ \\
\hline $\mathrm{b}^{*}$ & $5,6 \pm 0,07^{\mathrm{a}}$ & $5,9 \pm 0,07^{\mathrm{b}}$ \\
\hline
\end{tabular}

: Unterschiedliche Buchstaben $=$ Unterschiede mit $p \leq 0,05$

Sowohl 20 min p.m. als auch 4 h p.m. war der im M.pect.superfic. gemessene pHWert bei den 22 Wochen alten Tieren signifikant geringer, als bei den 12 Wochen alten Tieren (Tab.16). Die pH-Wertdifferenz $(\Delta \mathrm{pH})$ war bei den 22 Wochen alten Tieren mit 0,6 dagegen signifikant höher als bei den 12 Wochen alten Tieren mit 0,4. Hinsichtlich der 20 min. p.m. gemessenen Leitfähigkeitswerte (LF) ließ sich kein Einfluss des Alters signifikant absichern. Dagegen konnte $4 \mathrm{~h}$ später ein signifikanter Unterschied zwischen den 22 Wochen alten Tieren $(5,2 \mathrm{mS} / \mathrm{cm})$ und den zwölf Wochen alten Tieren $(4,2 \mathrm{mS} / \mathrm{cm})$ dargestellt werden.

Das Fleisch des M.pect.superfic. wurde mit zunehmendem Alter der Versuchstiere signifikant heller. Dies belegt ein $L^{*}$ - Wert von 43,1 bei den 22 Wochen alten Tieren gegenüber einem geringeren Wert von 41,9 bei der 12 Wochen alten Vergleichsgruppe. Ebenfalls konnte eine Erhöhung des Rotanteils bei den älteren Versuchstieren $\left(a^{*}=5,9\right)$ signifikant abgesichert werden. Die 12 Wochen alten Tiere zeigten dagegen einen geringeren $a^{*}-$ Wert von 5,6. Ein höherer Blauanteil im Fleisch der 12 Wochen alten Tiere $\left(b^{*}=-2,8\right)$ im Vergleich zu den 22 Wochen alten Puten $\left(b^{*}=-1,9\right)$ war signifikant.

Tab. 17: Parameter der Fleischqualität des M.pect.superfic. sowie CK - Aktivität und Laktatgehalt im Stichblut von Puten in zwei Altersstufen (LSM \pm SE)

\begin{tabular}{|l|c|c|}
\hline Alter (in Wochen) & 12 & 22 \\
\hline $\mathrm{n}$ & 198 & 201 \\
\hline Tropfsaftverlust (\%) & $2,8 \pm 0,1$ & $2,7 \pm 0,1$ \\
\hline Grillverlust (\%) & $20,1 \pm 0,4^{\mathrm{a}}$ & $21,6 \pm 0,3^{\mathrm{b}}$ \\
\hline Scherkraft (N) & $54,3 \pm 1,4^{\mathrm{a}}$ & $33,3 \pm 1,2^{\mathrm{b}}$ \\
\hline Scherarbeit (Nm) & $0,64 \pm 0,02^{\mathrm{a}}$ & $0,35 \pm 0,02^{\mathrm{b}}$ \\
\hline Blutpunkte (n) & $9,5 \pm 0,7^{\mathrm{a}}$ & $17,9 \pm 0,7^{\mathrm{b}}$ \\
\hline Blutpunkte (n)/ kg M.pect.superfic. & $31,0 \pm 1,2^{\mathrm{a}}$ & $17,0 \pm 1,1^{\mathrm{b}}$ \\
\hline CK-Aktivität (U/l) & $6654 \pm 1976^{\mathrm{a}}$ & $44147 \pm 1763^{\mathrm{b}}$ \\
\hline Laktatgehalt (mg/dl) & $72,2 \pm 1,9^{\mathrm{a}}$ & $62,5 \pm 1,6^{\mathrm{b}}$ \\
\hline
\end{tabular}

${ }^{a, 0}$ : Unterschiedliche Buchstaben $=$ Unterschiede mit $p \leq 0,05$ 
Der Tropfsaftverlust war bei den 12 Wochen alten Puten $(2,8 \%)$ im Gegensatz zu den 22 Wochen alten Tieren (2,7 \%) etwas größer, jedoch war dieser Unterschied nicht signifikant absicherbar (Tab.17).

Der Grillverlust hingegen war bei den 22 Wochen alten Tieren signifikant um 1,5\% höher, als bei der jüngeren Vergleichsgruppe.

Sowohl die Scherkraft- als auch die Scherarbeitswerte waren bei den 12 Wochen alten Tieren ca. doppelt so hoch, wie bei den 22 Wochen alten Tieren. Dieser Unterschied war signifikant.

Dem entgegen konnten, ebenfalls signifikant, nur halb so viele Blutpunkte bei den 12 Wochen alten Tieren $(n=9,5)$ gefunden werden, als bei den 22 Wochen alten Hähnen $(n=17,0)$. Bezieht man die Zahl der Blutpunkte auf das Gewicht des M.pect.superfic., so stellt sich ein genau umgekehrtes Verhältnis zwischen den beiden Altersgruppen dar. Die 12 Wochen alten Tiere zeigten mit 31 Blutpunkten pro $\mathrm{kg}$ M.pect.superfic. fast doppelt so viele Blutpunkte, wie die 22 Wochen alten Probanden (17 Blutpunkte / kg M.pect.superfic.)

Die Creatinkinase-Aktivität im Stichblut war bei den 22 Wochen alten Hähnen signifikant höher (6654 U/I), als bei den 12 Wochen alten Tieren (44147 U/I). Der Laktatgehalt im Stichblut war bei den 12 Wochen alten Tieren signifikant höher $(72,2$ $\mathrm{mg} / \mathrm{dl})$ als bei den 22 Wochen alten Tieren $(62,5 \mathrm{mg} / \mathrm{dl})$.

Tab. 18: Histologische Parameter des M.pect.superfic. von Puten in zwei Altersstufen (LSM \pm SE)

\begin{tabular}{|l|c|c|}
\hline Alter (in Wochen) & 12 & 22 \\
\hline $\mathrm{n}$ & 198 & 201 \\
\hline Fläche $\left(\mu \mathrm{m}^{2}\right)$ & $3193 \pm 117^{\mathrm{a}}$ & $9093 \pm 105^{\mathrm{b}}$ \\
\hline Durchmesser $\varnothing(\mu \mathrm{m})$ & $62,7 \pm 0,7^{\mathrm{a}}$ & $105,9 \pm 0,6^{\mathrm{b}}$ \\
\hline Durchmesser maximal $(\mu \mathrm{m})$ & $81,7 \pm 0,9^{\mathrm{a}}$ & $138,9 \pm 0,8^{\mathrm{b}}$ \\
\hline Durchmesser minimal $(\mu \mathrm{m})$ & $53,9 \pm 0,6^{\mathrm{a}}$ & $90,8 \pm 0,6^{\mathrm{b}}$ \\
\hline Umkreis $(\mu \mathrm{m})$ & $217,9 \pm 2,4^{\mathrm{a}}$ & $367,3 \pm 2,2^{\mathrm{b}}$ \\
\hline Anteil degenerierter Fasern $(\%)$ & $0,83 \pm 0,06$ & $0,91 \pm 0,05$ \\
\hline Anteil an Giant Fibres $(\%)$ & $0,82 \pm 0,06$ & $0,89 \pm 0,05$ \\
\hline Anteil angulärer Fasern $(\%)$ & $0,01 \pm 0,01^{\mathrm{a}}$ & $0,03 \pm 0,01^{\mathrm{b}}$ \\
\hline Kapillare/Zellen $(\mathrm{n})$ & $0,70 \pm 0,02^{\mathrm{a}}$ & $1,55 \pm 0,02^{\mathrm{b}}$ \\
\hline
\end{tabular}

: Unterschiedliche Buchstaben $=$ Unterschiede mit $p \leq 0,05$

Die Zellquerschnittsfläche der Muskelzellen der 22 Wochen alten Tiere $\left(9093 \mu \mathrm{m}^{2}\right)$ war dreimal so groß wie jene der 12 Wochen alten Tiere $\left(3193 \mu \mathrm{m}^{2}\right)$. Auch bei den Parametern maximaler, minimaler und mittlerer Durchmesser waren die größeren Werte allesamt bei den 22 Wochen alten Hähnen zu finden (Tab.18). Die angesprochenen Unterschiede waren durchweg signifikant.

Die Gesamtheit der degenerierten Muskelfasern im Gewebe den M.pect.superfic. war in beiden Altersstufen nicht signifikant unterschiedlich. So zeigten die 12 Wochen alten Puten 0,83 \% degenerierte Muskelfasern, die 22 Wochen alten Tiere 0,91 \%. Dieses Ergebnis zeigte sich ebenfalls bei der Anzahl der Riesenfasern, welche den größten Teil der degenerierten Muskelfasern ausmachten. Die Zahl der angulären Fasern war bei den 22 Wochen alten Tieren mit 0,03\% signifikant höher, als die der 12 Wochen alten Probanden $(0,01 \%)$, bei Betrachtung der absoluten Werte sind beide Zahlen jedoch vernachlässigbar gering. 
Die Anzahl der Kapillaren, welche jede Zelle zum An- und Abtransport von Stoffwechselsubstanzen benötigen, war bei der älteren Tiergruppe signifikant höher $(n=1,55)$, als bei den 12 Wochen alten Hähnen $(0,70 \%)$.

\subsection{Schlachtkörper- und Fleischbeschaffenheitsmerkmale in Abhängigkeit vom Genotyp innerhalb der Altersstufen}

\subsubsection{Durchgang 1}

Im ersten Durchgang des Versuchs wurden die Linien Big 6 von B.U.T. und BBB des Züchters Kelly miteinander verglichen.

Tab. 19: Gewichtsparameter des M.pect.superfic. der Herkünfte B.U.T. BIG 6 und Kelly's BBB im Alter von 12 Wochen (MW \pm SE)

\begin{tabular}{|l|c|c|}
\hline Genotyp & B.U.T. BIG 6 & BBB (Kelly's) \\
\hline Alter (in Wochen) & 12 & 12 \\
\hline $\mathrm{n}$ & $49\left(^{*} 47\right)$ & $49\left(^{*} 37\right)$ \\
\hline Schlachtkörpergewicht $(\mathrm{kg})^{*}$ & $4,6 \pm 0,1^{\mathrm{a}}$ & $3,6 \pm 0,1^{\mathrm{b}}$ \\
\hline${\text { Brustmuskelgewicht }(\mathrm{kg})^{*}}^{\text {Brustmuskelanteil Video (\%) }}$ & $2,0 \pm 0,1^{\mathrm{a}}$ & $1,6 \pm 0,1^{\mathrm{b}}$ \\
\hline $1 / 2$ Brustmuskelgewicht Labor $(\mathrm{g})$ & $43,3 \pm 0,2^{\mathrm{a}}$ & $44,5 \pm 0,3^{\mathrm{b}}$ \\
\hline M.pect.superfic. $(\mathrm{g})$ & $752,3 \pm 33,7^{\mathrm{a}}$ & $584,0 \pm 38,0^{\mathrm{b}}$ \\
\hline $\mathrm{a}, \mathrm{b}$. Unterschiedliche Buchstaben $=$ Unterschiede mit $\mathrm{p} \leq 0,05$ & $306,9 \pm 24,0^{\mathrm{b}}$ \\
\hline
\end{tabular}

Sowohl die Schlachtkörpergewichte $(4,6 \mathrm{~kg})$ als auch die Brustmuskelgewichte $(2,0$ $\mathrm{kg}$ ) waren bei der Herkunft BIG 6 im Alter von 12 Wochen signifikant höher, als bei der Herkunft BBB, welche geringere Schlachtkörpergewichte $(3,6 \mathrm{~kg})$ und geringere Brustmuskelanteile zeigten (Tab.19). Der Brustmuskelanteil war dagegen bei den BBB - Puten mit 44,5 \% signifikant höher, als bei den gleichaltrigen Probanden der Herkunft BIG 6 (43,3\%).

Tab. 20: Gewichtsparameter des M.pect.superfic. der Herkünfte B.U.T. BIG 6 und Kelly's BBB im Alter von 22 Wochen (MW \pm SE)

\begin{tabular}{|l|c|c|}
\hline Genotyp & B.U.T. BIG 6 & BBB (Kelly's) \\
\hline Alter (in Wochen) & 22 & 22 \\
\hline $\mathrm{n}$ & $48\left(^{*} 46\right)$ & $50\left(^{*} 47\right)$ \\
\hline Schlachtkörpergewicht $(\mathrm{kg})^{*}$ & $15,5 \pm 0,1^{\mathrm{a}}$ & $12,9 \pm 0,1^{\mathrm{b}}$ \\
\hline${\text { Brustmuskelgewicht }(\mathrm{kg})^{*}}^{\mathrm{b}}$ & $5,5 \pm 0,1^{\mathrm{a}}$ & $4,5 \pm 0,1^{\mathrm{b}}$ \\
\hline Brustmuskelanteil Video (\%) $^{*}$ & $35,7 \pm 0,2^{\mathrm{a}}$ & $35,0 \pm 0,2^{\mathrm{b}}$ \\
\hline $1 / 2$ Brustmuskelgewicht Labor $(\mathrm{g})$ & $2943,7 \pm 34,1^{\mathrm{a}}$ & $2340,2 \pm 33,7^{\mathrm{b}}$ \\
\hline M.pect.superfic. $(\mathrm{g})$ & $1563,2 \pm 21,6^{\mathrm{a}}$ & $1195,40 \pm 21,3^{\mathrm{b}}$ \\
\hline
\end{tabular}

: $:$ Unterschiedliche Buchstaben $=$ Unterschiede mit $p \leq 0,05$ 
Auch im Alter von 22 Wochen zeigten die BIG 6 - Puten die höchsten Schlachtkörpergewichte $(15,5 \mathrm{~kg})$ und Brustmuskelgewichte $(5,5 \mathrm{~kg})$. Die BBB Puten zeigten signifikant geringere Schlachtkörpergewichte $(12,9 \mathrm{~kg})$ und Brustmuskelgewichte $(4,5 \mathrm{~kg})$.

Es zeigte sich bei den 22 Wochen alten Tieren, dass die Herkunft BIG 6 einen signifikant höheren Brustmuskelanteil im Vergleich zu den BBB - Puten zeigte (Tab.20). Bei der 12 Wochen alten Vergleichsgruppe war dieser Sachverhalt noch umgekehrt vorhanden.

Tab. 21: Inhaltsstoffe und Trockenmassegehalte des M.pect.superfic. des ersten Durchgangs (MW \pm SE)

\begin{tabular}{|l|c|c|}
\hline Genotyp & B.U.T. BIG 6 & BBB (Kelly's) \\
\hline Alter (in Wochen) & 12 & 12 \\
\hline $\mathrm{n}$ & 49 & 49 \\
\hline Trockenmasse (\%) & $25,8 \pm 0,1$ & $25,9 \pm 0,1$ \\
\hline Rohprotein (\%) & $25,3 \pm 0,1$ & $25,4 \pm 0,1$ \\
\hline Rohfett (\%) & $0,41 \pm 0,03$ & $0,37 \pm 0,03$ \\
\hline Asche (\%) & $1,18 \pm 0,01$ & $1,17 \pm 0,01$ \\
\hline
\end{tabular}

${ }^{\mathrm{a}, \mathrm{b}}$ : Unterschiedliche Buchstaben $=$ Unterschiede mit $\mathrm{p} \leq 0,05$

Die Trockenmassegehalte beider Herkünfte unterschieden sich weder im Alter von 12 Wochen, noch im Alter von 22 Wochen signifikant $($ Tab.21 + 22). Auch die Rohproteingehalte (BIG 6: 25,3 \% bzw. BBB 25,4 \%) unterschieden sich zwischen den Herkünften ebenso wenig signifikant, wie die Rohfett- und Aschegehalte.

Tab. 22: Inhaltstoffe und Trockenmassegehalte des M.pect.superfic. des ersten Durchgangs (MW \pm SE)

\begin{tabular}{|l|c|c|}
\hline Genotyp & B.U.T. BIG 6 & BBB (Kelly's) \\
\hline Alter (in Wochen) & 22 & 22 \\
\hline $\mathrm{n}$ & 48 & 50 \\
\hline Trockenmasse (\%) & $25,8 \pm 0,1$ & $25,8 \pm 0,1$ \\
\hline Rohprotein (\%) & $24,8 \pm 0,1^{\mathrm{a}}$ & $24,9 \pm 0,1^{\mathrm{b}}$ \\
\hline Rohfett (\%) & $0,94 \pm 0,03^{\mathrm{a}}$ & $0,79 \pm 0,03^{\mathrm{b}}$ \\
\hline Asche (\%) & $1,07 \pm 0,01^{\mathrm{a}}$ & $1,09 \pm 0,01^{\mathrm{b}}$ \\
\hline
\end{tabular}

${ }^{a, b}$ : Unterschiedliche Buchstaben $=$ Unterschiede mit $p \leq 0,05$

Im Alter von 22 Wochen (Tab.22) war der Rohproteingehalt $(24,8 \%)$ bei den BIG 6 Probanden signifikant geringer, der Rohfettgehalt $(0,94 \%)$ dagegen höher, als bei den BBB - Puten (Rohprotein 24,9\%; Rohfett 0,79\%). Auch der Aschegehalt war bei den 22 Wochen alten BBB - Puten signifikant höher als bei den gleichaltrigen Probanden der Herkunft BIG 6. 
Tab. 23: pH-, LF- und L*a*b*-Werte des M.pect.superfic. der Herkünfte BIG 6 und BBB im Alter von 12 Wochen (MW $\pm S E)$

\begin{tabular}{|l|c|c|}
\hline Genotyp & B.U.T. BIG 6 & BBB (Kelly's) \\
\hline Alter (in Wochen) & 12 & 12 \\
\hline $\mathrm{n}$ & 49 & 49 \\
\hline $\mathrm{pH} 20$ min p.m. & $6,4 \pm 0,04$ & $6,5 \pm 0,04$ \\
\hline $\mathrm{pH}$ 4h p.m. & $6,3 \pm 0,03$ & $6,2 \pm 0,04$ \\
\hline$\Delta$ pH & $0,20 \pm 0,05$ & $0,29 \pm 0,05$ \\
\hline Leitfähigkeit 20min p.m. (mS/cm) & $4,1 \pm 0,2$ & $4,1 \pm 0,3$ \\
\hline Leitfähigkeit 4h p.m. (mS/cm) & $4,0 \pm 0,2$ & $4,6 \pm 0,3$ \\
\hline $\mathrm{L}^{*}$ & $43,7 \pm 0,3^{\mathrm{a}}$ & $42,6 \pm 0,4^{\mathrm{b}}$ \\
\hline $\mathrm{a}^{*}$ & $5,4 \pm 0,1^{\mathrm{a}}$ & $6,0 \pm 0,1^{\mathrm{b}}$ \\
\hline $\mathrm{b}^{*}$ & $-3,1 \pm 0,1$ & $-3,2 \pm 0,1$ \\
\hline
\end{tabular}

: Unterschiedliche Buchstaben $=$ Unterschiede mit $p \leq 0,05$

Die $\mathrm{pH}$ - Werte 20 min p.m. und 4h p.m. unterschieden sich zwischen den Herkünften BIG 6 und BBB im Alter von 12 Wochen nicht signifikant (Tab.23). Auch die $\mathrm{pH}-$ Wertdifferenz $(\Delta \mathrm{pH})$ unterschied sich zwischen beiden Herkünften nicht signifikant, bei Betrachtung der Werte zeigten die Probanden der Herkunft BBB aber mit 0,29 eine höhere $\mathrm{pH}$ - Wertdifferenz, als die BIG 6 - Puten mit 0,20.

Die Leitfähigkeitswerte unterschieden sich weder 20 min p.m., noch 4 h p.m. zwischen beiden Herkünften signifikant. Die BBB - Hähne zeigten jedoch auch hier mit 4,6 mS/cm höhere Werte, als die BIG 6 - Puten mit 4,0 mS/cm.

Der M.pect.superfic. war im Alter von 12 Wochen bei den BBB - Puten signifikant dunkler $\left(L^{*}=42,6\right)$ und zeigte einen höheren Rotanteil $\left(a^{*}=6,0\right)$ als die Probanden der Herkunft BIG $6\left(L^{*}=43,7 ; a^{*}=5,4\right)$. Hinsichtlich des Blau-Gelb-Wertes $b^{*}$ konnte kein signifikanter Unterschied abgesichert werden.

Tab. 24: pH-, LF- und L*a*b*-Werte des M.pect.superfic. der Herkünfte BIG 6 und BBB im Alter von 22 Wochen (MW \pm SE)

\begin{tabular}{|l|c|c|}
\hline Genotyp & B.U.T. BIG 6 & BBB (Kelly's) \\
\hline Alter (in Wochen) & 22 & 22 \\
\hline $\mathrm{n}$ & 48 & 50 \\
\hline $\mathrm{pH} 20$ min p.m. & $6,5 \pm 0,04$ & $6,5 \pm 0,04$ \\
$\mathrm{pH}$ 4h p.m. & $5,9 \pm 0,03^{\mathrm{a}}$ & $5,8 \pm 0,03^{\mathrm{b}}$ \\
\hline$\Delta$ pH & $0,54 \pm 0,05^{\mathrm{a}}$ & $0,76 \pm 0,05^{\mathrm{b}}$ \\
\hline Leitfähigkeit 20 min p.m. (mS) & $4,5 \pm 0,2^{\mathrm{a}}$ & $4,7 \pm 0,2$ \\
\hline Leitfähigkeit 4h p.m. (mS) & $4,9 \pm 0,3^{\mathrm{a}}$ & $6,8 \pm 0,2^{\mathrm{b}}$ \\
\hline $\mathrm{L}^{*}$ & $42,5 \pm 0,3^{\mathrm{a}}$ & $43,6 \pm 0,3^{\mathrm{b}}$ \\
\hline $\mathrm{a}^{*}$ & $6,0 \pm 0,1^{\mathrm{a}}$ & $5,5 \pm 0,1^{\mathrm{b}}$ \\
\hline $\mathrm{b}^{*}$ & $-2,0 \pm 0,1^{\mathrm{a}}$ & $-1,7 \pm 0,1^{\mathrm{b}}$ \\
\hline
\end{tabular}

${ }^{a, 0}$ : Unterschiedliche Buchstaben $=$ Unterschiede mit $p \leq 0,05$

Die 22 Wochen alten Puten beider Herkünfte unterschieden sich hinsichtlich der $\mathrm{pH}-$ Werte 20 min p.m. nicht signifikant Tab.24). Bei den 4 h p.m. gemessenen pHWerten konnte festgestellt werden, das der Genotyp BBB signifikant niedrigere $\mathrm{pH}-$ Werte $(5,75)$ im M.pect.superfic. aufwies, als die Vergleichsgruppe BIG $6(5,94)$. 
Dieses Ergebnis spiegelten sich auch in der $\mathrm{pH}$-Wertdifferenz $(\Delta \mathrm{pH})$ wieder, welche bei der BBB-Gruppe entsprechend größer war $(0,76)$, als bei den gleichaltrigen BIG 6 Hähnen (0,54). Dieser Unterschied war ebenfalls signifikant.

Bei den 22 Wochen alten Tieren konnte hinsichtlich der 20 min. p.m. gemessenen Leitfähigkeitswerte kein signifikanter Unterschied abgesichert werden. $4 \mathrm{~h}$ p.m. jedoch waren die LF-Werte von Kelly's BBB im M.pect.superfic. mit 6,8 ms signifikant höher, als jene der Gruppe Big 6, welche lediglich einen LF-Wert von 4,9 $\mathrm{mS} / \mathrm{cm}$ aufwiesen.

Die BBB - Puten zeigten mit $L^{*}$ - Werten von 43,6 ein helleres Fleisch im Vergleich zu den Probanden der Herkunft BIG 6 mit $L^{*}=42,5$. Damit haben sich die Verhältnisse bezüglich der Fleischhelligkeit im Alter von 12 Wochen umgekehrt.

Ähnlich verhält es sich bei den $a^{*}$ - und $b^{*}$-Werten. Hatten die BIG 6 Hähne im Alter von 12 Wochen noch die niedrigeren $a^{*}$ - und $b^{*}$-Werte (letztere allerdings nicht signifikant abgesichert), so waren die $a^{*}$-Werte signifikant $(6,0)$, die b-Werte signifikant geringer $(-2,0)$ als bei der Vergleichsgruppe BBB $\left(a^{*}=5,5\right.$; $\left.b^{*}=-1,7\right)$.

Tab. 25: Parameter der Fleischqualität des M.pect.superfic. sowie CK - Aktivität und Laktatgehalt der Herkünfte BIG 6 und BBB im Alter von 12 Wochen (MW \pm SE)

\begin{tabular}{|l|c|c|}
\hline Genotyp & B.U.T. BIG 6 & BBB (Kelly's) \\
\hline Alter (in Wochen) & 12 & 12 \\
\hline $\mathrm{n}$ & 49 & 49 \\
\hline Tropfsaftverlust (\%) & $3,4 \pm 0,2^{\mathrm{a}}$ & $2,7 \pm 0,2^{\mathrm{b}}$ \\
\hline Grillverlust (\%) & $20,9 \pm 0,6$ & $21,8 \pm 0,6$ \\
\hline Scherkraft (N) & $52,8 \pm 2,1$ & $58,4 \pm 2,3$ \\
\hline Scherarbeit (Nm) & $0,65 \pm 0,03^{\mathrm{a}}$ & $0,73 \pm 0,03^{\mathrm{b}}$ \\
\hline Blutpunkte (n) & $17,3 \pm 1,0^{\mathrm{a}}$ & $8,9 \pm 1,1^{\mathrm{b}}$ \\
\hline Blutpunkte (n)/ kg M.pect.superfic. & $47,8 \pm 2,5^{\mathrm{a}}$ & $28,8 \pm 2,1^{\mathrm{b}}$ \\
\hline Creatinkinaseaktivität (U/l) & $7809 \pm 2952$ & $5533 \pm 3327$ \\
\hline Laktatgehalt (mg/dl) & $73,6 \pm 2,8$ & $75,3 \pm 3,2$ \\
\hline
\end{tabular}

: Unterschiedliche Buchstaben $=$ Unterschiede mit $p \leq 0,05$

Die 12 Wochen alten Big 6 Hähne wiesen einen signifikant höheren prozentualen Tropfsaftverlust auf $(3,4 \%)$, als die der gleichaltrigen Vergleichsgruppe $(2,7 \%)$. Dagegen konnte kein signifikanter Unterschied zwischen den Herkünften hinsichtlich des Parameters Grillverlust abgesichert werden (Tab.25).

Die gemessene Scherkraft war bei den 12 Wochen alten Tieren des Genotyps BBB zwar höher $(58,4 \mathrm{~N})$ als bei der Herkunft BIG $6(52,8 \mathrm{~N})$, jedoch war dieser Unterschied nicht signifikant. Anders verhielt es sich dagegen bei dem Parameter Scherarbeit, bei dem der Unterschied zwischen den Herkünften signifikant anzusichern war; die BBB - Puten zeigten mit 0,73 Nm höhere Scherarbeitswerte, als die BIG 6 - Puten mit 0,65 Nm.

Im Alter von 12 Wochen hatten die BIG 6 Hähne etwa doppelt so viele und damit signifikant mehr Blutpunkte $(17,3)$ an den Schnittflächen, als die Vergleichsgruppe des Züchters Kelly $(8,9)$. Auch auf das Gewicht des M.pect.superfic. bezogen zeigte die Herkunft BIG 6 die signifikant höchsten Blutpunktzahlen.

Die Parameter Creatinkinaseaktivität und Laktatgehalt im Stichblut zeigten keine signifikanten Unterschiede zwischen den Herkünften. 
Tab. 26: Parameter der Fleischqualität des M.pect.superfic. sowie CK - Aktivität und Laktatgehalt im Stichblut der Herkünfte BIG 6 und BBB im Alter von 22 Wochen (MW \pm SE)

\begin{tabular}{|l|c|c|}
\hline Genotyp & B.U.T. BIG 6 & BBB (Kelly's) \\
\hline Alter (in Wochen) & 22 & 22 \\
\hline $\mathrm{n}$ & 48 & 50 \\
\hline Tropfsaftverlust (\%) & $2,6 \pm 0,2^{\mathrm{a}}$ & $4,2 \pm 0,2^{\mathrm{b}}$ \\
\hline Grillverlust (\%) & $21,2 \pm 0,6$ & $21,6 \pm 0,6$ \\
\hline Scherkraft (N) & $37,1 \pm 2,1^{\mathrm{a}}$ & $34,9 \pm 2,1^{\mathrm{b}}$ \\
\hline Scherarbeit (Nm) & $0,41 \pm 0,03$ & $0,37 \pm 0,03$ \\
\hline Blutpunkte (n) & $16,4 \pm 1,0$ & $15,3 \pm 1,0$ \\
\hline Blutpunkte (n)/ kg M.pect.superfic. & $10,7 \pm 0,7$ & $13,1 \pm 0,7$ \\
\hline Creatinkinaseaktivität (U/l) & $54202 \pm 2983$ & $53328 \pm 2952$ \\
\hline Laktatgehalt (mg/dl) & $58,1 \pm 2,9$ & $57,5 \pm 2,8$ \\
\hline
\end{tabular}

a,b: Unterschiedliche Buchstaben $=$ Unterschiede mit $p \leq 0,0$

Im Alter von 22 Wochen zeigten die BIG 6 Hähne den niedrigeren $(2,6 \%)$, die Probanden der Herkunft BBB den höheren Tropfsaftverlust (4,2\%). Dieser Unterschied war signifikant abzusichern (Tab.26). Ebenso wie bei den 12 Wochen alten Puten dieses Durchgangs war kein signifikanter Unterschied zwischen den Herkünften bei dem Parameter Grillverlust festzustellen.

Im Alter von 22 Wochen zeigte der Genotyp BIG 6 signifikant höhere Scherkraftwerte $(37,1 \mathrm{~N})$, als die gleichaltrige Vergleichsgruppe $(34,9)$. Betrachtet man jedoch den Parameter Scherarbeit, war bei den 22 Wochen alten Tieren kein signifikanter Unterschied abzusichern, wenngleich bei den BIG 6 Hähnen etwas höhere Werte gemessen wurden $(0,41 \mathrm{Nm})$, als bei den BBB - Puten $(0,37 \mathrm{Nm})$.

Mit 22 Wochen hatten die Probanden der Herkunft BIG 6 noch immer mehr Blutpunkte $(16,4)$ als die BBB - Puten $(15,3)$, jedoch war dieser Unterschied nicht mehr signifikant. Auch die Bezugnahme der Blutpunktzahl auf das Gewicht des M.pect.superfic. änderte dieses Ergebnis nicht.

Die Parameter Creatinkinaseaktivität und Laktatgehalt im Stichblut zeigten keine signifikanten Unterschiede zwischen den Herkünften.

Tab. 27: Histologische Parameter des M.pect.superfic. der Herkünfte BIG 6 und BBB im Alter von 12 Wochen $(M W \pm S E)$

\begin{tabular}{|l|c|c|}
\hline Genotyp & B.U.T. BIG 6 & BBB (Kelly's) \\
\hline Alter (in Wochen) & 12 & 12 \\
\hline $\mathrm{n}$ & 49 & 49 \\
\hline Faserquerschnittsfläche $\left(\mu \mathrm{m}^{2}\right)$ & $3225 \pm 178$ & $3109 \pm 201$ \\
\hline Faserdurchmesser $\varnothing(\mu \mathrm{m})$ & $62,8 \pm 1,1$ & $61,8 \pm 1,2$ \\
\hline Faserdurchmesser maximal $(\mu \mathrm{m})$ & $81,4 \pm 1,4$ & $80,6 \pm 1,6$ \\
\hline Faserdurchmesser minimal $(\mu \mathrm{m})$ & $54,3 \pm 0,9$ & $53,8 \pm 1,1$ \\
\hline Faserumfang $(\mu \mathrm{m})$ & $217,8 \pm 3,7$ & $216,2 \pm 4,1$ \\
\hline Anteil degenerierter Fasern $(\%)$ & $0,8 \pm 0,1$ & $1,0 \pm 0,1$ \\
\hline Anteil an Giant Fibres $(\%)$ & $0,8 \pm 0,1$ & $1,0 \pm 0,1$ \\
\hline Anteil angulärer Fasern $(\%)$ & $0,00 \pm 0,0$ & $0,02 \pm 0,02$ \\
\hline Anzahl Kapillaren pro Zelle & $0,77 \pm 0,03$ & $0,71 \pm 0,04$ \\
\hline
\end{tabular}

${ }^{a, b}$ : Unterschiedliche Buchstaben $=$ Unterschiede mit $p \leq 0,05$ 
Zwischen den Herkünften BIG 6 und BBB konnte kein signifikanter Unterschied bei der Muskelfaserquerschnittsfläche festgestellt werden (Tab.27). Die Fasern beider Herkünfte waren mit $3225 \mu^{2}$ (BIG 6) und $3109 \mu \mathrm{m}^{2}$ etwa gleich groß. Auch die anderen Parameter, welche die Zellgröße beschreiben, konnten keine signifikanten Unterschiede zwischen den Herkünften belegen.

Der Anteil degenerierter Muskelfasern war bei beiden Herkünften vergleichbar groß. So zeigten die BIG 6 - Puten einen Anteil von 0,8 \%, die BBB - Puten 1,0\% degenerierte Muskelfasern. Diese bestanden bei beiden Herkünften zum größten Teil aus Giant Fibres (Riesenfasern). Der Anteil angulärer Muskelfasern war sowohl bei den BIG 6 - Puten (0 \%), als auch bei den BBB - Puten $(0,02 \%)$ vernachlässigbar gering.

Die Anzahl an Kapillaren pro Zelle war bei den BIG 6 - Puten mit 0,77 nur unwesentlich höher, als bei den Probanden der Herkunft BBB mit 0,71. Auch dieser Unterschied war nicht signifikant.

Tab. 28: Histologische Parameter des M.pect.superfic. der Herkünfte BIG 6 und BBB im Alter von 22 Wochen (MW \pm SE)

\begin{tabular}{|l|c|c|}
\hline Genotyp & B.U.T. BIG 6 & BBB (Kelly's) \\
\hline Alter (in Wo.) & 22 & 22 \\
\hline $\mathrm{n}$ & 48 & 50 \\
\hline Faserquerschnittsfläche $\left(\mu \mathrm{m}^{2}\right)$ & $9969 \pm 180$ & $9734 \pm 178$ \\
\hline Faserdurchmesser $\varnothing(\mu \mathrm{m})$ & $110,8 \pm 1,1$ & $109,6 \pm 1,1$ \\
\hline Faserdurchmesser maximal $(\mu \mathrm{m})$ & $144,5 \pm 1,4$ & $142,0 \pm 1,4$ \\
\hline Faserdurchmesser minimal $(\mu \mathrm{m})$ & $95,8 \pm 1,0$ & $94,6 \pm 0,9$ \\
\hline Faserumfang $(\mu \mathrm{m})$ & $384,6 \pm 3,7$ & $378,2 \pm 3,7$ \\
\hline Anteil degenerierter Fasern $(\%)$ & $0,6 \pm 0,1^{\mathrm{a}}$ & $1,0 \pm 0,1^{\mathrm{b}}$ \\
\hline Anteil an Giant Fibres $(\%)$ & $0,6 \pm 0,1^{\mathrm{a}}$ & $1,0 \pm 0,1^{\mathrm{b}}$ \\
\hline Anteil angulärer Fasern $(\%)$ & $0,07 \pm 0,02^{\mathrm{a}}$ & $0 \pm 0,02^{\mathrm{b}}$ \\
\hline Anzahl Kapillaren pro Zelle & $1,65 \pm 0,03$ & $1,67 \pm 0,03$ \\
\hline
\end{tabular}

${ }^{a, b}:$ Unterschiedliche Buchstaben $=$ Unterschiede mit $p \leq 0,05$

Zwischen den Herkünften BIG 6 und BBB konnte kein signifikanter Unterschied bei der Muskelfaserquerschnittsfläche festgestellt werden (Tab.28). Die Fasern beider Herkünfte waren mit $9969 \mu^{2}$ (BIG 6) und $9734 \mu m^{2}$ etwa gleich groß. Auch die anderen Parameter, welche die Zellgröße beschreiben, konnten keine signifikanten Unterschiede zwischen den Herkünften belegen.

Der Anteil degenerierter Muskelfasern war bei den BIG 6 - Puten mit 0,6\% signifikant geringer als jener der Probanden der Herkunft BBB mit 1,0\% degenerierter Muskelfasern.

Wie schon bei den 12 Wochen alten Tieren bestand auch in dieser Altersstufe der weitaus größte Teil der degenerierten Fasern aus Giant Fibres. Dem entsprechend zeigte die Herkunft BBB auch den signifikant größeren Anteil an Giant Fibres $(1,0 \%)$ im Vergleich mit den BIG 6 - Puten (0,6 \%). Auch wenn die BIG 6 - Puten den signifikant größten Anteil an angulären Fasern zeigten $(0,07 \%)$, ist die absolute Häufigkeit vernachlässigbar gering.

Die Anzahl an Kapillaren pro Zelle war bei den BIG 6 - Puten mit 0,77 nur unwesentlich höher, als bei den Probanden der Herkunft BBB mit 0,71. Dieser Unterschied war nicht signifikant. 


\subsubsection{Durchgang 2}

Im zweiten Durchgang wurden die Linien Wrolstad (Kelly), Super Mini (Kelly) und BIG 6 (B.U.T.) in den Altersgruppen 12 und 22 Wochen miteinander verglichen.

\subsubsection{Altersgruppe 12 Wochen}

Tab. 29: Gewichtsparameter der Brustmuskulatur und des M.pect.superfic. der Herkünfte BIG 6, Wrolstad und Super Mini im Alter von 12 Wochen (MW \pm SE)

\begin{tabular}{|l|c|c|c|}
\hline Genotyp & B.U.T. BIG 6 & $\begin{array}{c}\text { Wrolstad } \\
\text { (Kelly's) }\end{array}$ & $\begin{array}{c}\text { Super Mini } \\
\text { (Kelly's) }\end{array}$ \\
\hline Alter (in Wochen) & 12 & 12 & 12 \\
\hline $\mathrm{n}$ & $33^{*}(28)$ & $34^{*}(18)$ & $33^{*}(20)$ \\
\hline $\begin{array}{l}\text { Schlachtkörpergewicht } \\
(\mathrm{kg})^{*}\end{array}$ & $4,7 \pm 0,2^{\mathrm{a}}$ & $3,1 \pm 0,2^{\mathrm{b}}$ & $3,2^{\mathrm{b}} \pm 0,2^{\mathrm{b}}$ \\
\hline $\begin{array}{l}\text { Brustmuskelgewicht } \\
(\mathrm{kg})^{*}\end{array}$ & $2,0 \pm 0,1^{\mathrm{a}}$ & $1,42 \pm 0,1^{\mathrm{b}}$ & $1,45 \pm 0,1^{\mathrm{b}}$ \\
\hline $\begin{array}{l}\text { Brustmuskelanteil } \\
(\%)^{*}\end{array}$ & $43,0 \pm 0,3^{\mathrm{a}}$ & $45,0 \pm 0,4^{\mathrm{b}}$ & $44,6 \pm 0,4^{\mathrm{b}}$ \\
\hline $\begin{array}{l}1 / 2 \text { Brustmuskelgewicht } \\
\text { Labor (g) }\end{array}$ & $656,8 \pm 43,7^{\mathrm{a}}$ & $456,7 \pm 54,5^{\mathrm{b}}$ & $404,9 \pm 51,7^{\mathrm{b}}$ \\
\hline $\begin{array}{l}\text { M.pect.superfic. Gewicht } \\
(\mathrm{g})\end{array}$ & $381,7 \pm 27,6^{\mathrm{a}}$ & $261,4 \pm 34,5^{\mathrm{b}}$ & $233,6 \pm 32,7^{\mathrm{b}}$ \\
\hline
\end{tabular}

: Unterschiedliche Buchstaben $=$ Unterschiede mit $p \leq 0,05$

Da es sich bei der BIG 6 um eine moderne Hochleistungspute handelt, war es zu erwarten, dass dieser Genotyp im Vergleich zu den kleineren Vergleichsgenotypen hinsichtlich der Schlachtkörpergewichte die höchsten Werte aufwies $(4,7 \mathrm{~kg})$. Die Unterschiede zwischen den Hähnen der Linie Wrolstad (mittelschwerer Typ; 3,1 kg) und Super Mini (leichter Typ; 3,2 kg) waren nicht signifikant (Tab.29). Es ist jedoch bemerkenswert, dass der mittelschwere Typ Wrolstad im Alter von 12 Wochen leichter war, als die leichte Linie Super Mini. Dieser Sachverhalt ließ sich auch bei dem Parameter Brustmuskelgewicht nachweisen.

Der prozentuale Brustmuskelanteil am Schlachtkörper war bei den 12 Wochen alten BIG 6 Hähnen signifikant geringer $(43,0 \%)$ als bei den beiden Vergleichsherkünften. Die Herkünfte Wrolstad und Super Mini unterschieden sich hinsichtlich dieses Parameters nicht signifikant.

Das Gewicht des M.pect.superfic. war bei der Herkunft BIG 6 signifikant höher $(381,7$ g) als bei den Herkünften Wrolstad (261,4 g) und Super Mini (233,6 g). Der Unterschied zwischen Letzteren war nicht signifikant. 
Tab. 30: Trockenmassegehalte und Inhaltstoffe des M.pect.superfic. der Herkünfte BIG 6, Wrolstad und Super Mini im Alter von 12 Wochen (MW \pm SE)

\begin{tabular}{|l|c|c|c|}
\hline Genotyp & B.U.T. BIG 6 & $\begin{array}{c}\text { Wrolstad } \\
\text { (Kelly's) }\end{array}$ & $\begin{array}{c}\text { Super Mini } \\
\text { (Kelly's) }\end{array}$ \\
\hline Alter (in Wochen) & 12 & 12 & 12 \\
\hline $\mathrm{n}$ & 33 & 34 & 33 \\
\hline TM \% & $26,4 \pm 0,1$ & $26,2 \pm 0,1$ & $26,3 \pm 0,1$ \\
\hline Rohprotein \% & $25,9 \pm 0,1$ & $25,8 \pm 0,1$ & $25,8 \pm 0,1$ \\
\hline Rohfett \% & $0,40 \pm 0,04$ & $0,34 \pm 0,05$ & $0,35 \pm 0,05$ \\
\hline Asche \% & $1,16 \pm 0,01^{\text {a }}$ & $1,10 \pm 0,02^{\mathrm{b}}$ & $1,16 \pm 0,02^{\mathrm{a}}$ \\
\hline
\end{tabular}

a,b,c: Unterschiedliche Buchstaben $=$ Unterschiede mit $p \leq 0,05$

Hinsichtlich der Trockenmassegehalte sowie der Inhaltstoffe Rohprotein und Rohfett konnte zwischen den 12 Wochen alten Tieren aller Genotypen kein signifikanter Unterschied abgesichert werden (Tab.30). Bei Betrachtung der absoluten Rohfettgehalte zeigte die Herkunft BIG 6 mit 0,4 \% den höchsten, Kelly's Wrolstad mit $0,34 \%$ den geringsten Wert. Obwohl die Linie Wrolstad einen signifikant geringeren Aschegehalt (1,10\%) als die beiden Vergleichsgruppen (1,16 \%) aufwies, war dieser Unterschied vernachlässigbar gering.

Tab. 31: pH-, LF- und $L^{*}, a^{*}, b^{*}-$ Werte des M.pect.superfic. der Herkünfte BIG 6, Wrolstad und Super Mini im Alter von 12 Wochen (MW \pm SE)

\begin{tabular}{|l|c|c|c|}
\hline Genotyp & B.U.T. BIG 6 & $\begin{array}{c}\text { Wrolstad } \\
\text { (Kelly's) }\end{array}$ & $\begin{array}{c}\text { Super Mini } \\
\text { (Kelly's) }\end{array}$ \\
\hline Alter (in Wochen) & 12 & 12 & 12 \\
\hline $\mathrm{n}$ & 33 & 34 & 33 \\
\hline $\mathrm{pH} \mathrm{20min}$ & $6,69 \pm 0,05^{\mathrm{a}}$ & $6,66 \pm 0,06^{\mathrm{ab}}$ & $6,54 \pm 0,06^{\mathrm{b}}$ \\
\hline $\mathrm{pH} 4 \mathrm{~h}$ & $6,23 \pm 0,04^{\mathrm{a}}$ & $6,11 \pm 0,05^{\mathrm{a}}$ & $6,17 \pm 0,05^{\mathrm{a}}$ \\
\hline$\Delta \mathrm{pH}$ & $0,47 \pm 0,06^{\mathrm{a}}$ & $0,55 \pm 0,07^{\mathrm{a}}$ & $0,37 \pm 0,07^{\mathrm{a}}$ \\
\hline $\mathrm{LF} \mathrm{20min} \mathrm{(mS/cm)}$ & $4,0 \pm 0,3^{\mathrm{a}}$ & $4,6 \pm 0,4^{\mathrm{a}}$ & $4,9 \pm 0,4^{\mathrm{a}}$ \\
\hline $\mathrm{LF} 4 \mathrm{~h}(\mathrm{mS} / \mathrm{cm})$ & $3,6 \pm 0,3^{\mathrm{a}}$ & $5,0 \pm 0,4^{\mathrm{b}}$ & $3,4 \pm 0,4^{\mathrm{a}}$ \\
\hline $\mathrm{L}^{*}$ & $40,3 \pm 0,5^{\mathrm{a}}$ & $41,4 \pm 0,5^{\mathrm{a}}$ & $41,1 \pm 0,5^{\mathrm{a}}$ \\
\hline $\mathrm{a}^{*}$ & $6,3 \pm 0,1^{\mathrm{a}}$ & $5,6 \pm 0,2^{\mathrm{b}}$ & $5,2 \pm 0,2^{\mathrm{b}}$ \\
\hline $\mathrm{b}^{*}$ & $-2,3 \pm 0,2^{\mathrm{a}}$ & $-2,7 \pm 0,2^{\mathrm{a}}$ & $-2,5 \pm 0,2^{\mathrm{a}}$ \\
\hline
\end{tabular}

: Unterschiedliche Buchstaben $=$ Unterschiede mit $p \leq 0,05$

Die 12 Wochen alten Super Mini-Hähne wiesen 20 min p.m. einen um 0,15 signifikant niedrigeren pH-Wert als die gleichaltrigen BIG 6 Hähne auf. 4 h p.m. war kein Unterschied mehr zwischen den Herkünften nachzuweisen (Tab.31). Auch hinsichtlich der $\mathrm{pH}$-Wertdifferenz konnten keine Unterschiede beobachtet werden, wenngleich die Herkunft Wrolstad mit 0,55 die höchste $\mathrm{pH}$ - Wertdifferenz zeigte, die Linie Super Mini dagegen mit 0,37 die geringste.

Die Leitfähigkeitswerte $20 \mathrm{~min}$. p.m. wiesen keine signifikanten Unterschiede zwischen den Genotypen auf. 4 h p.m. jedoch konnte ein signifikant höherer LF-Wert bei den 12 Wochen alten Wrolstad-Putern $(5,0 \mathrm{mS} / \mathrm{cm}) \mathrm{im}$ Gegensatz zu den beiden Vergleichsgenotypen ( BIG 6: 3,6 mS/cm; Super Mini: 3,4 mS/cm) aufgezeigt werden. 
Gab es bezüglich der $\mathrm{L}^{*}$ und $\mathrm{b}^{*}$-Werte keine nennenswerten Unterschiede zwischen den Genotypen, so konnte bei den $a^{*}$-Werten signifikant nachgewiesen werden, dass die Probanden der Herkunft BIG 6 einen höheren Rotanteil $(6,3)$ im M.pect.superfic. zeigten, als die beiden Vergleichsgenotypen Wrolstad $(5,6)$ und Super Mini $(5,2)$.

Tab. 32: Parameter der Fleischqualität des M.pect.superfic. sowie CK - Aktivität und Laktatgehalt im Stichblut der Herkünfte BIG 6, Wrolstad und Super Mini im Alter von 12 Wochen (MW \pm SE)

\begin{tabular}{|l|c|c|c|}
\hline Genotyp & B.U.T. BIG 6 & $\begin{array}{c}\text { Wrolstad } \\
\text { (Kelly's) }\end{array}$ & $\begin{array}{c}\text { Super Mini } \\
\text { (Kelly's) }\end{array}$ \\
\hline Alter (in Wochen) & 12 & 12 & 12 \\
\hline $\mathrm{n}$ & 33 & 34 & 33 \\
\hline Tropfsaftverlust (\%) & $2,0 \pm 0,2^{\mathrm{a}}$ & $2,3 \pm 0,3^{\mathrm{a}}$ & $3,1 \pm 0,3^{\mathrm{b}}$ \\
\hline Grillverlust (\%) & $17,4 \pm 0,74^{\mathrm{a}}$ & $19,1 \pm 0,9^{\mathrm{ab}}$ & $20,0 \pm 0,9^{\mathrm{b}}$ \\
\hline Scherkraft (N) & $47,7 \pm 2,7^{\mathrm{a}}$ & $52,4 \pm 3,3^{\mathrm{a}}$ & $55,7 \pm 3,2^{\mathrm{a}}$ \\
\hline Scherarbeit (Nm) & $0,54 \pm 0,03^{\mathrm{a}}$ & $0,57 \pm 0,04^{\mathrm{a}}$ & $0,64 \pm 0,04^{\mathrm{a}}$ \\
\hline Blutpunkte (n) & $13,3 \pm 1,3^{\mathrm{a}}$ & $8,3 \pm 1,6^{\mathrm{b}}$ & $4,9 \pm 1,5^{\mathrm{b}}$ \\
\hline $\begin{array}{l}\text { Blutpunkte (n) / kg } \\
\text { M.pect.superfic. }\end{array}$ & $34,5 \pm 4,2^{\mathrm{a}}$ & $31,3 \pm 2,8^{\mathrm{b}}$ & $20,4 \pm 1,8^{\mathrm{b}}$ \\
\hline $\begin{array}{l}\text { Creatinkinaseaktivität } \\
\text { (U/l) }\end{array}$ & $6328 \pm 3824^{\mathrm{a}}$ & $7028 \pm 4769^{\mathrm{a}}$ & $6801 \pm 4525^{\mathrm{a}}$ \\
\hline Laktat (mg/dl) & $73,9 \pm 3,7^{\mathrm{a}}$ & $64,8 \pm 4,6^{\mathrm{a}}$ & $75,0 \pm 4,3^{\mathrm{a}}$ \\
\hline
\end{tabular}

Unterschiedliche Buchstaben $=$ Unterschiede mit $p \leq 0,05$

Der prozentuale Tropfsaftverlust des Genotyps Super Mini $(3,1 \%)$ war um etwa ein Prozent höher, als bei den Vergleichsgruppen (BIG 6: 2,0; Wrolstad: 2,3 \%). Dieser Unterschied war signifikant (Tab.32).

Ähnliches zeigte sich beim Grillverlust, dessen Werte ebenfalls beim Genotyp Super Mini signifikant höher waren $(20,0 \%)$, als bei den Probanden der Herkunft BIG 6 $(17,4 \%)$.

Keine Unterschiede konnten zwischen den Genotypen hinsichtlich der Parameter Scherkraft und Scherarbeit nachgewiesen werden. Tendenziell zeigte die Herkunft Super Mini mit 55,7 N aber höhere Scherkraftwerte, als die Herkünfte Wrolstad $(52,4$ N) und BIG $6(47,7 \mathrm{~N})$.

Die Anzahl an Blutpunkten war bei den Probanden der Herkunft BIG 6 mit 13,3 signifikant höher, als bei den Vergleichsgruppen. Die geringste Anzahl zeigte der Genotyp Super Mini mit 4,9 Blutpunkten. Auch bei Bezug der Blutpunktzahl auf das Gewicht des M.pect.superfic. zeigte die Herkunft BIG 6 mit 34,5 Blutpunkten pro kg Muskel die signifikant höchsten Blutpunktzahlen. Auch wenn sich die beiden Vergleichsherkünfte hinsichtlich dieses Parameters nicht signifikant voneinander unterschieden, zeigte die Linie Super Mini mit 20,4 Blutpunkten pro kg geringere Werte, als die Linie Wrolstad mit 31,3 Blutpunkten pro kg.

Weder die CK- noch die Laktatwerte zeigten signifikante Unterschiede zwischen den Genotypen. 
Tab. 33: Histologische Parameter des M.pect.superfic. der Herkünfte BIG 6, Wrolstad und Super Mini im Alter von 12 Wochen $(M W \pm S E)$

\begin{tabular}{|l|c|c|c|}
\hline Genotyp & B.U.T. BIG 6 & $\begin{array}{c}\text { Wrolstad } \\
\text { (Kelly's) }\end{array}$ & $\begin{array}{c}\text { Super Mini } \\
\text { (Kelly's) }\end{array}$ \\
\hline Alter (in Wochen) & 12 & 12 & 12 \\
\hline $\mathrm{n}$ & 33 & 34 & 33 \\
\hline $\begin{array}{l}\text { Faserquerschnittsfläche } \\
\left(\mu \mathrm{m}^{2}\right)\end{array}$ & $3467 \pm 231^{\mathrm{a}}$ & $3315 \pm 288^{\mathrm{a}}$ & $3032 \pm 273^{\mathrm{a}}$ \\
\hline $\begin{array}{l}\text { Durchmesser } \\
(\mu \mathrm{m})\end{array}$ & $65,4 \pm 1,4^{\mathrm{a}}$ & $64,0 \pm 1,7^{\mathrm{ab}}$ & $61,1 \pm 1,6^{\mathrm{b}}$ \\
\hline $\begin{array}{l}\text { Durchmesser maximal } \\
(\mu \mathrm{m})\end{array}$ & $84,8 \pm 1,8^{\mathrm{a}}$ & $83,5 \pm 2,3^{\mathrm{a}}$ & $79,9 \pm 2,2^{\mathrm{a}}$ \\
$\begin{array}{l}\text { Durchmesser minimal } \\
(\mu \mathrm{m})\end{array}$ & $56,5 \pm 1,2^{\mathrm{a}}$ & $54,7 \pm 1,5^{\mathrm{ab}}$ & $52,1 \pm 1,4^{\mathrm{b}}$ \\
\hline $\begin{array}{l}\text { Umkreis } \\
(\mu \mathrm{m})\end{array}$ & $227,0 \pm 4,8^{\mathrm{a}}$ & $222,2 \pm 5,9^{\mathrm{ab}}$ & $211,8 \pm 5,6^{\mathrm{b}}$ \\
\hline $\begin{array}{l}\text { Anteil degenerierter } \\
\text { Muskelfasern (\%) }\end{array}$ & $0,7 \pm 0,12^{\mathrm{a}}$ & $0,73 \pm 0,14^{\mathrm{a}}$ & $0,83 \pm 0,14^{\mathrm{a}}$ \\
\hline $\begin{array}{l}\text { Anteil an Giant Fibres } \\
(\%)\end{array}$ & $0,69 \pm 0,12^{\mathrm{a}}$ & $0,71 \pm 0,15^{\mathrm{a}}$ & $0,83 \pm 0,14^{\mathrm{a}}$ \\
$\begin{array}{l}\text { Anteil an angulären } \\
\text { Fasern (\%) }\end{array}$ & $0,03 \pm 0,02^{\mathrm{a}}$ & $0,01 \pm 0,03^{\mathrm{a}}$ & $0 \pm 0,03^{\mathrm{a}}$ \\
\hline $\begin{array}{l}\text { Anzahl Kapillaren pro } \\
\text { Zelle }\end{array}$ & $0,82 \pm 0,04^{\mathrm{a}}$ & $0,72 \pm 0,05^{\mathrm{ab}}$ & $0,60 \pm 0,05^{\mathrm{b}}$ \\
\hline
\end{tabular}

,b,c: Unterschiedliche Buchstaben $=$ Unterschiede mit $p \leq 0,05$

Auch wenn der Genotyp BIG 6 die größten absoluten Werte hinsichtlich des Parameters Faserfläche $\left(3467 \mu \mathrm{m}^{2}\right)$ im Vergleich zu den Herkünften Wrolstad (3315 $\left.\mu \mathrm{m}^{2}\right)$ und Super Mini $\left(3032 \mu \mathrm{m}^{2}\right)$ aufwies, so waren diese Unterschiede zwischen den Genotypen nicht signifikant (Tab.33). Der Zelldurchmesser war bei den Super Mini Hähnen $(61,1 \mu \mathrm{m})$ signifikant geringer, als bei der Linie BIG $6(65,4 \mu \mathrm{m})$. Lediglich bei der Betrachtung des maximalen Durchmessers war der Größenunterschied nicht signifikant, absolut betrachtet war er jedoch auch in diesem Fall bei den Super Mini-Hähnen am geringsten. Ähnlich verhielt es sich beim Parameter Zellumfang. Dieser war bei den Super Mini erwartungsgemäß signifikant geringer $(211,8 \mu \mathrm{m})$, als bei den Probanden der Herkunft BIG $6(227,0 \mu \mathrm{m})$.

Hinsichtlich der Anteile degenerierter Muskelfasern am Gesamtgewebe konnte zwischen den Herkünften weder bei der Gesamtheit aller degenerierter Fasern, noch bei den Anteilen an Giant Fibres bzw. angulären Fasern ein signifikanter Unterschied nachgewiesen werden. Jedoch zeigte die Herkunft Super Mini einen tendenziell höheren Anteil degenerierter Muskelfasern (0,83\%), als die Herkünfte BIG $6(0,7 \%)$ und Wrolstad $(0,71 \%)$.

Die kapillare Versorgung der Muskelzellen war bei den Probanden der Herkunft BIG $6 \mathrm{im}$ Vergleich zu den anderen beiden Genotypen am besten. Da sie 0,82 Kapillaren pro Zelle zeigten. Die Herkünfte Wrolstad (0,72 Kapillaren pro Zelle) und Super Mini ( 0,60 Kapillaren pro Zelle) zeigten dagegen eine geringere Kapillardichte. 
Diesbezüglich war der Unterschied zwischen den Herkünften BIG 6 und Super Mini signifikant abzusichern.

\subsubsection{Altersgruppe 22 Wochen}

Tab. 34: Gewichtsparameter der Brustmuskulatur und des M.pect.superfic. der Herkünfte BIG 6 , Wrolstad und Super Mini im Alter von 22 Wochen (MW \pm SE)

\begin{tabular}{|l|c|c|c|}
\hline Genotyp & B.U.T. BIG 6 & $\begin{array}{c}\text { Wrolstad } \\
\text { (Kelly's) }\end{array}$ & $\begin{array}{c}\text { Super Mini } \\
\text { (Kelly's) }\end{array}$ \\
\hline Alter (in Wochen) & 22 & 22 & 22 \\
\hline $\mathrm{n}$ & $42^{*}(41)$ & $25^{*}(20)$ & $36^{*}(30)$ \\
\hline $\begin{array}{l}\text { Schlachtkörpergewicht } \\
(\mathrm{kg})^{*}\end{array}$ & $15,3 \pm 0,1^{\mathrm{a}}$ & $8,2 \pm 0,2^{\mathrm{b}}$ & $7,9 \pm 0,2^{\mathrm{b}}$ \\
\hline $\begin{array}{l}\text { Brustmuskelgewicht } \\
(\mathrm{kg})^{*}\end{array}$ & $6,4 \pm 0,1^{\mathrm{a}}$ & $3,6 \pm 0,1^{\mathrm{b}}$ & $3,4 \pm 0,1^{\mathrm{b}}$ \\
\hline $\begin{array}{l}\text { Brustmuskelanteil } \\
(\%)^{*}\end{array}$ & $41,9 \pm 0,2^{\mathrm{a}}$ & $43,4 \pm 0,4^{\mathrm{b}}$ & $43,7 \pm 0,3^{\mathrm{b}}$ \\
$\begin{array}{l}1 / 2 \text { Brustmuskelgewicht } \\
(\mathrm{g})\end{array}$ & $2688 \pm 36^{\mathrm{a}}$ & $1524 \pm 52^{\mathrm{b}}$ & $1431 \pm 42^{\mathrm{b}}$ \\
\hline $\begin{array}{l}\text { Gewicht des } \\
\text { M.pect.superfic. }(\mathrm{g})\end{array}$ & $1578 \pm 23^{\mathrm{a}}$ & $858 \pm 33^{\mathrm{b}}$ & $809,1 \pm 27^{\mathrm{b}}$ \\
\hline
\end{tabular}

${ }_{a, b, c}$ : Unterschiedliche Buchstaben $=$ Unterschiede mit $p \leq 0,05$

Da es sich bei der Herkunft BIG 6 um eine moderne Hochleistungspute handelt, war es zu erwarten, dass dieser Genotyp im Vergleich zu den kleineren Vergleichsgenotypen hinsichtlich der Schlachtkörpergewichte die höchsten Werte aufwies (15,3 kg). Die Unterschiede zwischen den Hähnen der Linie Wrolstad (mittelschwerer Typ; 8,2 kg) und Super Mini (leichter Typ; 7,9 kg) waren nicht signifikant (Tab.34). Dieser Umstand war schon bei den 12 Wochen alten Tieren zu beobachten gewesen.

Ein vergleichbarer Sachverhalt ließ sich auch bei dem Parameter Brustmuskelgewicht nachweisen, denn auch hier zeigte die Herkunft BIG 6 den signifikant höchsten Wert $(6,4 \mathrm{~kg})$. Die Herkünfte Wrolstad $(3,6 \mathrm{~kg})$ und Super Mini $(3,4 \mathrm{~kg})$ unterschieden sich bezüglich dieses Parameters nicht signifikant.

Der prozentuale Brustmuskelanteil am Schlachtkörper war bei den 12 Wochen alten BIG 6 Hähnen signifikant geringer $(41,9 \%)$ als bei den beiden Vergleichsherkünften Wrolstad (43,4 \%) und Super Mini (43,7 \%), welche sich untereinander nicht signifikant unterschieden.

Das Gewicht des M.pect.superfic. war bei der Herkunft BIG 6 signifikant höher (1578 g) als bei den Herkünften Wrolstad (858 g) und Super Mini (809 g). Der Unterschied zwischen Letzteren war nicht signifikant. 
Tab. 35: Trockenmassegehalte und Inhaltstoffe des M.pect.superfic. der Herkünfte BIG 6, Wrolstad und Super Mini im Alter von 22 Wochen (MW \pm SE)

\begin{tabular}{|l|c|c|c|}
\hline Genotyp & B.U.T. BIG 6 & $\begin{array}{c}\text { Wrolstad } \\
\text { (Kelly's) }\end{array}$ & $\begin{array}{c}\text { Super Mini } \\
\text { (Kelly's) }\end{array}$ \\
\hline Alter (in Wochen) & 22 & 22 & 22 \\
\hline $\mathrm{n}$ & 42 & 25 & 36 \\
\hline Trockenmasse (\%) & $26,3 \pm 0,1^{\mathrm{a}}$ & $26,8 \pm 0,1^{\mathrm{b}}$ & $27,1 \pm 0,1^{\mathrm{b}}$ \\
\hline Rohprotein (\%) & $25,1 \pm 0,1^{\mathrm{a}}$ & $25,8 \pm 0,1^{\mathrm{b}}$ & $25,9 \pm 0,1^{\mathrm{b}}$ \\
\hline Rohfett (\%) & $1,07 \pm 0,03^{\mathrm{a}}$ & $1,0 \pm 0,05^{\mathrm{ab}}$ & $0,91 \pm 0,04^{\mathrm{b}}$ \\
\hline Asche (\%) & $1,15 \pm 0,01^{\text {ab }}$ & $1,11 \pm 0,02^{\mathrm{a}}$ & $1,15 \pm 0,01^{\mathrm{b}}$ \\
\hline
\end{tabular}

${ }_{\mathrm{a}, \mathrm{b}, \mathrm{c}}$ : Unterschiedliche Buchstaben $=$ Unterschiede mit $\mathrm{p} \leq 0,05$

Der Trockenmassegehalt des M.pect.superfic. war bei den Probanden der Herkunft BIG 6 signifikant geringer (26,3\%), als bei den beiden Vergleichsgenotypen Wrolstad $(26,8 \%)$ und Super Mini $(27,1 \%)$, welche sich untereinender nicht signifikant unterschieden (Tab.35). Der Rohfettgehalt war bei den BIG 6 Puten signifikant höher $(1,07 \%)$, als bei den Probanden der Herkunft Super Mini $(0,91 \%)$. Die Herkunft Wrolstad unterschied sich nicht signifikant zu beiden Vergleichsgenotypen $(1,0 \%$ Rohfettgehalt).

Die Linie Wrolstad wies signifikant geringere Aschegehalte auf $(1,11 \%)$, als jene des Genotyps Super Mini (1,15\%).

Tab. 36: pH-, LF-, und $L^{*}, a^{*}, b^{*}$ - Werte des M.pect.superfic. der Herkünfte BIG 6, Wrolstad und Super Mini im Alter von 22 Wochen $(M W \pm S E)$

\begin{tabular}{|l|c|c|c|}
\hline Genotyp & B.U.T. BIG 6 & $\begin{array}{c}\text { Wrolstad } \\
\text { (Kelly's) }\end{array}$ & $\begin{array}{c}\text { Super Mini } \\
\text { (Kelly's) }\end{array}$ \\
\hline Alter (in Wo.) & 22 & 22 & 22 \\
\hline $\mathrm{n}$ & 42 & 25 & 36 \\
\hline $\mathrm{pH} 20 \mathrm{~min}$ & $6,27 \pm 0,04^{\mathrm{a}}$ & $6,33 \pm 0,06^{\mathrm{ab}}$ & $6,39 \pm 0,05^{\mathrm{b}}$ \\
\hline $\mathrm{pH} 4 \mathrm{~h}$ & $5,95 \pm 0,04^{\mathrm{a}}$ & $5,83 \pm 0,05^{\mathrm{b}}$ & $5,64 \pm 0,04^{\mathrm{c}}$ \\
\hline$\Delta \mathrm{pH}$ & $0,31 \pm 0,05^{\mathrm{a}}$ & $0,50 \pm 0,07^{\mathrm{b}}$ & $0,75 \pm 0,06^{\mathrm{c}}$ \\
\hline $\begin{array}{l}\text { Leitfähigkeit 20min } \\
\text { (mS/cm) }\end{array}$ & $3,9 \pm 0,3^{\mathrm{a}}$ & $3,4 \pm 0,4^{\mathrm{a}}$ & $3,8 \pm 0,3^{\mathrm{a}}$ \\
\hline $\begin{array}{l}\text { Leitfähigkeit 4h } \\
\text { (mS/cm) }\end{array}$ & $3,6 \pm 0,3^{\mathrm{a}}$ & $4,4 \pm 0,4^{\mathrm{ab}}$ & $5,2 \pm 0,0^{\mathrm{b}}$ \\
\hline $\mathrm{L}^{*}$ & $42,2 \pm 0,4^{\mathrm{a}}$ & $43,1 \pm 0,5^{\mathrm{ab}}$ & $43,3 \pm 0,4^{\mathrm{b}}$ \\
\hline $\mathrm{a}^{*}$ & $6,1 \pm 0,1^{\mathrm{a}}$ & $6,0 \pm 0,2^{\mathrm{a}}$ & $6,0 \pm 0,1^{\mathrm{a}}$ \\
\hline $\mathrm{b}^{*}$ & $-2,0 \pm 0,1^{\mathrm{a}}$ & $-1,9 \pm 0,2^{\mathrm{a}}$ & $-2,0 \pm 0,1^{\mathrm{a}}$ \\
\hline
\end{tabular}

: Unterschiedliche Buchstaben $=$ Unterschiede mit $p \leq 0,05$

Der geringste pH-Wert 20 min. p.m. konnte bei den BIG 6 Hähnen $(6,27)$ dieser Altersgruppe nachgewiesen werden, den höchsten Wert zeigte die Linie Super Mini $(6,39)$. Beide Herkünfte unterschieden sich signifikant (Tab.36).

Die Linie Wrolstad (pH 20 min: 6,33) unterschied sich von keiner der beiden Vergleichsgruppen signifikant.

4 h p.m. konnte der signifikant geringste pH-Wert $(5,64)$ und die größte $\mathrm{pH}$ Wertdifferenz $(0,75)$ bei den Puten des Genotyps Super Mini festgestellt werden. 
Den höchsten pH-Wert $(5,95)$ und die niedrigste $\mathrm{pH}$-Wertdifferenz $(0,31)$ wies entgegen den Erwartungen die Linie BIG 6 auf.

Die Linie Wrolstad lag signifikant unterschiedlich zu den beiden Vergleichsgenotypen hinsichtlich der Parameter pH - Wert 4 h p.m. $(5,83)$ und der $\mathrm{pH}$ - Wertdifferenz $(0,50)$ zwischen den Werten der anderen Linien.

Die Leitfähigkeitswerte unterschieden sich 20 min p.m. zwischen den Gruppen nicht signifikant voneinander. 4 h p.m. wies der Genotyp Super Mini die signifikant höchsten Leitfähigkeitswerte $(5,2 \mathrm{mS} / \mathrm{cm})$ im Vergleich zu den Probanden der Herkunft BIG 6 (3,6 mS/cm) auf. Die Linie Wrolstad lag mit 4,4 mS/cm zwischen den beiden Vergleichsgruppen und unterschied sich nicht signifikant von diesen.

Die 22 Wochen alten Super Mini-Hähne hatten ein signifikant helleres Fleisch $\left(L^{*}\right.$ 43,3) als die Probanden der Herkunft Big $6\left(L^{*} 42,2\right)$, die Linie Wrolstad $\left(L^{*} 43,1\right)$ unterschied sich nicht signifikant von den Vergleichsgenotypen.

Hinsichtlich der $a^{*}$ und $b^{*}$-Werte konnte kein signifikanter Unterschied zwischen den Genotypen abgesichert werden.

Tab. 37: Parameter der Fleischqualität des M.pect.superfic. sowie CK - Aktivität und Laktatgehalt im Stichblut der Herkünfte BIG 6, Wrolstad und Super Mini im Alter von 22 Wochen (MW \pm SE)

\begin{tabular}{|l|c|c|c|}
\hline Genotyp & B.U.T. BIG 6 & $\begin{array}{c}\text { Wrolstad } \\
\text { (Kelly's) }\end{array}$ & $\begin{array}{c}\text { Super Mini } \\
\text { (Kelly's) }\end{array}$ \\
\hline Alter (in Wochen) & 22 & 22 & 22 \\
\hline $\mathrm{n}$ & 42 & 25 & 36 \\
\hline Tropfsaftverlust (\%) & $1,3 \pm 0,2^{\mathrm{a}}$ & $2,3 \pm 0,3^{\mathrm{b}}$ & $2,3 \pm 0,2^{\mathrm{b}}$ \\
\hline Grillverlust (\%) & $22,0 \pm 0,6^{\mathrm{a}}$ & $21,9 \pm 0,9^{\mathrm{a}}$ & $21,3 \pm 0,7^{\mathrm{a}}$ \\
\hline Scherkraft (N) & $36,4 \pm 2,2^{\mathrm{a}}$ & $29,4 \pm 3,2^{\mathrm{a}}$ & $32,1 \pm 2,6^{\mathrm{a}}$ \\
\hline Scherarbeit (Nm) & $0,36 \pm 0,03^{\mathrm{a}}$ & $0,29 \pm 0,04^{\mathrm{a}}$ & $0,34 \pm 0,03^{\mathrm{a}}$ \\
\hline Blutpunkte (n) & $30,5 \pm 1,0^{\mathrm{a}}$ & $16,3 \pm 1,5^{\mathrm{b}}$ & $16,9 \pm 1,2^{\mathrm{b}}$ \\
\hline $\begin{array}{l}\text { Blutpunkte (n)/ kg } \\
\text { M.pect.superfic. }\end{array}$ & $19,2 \pm 0,9^{\mathrm{a}}$ & $20,0 \pm 1,3^{\mathrm{a}}$ & $22,3 \pm 1,3^{\mathrm{a}}$ \\
\hline $\begin{array}{l}\text { Creatinkinaseaktivität } \\
\text { (U/l) }\end{array}$ & $72061 \pm 3160^{\mathrm{a}}$ & $37563 \pm 4525^{\mathrm{b}}$ & $23082 \pm 3694^{\mathrm{c}}$ \\
\hline Laktatgehalt (mg/dl) & $57,9 \pm 3,0^{\mathrm{a}}$ & $67,5 \pm 4,3^{\mathrm{ab}}$ & $67,2 \pm 3,5^{\mathrm{b}}$ \\
\hline
\end{tabular}

Unterschiedliche Buchstaben $=$ Unterschiede mit $p \leq 0,05$

Die Genotypen des Züchters Kelly wiesen signifikant höhere Tropfsaftverluste auf (je $2,3 \%)$ als die BIG 6 - Puten von B.U.T. (1,3\%). Die Werte der Super Mini-Linie waren fast doppelt so hoch wie die der Linie BIG 6 (Tab.37).

Hinsichtlich des Parameters Grillverlust konnte kein signifikanter Unterschied zwischen den Genotypen abgesichert werden.

Die höchsten Scherkraftwerte zeigte im Alter von 22 Wochen die Herkunft BIG 6 $(34,4 \mathrm{~N})$, wenngleich der Unterschied zu den Herkünften Wrolstad $(29,4 \mathrm{~N})$ und Super Mini $(32,1 \mathrm{~N})$ nicht signifikant abzusichern war. Auch die Scherarbeitswerte zeigten keine signifikanten Unterschiede.

Die BIG 6 -Hähne wiesen fast doppelt so viele Blutpunkte $(30,5)$ im M.pect.superfic. auf, wie die Vergleichsgenotypen Wrolstad $(16,3)$ und Super Mini $(16,9)$. Dieser Unterschied zwischen den Herkünften des Züchters Kelly und den B.U.T. - Puten war signifikant nachzuweisen. Bezieht man jedoch die Zahl der Blutpunkte auf das Gewicht des M.pect.superfic., so ist kein signifikanter Unterschied zwischen den Herkünften mehr erkennbar. 
Die Probanden der Herkunft BIG 6 zeigten sogar mit 19,2 Blutpunkten pro kg M.pect.superfic. eine geringere Blutpunkthäufigkeit als die Herkünfte Wrolstad $(20,0$ $\mathrm{n} / \mathrm{kg})$ und Super Mini $(22,3 \mathrm{n} / \mathrm{kg})$.

Die CK-Aktivität im Stichblut war bei den BIG 6 Hähnen fast doppelt so hoch (72061 U/I) wie bei den Wrolstad - Hähnen (37563 U/I) und nahezu dreimal so hoch wie jene der Super Mini (23082 U/I). Diese Unterschiede waren signifikant.

Die Laktatgehalte im Stichblut waren bei den BIG 6 Puten am geringsten $(57,9 \mathrm{mg} / \mathrm{dl})$ und unterschieden sich damit signifikant von den Probanden der Herkunft Super Mini $(67,5 \mathrm{mg} / \mathrm{dl})$. Die Linie Wrolstad unterschied sich mit einem Laktatgehalt von 67,5 $\mathrm{mg} / \mathrm{dl}$ von keiner der beiden Vergleichslinien nicht signifikant.

Tab. 38: Histologische Parameter des M.pect.superfic. der Herkünfte BIG 6, Wrolstad und Super Mini im Alter von 22 Wochen (MW \pm SE)

\begin{tabular}{|l|c|c|c|}
\hline Genotyp & B.U.T. BIG 6 & $\begin{array}{c}\text { Wrolstad } \\
\text { (Kelly's) }\end{array}$ & $\begin{array}{c}\text { Super Mini } \\
\text { (Kelly's) }\end{array}$ \\
\hline Alter (in Wochen) & 22 & 22 & 22 \\
\hline $\mathrm{n}$ & 42 & 25 & 36 \\
\hline Faserfläche $\left(\mu m^{2}\right)$ & $10572 \pm 191^{\mathrm{a}}$ & $8538 \pm 273^{\mathrm{b}}$ & $7847 \pm 223^{\mathrm{c}}$ \\
\hline Durchmesser $(\mu \mathrm{m})$ & $114,2 \pm 1,1^{\mathrm{a}}$ & $102,8 \pm 1,6^{\mathrm{b}}$ & $98,8 \pm 1,3^{\mathrm{b}}$ \\
\hline Durchmesser maximal $(\mu \mathrm{m})$ & $149,4 \pm 1,5^{\mathrm{a}}$ & $137,0 \pm 2,2^{\mathrm{b}}$ & $130,0 \pm 1,8^{\mathrm{c}}$ \\
\hline Durchmesser minimal $(\mu \mathrm{m})$ & $98,0 \pm 1,0^{\mathrm{a}}$ & $87,3 \pm 1,4^{\mathrm{b}}$ & $84,5 \pm 1,2^{\mathrm{b}}$ \\
\hline Zellumfang $(\mu \mathrm{m})$ & $396,0 \pm 3,9^{\mathrm{a}}$ & $358,6 \pm 5,6^{\mathrm{b}}$ & $342,4 \pm 4^{\mathrm{c}}$ \\
\hline $\begin{array}{l}\text { Anteil degenerierter Fasern } \\
(\%)\end{array}$ & $0,63 \pm 0,10^{\mathrm{a}}$ & $1,14 \pm 0,14^{\mathrm{b}}$ & $0,85 \pm 0,10^{\mathrm{b}}$ \\
\hline Anteil an Giant Fibres $(\%)$ & $0,49 \pm 0,10^{\mathrm{a}}$ & $1,14 \pm 0,14^{\mathrm{b}}$ & $0,85 \pm 0,10^{\mathrm{b}}$ \\
\hline $\begin{array}{l}\text { Anteil an angulären Fasern } \\
(\%)\end{array}$ & $0,14 \pm 0,02^{\mathrm{a}}$ & $0 \pm 0,03^{\mathrm{b}}$ & $0 \pm 0,02^{\mathrm{b}}$ \\
\hline $\begin{array}{l}\text { Anzahl Kapillaren }(\mathrm{n}) \text { pro } \\
\text { Zelle }\end{array}$ & $1,82 \pm 0,04^{\mathrm{a}}$ & $1,38 \pm 0,05^{\mathrm{b}}$ & $1,42 \pm 0,04^{\mathrm{b}}$ \\
\hline
\end{tabular}

a,b,c: Unterschiedliche Buchstaben = Unterschiede mit $p \leq 0,05$

Die Muskelfaserquerschnittsfläche der Muskelzellen war bei den BIG 6 Hähnen signifikant größer $\left(10572 \mu^{2}\right)$ als jene Werte der Vergleichslinien Wrolstad (8538 $\mu \mathrm{m}^{2}$ ) und Super Mini $\left(7847 \mu \mathrm{m}^{2}\right)$, welche sich untereinander ebenfalls signifikant unterschieden (Tab.38). Dementsprechend war auch der Zelldurchmesser bei den BIG 6 - Puten größer (114,2 $\mu \mathrm{m})$ größer, als bei den Herkünften Wrolstad (102,8 $\mu \mathrm{m})$ und Super Mini $(98,8 \mu \mathrm{m})$.

Den geringsten Anteil an degenerierten Fasern wies der Genotyp BIG 6 auf (0,63 \%), den höchsten der Genotyp Wrolstad (1,14 \%); der Unterschied zwischen diesen beiden Genotypen war signifikant.

Auch bei den 22 Wochen alten Tieren bestand der weitaus größte Teil der Zelldegenerationen aus Giant Fibres (Riesenfasern). Den größten Anteil an angulären Fasern zeigte die Herkunft BIG $6 \quad(0,14 \%)$; die beiden Vergleichsgenotypen wiesen dagegen $0,0 \%$ dieser Zelldegeneration auf.

Mit 1,82 Kapillaren pro Muskelzelle war das Kapillar-Zellverhältnis bei den Probanden der Herkunft BIG 6 signifikant höher, als bei den beiden Vergleichsgenotypen Wrolstad $(1,38)$ und Super Mini $(1,42)$, welche sich nicht signifikant voneinander unterschieden. 


\subsection{Korrelationen der Merkmale der Grundgesamtheit aller Versuchstiere}

Im Folgenden werden die Korrelationen zwischen den Parametern der Grundgesamtheit aller untersuchter Puten aufgeführt. Auf die Darstellung der Wechselbeziehungen der Parameter innerhalb der einzelnen Versuchstiergruppen wurde aus Gründen der besseren Übersicht verzichtet, zumal sie tendenziell vergleichbar sind.

Tab. 39: Korrelation zwischen den Gewichtsparametern und den Parametern pH, LF und $L^{*}, a^{*}, b^{*}$ des M.pect.superfic von Puten

\begin{tabular}{|l|c|c|c|c|c|}
\hline Parameter & $\begin{array}{c}\text { Schlacht- } \\
\text { körpergewicht } \\
(\mathrm{kg})(\mathrm{n}=334)\end{array}$ & $\begin{array}{c}\text { Brustmuskel- } \\
\text { Anteil }(\%) \\
(\mathrm{n}=334)\end{array}$ & $\begin{array}{c}\text { Brustmuskel- } \\
\text { gewicht }(\mathrm{kg}) \\
(\mathrm{n}=334)\end{array}$ & $\begin{array}{c}1 / 2 \text { Brust- } \\
\text { Muskel- } \\
\text { gewicht } \\
\text { Labor }(\mathrm{g}) \\
(\mathrm{n}=399)\end{array}$ & $\begin{array}{c}\text { M.pect. } \\
\text { superfic. }- \\
\text { gewicht } \\
(\mathrm{g}) \\
(\mathrm{n}=399)\end{array}$ \\
\hline $\mathrm{pH} 20 \mathrm{~min}$ & $-0,20$ & $-0,04$ & $-0,25$ & $-0,19$ & $-0,20$ \\
\hline $\mathrm{pH} 4 \mathrm{~h}$ & $-0,41^{*}$ & $0,29^{*}$ & $-0,41^{*}$ & $-0,43^{*}$ & $-0,41^{*}$ \\
\hline$\Delta \mathrm{pH}$ & 0,19 & $-0,28^{*}$ & 0,15 & 0,22 & 0,20 \\
\hline $\mathrm{LF} 20 \mathrm{~min}$ & 0,02 & $-0,08$ & $-0,01$ & 0,02 & 0,01 \\
\hline $\mathrm{LF} 4 \mathrm{~h}$ & 0,17 & $-0,31^{*}$ & 0,12 & 0,20 & 0,15 \\
\hline $\mathrm{L}^{*}$ & 0,10 & $-0,07$ & 0,11 & 0,13 & 0,12 \\
\hline $\mathrm{a}^{*}$ & 0,11 & 0,00 & 0,13 & 0,09 & 0,10 \\
\hline $\mathrm{b}^{*}$ & $0,45^{*}$ & $-0,33^{*}$ & $0,45^{*}$ & $0,46^{*}$ & $0,46^{*}$ \\
\hline
\end{tabular}

$\left(^{*}\right)=$ signifikante Korrelation $(p \leq 0,05)$

Die vorliegenden Untersuchungen belegten eine negative Korrelation in Höhe von $-0,41$ zwischen den p.H.-Werten 4 h p.m. und den Parametern Schlachtkörpergewicht, Brustmuskelgewicht und M.pect.superfic.-gewicht (Tab.39). Zwischen den Brustmuskelanteilen und den $\mathrm{pH}-$ Werten $4 \mathrm{~h}$ p.m. war eine positive Beziehung $(0,29)$ signifikant nachweisbar.

Keine signifikanten Einflüsse auf die Parameter 'pH-Wertdifferenz' und 'LF 20 min'. konnten sich für die Gewichtsparameter nachweisen lassen. Es gab allerdings eine signifikant nachweisbare negative Wechselbeziehung zwischen dem Brustmuskelanteil und den LF-Werten 4 h p.m. $(-0,31)$.

Auch wenn hinsichtlich der $L^{*}$ und $a^{*}$ - Werte keine signifikante Korrelation erkennbar war, so konnte ein signifikanter Einfluss der Gewichtsparameter auf die $b^{*}$-Werte aufgezeigt werden (0,45 bzw. 0,46 beim 12 Brustmuskelgewicht). Die BMA - Werte waren mit den $b^{*}$ - Werten negativ korreliert $(0,33)$. 
Tab. 40: Korrelation zwischen den Gewichtsparametern und den Muskelinhaltstoffen von Puten

\begin{tabular}{|l|c|c|c|c|c|}
\hline Parameter & $\begin{array}{c}\text { Schlacht- } \\
\text { körper- } \\
\text { gewicht } \\
(\mathrm{kg}) \\
(\mathrm{n}=334)\end{array}$ & $\begin{array}{c}\text { Brust- } \\
\text { muskel- } \\
\text { Anteil }(\%) \\
(\mathrm{n}=334)\end{array}$ & $\begin{array}{c}\text { Brust- } \\
\text { muskel- } \\
\text { gewicht }(\mathrm{kg}) \\
(\mathrm{n}=334)\end{array}$ & $\begin{array}{c}1 / 2 \text { Brust- } \\
\text { Muskel- } \\
\text { gewicht } \\
\text { Labor }(\mathrm{g}) \\
(\mathrm{n}=399)\end{array}$ & $\begin{array}{c}\text { M.pect. } \\
\text { superfic. } \\
\text { gewicht }(\mathrm{g}) \\
(\mathrm{n}=399)\end{array}$ \\
\hline $\begin{array}{l}\text { Proteingehalt } \\
(\%)\end{array}$ & $-0,51^{*}$ & $0,44^{*}$ & $-0,48^{*}$ & $-0,54^{*}$ & $-0,52^{*}$ \\
$\begin{array}{l}\text { Fettgehalt } \\
(\%)\end{array}$ & $0,74^{*}$ & $-0,35^{*}$ & $0,78^{*}$ & $0,76^{*}$ & $0,78^{*}$ \\
\hline $\begin{array}{l}\text { Aschegehalt } \\
(\%)\end{array}$ & $-0,33^{*}$ & $0,38^{*}$ & $-0,27^{*}$ & $-0,34^{*}$ & $-0,32^{*}$ \\
\hline $\begin{array}{l}\text { Trocken- } \\
\text { masse (\%) }\end{array}$ & $-0,15$ & $0,32^{*}$ & $-0,08$ & $-0,17$ & $-0,14$ \\
\hline
\end{tabular}

$\left({ }^{*}\right)=$ signifikante Korrelation $(p \leq 0,05)$

Sämtliche Gewichtsparameter waren mit den Proteingehalten negativ korreliert, das Brustmuskelgewicht mit $-0,48$ am schwächsten, der Parameter

$1 / 2$ Brustmuskelgewicht (Labor) mit $-0,54$ am stärksten (Tab.40). Eine positive Wechselbeziehung konnte zwischen dem prozentualen Brustmuskelanteil und dem Proteingehalt des M.pect.superfic. aufgezeigt werden $(0,44)$.

Einen sehr starken Einfluss auf den Fettgehalt übten, signifikant nachweisbar, alle ermittelten Gewichtsparameter auf. Den größten Korrelationskoeffizienten $(0,78)$ zeigte der Parameter M.pect.superfic.-gewicht den kleinsten mit 0,74.

Der Brustmuskelanteil korrelierte negativ mit den Fettgehalten des M.pect.superfic. $(-0,35)$. Keine Beziehungen konnten zwischen den Gewichtsparametern und dem Trockenmassegehalten nachgewiesen werden. Der BMA korrelierte jedoch positiv mit dem Trockenmassegehalt $(0,32)$. 
Tab. 41: Korrelation zwischen den Gewichtsparametern und den physikalischen Parametern sowie den Stichblutwerten von Puten

\begin{tabular}{|c|c|c|c|c|c|}
\hline Parameter & $\begin{array}{c}\text { Schlacht- } \\
\text { körper- } \\
\text { gewicht } \\
(\mathrm{kg}) \\
(\mathrm{n}=334)\end{array}$ & $\begin{array}{c}\text { Brust- } \\
\text { muskel- } \\
\text { Anteil (\%) } \\
(n=334)\end{array}$ & $\begin{array}{c}\text { Brust- } \\
\text { muskel- } \\
\text { gewicht } \\
(\mathrm{kg}) \\
(\mathrm{n}=334)\end{array}$ & $\begin{array}{l}1 / 2 \text { Brust- } \\
\text { Muskel- } \\
\text { gewicht } \\
\text { Labor }(\mathrm{g}) \\
(\mathrm{n}=399)\end{array}$ & $\begin{array}{c}\text { M.pect. } \\
\text { superfic. - } \\
\text { gewicht (g) } \\
(\mathrm{n}=399)\end{array}$ \\
\hline $\begin{array}{l}\text { Tropfsaft- } \\
\text { Verlust (\%) }\end{array}$ & $-0,08$ & $-0,21$ & $-0,15$ & $-0,06$ & $-0,11$ \\
\hline Grillverlust (\%) & 0,18 & $-0,07$ & 0,20 & 0,19 & 0,19 \\
\hline Scherkraft (N) & $-0,43^{*}$ & $0,29^{*}$ & $-0,43^{*}$ & $-0,44^{*}$ & $-0,45^{*}$ \\
\hline $\begin{array}{l}\text { Scherarbeit } \\
(\mathrm{Nm})\end{array}$ & $-0,47^{*}$ & $0,30^{*}$ & $-0,48^{*}$ & $-0,48$ & $-0,49^{*}$ \\
\hline Blutpunkte (n) & $0,48^{*}$ & $-0,12$ & $0,54^{*}$ & $0,47^{*}$ & $0,51^{*}$ \\
\hline $\begin{array}{l}\text { Blutpunkte (n)/ } \\
\text { kg } \\
\text { M.pect.superfic. }\end{array}$ & $-0,53^{*}$ & $0,43^{*}$ & $-0,50^{*}$ & $-0,49^{*}$ & $-0,49^{*}$ \\
\hline $\begin{array}{l}\text { Creatinkinase- } \\
\text { Aktivität (U/I) }\end{array}$ & $0,80^{*}$ & $-0,47^{*}$ & $0,82^{*}$ & $0,81^{*}$ & $0,82^{*}$ \\
\hline $\begin{array}{l}\text { Laktatgehalt im } \\
\text { Stichblut } \\
\text { (mg/dl) }\end{array}$ & $-0,33^{*}$ & $0,31^{*}$ & $-0,31^{*}$ & $-0,32^{*}$ & $-0,32^{*}$ \\
\hline
\end{tabular}

$\left({ }^{*}\right)=$ signifikante Korrelation $(p \leq 0,05)$

Zwischen den Gewichtsparametern sowie dem Brustmuskelanteil und den Parametern Tropfsaftverlust und Grillverlust konnte keine Beziehung nachgewiesen werden (Tab.41).

Die Scherkraftwerte korrelierten mit einem Koeffizienten von -0,43 mit den Parametern Schlachtkörpergewicht und Brustmuskelgewicht. In vergleichbarer Größenordnung bestanden Beziehungen zum 1/2 Brustgewicht $(-0,44)$ und dem M.pect.superfic.-gewicht $(-0,45)$. Die Scherarbeitswerte verhielten sich hinsichtlich Ihrer Korrelation mit den Gewichtsparametern sehr ähnlich. Der Brustmuskelanteil war, wenngleich signifikant positiv, nur gering mit den Scherkraft- $(0,29)$ und Scherarbeitswerten $(0,30)$ korreliert.

Die Brustmuskelgewichte $(0,54)$, die $1 / 2$ Brustmuskelgewichte $(0,47)$ und die im Labor ermittelten Gewichte des M.pect.superfic. $(0,51)$ korrelierten positiv mit der Anzahl an Blutpunkten. Keine Beziehung konnte dagegen zwischen der Blutpunktzahl und dem Brustmuskelanteil nachgewiesen werden.

Auch der Parameter „Blutpunktzahl pro kg M.pect.superfic.“ zeigte in vergleichbarer Größenordnung die zuvor aufgezeigten Beziehungen. Ein Unterschied bestand aber hinsichtlich der Korrelation zum Brustmuskelanteil, welcher mit einem Koeffizienten von 0,43 abgesichert werden konnte.

Hinsichtlich der Blutparameter konnten signifikante Korrelationen mit den Gewichtsparametern Brustmuskelanteil, Brustmuskelgewicht (Schlachthof) und dem im Labor ermittelten Gewicht des M.pect.superfic. aufgezeigt werden. 
Tab. 42: Korrelationen zwischen den Gewichtsparametern und den histologischen Parametern des M.pect.superfic. von Puten

\begin{tabular}{|l|c|c|c|c|c|}
\hline Parameter & $\begin{array}{c}\text { Schlacht- } \\
\text { körper- } \\
\text { gewicht } \\
(\mathrm{kg}) \\
(\mathrm{n}=334)\end{array}$ & $\begin{array}{c}\text { Brust- } \\
\text { muskel- } \\
\text { Anteil }(\%) \\
(\mathrm{n}=334)\end{array}$ & $\begin{array}{c}\text { Brust- } \\
\text { muskel- } \\
\text { gewicht } \\
(\mathrm{kg}) \\
(\mathrm{n}=334)\end{array}$ & $\begin{array}{c}1 / 2 \text { Brust- } \\
\text { Muskel- } \\
\text { gewicht } \\
\text { Labor }(\mathrm{g}) \\
(\mathrm{n}=399)\end{array}$ & $\begin{array}{c}\text { M.pect. } \\
\text { superfic. } \\
\text { gewicht }(\mathrm{g}) \\
(\mathrm{n}=399)\end{array}$ \\
\hline $\begin{array}{l}\text { Zellfläche } \\
\left(\mu \mathrm{m}^{2}\right)\end{array}$ & $0,91^{*}$ & $-0,60^{*}$ & $0,91^{*}$ & $0,92^{*}$ & $0,93^{*}$ \\
$\begin{array}{l}\text { Zell- } \\
\text { durchmesser } \\
(\mu \mathrm{m})\end{array}$ & $0,91^{*}$ & $-0,61^{*}$ & $0,91^{*}$ & $0,92^{*}$ & $0,92^{*}$ \\
\hline $\begin{array}{l}\text { Durchmesser } \\
\text { maximal }(\mu \mathrm{m})\end{array}$ & $0,90^{*}$ & $-0,59^{*}$ & $0,90^{*}$ & $0,91^{*}$ & $0,92^{*}$ \\
\hline $\begin{array}{l}\text { Durchmesser } \\
\text { minimal }(\mu \mathrm{m})\end{array}$ & $0,91^{*}$ & $-0,62^{*}$ & $0,90^{*}$ & $0,92^{*}$ & $0,92^{*}$ \\
\hline $\begin{array}{l}\text { Zellumfang } \\
(\mu \mathrm{m})\end{array}$ & $0,91^{*}$ & $-0,60^{*}$ & $0,91^{*}$ & $0,92^{*}$ & $0,92^{*}$ \\
\hline $\begin{array}{l}\text { Anteil } \\
\text { degenerierter } \\
\text { Fasern (\%) }\end{array}$ & $-0,08$ & 0,02 & $-0,10$ & $-0,07$ & $-0,08$ \\
\hline $\begin{array}{l}\text { Anteil an Giant } \\
\text { Fibres (\%) }\end{array}$ & $-0,13$ & 0,02 & $-0,15$ & $-0,12$ & $-0,14$ \\
\hline $\begin{array}{l}\text { Anteil an } \\
\text { angulären } \\
\text { Fasern (\%) }\end{array}$ & $0,26^{*}$ & $-0,04$ & $0,30^{*}$ & $0,27^{*}$ & $0,31^{*}$ \\
\hline $\begin{array}{l}\text { Anzahl an } \\
\text { Kapillaren (n) } \\
\text { pro Zelle }\end{array}$ & $0,88^{*}$ & $-0,58^{*}$ & $0,88^{*}$ & $0,88^{*}$ & $0,89^{*}$ \\
\hline
\end{tabular}

$\left({ }^{*}\right)=$ signifikante Korrelation $(p \leq 0,05)$

Hinsichtlich aller ermittelten Gewichtsparameter konnte eine sehr enge, signifikante Korrelation $(r \geq 0,90)$ zu den metrisch ermittelbaren, histologischen Parametern nachgewiesen werden (Tab.42). Dieses schließt ebenfalls eine, wenngleich negative Korrelation bezüglich des prozentualen Brustmuskelanteils ein, auch wenn diese Korrelationskoeffizienten nicht in der gleichen Höhe vorlagen.

Der Anteil an degenerierten Muskelfasern im Allgemeinen, sowie jener an Riesenfasern im speziellen hatte keinen nachweisbaren Einfluss durch die Gewichtsparameter erfahren. Lediglich der Anteil an angulären Fasern wurde von den Gewichtsparametern, wenn auch nur im geringen Maße, signifikant beeinflusst. Einen vergleichsweise starken Einfluss übten die Gewichtsparameter auf das Kapillar/Zellverhältnis aus $(r \geq 0,88)$. Je höher die ermittelten Gewichte, desto mehr Kapillare stehen für eine Muskelzelle zur Verfügung.

Der Brustmuskelanteil korrelierte Negativ mit dem Kapillar/Zellverhältnis $(-0,58)$. 
Tab. 43: Korrelationen zwischen den Muskelinhaltstoffen (inkl. Trockenmasse) und den Parametern pH, LF und L*, $a^{*}, b^{*}$ des M.pect.superfic. von Puten $(n=399)$

\begin{tabular}{|l|c|c|c|c|}
\hline Parameter & $\begin{array}{c}\text { Proteingehalt } \\
(\%)\end{array}$ & $\begin{array}{c}\text { Fettgehalt } \\
(\%)\end{array}$ & $\begin{array}{c}\text { Aschegehalt } \\
(\%)\end{array}$ & $\begin{array}{c}\text { Trockenmasse } \\
(\%)\end{array}$ \\
\hline $\mathrm{pH} \mathrm{20} \mathrm{min}$ & 0,12 & $-0,21$ & $-0,07$ & $-0,05$ \\
\hline $\mathrm{pH}$ 4h & 0,15 & $-045^{*}$ & 0,17 & $-0,13$ \\
\hline$\Delta \mathrm{pH}$ & 0,04 & 0,22 & $-0,19$ & 0,07 \\
\hline $\begin{array}{l}\text { Leitfähigkeit } \\
\text { (m min p.m. }\end{array}$ & $-0,13$ & $-0,06$ & $-0,03$ & $-0,20$ \\
\hline $\begin{array}{l}\text { Leitfähigkeit } \\
\text { 4h p.m. } \\
\text { (mS/cm) }\end{array}$ & $-0,17$ & 0,04 & $-0,07$ & $-0,14$ \\
\hline $\mathrm{L}^{*}$ & & & & \\
\hline $\mathrm{a}^{*}$ & $-0,31^{*}$ & 0,17 & 0,02 & $-0,24^{*}$ \\
\hline $\mathrm{b}^{*}$ & 0,02 & 0,18 & $-0,05$ & 0,16 \\
\hline
\end{tabular}

$\left(^{*}\right)=$ signifikante Korrelation $(p \leq 0,05)$

Konnte zwischen dem pH-Wert 20 min. p.m. keine Beziehung zu den Inhaltstoffen (inkl. TM) hergestellt werden (Tab.43), so war der pH-Wert $4 \mathrm{~h}$ p.m. negativ mit dem Fettgehalt des M.pect.superfic. korreliert $(r=-0,45)$. Zur $\mathrm{pH}$ - Wertdifferenz konnte eine Wechselbeziehung mit den Inhaltstoffen ebenso wenig nachgewiesen werden, wie bei den Leitfähigkeitswerten 20 min. und 4 h p.m. .

Eine signifikante, negative Wechselwirkung zu den Helligkeitswerten $\left(L^{*}\right)$ konnte in sehr geringem Umfang für die Proteingehalte $(r=-0,31)$ und Trockenmassegehalte (Korrelationskoeffizient $-0,24$ ) nachgewiesen werden.

Hinsichtlich der $a^{*}$-Werte konnte keine Korrelation abgesichert werden, bei den Blau/Gelb-Werten jedoch nahm der Fettgehalt mit einem Korrelationskoeffizienten von 0,47 signifikanten Einfluss.

Tab. 44: Korrelationen zwischen den Muskelinhaltstoffen (inkl. Trockenmasse) und den physikalischen Parametern sowie den Stichblutwerten von Puten ( $n=399)$

\begin{tabular}{|l|c|c|c|c|}
\hline Parameter & $\begin{array}{c}\text { Proteingehalt } \\
(\%)\end{array}$ & $\begin{array}{c}\text { Fettgehalt } \\
(\%)\end{array}$ & $\begin{array}{c}\text { Aschegehalt } \\
(\%)\end{array}$ & $\begin{array}{c}\text { Trockenmasse } \\
(\%)\end{array}$ \\
\hline Tropfsaftverlust (\%) & $-0,14$ & $-0,17$ & $-0,06$ & $-0,29^{*}$ \\
\hline Grillverlust (\%) & $-0,23^{*}$ & $0,25^{*}$ & 0,01 & $-0,12$ \\
\hline Scherkraft (N) & 0,12 & $-0,44^{*}$ & 0,19 & $-0,10$ \\
\hline Scherarbeit (Nm) & 0,12 & $-0,48^{*}$ & 0,20 & $-0,13$ \\
\hline Blutpunkte (n) & $-0,27^{*}$ & $0,43^{*}$ & $-0,01$ & $-0,02$ \\
\hline $\begin{array}{l}\text { Blutpunkte (n)/ kg } \\
\text { M.pect.superfic. }\end{array}$ & $0,20^{*}$ & $-0,41^{*}$ & $0,15^{*}$ & 0,02 \\
\hline CK-Wert (U/l) & $-0,48^{*}$ & $0,67^{*}$ & $-0,24^{*}$ & $-0,16$ \\
\hline Laktatwert (mg/dl) & 0,08 & $-0,25^{*}$ & 0,13 & 0,00 \\
\hline
\end{tabular}

$\left(^{*}\right)=$ signifikante Korrelation $(p \leq 0,05)$ 
Weder die Muskelinhaltstoffe, noch die Trockenmassegehalte nahmen nennenswert Einfluss auf den Tropfsaftverlust des M.pect.superfic. (Tab.44). Ähnlich verhielt es sich hinsichtlich des Parameters Grillverlust, der nur sehr geringe Korrelationen zu den Parametern Rohproteingehalt $(-0,23)$ und Fettgehalt $(0,25)$ zeigte.

Auch bei den Parametern Scherkraft $(-0,44)$ und Scherarbeit $(-0,48)$ war es der Fettgehalt, zu welchem signifikant eine Wechselbeziehung hergestellt werden konnte.

Der Fettgehalt $(0,43)$ des M.pect.superfic. korrelierte mit der Anzahl an Blutpunkten. Der Proteingehalt korrelierte zwar negativ mit der Blutpunktanzahl $(-0,27)$, jedoch war dieser Einfluss nur in geringem Maße nachweisbar. In vergleichbarer Größenordnung konnten Beziehungen zwischen den Parametern Fett- und Proteingehalt und der Anzahl an Blutpunkten pro kg M.pect.superfic. aufgezeigt werden.

Eine Wechselbeziehung zwischen dem CK-Wert und dem Fettgehalt konnte ebenso signifikant abgesichert werden $(0,67)$, wie eine negative Korrelation $(-0,48)$ zum Proteingehalt. Zwar existierte auch ein signifikanter Einfluss des Aschegehaltes auf die CK-Werte, dieser war jedoch nur gering $(-0,24)$. Ebenso gering war die negative Korrelation des Fettgehaltes auf die Laktatwerte $(0,25)$.

Tab. 45: Korrelation zwischen den Muskelinhaltstoffen (inkl. TM) und den histologischen Parametern des M.pect.superfic. von Puten $(n=399)$

\begin{tabular}{|l|c|c|c|c|}
\hline Parameter & $\begin{array}{c}\text { Proteingehalt } \\
(\%)\end{array}$ & $\begin{array}{c}\text { Fettgehalt } \\
(\%)\end{array}$ & $\begin{array}{c}\text { Aschegehalt } \\
(\%)\end{array}$ & $\begin{array}{c}\text { Trockenmasse } \\
(\%)\end{array}$ \\
\hline $\begin{array}{l}\text { Zellfläche } \\
\left(\mu m^{2}\right)\end{array}$ & $-0,42^{*}$ & $0,79^{*}$ & $-0,33^{*}$ & $-0,02$ \\
$\begin{array}{l}\text { Durchmesser } \\
(\mu \mathrm{m})\end{array}$ & $-0,40^{*}$ & $0,80^{*}$ & $-0,33^{*}$ & 0,01 \\
\hline $\begin{array}{l}\text { Durchmesser } \\
\text { Maximal }(\mu \mathrm{m})\end{array}$ & $-0,39^{*}$ & $0,79^{*}$ & $-0,33^{*}$ & 0,03 \\
\hline $\begin{array}{l}\text { Durchmesser } \\
\text { Minimal }(\mu \mathrm{m})\end{array}$ & $-0,41^{*}$ & $0,79^{*}$ & $-0,34^{*}$ & 0,00 \\
\hline $\begin{array}{l}\text { Zellumfang } \\
(\mu \mathrm{m})\end{array}$ & $-0,40^{*}$ & $0,80^{*}$ & $-0,33^{*}$ & 0,01 \\
\hline $\begin{array}{l}\text { Anteil } \\
\text { degenerierter } \\
\text { Muskelfasern }(\%)\end{array}$ & $-0,02$ & $-0,08$ & 0,01 & $-0,05$ \\
\hline $\begin{array}{l}\text { Anteil an } \\
\text { Giant Fibres }(\%)\end{array}$ & 0,01 & $-0,11$ & 0,02 & $-0,03$ \\
\hline $\begin{array}{l}\text { Anteil an } \\
\text { angulären } \\
\text { Fasern(\%) }\end{array}$ & $-0,16$ & 0,17 & $-0,05$ & $-0,08$ \\
\hline Kapillare $(\mathrm{n}) /$ Zelle & $-0,42^{*}$ & $0,73^{*}$ & $-0,30^{*}$ & $-0,03$ \\
\hline
\end{tabular}

$\left({ }^{*}\right)=$ signifikante Korrelation $(p \leq 0,05)$

Die Trockenmasse nahm keinen nachweisbaren Einfluss auf sämtliche histologische Parameter (Tab.45).

Der Proteingehalt korrelierte signifikant negativ mit allen metrisch ermittelbaren Parametern. Die Korrelationskoeffizienten lagen diesbezüglich in vergleichbarer Größenordnung zwischen -0,39 und -0,42. Keine Beziehung konnte dagegen zu den 
Anteilen an degenerierten Muskelfasern abgesichert werden. Das Kapillar/Zellverhältnis korrelierte mit dem Proteingehalt negativ $(-0,42)$.

Der Fettgehalt des M.pect.superfic. korrelierte positiv und sehr eng mit sämtlichen metrisch ermittelbaren, histologischen Parametern $(0,79-0,80)$. Kein Einfluss des Fettgehaltes konnte hinsichtlich der degenerierten Muskelfasern beobachtet werden.

Dagegen zeigte sich eine signifikante Wechselbeziehung zwischen dem Fettgehalt und dem Kapillar/Zellverhältnis $(0,73)$.

Ähnlich wie bei dem Parameter Proteingehalt verhielt sich der Parameter Aschegehalt zu den metrisch ermittelbaren, histologischen Parametern, wenngleich auf einem niedrigeren Niveau. Auch hier konnte keine Beziehung zu den degenerierten Fasern verifiziert werden.

Tab. 46: Korrelationen zwischen den physikalischen Parametern und den Parametern pH, LF, $L^{*}, a^{*}, b^{*}$ des M.pect.superfic. bei Puten $(n=399)$

\begin{tabular}{|l|c|c|c|c|}
\hline Parameter & $\begin{array}{c}\text { Tropfsaftverlust } \\
(\%)\end{array}$ & $\begin{array}{c}\text { Grillverlust } \\
(\%)\end{array}$ & $\begin{array}{c}\text { Scherkraft } \\
(\mathrm{N})\end{array}$ & $\begin{array}{c}\text { Scherarbeit } \\
(\mathrm{Nm})\end{array}$ \\
\hline $\mathrm{pH}$ 20 min & $-0,01$ & $-0,24^{*}$ & 0,05 & 0,06 \\
\hline $\mathrm{pH}$ 4h & $-0,09$ & $-0,11$ & $0,38^{*}$ & $0,39^{*}$ \\
\hline$\Delta \mathrm{pH}$ & 0,07 & $-0,08$ & $-0,28^{*}$ & $-0,29^{*}$ \\
\hline $\begin{array}{l}\text { Leitfähigkeit } \\
\text { 20 min p.m. (mS/cm) }\end{array}$ & 0,11 & 0,00 & $-0,05$ & $-0,05$ \\
\hline $\begin{array}{l}\text { Leitfähigkeit } \\
\text { 4h p.m. (mS/cm) }\end{array}$ & $0,36^{*}$ & 0,13 & $-0,06$ & $-0,06$ \\
\hline $\mathrm{L}^{*}$ & 0,18 & $0,28^{*}$ & $-0,04$ & $-0,03$ \\
\hline $\mathrm{a}^{*}$ & $-0,24^{*}$ & $-0,09$ & $-0,20$ & $-0,19$ \\
\hline $\mathrm{b}^{*}$ & 0,04 & 0,07 & $-0,35^{*}$ & $-0,39^{*}$ \\
\hline
\end{tabular}

$\left({ }^{*}\right)=$ signifikante Korrelation $(p \leq 0,05)$

Zwischen den Parametern Tropfsaftverlust und den pH-Werten, sowie den LF 20 min-Werten konnte kein nennenswerter Zusammenhang gefunden werden (Tab.46). Eine positive Korrelation ließ sich zwischen dem Tropfsaftverlust und den Leitfähigkeitswerten 4 h p.m. signifikant $(0,36)$ absichern. Auch wenn der Tropfsaftverlust keinen signifikanten Einfluss auf die $L^{*}$ und $b^{*}$-Werte nehmen konnte, so war doch ein geringer, aber dennoch signifikanter negativer Einfluss mit einem Korrelationskoeffizienten von $-0,24$ auf die $a^{*}$-Werte nachweisbar.

Wenngleich geringe, so doch signifikante Korrelationen konnten zwischen dem Parameter Grillverlust und den Parametern pH-Wert 20 min p.m. $(-0,24)$ sowie den $L^{*}$-Werten $(0,28)$ nachgewiesen werden.

Die Parameter Scherkraft $(0,38)$ und Scherarbeit $(0,39)$ korrelierten positiv mit dem $\mathrm{pH}-$ Wert 4 h p.m.. Eine negative Beziehung wurde zwischen den Scherkraft - bzw. Scherarbeitswerten und der $\mathrm{pH}$ - Wertdifferenz mit einem Koeffizienten von -0,28 bzw. $-0,29$ aufgezeigt. Zwischen den Parametern $L^{*}$ und $a^{*}$ und den Scherwerten zeigte sich kein signifikanter Zusammenhang. Der Blau-Gelbwert $b^{*}$ korrelierte negativ mit den Scherkraftwerten $(-0,35)$ und Scherarbeitswerten $(-0,39)$. 
Tab. 47: Korrelationen zwischen den Blutparametern/Blutpunktzahlen und pH-Werten, Leitfähigkeitswerten sowie Helligkeits- und Farbwerten bei Puten $(n=399)$

\begin{tabular}{|l|c|c|c|c|}
\hline Parameter & Blutpunkte (n) & $\begin{array}{c}\text { Blutpunkte (n) } \\
\text { pro kg M.pect. } \\
\text { superfic. }\end{array}$ & $\begin{array}{c}\text { Creatinkinase- } \\
\text { aktivität (U/l) }\end{array}$ & $\begin{array}{c}\text { Laktatgehalt } \\
\text { (mg/dl) }\end{array}$ \\
\hline pH 20 min & $-0,22^{*}$ & 0,08 & $-0,20^{*}$ & $-0,14$ \\
\hline $\mathrm{pH} 4 \mathrm{~h}$ & $-0,15$ & $0,37^{*}$ & $-0,36^{*}$ & 0,12 \\
\hline $\begin{array}{l}\mathrm{pH} \\
\text { Leitfähigkeit }\end{array}$ & $-0,04$ & $-0,26^{*}$ & 0,15 & $-0,21$ \\
$\begin{array}{l}20 \text { min p.m. } \\
\text { (mS/cm) }\end{array}$ & $-0,07$ & $-0,8$ & 0,00 & 0,06 \\
$\begin{array}{l}\text { Leitfähigkeit 4h p.m. } \\
\text { (mS/cm) }\end{array}$ & $-0,09$ & $-0,19^{*}$ & 0,17 & 0,01 \\
\hline $\mathrm{L}^{*}$ & 0,13 & $-0,05$ & 0,12 & 0,08 \\
\hline $\mathrm{a}^{*}$ & 0,10 & 0,6 & 0,06 & $-0,10$ \\
\hline $\mathrm{b}^{*}$ & $0,23^{*}$ & $-0,27^{*}$ & $0,39^{*}$ & $-0,10$ \\
\hline
\end{tabular}

$\left(^{*}\right)=$ signifikante Korrelation $(p \leq 0,05)$

Die Anzahl an Blutpunkten im M.pect.superfic. war weder von den pH- bzw. Leitfähigkeitswerten, noch von den $L^{*}-, a^{*}$ - oder $b^{*}$ - Werten im nennenswerten Umfang abhängig (Tab.47).

Dagegen zeigte der Parameter „Blutpunkte pro kg M.pect.superfic.“ mit einem Koeffizienten von 0,37 eine signifikante Korrelation zum 4 h p.m. gemessenen pH Wert. Die Beziehung zur $\mathrm{pH}$ - Wertdifferenz war negativ und mit einem Koeffizienten von $-0,26$ geringer als zum pH - Wert 4 h p.m.. Noch geringer war die Beziehung zum Leitfähigkeitswert 4 h p.m. $(-0,19)$. Zu den $L^{*}$ - und $a^{*}-$ Werten konnte keine signifikante Abhängigkeit zur Blutpunktzahl pro kg M.pect.superfic. nachgewiesen werden. Der $b^{*}$ - Wert korrelierte allerdings negativ $(-0,27)$ zu diesem Parameter.

Auch wenn von den Stichblutwerten ansonsten keine Beziehungen zwischen den Laktatwerten und den übrigen in Tabelle 47 aufgeführten Parametern nachgewiesen werden konnten, so bestand eine negative Korrelation der Creatinkinaseaktivität mit dem pH-Wert 4 h p.m. $(-0,36)$ und eine positive Beziehung zu den $b^{*}$ - Werten $(0,39)$. Zwischen den Tropfsaft- bzw. Grillverlustwerten und den histologischen Parametern konnte keine nennenswerte Wechselbeziehung festgestellt werden (Tab.48).

$\mathrm{Zu}$ allen metrisch ermittelbaren histologischen Parametern konnte eine negative Wechselbeziehung der Parameter Scherkraft $(-0,48$ bis $-0,50)$ und Scherarbeit $(-0,53$ bis $-0,55$ ) aufgezeigt werden.

Zwischen den Scherkraft- bzw. Scherarbeitswerten und den Anteilen an degenerierten Muskelfasern bestand keine signifikante Korrelation. Beide Parameter korrelierten mit vergleichbaren Koeffizienten negativ $(-0,48-$ bzw. $-0,35)$ mit dem Kapillar/Zellverhältnis. 
Tab. 48: Korrelationen zwischen den physikalischen Parametern des M.pect.superfic. und den histologischen Parametern $(n=399)$

\begin{tabular}{|c|c|c|c|c|}
\hline Parameter & $\begin{array}{c}\text { Tropfsaftverlust } \\
(\%)\end{array}$ & $\begin{array}{c}\text { Grillverlust } \\
(\%)\end{array}$ & $\begin{array}{c}\text { Scherkraft } \\
(\mathrm{N})\end{array}$ & $\begin{array}{c}\text { Scherarbeit } \\
(\mathrm{Nm})\end{array}$ \\
\hline $\begin{array}{l}\text { Zellquerschnittsfläche } \\
\left(\mu \mathrm{m}^{2}\right)\end{array}$ & $-0,08$ & $0,22^{*}$ & $-0,48^{*}$ & $-0,53^{*}$ \\
\hline $\begin{array}{l}\text { Zelldurchmesser } \\
(\mu \mathrm{m})\end{array}$ & $-0,08$ & $0,21^{*}$ & $-0,50^{*}$ & $-0,55^{*}$ \\
\hline $\begin{array}{l}\text { Zelldurchmesser } \\
\text { maximal }(\mu \mathrm{m})\end{array}$ & $-0,10$ & $0,20^{*}$ & $-0,50^{*}$ & $-0,55^{*}$ \\
\hline $\begin{array}{l}\text { Zelldurchmesser } \\
\text { Minimal }(\mu \mathrm{m})\end{array}$ & $-0,07$ & $0,21^{*}$ & $-0,50^{*}$ & $-0,55^{*}$ \\
\hline Zellumfang $(\mu \mathrm{m})$ & $-0,09$ & $0,21^{*}$ & $-0,50^{*}$ & $-0,55^{*}$ \\
\hline $\begin{array}{l}\text { Anteil degenerierter } \\
\text { Muskelfasern (\%) }\end{array}$ & 0,15 & 0,09 & $-0,04$ & $-0,04$ \\
\hline $\begin{array}{l}\text { Anteil an Giant Fibres } \\
(\%)\end{array}$ & 0,17 & 0,07 & $-0,03$ & $-0,03$ \\
\hline $\begin{array}{l}\text { Anteil an angulären } \\
\text { Muskelfasern }(\%)\end{array}$ & $-0,13$ & 0,08 & $-0,04$ & 0,04 \\
\hline Kapillare/Zelle & $-0,11$ & 0,16 & $-0,48^{*}$ & $-0,53^{*}$ \\
\hline
\end{tabular}

$\left({ }^{*}\right)=$ signifikante Korrelation $(p \leq 0,05)$

Tab. 49: Korrelationen zwischen den Blutparametern bzw. Blutpunkten und den histologischen Parametern des M.pect.superfic. bei Puten $(n=399)$

\begin{tabular}{|l|c|c|c|c|}
\hline Parameter & $\begin{array}{c}\text { Blutpunkte } \\
(\mathrm{n})\end{array}$ & $\begin{array}{c}\text { Blutpunkte } \\
(\mathrm{n}) / \mathrm{kg} \mathrm{M.pect.} \\
\text { superfic. }\end{array}$ & $\begin{array}{c}\text { Creatinkinase- } \\
\text { aktivität }(\mathrm{U} / \mathrm{l})\end{array}$ & $\begin{array}{c}\text { Laktatgehalt } \\
(\mathrm{mg} / \mathrm{dl})\end{array}$ \\
\hline $\begin{array}{l}\text { Zellquerschnitts- } \\
\text { fläche }\left(\mu \mathrm{m}^{2}\right)\end{array}$ & $0,44^{*}$ & $-0,51^{*}$ & $0,80^{*}$ & $-0,32^{*}$ \\
$\begin{array}{l}\text { Zelldurchmesser } \\
(\mu \mathrm{m})\end{array}$ & $0,44^{*}$ & $-0,52^{*}$ & $0,79^{*}$ & $-0,32^{*}$ \\
\hline $\begin{array}{l}\text { Zelldurchmesser } \\
\text { maximal }(\mu \mathrm{m})\end{array}$ & $0,44^{*}$ & $-0,52^{*}$ & $0,78^{*}$ & $-0,32^{*}$ \\
$\begin{array}{l}\text { Zelldurchmesser } \\
\text { Minimal }(\mu \mathrm{m})\end{array}$ & $0,44^{*}$ & $-0,52^{*}$ & $0,78^{*}$ & $-0,32^{*}$ \\
\hline $\begin{array}{l}\text { Zellumfang } \\
(\mu \mathrm{m})\end{array}$ & $0,44^{*}$ & $-0,52^{*}$ & $0,79^{*}$ & $-0,32^{*}$ \\
\hline $\begin{array}{l}\text { Anteil degenerierter } \\
\text { Muskelfasern }(\%)\end{array}$ & $-0,02$ & 0,02 & 0,01 & 0,06 \\
\hline $\begin{array}{l}\text { Anteil an } \\
\text { Giant Fibres (\%) }\end{array}$ & $-0,09$ & 0,03 & $-0,03$ & 0,06 \\
$\begin{array}{l}\text { Anteil an angulären } \\
\text { Muskelfasern }(\%)\end{array}$ & $0,37^{*}$ & $-0,05$ & 0,21 & 0,01 \\
\hline Kapillare/Zelle & $0,43^{*}$ & $-0,48^{*}$ & $0,76^{*}$ & $-0,35^{*}$ \\
\hline
\end{tabular}

$\left(^{*}\right)=$ signifikante Korrelation $(p \leq 0,05)$ 
Die Anzahl an Blutpunkten im M.pect.superfic. korrelierte signifikant positiv $(0,44)$ zu allen metrisch ermittelbaren histologischen Parametern (Tab.49). Weitere positive Wechselbeziehungen konnten zu dem Anteil an angulären Fasern $(0,37)$ und zum Kapillar/Zellverhältnis $(0,43)$ aufgezeigt werden.

Die Zahl an Blutpunkten pro kg M.pect.superfic. korrelierte mit einem Koeffizienten von $-0,51$ bzw. $-0,52$ zu allen Parametern, welche die Zellgröße beschreiben. Auch zum Kapillar/Zellverhältnis bestand eine negative Beziehung $(-0,48)$.

Die Creatinkinaseaktivität zeigte mit Koeffizienten zwischen 0,78 und 0,80 eine vergleichsweise enge Korrelation zu den metrisch ermittelbaren Zellparametern. In ähnlicher Größenordnung bestand zudem Parameter „Kapillar/Zellverhältnis“ eine signifikante Abhängigkeit $(0,76)$.

Der Laktatgehalt korrelierte im Gegensatz zur Creatinkinaseaktivität negativ mit den Parametern, welche die Zellgröße und die Anteile an Zelldegenerationen beschreiben.

Tab. 50: Korrelationen zwischen histologischen Parametern und den Parametern pH, LF, $L^{*}, a^{*}, b^{*}$ des M.pect.superfic. bei Puten $(n=399)$

\begin{tabular}{|c|c|c|c|c|c|}
\hline Parameter & $\begin{array}{c}\text { Zellquer- } \\
\text { schnitts- } \\
\text { fläche } \\
\left(\mu \mathrm{m}^{2}\right)\end{array}$ & $\begin{array}{c}\text { Zelldurch- } \\
\text { messer } \\
(\mu \mathrm{m})\end{array}$ & $\begin{array}{c}\text { Zelldurch- } \\
\text { messer } \\
\text { Maximum } \\
(\mu \mathrm{m})\end{array}$ & $\begin{array}{c}\text { Zelldurch- } \\
\text { messer } \\
\text { Minimum } \\
(\mu \mathrm{m})\end{array}$ & $\begin{array}{l}\text { Zellumfang } \\
(\mu \mathrm{m})\end{array}$ \\
\hline $\mathrm{pH} 20$ min & $-0,21$ & $-0,21$ & $-0,21$ & $-0,22$ & $-0,21$ \\
\hline $\mathrm{pH} 4 \mathrm{~h}$ & $-0,52^{*}$ & $-0,54^{*}$ & $-0,54^{*}$ & $-0,54^{*}$ & $-0,54^{*}$ \\
\hline$\Delta \mathrm{pH}$ & $0,28^{*}$ & $0,30^{*}$ & $0,30^{*}$ & $0,29^{*}$ & $0,30^{*}$ \\
\hline $\begin{array}{l}\text { Leitfähigkeit } \\
20 \text { min. p.m. } \\
\text { (mS/cm) }\end{array}$ & 0,01 & 0,01 & 0,00 & 0,01 & 0,00 \\
\hline $\begin{array}{l}\text { Leitfähigkeit } \\
\text { 4h p.m. } \\
\text { (mS/cm) }\end{array}$ & $0,22^{*}$ & $0,23^{*}$ & $0,21^{*}$ & $0,23^{*}$ & $0,22^{*}$ \\
\hline $\mathrm{L}^{*}$ & 0,16 & 0,16 & 0,15 & 0,16 & 0,15 \\
\hline$a^{*}$ & 0,08 & 0,08 & 0,09 & 0,08 & 0,09 \\
\hline$b^{*}$ & $0,51^{*}$ & $0,51^{*}$ & $0,51^{*}$ & $0,50^{*}$ & $0,51^{*}$ \\
\hline
\end{tabular}

$\left(^{*}\right)=$ signifikante Korrelation $(p \leq 0,05)$

Auch wenn zwischen den pH-Werten 20 min. p.m. und den histologischen Parametern keine signifikante Korrelation nachgewiesen werden konnte (Tab.50), so gab es doch eine negative Wechselbeziehung zwischen den pH-Werten $4 \mathrm{~h}$ p.m. und den metrisch ermittelbaren, histologischen Parametern $(-0,52$ bis $-0,54)$. Ähnlich wie bei den pH-Werten 4 h p.m. verhielten sich die Korrelationen zwischen den $\mathrm{pH}-$ Wertdifferenzen und den histologischen Parametern. Allerdings waren diese Korrelationen positiv und auf deutlich geringerem Niveau abzusichern.

Hinsichtlich der LF-Werte 20 min p.m. konnte keinerlei Wechselbeziehung zu den histologischen Parametern verifiziert werden. 4 h p.m. konnten bei den Leitfähigkeitswerten positive Korrelationen zu den Parametern, welche die Zellgröße beschreiben festgestellt werden, wenngleich sich diese auf einem sehr niedrigen Niveau befanden. 
Zwischen den $L^{*}$ und $a^{*}$ - Werten und den histologischen Parametern gab es keinerlei signifikante Einflüsse. Der $b^{*}$ - Wert jedoch korrelierte positiv mit den metrisch ermittelbaren, histologischen Parametern $(0,50$ bis 0,51$)$.

Tab. 51: Korrelationen zwischen den Anteilen degenerierter Fasern sowie dem Kapillar/Zellverhältnis und den Parametern pH, LF, $L^{*}, a^{*}, b^{*}$ des M.pect.superfic. bei Puten $(n=399)$

\begin{tabular}{|l|c|c|c|c|}
\hline Parameter & $\begin{array}{c}\text { (\%) Anteil } \\
\text { degenerierter } \\
\text { Muskelfasern }\end{array}$ & $\begin{array}{c}\text { (\%) Anteil } \\
\text { an Giant } \\
\text { Fibres }\end{array}$ & $\begin{array}{c}\text { (\%) Anteil an } \\
\text { angulären } \\
\text { Fasern }\end{array}$ & $\begin{array}{c}\text { Kapillare (n) } \\
\text { /Zelle }\end{array}$ \\
\hline $\mathrm{pH}$ 20 min & $-0,13$ & $-0,12$ & $-0,05$ & $-0,20$ \\
\hline $\mathrm{pH}$ 4h & $-0,15$ & $-0,15$ & 0,05 & $-0,52^{*}$ \\
\hline$\Delta \mathrm{pH}$ & 0,03 & 0,04 & $-0,08$ & $0,28^{*}$ \\
\hline $\begin{array}{l}\text { Leitfähigkeit } \\
\text { 20 min p.m. (mS/cm) }\end{array}$ & $-0,03$ & $-0,02$ & $-0,01$ & 0,01 \\
$\begin{array}{l}\text { Leitfähigkeit } \\
\text { 4h p.m. (mS/cm) }\end{array}$ & $0,26^{*}$ & $0,27^{*}$ & $-0,08$ & $0,25^{*}$ \\
\hline $\mathrm{L}^{*}$ & 0,14 & 0,13 & 0,02 & 0,13 \\
\hline $\mathrm{a}^{*}$ & $-0,13$ & $-0,13$ & 0,00 & 0,15 \\
\hline $\mathrm{b}^{*}$ & $-0,09$ & $-0,11$ & 0,13 & $0,48^{*}$ \\
\hline
\end{tabular}

$\left(^{*}\right)=$ signifikante Korrelation $(p \leq 0,05)$

Die pH - Werte 20 min. p.m. und die pH - Werte 4 h p.m. sowie die pH Wertdifferenz zeigten keinerlei Abhängigkeit zu den prozentualen Anteilen degenerierter Muskelfasern (Tab.51). Der pH - Wert $4 \mathrm{~h}$ p.m. zeigte eine negative Korrelation zum Kapillar/Zellverhältnis $(0,28)$.

Die Leitfähigkeitswerte zeigten 20 min p.m. keinerlei Abhängigkeitsverhältnis zu den Anteilen degenerierter Muskelfasern. 4 h p.m. konnten signifikante Korrelationen zu den Anteilen an degenerierten Muskelfasern $(0,26)$, Anteilen an Giant Fibres $(0,27)$ und dem Kapillar/Zellverhältnis $(0,25)$ nachgewiesen werden.

Weder die $L^{*}-$ noch die $a^{*}$ - Werte zeigten eine Beziehung zu Muskelfaserdegenerationen oder dem Kapillar/Zellverhältnis. Ähnlich verhielt es sich bezüglich der $b^{*}$-Werte, welche aber mit einem Korrelationskoeffizienten von 0,48 Einfluss auf das Kapillar/Zellverhältnis ausübten. 


\section{Diskussion der Ergebnisse}

\subsection{Einfluss des Alters auf Schlachtkörper- und Fleischbeschaffenheitsmerkmale}

\subsubsection{Gewichtsparameter und Inhaltstoffe des Brustmuskels}

Ausnahmslos alle ermittelten Gewichtsparameter waren bei den 22 Wochen alten Tieren signifikant höher, als bei den 12 Wochen alten Tieren. Dies war aufgrund des bekannten Wachstumsverlaufs (Tab.32 + 33) auch so zu erwarten.

Der prozentuale Trockenmasseanteil des M. pect. superfic. war bei den 22 Wochen alten Tieren signifikant, wenn auch geringfügig höher als bei den 12 Wochen alten Tieren. Der Grund dafür liegt in dem Phänomen der „Physiologischen Austrocknung“ (LEESON und SUMMERS, 1980). Darunter wird eine Verschiebung der Inhaltstoffe der Muskulatur zugunsten des Fettgehaltes auf Kosten des Proteingehaltes verstanden. Das Fettgewebe bindet weniger Wasser als Muskelproteine. Auch die Proteine selbst, insbesondere das Bindegewebe, vernetzen sich mit zunehmendem Alter fortschreitend, was ebenfalls mit einem verminderten Wasserbindungsvermögen einhergeht. Der beschriebene Vorgang deckt sich mit den Ergebnissen der eigenen Untersuchungen, denn der Proteingehalt des M.pect. superfic. war bei den 22 Wochen alten Putern signifikant geringer als bei der 12 Wochen alten Gruppe. Entsprechend umgekehrt verhielt es sich beim Fettgehalt (Tab.15). Die in den eigenen Untersuchungen gefundenen Werte für die Muskelinhaltstoffe stehen im Widerspruch zu einigen in der Literatur veröffentlichten Angaben. So gibt SIELAFF (1996) einen Fettgehalt von 7,5\% im Putenfleisch an, dem gegenüber stehen die eigenen Ergebnisse mit Werten unter $1 \%$. Die Angaben der Autoren SLOWINSKI und STOLARSKI (1998) sowie von WERLEIN und WATKINSON (1998) hinsichtlich des Fettgehaltes beim Putenbrustfleisch lagen mit $1-1,5 \%$ schon deutlich näher an den hier ermittelten Werten. Auffällig war auch der Unterschied beim Proteingehalt des Brustmuskels.

Lediglich die Angaben von FERNANDEZ et al. (2001) decken sich mit den ermittelten Werten. Andere Autoren, insbesondere jene älteren Datums, gaben deutlich geringere Proteingehalte in der Brustmuskulatur an. Möglicherweise ist dieser Umstand darauf zurückzuführen, dass die intensive Selektion auf hohe Schlachkörpergewichte und Brustmuskelanteile ebenfalls einen Einfluss auf die Verteilung der Muskelinhaltstoffe genommen hat. Die ermittelten Werte zur Trockenmasse stimmen mit denen von FERNANDEZ et al. (2001) überein.

Der geringe Unterschied zwischen den Aschegehalten der 12 und 22 Wochen alten Tiere kann ebenfalls mit den höheren Fettgehalten der älteren Tiere erklärt werden, welche zu einer Verschiebung der prozentualen Gehalte der anderen Stofffraktionen führt. Da der Fettgehalt der älteren Tiere im Vergleich höher liegt, als bei der jüngeren Vergleichsgruppe, liegen die anderen Inhaltstoffe (oder zumindest einer davon) in geringerem Maße vor, in diesem Falle Protein und Asche. 


\subsection{2 pH - und Leitfähigkeitswerte}

Schon 20 min p.m. unterschieden sich die postmortalen pH - Werte der beiden Altersstufen signifikant um 0,15 Einheiten. 4 Stunden p.m. war der Unterschied auf $0,4 \mathrm{pH}$-Einheiten angestiegen, wobei die 12 Wochen alten Tiere in beiden Fällen den höheren $\mathrm{pH}$ - Wert aufwiesen (Tab.16). Die pH - Wertdifferenz zwischen den Messzeitpunkten war bei den 22 Wochen alten Tieren am größten, obwohl sie mit einem niedrigeren Eingangswert ( $\mathrm{pH} 20 \mathrm{~min}$ ) aufwarteten, als die jüngere Vergleichsgruppe. Offensichtlich fand die Glycolyse bei den älteren Tieren schneller statt, worauf der pH-Wert 20 min p.m. schon signifikant geringere Werte zeigte. Ursache dafür mag im höheren Schlachtkörpergewicht der älteren Tiere liegen. Zum einen kann der größere Schlachtkörper nicht so schnell auskühlen wie bei der jüngeren Vergleichsgruppe, zum anderen konnten OTTO und WEGNER (1976) nachweisen, dass mit zunehmendem Muskelfaserdurchmesser der Extrazellularraum im Vergleich zur Zellmasse abnimmt. Die Glycolyse findet in der Muskelfaser in Abhängigkeit von der Umgebungstemperatur statt. Somit läuft die bevorzugt in warmen Gewebe mit hohem Anteil an Muskelzellmasse statt. Ferner kann Stress eine schnelle Glycolyse begünstigen. So konnten MC KEE und SAMS 1997 nachweisen, dass männliche Nicholas-Puter, welche vor dem Schlachten einem definierten Hitzestress ausgesetzt wurden, einen schnelleren $\mathrm{pH}$ - Wert - Abfall p.m. im Brustmuskel zeigten, als die ungestresste Vergleichsgruppe. Auch wenn im Versuch alle Tiere weitestgehend gleichen Haltungs- und Transportbedingungen unterlagen, deutet der schnellere $\mathrm{pH}$ - Wertabfall der älteren und damit schwereren Tiere darauf hin, das eine höhere Stressempfindlichkeit vorliegt, als bei der jüngeren und vor allem leichteren Vergleichsgruppe. Der direkte Zusammenhang zwischen dem Gewicht der Tiere (hier Schlachtkörpergewicht) und dem pH - Wert 4 h p.m. wurde zudem durch einen Korrelationskoeffizienten von -,41 signifikant nachgewiesen, welcher bedeutet, dass mit zunehmendem Schlachtkörpergewicht der $\mathrm{pH}$ - Wert 4 h p.m. sinkt.

Die Leitfähigkeitswerte 20 min p.m. unterschieden sich nicht signifikant. Offenbar war der $\mathrm{pH}$ - Wertabfall noch nicht stark genug, um Zellläsionen zu verursachen.

Vier Stunden p.m. jedoch waren die Leitfähigkeitswerte bei den älteren Tieren signifikant höher, als bei der jüngeren Vergleichsgruppe. Ursache hierfür ist in den zuvor erwähnten $\mathrm{pH}-$ Wertverhältnissen zu suchen. Ein schneller $\mathrm{pH}-$ Wertabfall konnte schon 2001 von HAHN et al. $a+b$ als Grund für hohe Leitfähigkeitswerte nachgewiesen werden. Zudem wiesen SLOWINSKI und STOLARSKI (1998) einen Zusammenhang zwischen dem Körpergewicht und den Leitfähigkeitswerten nach. Dieser Zusammenhang wird ebenfalls über $\mathrm{pH}$ - Wertverhältnisse bei zunehmendem Schlachtkörpergewicht erklärt. Durch die rasche $\mathrm{pH}$-Wertabsenkung der älteren und größeren Tiere wird die Membran der Muskelzellen hinsichtlich ihrer Integrität geschwächt. Der Austritt ionenhaltiger Intrazellulärflüssigkeit ist die Folge, was zu höheren Leitfähigkeitswerten in der betroffenen Gruppe führt. Belegt wird dieser Vorgang auch durch die signifikante Korrelation zwischen den Leitfähigkeitswerten 4 h p.m. und den pH - Werten 4 h p.m. mit einem Koeffizienten von -0,43. Dieser Korrelationskoeffizient zeigt, dass in der vorliegenden Untersuchung mit abnehmenden pH - Werten 4 h p.m. die Leitfähigkeitswerte 4 h p.m. zunehmen. 


\subsubsection{Helligkeits- und Farbwerte}

Das Brustfleisch des M.pect. superfic. der 22 Wochen alten Tiere war signifikant heller als das der jüngeren und damit leichteren Tiere. Ein Grund könnte die von WYNVEEN et al. (1999) beschriebene Tatsache sein, dass Fleisch bei niedrigen $\mathrm{pH}$ - Werten in der Regel höhere Helligkeitswerte zeigt. Darauf deutet auch eine, wenn auch sehr geringe Korrelation zwischen den Parametern mit einem Koeffizienten von $-0,194$ h p.m. hin. Des Weiteren ist belegt, dass bei gleichem Messzeitpunkt im Schlachtkörper der schwereren Tiere eine höhere Temperatur herrscht, als bei den jüngeren Vergleichstieren, was nach Aussagen von SIELAFF (1996) neben dem pH - Wert zu Unterschieden hinsichtlich der Fleischhelligkeit führen kann.

Die $a^{*}$ - Werte der 22 Wochen alten Tiere waren zwar signifikant höher, jedoch betrug der Unterschied zwischen den beiden Altersgruppen nur 0,2 Einheiten, ein vernachlässigbar geringer Unterschied.

Die $b^{*}$ - Werte hingegen deuteten bei den 12 Wochen alten Tieren auf einen signifikant höheren Blauanteil hin. HAHN et al. (2001) konnten in eigenen Versuchen nachweisen, dass sich ein niedriger $\mathrm{pH}$ - Wert reziprok zum $b^{*}$ - Wert verhält. Da nun bei der älteren Gruppe ein signifikant niedrigerer $\mathrm{pH}$ - Wert im Vergleich zur jüngeren Vergleichgruppe vorzufinden war, ist ein höherer $b^{*}$ - Wert des $M$. pect. superfic. der älteren Tiere keine Überraschung. Dies belegt auch ein Korrelationskoeffizient von -0,34 zwischen den Parametern pH - Wert 4 h p.m. und $b^{*}$. Eine weitere Ursache für die höheren $b^{*}$ - Werte der 22 Wochen alten Puten kann der, wenn auch nur gering höhere Fettgehalt der Muskulatur älterer Tiere sein. Die Anwesenheit von Fettgewebe erhöht (je nach Futterfett in verschiedener Intensität) die $b^{*}$ - Werte.

\subsubsection{Physikalische Fleischqualitätsparameter}

Hinsichtlich des Tropfsaftverlustes konnte zwischen den beiden Altersstufen kein signifikanter Unterschied abgesichert werden. Es ist jedoch anzumerken, dass die Mm.pect.superfic. aus eigener Untersuchung im Mittel einen deutlich höheren Tropfsaftverlust zeigten, als die in der Literatur gefundenen Angaben. So zeigte RAMMOUZ et al. (2004) über einen Zeitraum von drei Tagen hinweg einen Tropfsaftverlust von $0,57 \%$, die eigenen Untersuchungen zeigten jedoch Tropfsaftverluste von 2,7 \% (12 Wochen alte Puten) bzw. 2,8 \% (22 Wochen alte Puten) bereits nach zwei Tagen. Die Unterschiede lassen sich möglicherweise mit verschiedenen Rahmenbedingungen der Probennahme bzw. -lagerung erklären.

Der Grillverlust war bei den 22 Wochen alten Tieren signifikant höher, als bei den 12 Wochen alten Tieren. Dieser Umstand lässt sich durch die Tatsache erklären, dass die älteren Tiere größere Muskelfaserdurchmesser aufweisen. Bei den thermisch bedingten Denaturierungsvorgängen kann deshalb auch mehr Intrazellulärflüssigkeit aus den Zellen austreten, als bei Tieren mit kleinerem Zelldurchmesser. Offenbar neigen größere Muskelfasern unter thermischer Einwirkung eher zu Schädigungen als kleinere. Dass es sich bei dem Grillverlust ausschließlich um Bindegewebsflüssigkeit handelt, kann weitgehend ausgeschlossen werden, denn die jüngeren Versuchstiere zeigen einen höheren Proteingehalt als die älteren, was auch einen höheren Wassergehalt im Muskel mit sich bringt. Somit müssten in dem Falle die jüngeren Puten den höheren Grillverlust zeigen, genau das Gegenteil war aber der Fall. Es finden sich in der Literatur keine Anhaltspunkte, welche diesen Sachverhalt plausibel erklären. 
Möglicherweise hängt der Unterschied im Grillverlust mit dem intramuskulären Fettgehalt zusammen, denn die eigenen Untersuchungen zeigen einen Korrelationskoeffizienten von 0,25 und der Fettgehalt der 22 Wochen alten Tiere lag signifikant über denen der 12 Wochen alten Tiere.

Die Scherkraftwerte der 22 Wochen alten Puten lagen signifikant unter den Werten der jüngeren Vergleichsgruppe. Die Ursache dafür ist vermutlich bei dem größeren Zelldurchmesser der älteren Tiere zu suchen.
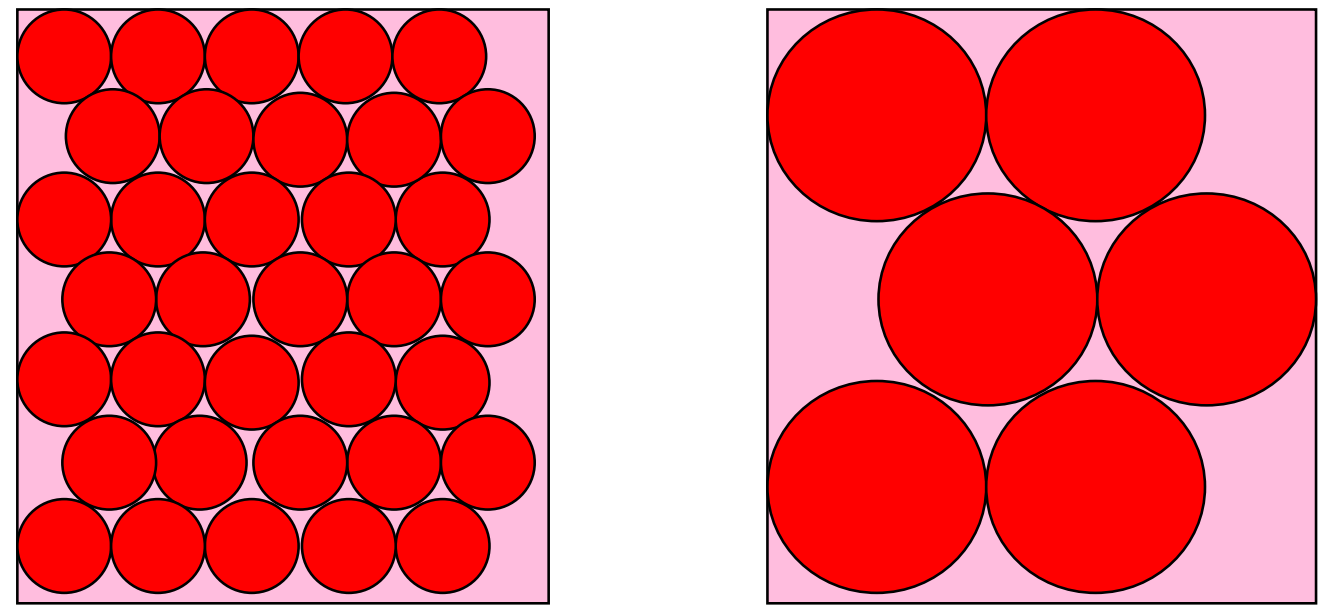

Abb. 14: Schematische Darstellung von verschiedenen Muskelfaserdurchmessern pro Flächeneinheit

Wie in der schematischen Darstellung (Abb. 14) zu erkennen ist, befinden sich bei kleinem Muskelfaserdurchmesser wesentlich mehr Fasern in einer definierten Flächeneinheit, als das bei den erheblich größeren Muskelfasern der Fall sein könnte. Nun sind die strukturgebenden Elemente der Muskelfasern die Zellmembranen der Muskelzellen, welche gleichfalls den größten Widerstand der Muskelzelle bei der Scherkraftmessung darstellen. Wie der Abb. 14 auch ohne direkte Messung rein optisch zu erkennen ist, befindet sich bei kleinen Muskelfasern erheblich mehr Zellmembranmaterial in einer definierten Flächeneinheit, als bei den großen Fasern. Dieser Sachverhalt erklärt die geringeren Scherkraftwerte der Muskelproben älterer Puten und wird durch den in eigenen Untersuchungen ermittelten Korrelationskoeffizienten von -0,45 zwischen den Parametern Scherkraft und Zellquerschnittsfläche untermauert. Dieser Sachverhalt steht jedoch im Widerspruch zu der von SIELAFF (1996) aufgestellten These, dass jüngere Tiere durchweg zarteres Fleisch liefern, als ältere Artgenossen. Er begründete dies mit der Aussage, dass sich mit zunehmendem Alter Quervernetzungen zwischen den Strukturproteinen ausbilden, welche den Scherkraftwiderstand erhöhen. Nun sind Puten im Alter von 22 Wochen keinesfalls ausgewachsen und es darf nach Berücksichtigung der eigenen Untersuchungsergebnisse unterstellt werden, dass die Quervernetzungen zwischen den Strukturproteinen noch nicht in nennenswertem Umfang stattgefunden haben. Generell weißt schieres Putenbrustfleisch einen sehr geringen Bindegewebsanteil auf und ist diesbezüglich zarter als Fleisch von anderen Nutztieren. Einen weiteren Erklärungsansatz liefert die

Rohnährstoffzusammensetzung des Muskelgewebes. Wie in Tab. 15 zu sehen ist, zeigten die älteren und schwereren Puten einen signifikant höheren Fettgehalt im M.pect.superfic. als die jüngeren Tiere, was nach SIELAFF (1996) ebenfalls einen 
Einfluss auf die Scherkraftwerte ausübt. Belegt wird dieser Zusammenhang zwischen dem intramuskulären Fettgehalt und den Scherkraftwerten auch durch den in eigenen Untersuchungen nachgewiesenen Korrelationskoeffizienten zwischen den genannten Parametern in Höhe von -0,44. Da aber bei den 22 Wochen alten Puten ein sehr niedriger Fettgehalt im Muskel vorliegt (0,93\%), ist es unwahrscheinlich, dass der Rohfettgehalt allein für die verminderten Scherkraftwerte verantwortlich ist. Entsprechende Untersuchungen zu diesem Sachverhalt, welche plausible Erklärungen liefern, liegen bislang nicht vor.

\subsubsection{Blutparameter}

Die Anzahl der Blutpunkte im M.pect.superfic war bei den 22 Wochen alten Tieren nahezu doppelt so hoch, wie bei den jüngeren Tieren. Wie bereits von KRANEN et al. (2000) beschrieben, wird durch die elektrische Betäubung ein Muskelreiz ausgeübt, welcher den intramuskulären Druck erhöht, der sich auch auf die im Muskel befindlichen Blutgefäße auswirkt. Ferner kann unterstellt werden, dass größere Muskelfasern auch in der Lage sind, einen größeren Druck auf das umgebende Gewebe ausüben kann, als kleine Muskelfasern. Somit wird von größeren Muskelfasern auch ein größerer Druck auf die Blutgefäße, insbesondere die vergleichsweise dünnen Kapillaren, ausgeübt, was ein häufigeres auftreten von Schädigungen derselben erklärt. Auch das höhere Körpergewicht der 22 Wochen alten Puten im Vergleich zur 12 Wochen alten Vergleichsgruppe nimmt Einfluss auf die Anzahl an Blutpunkten im M.pect.superfic. Belegt wird dies durch einen Korrelationskoeffizienten von 0,48, welcher zeigt, dass mit zunehmendem Schlachtkörpergewicht auch die Zahl an Blutpunkten im Brustmuskelgewebe zunimmt. Petechien gelten als Indiz für Sauerstoffmangel, was ebenfalls die Unterschiede zwischen den beiden Altersstufen erklärt, denn die älteren Tiere sind größer und haben somit einen höheren Sauerstoffbedarf als die kleineren Tiere. Da durch die Betäubung sowie durch die Entblutung ein Sauerstoffmangel entsteht, wäre dies eine Erklärung für das auftreten von Petechien im Allgemeinen, wie bei den schwereren Tieren im Besonderen. So konnte in Versuchen gezeigt werden, das bei der Gasbetäubung mit Argon bei Mastschweinen etwa $30 \%$ der Tiere im Schinken Blutpunkte zeigten, welche auf Hypoxie bzw. Anoxie in Verbindung mit krampfartigen Muskelkontraktionen zurückgeführt werden konnten (dip.bundestag.de, 2006). Ein anderes Bild zeigt die Blutpunktproblematik, wenn die Anzahl an Blutpunkten auf das Gewicht des M.pect.superfic. bezogen wird. In dem Falle zeigt sich, dass die 12 Wochen alten Tiere nahezu doppelt so viele Blutpunkte pro kg M.pect.superfic. zeigten, als die 22 Wochen alten Vergleichstiere. Diese Beurteilungsweise, welche in erster Linie für den Verbraucher bzw. für den Geflügelfleischvermarkter interessant ist, berücksichtigt aber nicht die Tatsache, dass die Zahl der Blutpunkte bezogen auf das Muskelgewebe (Muskelfaserzahl) bei den 22 Wochen alten Tieren trotzdem höher ist, denn die Anzahl an Muskelzellen im Gesamtgewebe ist bei den 12 Wochen alten Tieren genau dieselbe, wie bei den 22 Wochen alten Tieren. Das Muskelwachstum zwischen den beiden Altersstufen beruht bekanntlich nur auf der Zellvergrößerung (Hypertrophie) und nicht auf der Zellvermehrung (Hyperplasie) (SMITH, 1963). 
Die CK - Aktivität der 22 Wochen alten Puten war um etwa das achtfache größer, als bei den jüngeren Tieren. Dieser signifikante Unterschied lässt sich mit dem Umstand begründen, dass die älteren Tiere deutlich schwerer sind, als die 12 Wochen alten Tiere. Da die Creatinkinase - Aktivität in der klinischen Diagnostik als Marker für Muskelschäden Verwendung findet, liegt die Vermutung nahe, dass die älteren und damit schwereren Puten eher zu Muskelschädigungen neigen, als die jüngeren und leichteren Tiere. Da aber zwischen den Anteilen an degenerierten Muskelfasern beider Altersstufen kein signifikanter Unterschied abgesichert werden konnte und auch keine signifikante Korrelation zwischen den Parametern CK - Aktivität und den Anteilen an degenerierten Muskelfasern abgesichert werden konnte, ist fraglich, ob die Muskelschädigungen allein für die hohen CK-Werte im Stichblut der 22 Wochen alten Tiere verantwortlich sind. Es sieht vielmehr so aus, als wenn die CK-Aktivität im Stichblut direkt mit dem Gewicht der Tiere zusammenhängt. Eine enge Korrelation zwischen den Parametern CK-Aktivität und Schlachtkörpergewicht $(r=0.80)$ deutet darauf hin. Über die genauen Zusammenhänge gibt die Literatur bislang keine Auskunft.

Der Laktatgehalt im Stichblut der 22 Wochen alten Tiere war signifikant geringer als bei den 12 Wochen alten Putern. Die Erklärung dafür ist in der Nüchterungszeit vor dem Schlachten zu suchen. In beiden Altersstufen wurde 12 h a.m. das Futter entfernt. Den älteren und damit deutlich schwereren Tieren kann ein höherer Nährstoffbedarf unterstellt werden, als den jüngeren. Deshalb sind die im Körper gespeicherten Nährstoffreserven bei den älteren Tieren schneller auf oxidativem Wege verstoffwechselt worden, als bei den 12 Wochen alten Tieren, und es liegen deshalb p.m. weit weniger Nährstoffe für die anaerobe Glycolyse vor. Somit kann auch bei den schwereren Tieren weniger Laktat im Stichblut nachgewiesen werden, als bei den jüngeren Probanden. Dieser Erklärungsversuch wird durch einen Korrelationskoeffizienten von -0,33 zwischen den Parametern "Laktatgehalt im Stichblut" und "Schlachtkörpergewicht“ signifikant gestützt.

\subsubsection{Histologische Parameter}

Wie schon WISKUS et al. (1976) feststellte, besteht der Brustmuskel von Mastputen zu nahezu $100 \%$ aus weißen Muskelfasern (Abb.15). Tatsächlich konnten auch bei allen eigenen Tieren keine intermediären oder roten Muskelfasern in den untersuchten Proben festgestellt werden. ELMINOWSKA-WENDA et al. (2005) fanden bei Hähnen des Genotyps B.U.T. Big 6 immerhin 8,4 \% Fasern mit oxidativen Anteilen. Da der genaue Ort der Probennahme in der Literatur nicht angegeben wurde, ist es möglich, das der $M$. pect superfic. in bestimmten Teilbereichen oxidative Fasern enthält, in dem im Teil „Material und Methoden“ beschriebenen Bereich jedoch nicht. 


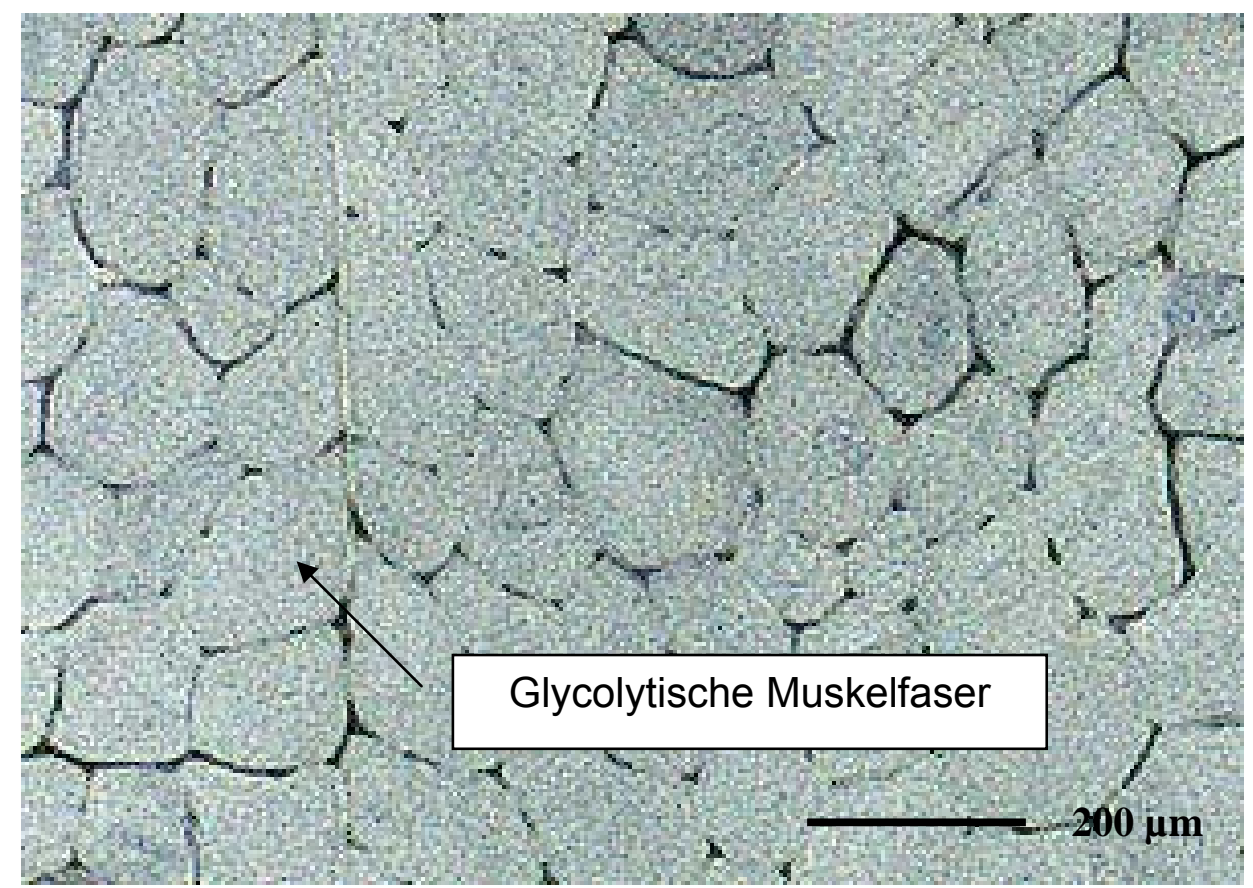

Abb. 15 : Charakteristischer Ausschnitt einer Probe des M.pect.superfic. (B.U.T. BIG 6, 22 Wochen, ATPase-Färbung)

Der Durchmesser und der Umfang der Muskelfasern war bei den 22 Wochen alten Putern signifikant höher, als bei der 12 Wochen alten Vergleichsgruppe (Abb. 16 $a+b)$. Die Aussagen von DRANSFIELD und SOSNICKI (1999) stützen die eigenen Untersuchungsergebnisse, welche die Zunahme des Muskelfaserdurchmessers während des Wachstums formulierten, zum anderen wird offenkundig, dass das Wachstum des Brustmuskels nicht auf Zellvermehrung, sondern auf Zellvergrößerung beruht. Schon 1963 konnte SMITH belegen, dass postnatales Wachstum nicht auf Hyperplasie sondern auf Hypertrophie beruht. Darauf deuten auch die sehr hohen Korrelationskoeffizienten zwischen den Parametern "Muskelzellquerschnittsfläche" und dem "Schlachtkörpergewicht" $(0,91)$ bzw. „Brustmuskelgewicht“ $(0,92)$ hin.
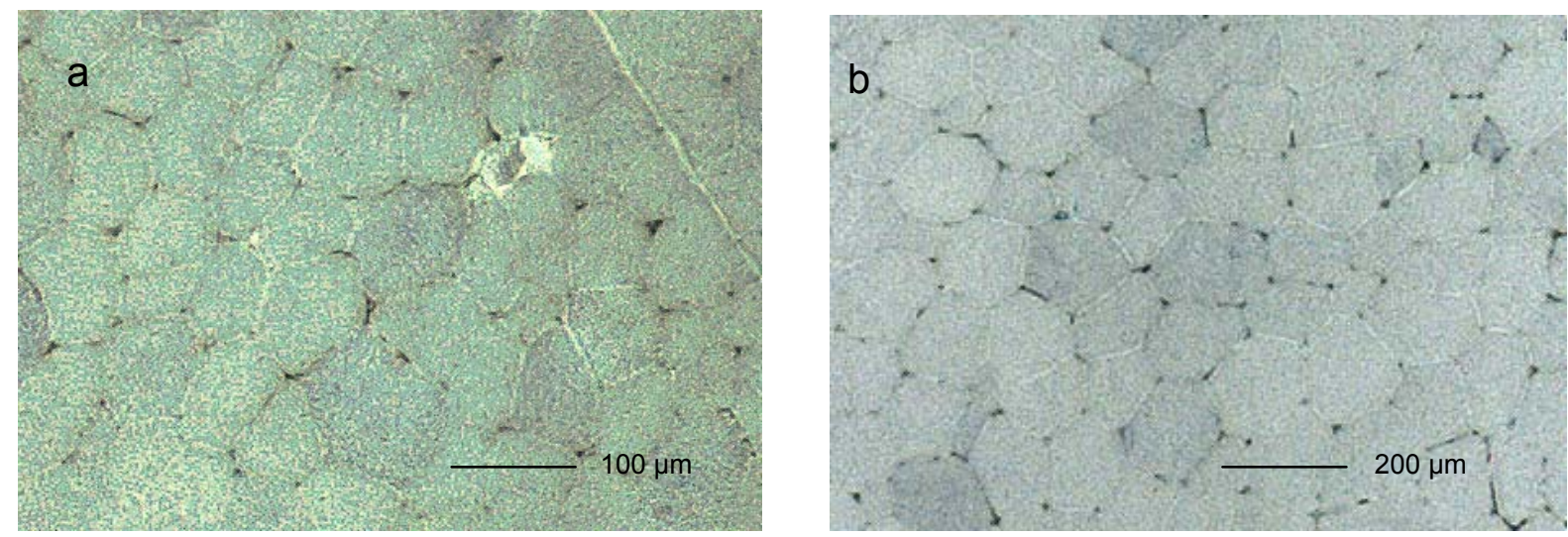

Abb. 16 a+b: Mm.pect.superfic. von B.U.T. BIG 6 - Puten im Alter von 12 Wochen (a) und 22 Wochen (b) 
Der Anteil an degenerierten Muskelfasern war bei beiden Altersstufen nahezu gleich groß. Der größte Anteil an den degenerierten Fasern bestand aus Riesenfasern (Abb. 17), der Anteil an angulären Fasern an der Gesamtfaserzahl lag unter 0,05\%. Bei der vorliegenden Untersuchung zeigten die Riesenfasern häufig eine höhere Farbintensität, als die Zellen ohne Degenerationserscheinungen.

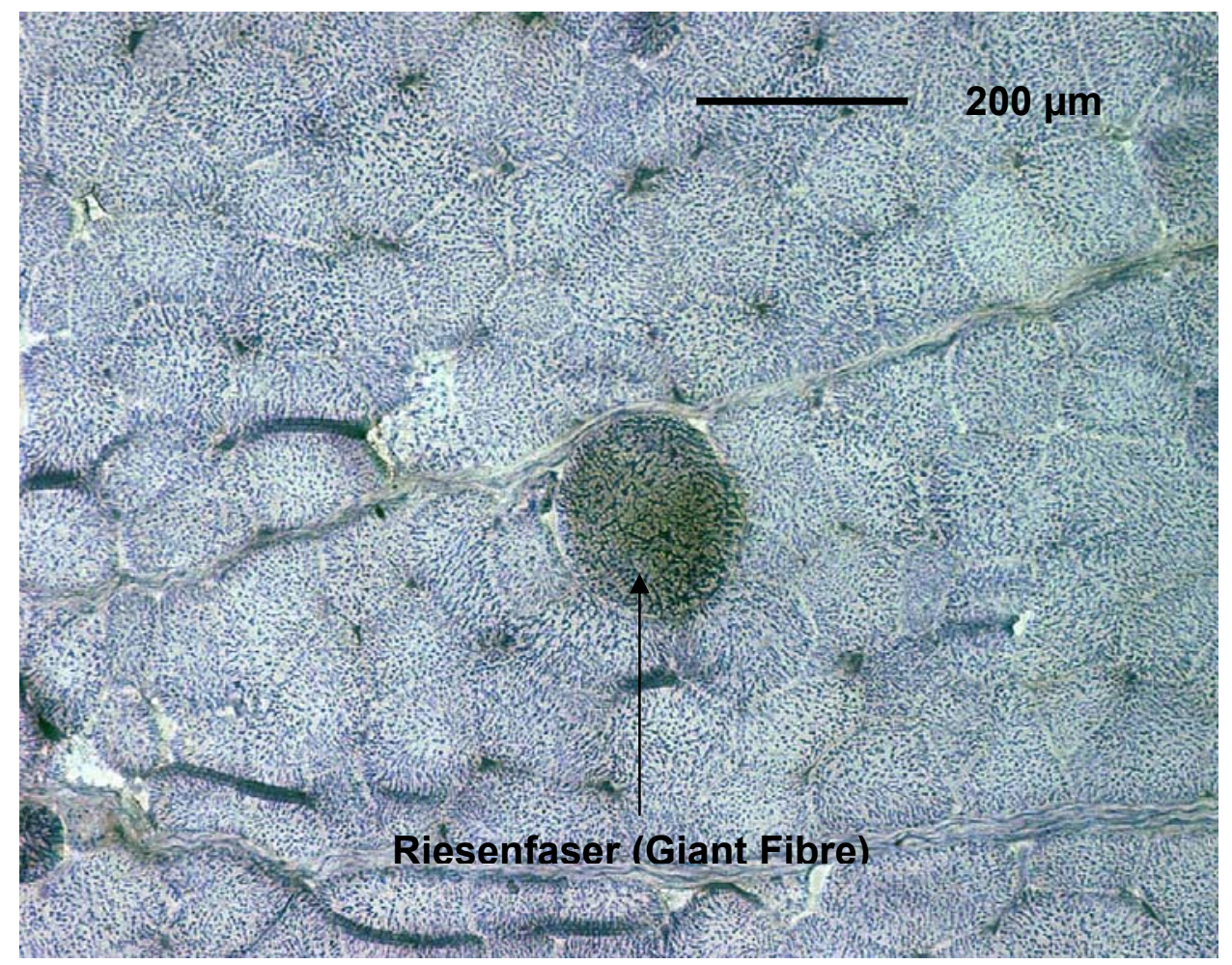

Abb. 17: Riesenfaser (Giant Fibre) umgeben von pathologisch unverändertem Gewebe im M.pect.superfic einer 22 Wochen alten B.U.T. BIG 6 - Pute

Die Riesenfasern wurden am häufigsten an den Rändern der Perimysien gefunden, und so gut wie gar nicht in zentraler Position eines Faserbündels. Der Anteil an Riesenfasern am Gesamtgewebe war zwischen den beiden Altersstufen nicht signifikant zu unterscheiden. In der Literatur wird kein Einfluss des Alters auf das Auftreten von Riesenfasern beschrieben.

Die angulären Muskelfasern waren, sofern überhaupt vorhanden, nur in sehr geringer Anzahl zu finden (Abb.18). Zwar gab es bei den 22 Wochen alten Tieren signifikant mehr Fasern dieses Typs als bei den 12 Wochen alten Tieren, jedoch ist der Unterschied äußerst gering. BENTLEY (1999) belegte, dass es sich bei den angulären Fasern um Reste einer Muskelfaserreparatur handelt. Die gezeigten Ergebnisse legen die Vermutung nahe, dass bei den jüngeren Tieren weniger Zellen repariert werden mussten, als bei den älteren. 


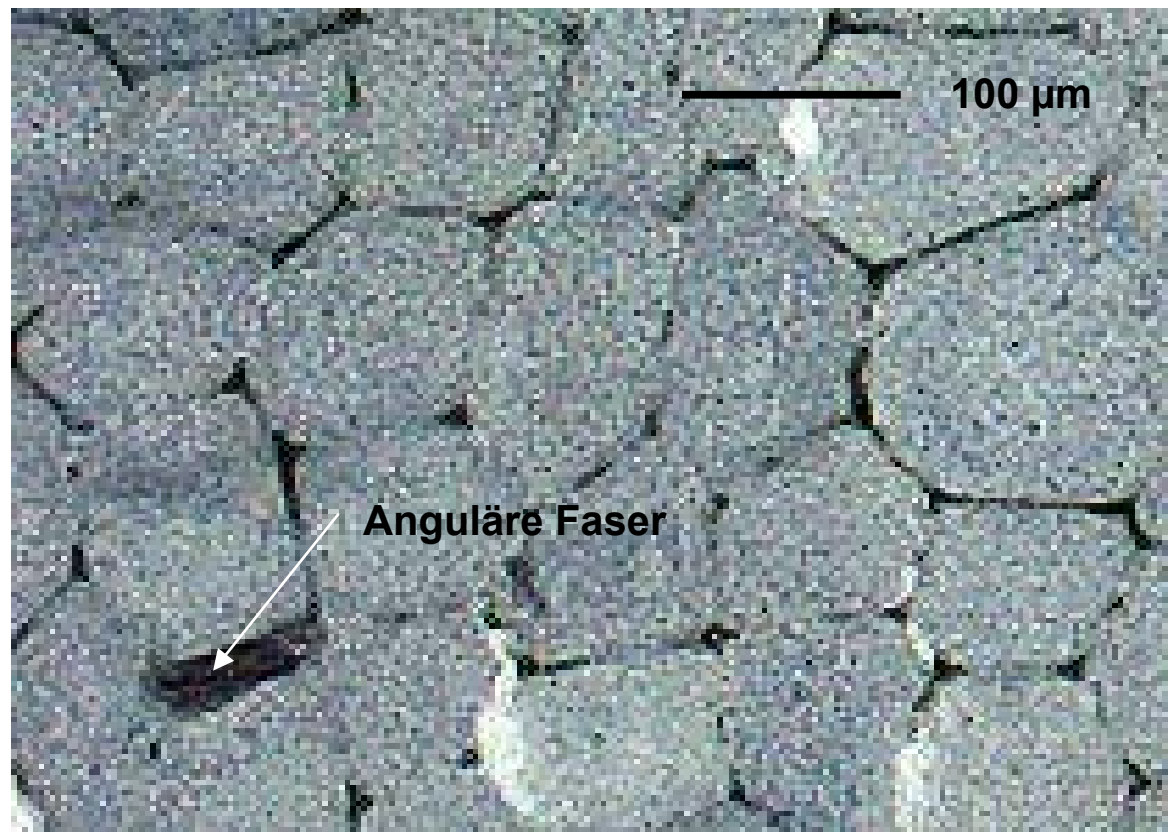

Abb. 18: Anguläre Faser im Verbund nicht pathologischer Muskelfasern im M.pect.superfic. einer B.U.T. BIG 6 - Pute im Alter von 22 Wochen

Die 22 Wochen alten Tiere wiesen mehr als doppelt so viele Kapillaren pro Muskelfaser auf, als die 12 Wochen alten Puten.

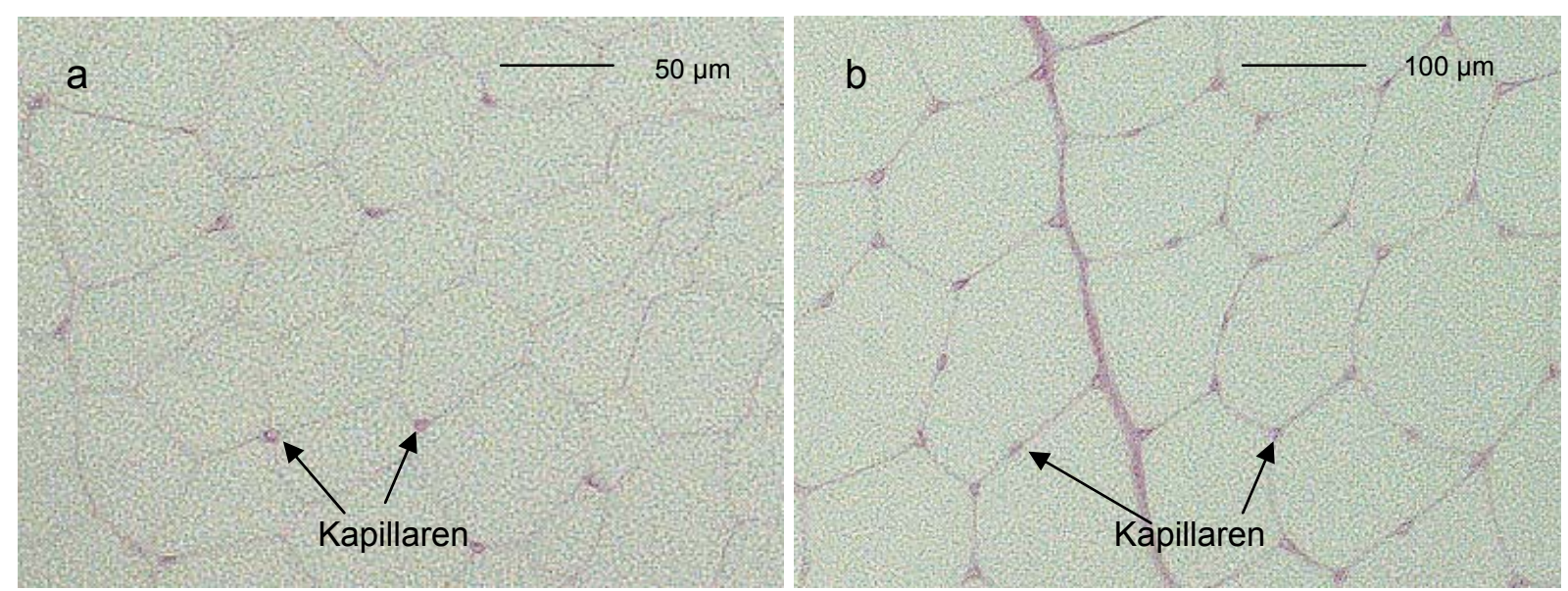

Abb. 19: Verteilung der Kapillaren im Gewebe des M.pect.superfic. von B.U.T. BIG 6 - Puten im alter von 12 (a) und 22Wochen (b).

Es gibt für diese signifikante Tatsache verschiedene Erklärungsversuche.

Die Kapillaren befinden sich am häufigsten an den Stellen, an denen drei Muskelfasern aneinander liegen (Abb.19). Bei den 22 Wochen alten Tieren sind aber auch dort Kapillaren zu finden, wo nur 2 Muskelfasern aufeinander treffen. Letztere sind kleiner und unscheinbarer als die an einer Drei-Zell-Verbindungsstelle. Wie schon beschrieben, sind die Muskelfasern der 12 Wochen alten Tiere erheblich kleiner, als die der 22 Wochen alten Tiere. Dem zufolge besteht die Möglichkeit, dass bei den 12 Wochen alten Tieren ebenfalls Kapillaren an Zwei-Zell-Verbindungen (Abb.20) vorhanden sind, diese aber aufgrund ihres geringen Durchmessers kaum erkennbar sind und sich aufgrund der dünneren Kapillarwand auch schlechter anfärben lassen. 


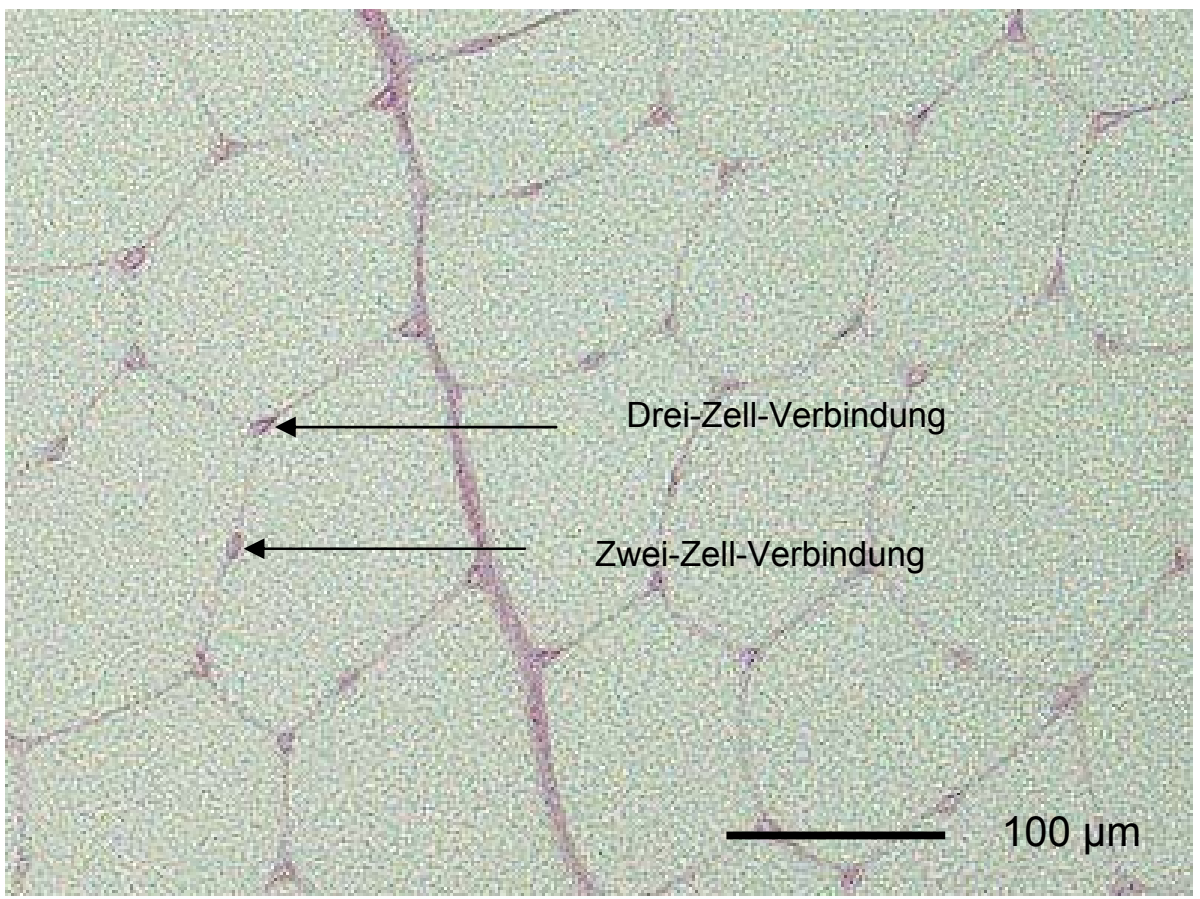

Abb. 20: Anordnung von Kapillaren im Gewebe des M.pect.superfic. von B.U.T. BIG 6 Puten im Alter von 22 Wochen.

Eine andere mögliche Erklärung ist, dass die Anzahl der gezählten Kapillaren der tatsächlich vorhandenen entspricht. Grund dafür könnte der Umstand sein, das sich im Laufe des Wachstums neue Kapillaren bilden, da die Versorgung der sehr großen Muskelzellen ausschließlich mit Kapillaren an Drei-Zell-Verbindungsstellen nicht mehr gewährleistet werden kann. Dieser Erklärungsversuch steht aber im Widerspruch zu den Untersuchungsergebnissen von ELMINOWSKA-WENDA et al. (2005), welche eine zunehmende Kapillarisierung mit fortschreitendem Zellwachstum ausschließen. Letztere Aussage wird zudem durch die in eigenen Untersuchungen gefundenen Korrelationskoeffizienten zwischen den Parametern der Zellgröße $(0,92$ - 0,93) und dem Kapillar/Zellverhältnis widerlegt. Sowohl MICHEL und SALOMON (1977) als auch SOSNICKI und WILSON (1991) konnten belegen, dass sich die Anzahl an Kapillaren durch Training beeinflussen lässt. Inwieweit aber in der vorliegenden Untersuchung die Brustmuskel der 22 Wochen alten Puten trainierter sein sollen, als jene der 12 Wochen alten Puten, lässt sich aus dem Versuch nicht ableiten. 


\subsection{Einfluss des Genotyps auf Schlachtkörper- und Fleischbeschaffenheitsmerkmale}

\subsubsection{Durchgang 1: B.U.T. BIG 6 vs. Kelly's BBB}

\section{Gewichtsparameter}

Erwartungsgemäß war in beiden Altersstufen der Genotyp BIG 6 von B.U.T. in allen Gewichtsparametern dem Genotyp BBB signifikant überlegen. Damit entwickelten sie sich analog zur Lebendgewichtentwicklung (Tab.52) der beiden Herkünfte (www.kelly-turkeys.com; MEYER, 1991).

Tab. 52: Lebendgewichtsentwicklung beim Herkunftsvergleich B.U.T. BIG 6 - Kellys BBB

\begin{tabular}{|l|c|c|}
\hline Alter in Wochen & $\begin{array}{c}\text { Gewicht B.U.T. BIG 6 } \\
(\mathrm{kg})\end{array}$ & Gewicht Kellys BBB (kg) \\
\hline 8 & 3,87 & 3,72 \\
\hline 12 & 8,29 & 7,43 \\
\hline 16 & 12,56 & 11,16 \\
\hline 20 & 17,07 & 14,70 \\
\hline 21 & 18,58 & 15,53 \\
\hline
\end{tabular}

Da die Puten des Züchters Kelly für extensive bzw. Freilandhaltung empfohlen werden, ist aufgrund der verschiedenen Umwelteinflüsse ein höheres Bewegungspotential zu unterstellen, als bei der Intensivhaltung von Puten. Offenbar ist der Wachstumsverlauf beider Genotypen verschieden, denn während sich im Alter von 12 Wochen bei den Probanden der Herkunft BBB mit 44,5\% ein höherer Brustmuskelanteil nachweisen ließ als bei den Big 6, so lag derselbe Genotyp im Alter von 22 Wochen signifikant hinter dem B.U.T. - Produkt zurück. Eine genaue Überprüfung des Wachstumsverlaufs der einzelnen Teilstücke der verschiedenen Genotypen gilt es in Folgeversuchen zu klären.

\section{Inhaltstoffe und TM}

Im Alter von 12 Wochen konnten keine signifikanten Unterschiede zwischen den beiden Genotypen nachgewiesen werden. Es war allerdings auch nicht zu erwarten, dass sich in dieser Altersstufe große Unterschiede zeigen würden.

Im Alter von 22 Wochen zeigte der Genotyp BIG 6 signifikant höhere Fettgehalte im M. pect. superfic.. Der Unterschied war bei einer Größenordnung von 0,15 \% nur gering. Da eine Zunahme des Fettgehaltes in der Regel mit zunehmendem Alter bzw. Wachstumsverlauf stattfindet, kann daraus geschlossen werden, dass sich die Probanden der Herkunft BIG 6 trotz gleichen Alters schneller entwickelt haben, als jene des Genotyps BBB. Natürlich zeigten sich auch signifikante Unterschiede bei den Inhaltstoffen Protein und Asche, diese Unterschiede beruhen aber auf der Verschiebung der Mengenanteile durch den erhöhten Fettgehalt der Mm.pect.superfic. der BIG 6 - Puten. 
pH, LF, L*, $a^{*}, b^{*}$

Hinsichtlich der $\mathrm{pH}$ - und LF - Werte der 12 Wochen alten Puten konnten keine signifikanten Unterschiede abgesichert werden. Zu diesem Zeitpunkt des Wachstums war allerdings auch kein großer Unterschied zu erwarten gewesen.

Sowohl die pH-Werte 20 min. p.m. der 12 Wochen alten Tiere, als auch jene der 22 Wochen alten Tiere bestätigen die Aussage von DRANSFIELD und SOSNICKI (1999), welche die pH-Werte von Puten 20 min. p.m. mit 6,2 - 6,8 bezifferten.

Im Alter von 22 Wochen zeigten die Probanden der Herkunft BBB sowohl niedrigere $\mathrm{pH}$ - Werte 4 h p.m., als auch bei der pH - Wertdifferenz zwischen dem pH - Wert 20 min p.m. und dem pH - Wert 4h p.m., verglichen mit der Herkunft B.U.T. BIG 6.

$\mathrm{Da}$ die $\mathrm{pH}$ - Wertverhältnisse der Linie BBB weder mit histologischen, noch mit Gewichtsparametern erklärt werden können, bleibt als Begründung für diesen Umstand nur eine gesteigerte Stresslabilität dieser Linie zu nennen. Auch die Leitfähigkeitswerte 20 min p.m. weisen auf eine Neigung zur Stressanfälligkeit bei den BBB - Hähnen hin. Obwohl die Unterschiede nicht signifikant waren, so lag doch der Mittelwert 20 min. p.m. um 0,24 mS/cm über den Werten der BIG 6 Hähne. Nach 20 min p.m. dürften sich noch keine Zellschädigungen aufgrund postmortaler Stoffwechselvorgänge zeigen (MEIERING 1995). Somit ist auch dieses Ergebnis auf eine höhere Stressanfälligkeit der Probanden der Herkunft BBB zurückzuführen. Dieser Unterschied der Leitfähigkeitswerte wird 4 h p.m. noch deutlicher, da die BBB Hähne mit 6,78 mS/cm etwa 2 mS/cm über den Werten des BIG 6 - Genotyps lagen. $\mathrm{Da}$ die Puten des Züchters Kelly in Deutschland für extensive Haltung/Freilandhaltung empfohlen werden, ist die vergleichsweise geringe Stressresistenz umso bemerkenswerter.

Im Alter von 12 Wochen wiesen die BIG 6 - Hähne einen signifikant helleren M.pect.superfic. auf, als die Probanden der Herkunft BBB. Dieser Unterschied hat sich im Alter von 22 Wochen umgekehrt. Da aber in beiden Altersstufen der jeweilige Unterschied zwar signifikant, jedoch absolut betrachtet nur gering ist, kann dieses Ergebnis vernachlässigt werden, zumal der Helligkeitsunterschied mit bloßem Auge nicht erkennbar ist. Legt man die von RAMMOUZ et al. (2004) gefundenen $L^{*}$ - Werte für Putenbrustfleisch 24 h p.m. für die Beurteilung der $L^{*}$ - Werte aus der eigenen Untersuchung zugrunde, so liegen beide Ergebnisse in vergleichbarem Rahmen.

Bei den $a^{*}$ - Werten verhält es sich ähnlich, wie bei den $L^{*}$ - Werten. Im Alter von 12 Wochen zeigten die BBB - Hähne die höheren Rotanteile, im Alter von 22 Wochen lagen die BIG 6 - Hähne vorn. Da im Alter von 12 Wochen die BBB - Hähne nur etwa halb so viel Blutpunkte im Gewebe nachgewiesen werden konnten, wie bei der Vergleichsgruppe, kann eine Erhöhung der $a^{*}$ - Werte durch intramuskuläre Einblutungen ausgeschlossen werden. Da sowohl bei den $a^{*}$, wie auch bei den $b^{*}$ Werten die Unterschiede zwar oft signifikant, jedoch absolut betrachtet als gering einzustufen sind, können auch hier die Unterschiede vernachlässigt werden. Die von HAHN et al. (2001a,b) beschriebene Korrelation zwischen dem pH - Wert 20 min. p.m. und den $a^{*}$ - Werten konnte durch die vorliegenden Untersuchungen nicht gestützt werden. 


\section{Physikalische und chemisch-biologische Parameter}

Im Alter von 12 Wochen zeigten die Hähne der Linie BIG 6 mit 3,37 \% einen um 0,5 Prozentpunkte höheren Tropfsaftverlust als der gleichaltrige Genotyp BBB (2,72 \%). Zur Klärung dieses Sachverhaltes sind weitere Untersuchungen erforderlich. Die gefundenen Tropfsaftverluste, welche 2 Tage p.m. ermittelt wurden, waren deutlich höher, als

die in der Literatur gefundenen Werte. So konnten RAMMOUZ et al. (2004) nach drei Tagen lediglich einen mittleren Tropfsaftverlust von 0,57 \% nachweisen. Ferner gilt es zu klären, warum die 12 Wochen alten BIG 6 - Puten zwar die höheren Tropfsaftverluste, aber auch die geringsten Leitfähigkeitswerte zeigten, denn auch in den eigenen Untersuchungen sind die Tropfsaftverluste und die Leitfähigkeitswerte 4 h p.m. positiv miteinander korreliert $(0,36)$.

Sehr gut erklären läst sich dagegen der signifikante Unterschied zwischen den 22 Wochen alten Tieren hinsichtlich des Tropfsaftverlustes. Die signifikant höheren Werte bei den Probanden der Herkunft BBB begründen sich durch die vergleichsweise hohen Leitfähigkeitswerte und niedrigen $\mathrm{pH}$ - Werte. Durch die niedrigen $\mathrm{pH}$ - Werte werden, wie im Literaturteil bereits beschrieben (RAMMOUZ et al., 2004; WYNVEEN et al., 1999), die Muskelzellmembranen geschädigt. Die austretende, elektrolythaltige Zellflüssigkeit erhöht die Leitfähigkeit des Gewebes. Die geschädigten Zellen verlieren Intrazellulärflüssigkeit, welche durch die Tropfsaftermittlung quantifizierbar ist. Die Tatsache, dass es keine signifikanten Unterschiede beim Grillverlust zwischen den Genotypen beiderlei Altersstufen zu vermerken gab, wohl aber beim Tropfsaftverlust, lässt sich damit begründen, dass die Tropfsaftprobe $48 \mathrm{~h}$ bei $4^{\circ} \mathrm{C}$ gelagert wurde. Die Grillverlustproben wurden etwa 4 h p.m. eingefroren und erst kurz vor dem Grillen aufgetaut. Der Flüssigkeitsverlust beim Auftauen (Tauverlust) wurde nicht ermittelt, so das davon ausgegangen werden kann, dass die auf Zellschäden beruhenden Flüssigkeitsverluste entweder im Tauverlust zu finden sind - oder aufgrund der geringen Zeit im nicht gefrorenem Zustand noch nicht durch das Gewebe nach außen gelangen konnten. Beim Grillen wird die Oberfläche der Probenstücke versiegelt, weshalb es während des Grillens nicht zu wesentlichen Unterschieden zwischen den Proben kommen kann.

Bei den 12 Wochen alten Putern beiderlei Genotyps konnten hinsichtlich der Scherkräfte keinerlei signifikante Unterschiede abgesichert werden.

Bei der Scherarbeit wiesen die Probanden der Herkunft BBB die signifikant höheren Werte auf. Da bei der Scherarbeit die Scherkraft mit dem im Gewebe zurückgelegten Weg multipliziert wird, werden bei dieser Betrachtungsweise auftretende Bindegewebswiderstände, welche zu Scherkraftspitzen führen können, weitgehend relativiert und die Scherkraft über das gesamte Gewebe berücksichtigt. So ist es auch zu erklären, dass die 22 Wochen alten BIG 6 - Puten zwar signifikant höhere Scherkraftwerte $(37,06 \mathrm{~N})$ im Vergleich zu den BBB - Puten $(34,86 \mathrm{~N})$ zeigten, jedoch keinen signifikanten Unterschied bei den Scherarbeitswerten aufwiesen. Die Scherkraftwerte der 22 Wochen alten Puten aus den eigenen Versuchen decken sich weitgehend mit denen, welche RAMMOUZ et al. (2004) am Brustfleisch von B.U.T. 9 - Puten nachweisen konnte $(34,2 \mathrm{~N})$.

Im Alter von 12 Wochen wiesen die BIG 6 - Hähne signifikant mehr Blutpunkte im Gewebe auf, als die Probanden der Herkunft BBB. Dieser Unterschied ist im Alter von 22 Wochen allerdings nicht mehr nachweisbar. Offenbar ist das Auftreten von Blutpunkten eine wachstumsabhängige Erscheinung. Schon bei der Betrachtung des Fettgehaltes wurde vermutet, dass der Wachstumsverlauf der BIG 6 - Hähne weiter fortgeschritten zu sein scheint, als das bei den BBB - Hähnen der Fall war. 
Da zwischen den Herkünften bei den Parametern „Zellquerschnittsfläche“ und „Anzahl an Kapillaren pro Zelle" keine signifikanten Unterschiede abzusichern waren, können mikroanatomische Ursachen nicht für die erhöhte Blutpunktzahl der 12 Wochen alten B.U.T. BIG 6 - Puten verantwortlich gemacht werden. Auch das höhere Schlachtkörpergewicht der 12 Wochen alten B.U.T. BIG 6 - Puten im Vergleich zu den BBB Puten, kann nicht als Ursache für die erhöhte Blutpunktzahl herangezogen werden, denn dieser Parameter war auch bei den 22 Wochen alten B.U.T. BIG 6 - Puten höher als bei der Vergleichsgruppe, die Blutpunktzahl unterschied sich aber in dieser Altersstufe zwischen beiden Herkünften nicht signifikant.

Die Creatinkinaseaktivitäten unterschieden sich zwischen den beiden Genotypen nicht signifikant. Da beide Genotypen ähnliche histologische Gewebsausprägungen zeigten und die Anteile an degenerierten Muskelfasern sich bei den 22 Wochen alten Tieren zwar signifikant unterschieden, absolut betrachtet jedoch dicht beieinander lagen, sind Unterschiede der CK-Aktivität zunächst nicht zu erwarten gewesen. Da aber mit einem Korrelationskoeffizienten von 0,80 eine enge Verbindung zwischen den Parametern "CK - Aktivität" und "Schlachtkörpergewicht" besteht, müsste demnach die Herkunft BIG 6 im Alter von 22 Wochen die höhere Creatinkinaseaktivität zeigen, denn sie war signifikant schwerer als die Vergleichsherkunft. Tatsächlich zeigten die BIG 6 - Puten auch eine gesteigerte CK - Aktivität, jedoch war dieser Unterschied nicht signifikant.

Auch die Laktatgehalte im Stichblut waren zwischen den Genotypen nicht signifikant verschieden. Als Grund dafür ist ebenfalls die gleiche histologische Gewebsausprägung und der ähnliche körperliche Habitus zu nennen.

\section{Histologische Parameter}

Die histologischen Parameter die Zellgröße betreffend, zeigten keine signifikanten Unterschiede zwischen den Genotypen. Da die BIG 6 Hähne deutlich höhere Gewichtsparameter zeigten, wäre zu erwarten gewesen, dass Sie auch größere Muskelzellen zeigen würden, zumal zwischen diesen Parametern ausnahmslos eine enge Korrelation besteht (Tab.42). Dies war zwar auch der Fall, jedoch außerhalb der gesetzten Signifikanzgrenzen.

Der Anteil degenerierter Muskelfasern war bei den Probanden der Herkunft BBB im Alter von 22 Wochen signifikant höher, als bei den BIG 6 - Hähnen. Diesem Umstand wird auch durch höhere Tropfsaftverluste und LF - Werte 4 h p.m. Rechnung getragen. Der größte Anteil der degenerierten Zellen bestand aus den Riesenfasern. REMIGNON et al. (2000) beschrieb als Ursache für die Bildung von Riesenfasern das Unvermögen der Sarkomere, sich wieder zu entspannen. Dies wiederum ist auf unzureichende Mitochondrientätigkeit und/oder Defekte des sarkoplasmatischen Retikulums zurückzuführen. Es ist demnach zu unterstellen, dass die BBB - Hähne zumindest einen der genannten physiologischen Unzulänglichkeiten aufweist.

Die BIG 6 - Hähne zeigten im Alter von 22 Wochen 0,07 \% anguläre Fasern, die Probanden der Herkunft BBB so gut wie keine. Auch wenn der Unterschied durchaus signifikant war, so ist dieser Wert absolut betrachtet sehr gering. Sie weisen allerdings darauf hin, das die BIG 6 - Hähne ante mortem mehr geschädigte Zellen zeigten, als die BBB - Puten. Dieser Umstand wird auch durch einen Korrelationskoeffizienten von 0,31 zwischen dem M.pect.superfic.- Gewicht, welches bei den BIG 6 - Puten über denen der Vergleichsgruppe lag und dem Anteil degenerierter Muskelfasern untermauert. 
Aufgrund der sehr ähnlichen histologischen Eigenschaften beider Linien, ist es naheliegend, dass auch keine Unterschiede hinsichtlich der Kapillarisierung des Gewebes zu finden sind. Tatsächlich waren keinerlei signifikante Unterschiede bei diesem Parameter abzusichern.

\subsubsection{Durchgang 2}

Im zweiten Versuchsdurchgang wurden die Genotypen BIG 6 (B.U.T.), Wrolstad (Kelly's) und Super Mini (Kelly's) miteinander verglichen.

\subsubsection{Altersgruppe 12 Wochen}

\section{Gewichtsparameter}

Bei allen Gewichtsparametern wiesen die Probanden der Herkunft BIG 6 die signifikant höheren Werte auf. Dieses Ergebnis war zu erwarten gewesen, da die BIG 6 eine Hochleistungspute darstellt. Wrolstad ist dagegen eine mittelschwere Linie und die Super Mini ein sehr kleiner Genotyp (Tab.53). Nicht erwartungsgemäß war allerdings, dass kein signifikanter Unterschied zwischen den Linien Wrolstad und Super Mini erkennbar war. Noch bemerkenswerter war der Umstand, dass die mittelschwere Linie Wrolstad absolut geringere Werte bei den Parametern Schlachtkörpergewicht und Brustmuskelgewicht aufwies, als die leichte Linie Super Mini. Hier gilt es in Folgeversuchen die genauen Wachstumsverläufe zu dokumentieren. Zwar existieren Angaben über die Gewichtsentwicklung der untersuchten Herkünfte (Tab.53), diese beziehen sich jedoch nur auf die Lebendgewichte und lassen nur Schätzungen bezüglich der Schlachtkörper- und Teilstückgewichte sowie der Schlachtkörperzusammensetzung zu.

Tab. 53: Lebendgewichtsentwicklung beim Herkunftsvergleich B.U.T. BIG 6 - Wrolstad - Super Mini (www.kelly-turkeys.com; MEYER, 1991)

\begin{tabular}{|l|c|c|c|}
\hline $\begin{array}{l}\text { Alter in } \\
\text { Wochen }\end{array}$ & $\begin{array}{c}\text { Gewicht B.U.T. BIG 6 } \\
(\mathrm{kg})\end{array}$ & $\begin{array}{c}\text { Gewicht Kellys } \\
\text { Wrolstad }(\mathrm{kg})\end{array}$ & $\begin{array}{c}\text { Gewicht Kellys } \\
\text { Super Mini (kg) }\end{array}$ \\
\hline 8 & 3,87 & 2,69 & 2,43 \\
\hline 12 & 8,29 & 5,25 & 4,75 \\
\hline 16 & 12,56 & 7,85 & 7,10 \\
\hline 20 & 17,07 & 10,36 & 9,37 \\
\hline 21 & 18,58 & 10,87 & 10,56 \\
\hline
\end{tabular}

Der Brustmuskelanteil der BIG 6 - Puten lag signifikant unter denen der Linien Wrolstad und Super Mini, welche sich untereinander nicht signifikant unterschieden. Die Probanden der Herkunft BIG 6 sind im Alter von 12 Wochen schon wesentlich deutlicher im Wachstum fortgeschritten, als die beiden Vergleichsgenotypen. Bei allen beschriebenen Versuchen war erkennbar, dass eine negative Beziehung zwischen dem Schlachtkörpergewicht und dem Brustmuskelanteil besteht. Der Brustmuskelanteil war deshalb zwar geringer, die ermittelten Brustmuskelgewichte jedoch signifikant höher als bei den Vergleichsgenotypen. Auch bei der quantitativen Betrachtung des Brustmuskelgewichtes und des Gewichtes des M.pect.superfic. konnten keine signifikanten Unterschiede zwischen den beiden Linien des Züchters Kelly abgesichert werden. 


\section{Inhaltstoffe und Trockenmasse}

Sowohl bei der Betrachtung der Trockenmasse, als auch bei den meisten Muskelinhaltstoffen konnten keine signifikanten Unterschiede abgesichert werden. Dies deutet darauf hin, dass auch bei unterschiedlichem Wachstumsvermögen der Linien der Protein- und Fettansatz der untersuchten Genotypen im Alter von 12 Wochen vergleichbar ist. Lediglich beim Aschegehalt konnte ein signifikant geringerer Wert bei der Linie Wrolstad abgesichert werden. Stoffwechselphysiologisch gibt es für Unterschiede im Aschegehalt vergleichbarer Tiere außer dem Fütterungsregime keinerlei Erklärungen für dieses Phänomen. Da sich aber die Fütterung bei allen drei Genotypen gleich gestaltete, kann dieser Erklärungsansatz vernachlässigt werden.

\section{pH, Leitfähigkeit (LF), L*, a*, b*}

Der pH - Wert 20 min. p.m. war bei dem Genotyp Super Mini signifikant niedriger als bei den BIG 6 Hähnen. Dieses Ergebnis entspricht nicht den Erwartungen, denn ein rascher $\mathrm{pH}$ - Wert-Abfall p.m. wird in der Literatur grundsätzlich den Hochleistungsgenotypen unterstellt (WICKE et al., 2000). Offenbar neigt die Herkunft Super Mini eher als die Linie BIG 6 zur Stressanfälligkeit.

4 h p.m. war kein signifikanter Unterschied zwischen den Genotypen hinsichtlich des $\mathrm{pH}$ - Wertes erkennbar. Auch die ermittelten $\mathrm{pH}$ - Wertdifferenzen zeigten keine Unterschiede. Es sei aber erwähnt, dass die Linie Wrolstad die höchste $\mathrm{pH}$ Wertdifferenz der untersuchten Genotypen zeigte. Da eine hohe pH - Wertdifferenz in der Regel mit Zellschäden verbunden ist, sind entsprechende Ergebnisse bei der Betrachtung der Leitfähigkeitswerte zu erwarten, zumal eine positive, wenn auch geringe Korrelation $(r=0,19)$ zwischen den beiden Parametern besteht. Und tatsächlich wies die Linie Wrolstad 4 h. p.m. die signifikant höchsten Leitfähigkeitswerte auf. Die beiden Vergleichslinien unterschieden sich dagegen nicht signifikant.

Hinsichtlich der Helligkeits- und $b^{*}$ - Werte gab es keine signifikanten Unterschiede. Aufgrund der $\mathrm{pH}$ - und Leitfähigkeitswerte der Linie Wrolstad wäre bei der besagten Linie ein signifikant helleres Fleisch wahrscheinlich gewesen. Wie es scheint, waren die aufgezeigten Unterschiede nicht groß genug, um die Fleischhelligkeit nennenswert zu beeinflussen.

Der Vergleich der $a^{*}$ - Werte zeigte einen signifikant höheren Rotanteil des M.pect.superfic. der BIG 6 - Hähne im Vergleich zu denen der anderen Genotypen. Da die Probanden der Herkunft BIG 6 sowohl die höchste Zahl an Kapillaren, als auch die meisten Blutpunkte im Gewebe zeigten, ist naheliegend, dass der höhere Rotanteil auf im Muskel befindliches Hämoglobin zurückzuführen ist.

\section{Physikalische Parameter und Blutparameter}

Sowohl beim Tropfsaft, wie beim Grillverlust zeigte die Linie Super Mini im Alter von 12 Wochen die signifikant höchsten Werte. Erklärt werden kann dies mit dem Umstand, dass es bei den Super Mini bereits 20 min p.m. die signifikant niedrigsten $\mathrm{pH}$ - Werte zeigten. Ein überstürzter $\mathrm{pH}$ - Wertabfall führt in der Regel zu Zellschädigungen (RAMMOUZ et al., 2004; WYNVEEN et al., 1999). Dies ist offenbar auch im vorliegenden Fall geschehen, denn die vergleichsweise höheren Tropf- und Grillverlustwerte sprechen für austretende Zellflüssigkeit. 
Allerdings sei in diesem Zusammenhang angemerkt, dass die höchsten Leitfähigkeitswerte nicht bei den Super Mini - Puten im Vergleich zu den anderen Herkünften gefunden wurden. Dies wäre aber zu erwarten gewesen, da zwischen den Parametern Leitfähigkeit 4 h p.m. und Tropfsaftverlust eine positive Korrelation $(0,36)$ bestand.

Hinsichtlich der Scherkraft und Scherarbeitswerte konnten keine signifikanten Unterschiede abgesichert werden. Es fällt jedoch auf, dass die Super Mini bei beiden Parametern die höchsten, die BIG 6 - Hähne dagegen die geringsten Werte zeigte. Dieser Umstand stützt die Eingangs der Diskussion beschriebene These, dass kleinere Zelldurchmesser zu höheren Scherkraftwerten führen. Da diese These im Widerspruch zur aktuellen Literatur steht (SIELAFF, 1996), gilt es in Folgeversuchen zur Klärung des Sachverhaltes beizutragen. Jedoch spricht auch eine Korrelation zwischen dem Zelldurchmesser und den Scherkraftwerten mit einem Koeffizienten von $-0,50$ für diese These.

Die absolute Zahl der Blutpunkte sowie die Anzahl der Blutpunkte pro kg M.pect.superfic. war bei den BIG 6 - Hähnen signifikant höher, als bei den beiden Vergleichsgenotypen. Da die Probanden der Herkunft BIG 6 höhere Schlachtkörpergewichte (ebenfalls Brustmuskelgewicht, Gewicht des M.pect.superfic.) und größere Muskelzellen aufwiesen, als die Vergleichslinien, muss auch eine entsprechend stärkere Blutversorgung gewährleistet sein. Tatsächlich lassen sich bei den 12 Wochen alten BIG 6 - Puten die meisten Kapillaren pro Zelle finden. Dafür spricht auch eine sehr enge Korrelation zwischen der Anzahl an Kapillaren pro Zelle und der Zellquerschnittsfläche $(r=0,92)$. Bei hoher Stoffwechselaktivität (fangen, verladen, einhängen, betäuben) reicht die genetisch determinierte Blutversorgung offenbar nicht mehr aus und es kommt zu Blutgefäßschäden. Ferner wirken bei den angesprochenen mechanischen Belastungen der Tiere kurz vor dem Schlachten aufgrund der hohen Eigengewichte der Tiere größere Druck- und Zugkräfte auf das Tier, wodurch die Gefahr einer Ruptur gesteigert wird. Da nun bei den BIG 6 - Puten zudem mehr Kapillaren pro Zelle gefunden wurden, ist rein rechnerisch die Gefahr einer Schädigung höher. Daraus folgt: Je größer und schwerer das Tier, umso häufiger treten Blutpunkte auf. Dies wird auch durch die in eigenen Untersuchungen gefundene Korrelation zwischen dem Schlachtkörpergewicht und der Blutpunktzahl mit einem Koeffizienten in Höhe von 0,48 bestätigt.

Die CK- und Laktatwerte der 12 Wochen alten Tiere unterschieden sich nicht signifikant. Bei der Betrachtung der absoluten Werte fällt auf, dass die Linie BIG 6 die niedrigsten CK - Werte aufwies. Hohe CK - Werte sind, wie im Literaturteil beschrieben (MITCHEL und SANDERCOCK, 1995; HAHN, 2000) ein Marker für Skelettmuskelschädigungen. Und tatsächlich wiesen die BIG 6 - Hähne tendenziell den geringsten Anteil an Zellschädigungen im Vergleich zu den anderen Linien auf (Tab.28, Anteile degenerierter Muskelfasern).

Auch wenn die absoluten Laktatgehalte im Stichblut bei den Probanden der Herkunft Wrolstad etwa $10 \mathrm{mg} / \mathrm{dl}$ niedriger waren als bei den Vergleichsherkünften, so waren diese Unterschiede nicht signifikant abzusichern. Nach APPLE et al. (1995) würde dies bedeuten, dass auch kein signifikanter Unterschied hinsichtlich der Stressanfälligkeit zwischen den Herkünften besteht. 


\section{Histologische Parameter}

Die Probanden der Herkunft BIG 6 wiesen zwar absolut, aber nicht signifikant die größten Muskelfaserdurchmesser auf. Dies ist auch naheliegend, da die BIG 6 Hähne auch die höchsten Schlachtkörper- und Brustmuskelgewichte zeigten. Auffällig ist die um $300 \mu \mathrm{m}^{2}$ größere Zellquerschnittsfläche der Linie Wrolstad im Vergleich zur Linie Super Mini. Da die Linie Wrolstad in der Altersgruppe 12 Wochen die geringsten Schlachtkörper- und Brustmuskelgewichte zeigte, deutet alles darauf hin, dass bei dieser Linie in dieser Altersstufe das Zellwachstum auf Kosten des Wachstums des restlichen Körpers stattfindet. Bei der Betrachtung des Zelldurchmessers (sowohl beim durchschnittlichen Zelldurchmesser, wie auch beim minimalen Durchmesser und des Zellumfangs) wird diese Aussage bestätigt.

Der Anteil an degenerierten Muskelfasern wies keinen signifikanten Unterschied zwischen den Genotypen auf. Es sei jedoch angemerkt, dass der Genotyp BIG 6 trotz höchster Schlachtkörper- und Brustmuskelgewichte sowie der absolut größten Muskelzellen den geringsten Prozentsatz (bei Betrachtung der absoluten Werte) an degenerierten Muskelfasern aufwies. Der Genotyp Super Mini zeigte die meisten Zellschädigungen. Damit ist die Aussage von DRANSFIELD und SOSNICKI (1999) widerlegt, nach welcher schnell wachsende männliche Hühner eine höhere Anzahl an Riesenfasern aufweisen, als die langsamer wachsenden Vergleichstiere. Da es sich bei Puten auch im weiteren Sinne um Hühnervögel handelt, müsste dieses Ergebnis auch unter Vorbehalt auf Puten übertragbar sein. Auch WILSON et al. (1990) beschrieben bei schnellwüchsigen Puten, zu denen die Herkunft BIG 6 gezählt werden darf, mehr Muskelschädigungen, als bei langsam wachsenden Vergleichstieren. Auch dieses Ergebnis kann durch die eigenen Untersuchungen nicht bestätigt werden.

Der weitaus größte Anteil an degenerierten Muskelfasern bestand bei allen Genotypen aus Riesenfasern.

Das Kapillar/Zell - Verhältnis war bei den Probanden der Herkunft BIG 6 am größten, bei den Super Mini - Hähnen signifikant am geringsten. Der Genotyp Wrolstad zeigte Werte zwischen den beiden erstgenannten Linien. Dieser Umstand deutet darauf hin, dass eine Beziehung zwischen Zellgröße und der Kapillarisierung des Gewebes besteht. Die Linie BIG 6 hat im Alter von 12 Wochen die größten Muskelzellen und die meisten Kapillaren. Die Linie Super Mini hat die kleinsten Muskelzellen und die geringste kapillare Versorgung. Die Linie Wrolstad lag sowohl bei der Kapillarisierung, wie auch hinsichtlich der Zellgröße zwischen den beiden erstgenannten Genotypen. Bestätigt wird dieses Ergebnis durch die vergleichsweise enge Korrelation mit einem Koeffizienten von 0,92 zwischen dem Parameter Kapillar/Zellverhältnis und der Zellquerschnittsfläche.

\subsubsection{Altersstufe 22 Wochen}

\section{Gewichtsparameter}

Im Alter von 22 Wochen zeigte sich deutlich, dass es sich bei dem Genotyp BIG 6 um eine Hochleistungspute handelt. Bei allen Gewichtsparametern konnten bei den BIG 6 - Hähnen fast doppelt so hohe Werte nachgewiesen werden, als bei den beiden anderen Genotypen. Es ist bemerkenswert, dass trotz des sensiblen statistischen Fischer - LSD - Tests kein signifikanter unterschied zwischen den Genotypen Wrolstad und Super Mini abgesichert werden konnte. 
Die absoluten Durchschnittswerte bei den Gewichtsparametern waren zwar bei der Linie Wrolstad tendenziell höher, jedoch nicht in dem Unfang und auch nicht signifikant, wie es zwischen den Genotypen zu erwarten gewesen wäre (Siehe Tab. 33).

Der prozentuale Brustmuskelanteil ist bei den Probanden der Herkunft Big 6 am geringsten, bei den Probanden der Herkunft Super Mini am größten. Es scheint eine negative Wechselbeziehung zwischen dem Schlachtkörpergewicht und dem Brustmuskelanteil zu geben, welche mit einem Korrelationskoeffizienten in Höhe von $-0,71$ signifikant abgesichert werden konnte.

\section{Trockenmasse und Muskelinhaltstoffe}

Die Linie BIG 6 wies im Alter von 22 Wochen die geringsten Trockenmassegehalte des M.pect.superfic. auf, die Linie Super Mini die höchste. Eine mögliche Erklärung liefert die histologische Betrachtung des Brustmuskels. Die Probanden der Herkunft BIG 6 zeigten die größten Muskelzellen, die Super Mini Puten die kleinsten. Je größer die Muskelzellen sind, desto mehr verschiebt sich das Verhältnis zwischen Membranbestandteilen und Zelllumen zugunsten des Zellinneren. Je größer also die Zellen sind, desto mehr Zellflüssigkeit und weniger Membranbestandteile liegen im Gewebe vor. Mit diesem Umstand lässt sich neben den Trockenmasseverhältnissen auch die geringen Rohproteingehalte des Genotyps BIG 6 erklären, denn die Zellmembranen bestehen zu einem wesentlichen Teil aus Proteinen. Es konnte zudem zwischen den Parametern Trockenmassegehalt und Rohproteingehalt eine signifikante Korrelation mit einem Koeffizienten von 0,68 abgesichert werden. Im Wesentlichen decken sich die gefundenen Rohproteingehalte im M.pect.superfic. der drei Herkünfte $(25,1 \%$ - 25,9 \%) mit den von FERNANDEZ et al. (2001) angegebenen Rohproteingehalten, welche mit 24,8 \% - 26,9 \% beziffert wurden.

Der höhere Fettgehalt der Probanden der Herkunft BIG $6(1,07 \%)$ ist auf den Umstand zurück zu führen, dass sie im Vergleich zu den beiden anderen Herkünften einen schnelleren Wachstumsverlauf zeigten. Je weiter das Wachstum fortschreitet, desto mehr setzt eine Verfettung der Tiere ein. Zudem korrelierte sowohl der

Parameter Schlachtkörpergewicht $(0,74)$, als auch der Parameter Zellquerschnittsfläche $(0,79)$ eng mit dem Rohfettgehalt. Da aber alle drei Herkünfte hinsichtlich inrer Rohfettgehalte $(0,91 \%$ - 1,07 \%) deutlich unter den Angaben aus der Literatur lagen (FERNANDEZ et al. (2002) bezifferten die Fettgehalte im M. pect. superfic. von Puten mit 1,51\%), mag man an dieser Stelle kaum von Verfettung sprechen.

pH, LF, L*, $\mathbf{a}^{*}, \mathbf{b}^{*}$

20 min p.m. zeigten die Probanden der Herkunft BIG 6 um 0,12 pH - Einheiten signifikant geringere $\mathrm{pH}$ - Werte, als die Super Mini - Hähne. Sofern man davon ausgehen kann, dass zum Zeitpunkt des Tötens im Brustgewebe ein $\mathrm{pH}$ - Wert um 7,0 vorgelegen hat, ist den BIG 6 - Hähnen ein schnellerer anaerober Stoffwechsel als den Vergleichsgenotypen zu unterstellen.

4 Stunden p.m. jedoch waren die Verhältnisse sowohl der $\mathrm{pH}$ - Werte, als auch der $\mathrm{pH}$ - Wertdifferenzen gänzlich anders. Die BIG 6 - Puten zeigten 4 h p.m. den höchsten $\mathrm{pH}$ - Wert und die geringste $\mathrm{pH}$ - Wertdifferenz zum $\mathrm{pH}$ - Wert 20 min p.m.. Genau umgekehrte Verhältnisse liegen bei der Linie Super Mini vor, niedrigste $\mathrm{pH}$ - Werte 4 h p.m., höchste $\mathrm{pH}$ - Wertdifferenz $\mathrm{zu}$ den $\mathrm{pH}$ - Werten, gemessen 20 
min p.m.. Die Linie Wrolstad lag mit ihren Werten zwischen den beiden erstgenannten Linien, unterschied sich jedoch ebenfalls signifikant von diesen.

Warum nun die BIG 6 - Puten 20 min. p.m. die geringsten, 4 h p.m. dagegen die höchsten $\mathrm{pH}$ - Werte im Vergleich zu den zwei Herkünften des Züchters Kelly zeigten, lässt sich mit diesem Versuchsaufbau nicht klären. Es bestehen aber zwischen den Herkünften offenkundig Unterschiede im postmortalen Stoffwechsel.

MC KEE et al. (1998) konnten 4 h p.m. an 44 Putern der Linie Nicholas einen mittleren $\mathrm{pH}-$ Wert von 5,94 bestimmen. Zumindest lässt sich festhalten, dass sich die Herkünfte BIG 6 ( $\mathrm{pH} \mathrm{5,95)} \mathrm{und} \mathrm{Wrolstad}(\mathrm{pH} \mathrm{5,83)} \mathrm{hinsichtlich} \mathrm{ihrer} 4$ h p.m. gemessenen $\mathrm{pH}$ - Werte (Mittelwerte) mit diesen Aussagen decken. Warum die Herkunft Super Mini mit einem pH - Wert von 5,64 4 h p.m. so weit unterhalb der Vergleichsherkünfte liegt, lässt sich aus dem Versuch nicht ableiten.

Die Leitfähigkeitswerte 20 min p.m. waren bei allen drei Genotypen vergleichbar. $4 \mathrm{~h}$ p.m. jedoch zeigten sich beim Genotyp Super Mini die höchsten Leitfähigkeitswerte, bei den BIG 6 - Hähnen dagegen die geringsten. Allein durch den Verweis auf die Anzahl an degenerierten Muskelfasern lässt sich dieses Ergebnis nur für die BIG 6 Hähne erklären, welche sowohl die geringste Anzahl an degenerierten Muskelfasern, als auch die geringsten Leitfähigkeitswerte 4 h p.m. zeigten. Die Linie Wrolstad zeigt zwar die größte Anzahl an degenerierten Muskelfasern, jedoch nicht die höchsten Leitfähigkeitswerte, diese fanden sich nämlich bei der Linie Super Mini, welche allerdings mit der Anzahl der geschädigten Muskelzellen nur an zweiter Stelle lagen. Eine mögliche Erklärung liefert die Betrachtung des $\mathrm{pH}-$ Wertes $4 \mathrm{~h}$ p.m. Dieser war nämlich, wie bereits erwähnt, bei den BIG 6 - Puten am höchsten, bei den Probanden der Herkunft Super Mini dagegen am geringsten. Ein niedriger intramuskulärer $\mathrm{pH}$ - Wert, also eine höhere Säurekonzentration, vermag leichter die Zellmembranen zu schädigen, als ein hoher $\mathrm{pH}$ - Wert; ein Zusammenhang, der schon von HAHN et al. $(2001 a, b)$ eingehend beschrieben wurde. Zudem ist durch einen Korrelationskoeffizienten von $-0,43$ eine Beziehung zwischen den Leitfähigkeitswerten 4 h p.m. und den $\mathrm{pH}$ - Werten 4 h p.m. belegt.

Die $L^{*}$ - Werte konnten bei den BIG 6 - Puten am geringsten $\left(L^{*} 42,2\right)$, bei den Super Mini - Puten am höchsten $\left(L^{*} 43,3\right)$ nachgewiesen werden. Der in der Literatur beschriebene Zusammenhang zwischen den $L^{*}$ - Werten und den zu verschiedenen Zeitpunkten gemessenen $\mathrm{pH}$ - Werten konnte bei den vorliegenden Ergebnissen dieses Versuchsabschnitts bestätigt werden. Die Super Mini - Hähne zeigten $4 \mathrm{~h}$ p.m. die niedrigsten $\mathrm{pH}$ - Werte und die größte $\mathrm{pH}$ - Wertdifferenz, verglichen mit den beiden Vergleichsgenotypen und zudem die höchsten $L^{*}$ - Werte, also das hellste Fleisch. Bei den Probanden der Herkunft BIG 6 waren die Verhältnisse genau umgekehrt. 4 h p.m. zeigte diese Linie die höchsten $\mathrm{pH}-$ Werte, die geringste $\mathrm{pH}-$ Wertdifferenz und auch die niedrigsten $L^{*}$ - Werte, also das dunkelste Fleisch der Versuchsgruppe. Diese Ergebnisse deuten darauf hin, dass der von LAAK et al. (2000) und FLETCHER (2002) sowie von HAHN (2001b) beschriebene Zusammenhang zwischen den $\mathrm{pH}$ - Wertverhältnissen und den $L^{*}$ - Werten tatsächlich besteht.

Die ermittelten Werte aller drei Genotypen zeigten ein relativ dunkles Fleisch, denn in der Literatur wird für normales Putenbrustfleisch ein $L^{*}$ - Wert von ca. 50 angegeben. Sowohl BARBUT et al. (2005) als auch PETRACCl et al. (2004) definierten Putenfleisch mit $L^{*}$ - Werten unter 44,8 bzw. $50 L^{*}$ als dunkel (Voraussetzung für DFD - Fleisch). Die untersuchten Genotypen zeigten in dieser Altersstufe $L^{*}$ - Werte zwischen 42,2 und 43,3, also deutlich unter den in der Literatur angegebenen Werte für dunkles Putenbrustfleisch. 
Hinsichtlich der $a^{*}$ und $b^{*}$ - Werte konnte kein signifikanter Unterschied abgesichert werden. Auch bei der Betrachtung der absoluten Werte zeigten sich nur sehr geringe Unterschiede.

\section{Physikalische Parameter}

Der Tropfsaftverlust war bei den BIG 6 - Hähnen um etwa $1 \%$ signifikant geringer, als bei den beiden anderen Genotypen dieser Vergleichsgruppe. Mit diesem Ergebnis wird die Aussage von FERNANDEZ et al. (2002) bestätigt, welcher bei schnell wachsenden Putengenotypen einen geringeren Tropfsaftverlust feststellte, als bei langsam wachsenden Vergleichsgenotypen.

Nicht bestätigt werden konnte dagegen der von FERNANDEZ et al. (2002) und MOLETTE et al. (2003a) beschriebene Zusammenhang zwischen dem Tropfsaftverlust und dem frühpostmortalen $\mathrm{pH}$ - Wert. Beide Autoren formulierten, dass ein frühpostmortal niedriger $\mathrm{pH}$ - Wert hohe Tropfsaftverluste bedingt und umgekehrt. In der vorliegenden Untersuchung konnte aber keine signifikante Korrelation zwischen den $\mathrm{pH}$ - Werten (früh- wie spätpostmortal) und dem Tropfsaftverlust abgesichert werden Die vorliegenden Ergebnisse zeigen zudem, dass die BIG 6 - Hähne den geringsten postmortalen $\mathrm{pH}$ - Wert, aber auch den geringsten Tropfsaftverlust vorzuweisen hatten. Ist die postmortale $\mathrm{pH}-$ Wertdifferenz sehr groß und der $\mathrm{pH}$ - Wert 4 h. p.m. vergleichsweise gering, ist aufgrund der gesteigerten Säurekonzentration eine Zellschädigung wahrscheinlich. Es ist nachvollziehbar, dass aus beschädigten Muskelzellen mehr Flüssigkeit austreten kann, als aus intakten Zellen. Die Unterschiede hinsichtlich des Grillverlustes waren zwischen den Herkünften nicht signifikant abzusichern.

Sowohl die Scherkraft- als auch die Scherarbeitswerte waren bei den BIG 6 Hähnen am höchsten, bei der Linie Wrolstad dagegen am geringsten. Der Unterschied war zwar nicht signifikant abzusichern, jedoch tendenziell erkennbar. Mit histologischen Parametern lassen sich diese Ergebnisse nicht erklären, da die Linie Super Mini die kleinsten Muskelfasern, aber nicht die geringsten Scherkraft- bzw. Scherarbeitswerte zeigte. Es ist vielmehr zu vermuten, dass die Linie BIG $6 \mathrm{im}$ Wachstum schon weiter fortgeschritten ist, als die Vergleichsgenotypen, die Linie Wrolstad dagegen einen relativ langsamen Wachstumsverlauf zeigt. Wie bereits beschrieben (SIELAFF 1996) findet mit zunehmendem Alter der Tiere eine intensive Quervernetzung der Strukturproteine statt. Dieser Umstand scheint auch in diesem Fall ausschlaggebend für die gefundenen Werte zu sein.

\section{Blutparameter}

Die Zahl der Blutpunkte war bei der Linie BIG 6 signifikant am höchsten, zwischen den beiden anderen Genotypen gab es jedoch keinerlei signifikante Auffälligkeiten.

Des Weiteren wiesen die Probanden der Herkunft BIG 6 eine höhere Anzahl an Kapillaren pro Zelle auf, was den Schluss zulässt, dass mehr Kapillaren geschädigt sind, weil auch mehr Kapillaren vorhanden sind und deshalb auch die Wahrscheinlichkeit einer Schädigung deutlich höher ist. Hinsichtlich des Parameters „Blutpunkte pro kg M.pect.superfic.“ konnte dagegen kein Unterschied zwischen den Herkünften abgesichert werden.

Der CK - Wert war bei den BIG 6 - Puten signifikant am höchsten, bei den Super Mini - Hähnen am geringsten. Betrachtet man die Unterschiede hinsichtlich der CK Aktivität unter Berücksichtigung der Schlachtkörper- und Brustmuskelgewichte, so ist ein Zusammenhang zwischen den Gewichtsparametern und den CK - Werten 
offenkundig. Die signifikante Korrelation zwischen den beiden Parametern wurde bereits an anderer Stelle diskutiert. Es darf unterstellt werden, dass der mögliche Marker für Zellschädigungen von dem Einfluss des Körpergewichts auf die CK Werte überdeckt wird. Somit eignet sich die CK - Aktivität im Stichblut nur als Marker für Zellschädigungen, sofern die miteinander verglichenen Genotypen dasselbe Körpergewicht und Alter aufweisen. Es ist auch möglich, dass sich im M.pect.superfic. der BIG 6 - Puten tatsächlich mehr Zellschädigungen als bei den Vergleichsherkünften finden lassen, welche aber histologisch nicht nachweisbar waren.

Der Laktatgehalt im Stichblut war bei den Probanden der Herkunft BIG 6 am geringsten, bei der Linie Wrolstad am höchsten. Da ein hoher Laktatgehalt im Stichblut als Anzeichen für prämortal hohe Stoffwechselaktivität bei Sauerstoffunterversorgung anzusehen ist, kann den Genotypen Super Mini und Wrolstad eine gewisse Stresslabilität unterstellt werden. Es besteht auch die Möglichkeit, dass die der Linie BIG 6 zur Verfügung stehende Energiegewinnungsgrundlage - sei es aus der Nahrung oder aus Glycogenreserven - bereits verbraucht ist und deshalb nur wenig Laktat gebildet werden kann. Beide Theorien lassen sich mit diesem Versuchsaufbau aber weder bestätigen, noch dementieren.

\section{Histologische Parameter}

Die BIG 6 - Hähne zeigten hinsichtlich aller histologischen Parameter, welche die Größe betreffen, die signifikant höchsten Ergebnisse. Dies ist aufgrund der Schlachtkörper und Brustmuskelgewichte auch zu erwarten gewesen. Die größenabhängigen Zellparameter unterschieden sich zwischen den Genotypen Wrolstad und Super Mini signifikant. Keinen signifikanten Unterschied, wohl aber einen hinsichtlich der absoluten Werte, konnte man dagegen hinsichtlich der Gewichtsparameter absichern. So zeigten die Wrolstad - Hähne leicht höhere Gewichtsparameter, als die Linie Super Mini. So lassen sich auch die größeren Muskelfasern der Linie Wrolstad erklären. Dieser Größenunterschied zwischen den beiden Linien konnte bei den Parametern der durchschnittlichen Zelldurchmesser und dem minimalen Durchmesser nicht nachgewiesen werden. Dies zeigt zum einen, dass die Parameter Zellquerschnittsfläche, maximaler Zelldurchmesser und Zellumfang sensibler Unterschiede aufzeigen, als die Parameter Durchschnittlicher Zelldurchmesser und minimaler Durchmesser. Zum anderen belegt es die Tatsache, dass sich die beiden Genotypen Super Mini und Wrolstad sowohl hinsichtlich der Gewichtsparameter, als auch auf mikroskopischer Ebene derart gering voneinander unterscheiden, dass eine Trennung der beiden Linien kaum gerechtfertigt erscheint.

Der Anteil an degenerierten Muskelfasern ist bei den BIG 6 - Puten signifikant geringer, als bei den beiden anderen Genotypen, welche sich nicht signifikant voneinander unterschieden. Letztere wiesen ausschließlich Riesenfasern als Zelldegenrationen auf, die Probanden der Herkunft BIG 6 hingegen zeigten zu einem gewissen Prozentsatz neben den Riesenfasern auch anguläre Muskelfasern. Diese Ergebnisse deuten darauf hin, dass während der letzten Lebenstage oder Wochen bei den BIG 6 - Hähnen Zellschädigungen aufgetreten sind, denn die angulären Fasern gelten als Fragmente degenerierter Zellen. Nach dem Tod jedoch zeigt die Linie BIG 6 erheblich weniger Riesenfasern als die Vergleichsgenotypen, was die Ergebnisse von DRANSFIELD und SOSNICKI (1999) in Frage stellt, welche schnell wachsenden Genotypen eine höhere Anzahl an Riesenfasern unterstellen. 
Es sollte also eher der Argumentation von REMIGNON et al. (2000) Aufmerksamkeit geschenkt werden, welcher das Auftreten von Riesenfasern mit mitochondrialen Defekten oder wenig aktivem, sarkoplasmatischen Retikulum begründete. Diese Ursachen können dementsprechend den Genotypen Super Mini und Wrolstad unterstellt werden.

Das günstigste Kapillar-/ Zellverhältnis wies die Linie BIG 6 auf, das ungünstigste dagegen die Linie Wrolstad. Die Probanden der Herkunft BIG 6 wiesen den größten Zelldurchmesser auf, was nahe legt, dass diese großen Zellen auch eine umfangreichere kapillare Versorgung benötigen. Die Tatsache, dass die Linie Wrolstad trotz größerer Zelldurchmesser im Vergleich zur Linie Super Mini das geringere Kapillar-/ Zellverhältnis zeigte, belegt die züchterische Einflussnahme auf diesen Parameter.

\subsection{PSE - Inzidenz der untersuchten Probanden}

In der Literatur wird das Thema PSE im Putenbrustfleisch zwar intensiv behandelt, die Rahmenbedingungen für PSE - Fleisch bei Puten wurden aber für die Brustmuskulatur entweder gar nicht konkretisiert oder anhand subjektiver Beurteilungen innerhalb einer Versuchsgruppe festgelegt, so das eine direkte Übertragbarkeit auf konventionell produziertes Putenbrustfleisch im Allgemeinen, wie für die vorliegende Untersuchung im Besonderen unzulässig erscheint.

Lediglich BARBUT (1997b) benennt für Fleisch mit PSE - Charakter einen L* - Wert von $\geq 52$. Anhand dieses Parameters konnte er in 7 verschiedenen Betrieben eine PSE - Häufigkeit zwischen $5 \%$ und $40 \%$ aufzeigen. Übertragen auf die vorliegende Untersuchung würde das bedeuten, dass keine Mm.pect.superfic. mit PSE Charakter vorlagen (Abb.21), denn der maximale $L^{*}$ - Wert aus der Gesamtheit aller Tiere lag bei 50,27 .

Dies war auch das einzige Tier, welches einen $L^{*}$ - Wert über 50 zeigte. BARBUT (1997b) zeigte zudem Korrelationen zwischen dem $L^{*}$ - Wert und dem End - $\mathrm{pH}-$ Wert $(-0,59)$ und dem Wasserbindungsvermögen $(-0,60)$ auf. Diese Angaben konnten durch die vorliegenden Untersuchungen entweder gar nicht oder nur in geringem Umfang bestätigt werden, denn zum End - $\mathrm{pH}$ - Wert konnte nur ein geringer Korrelationskoeffizient in Höhe von $-0,19$ und zum Tropfsaftverlust ein positiver Korrelationskoeffizient von 0,18 nachgewiesen werden. 


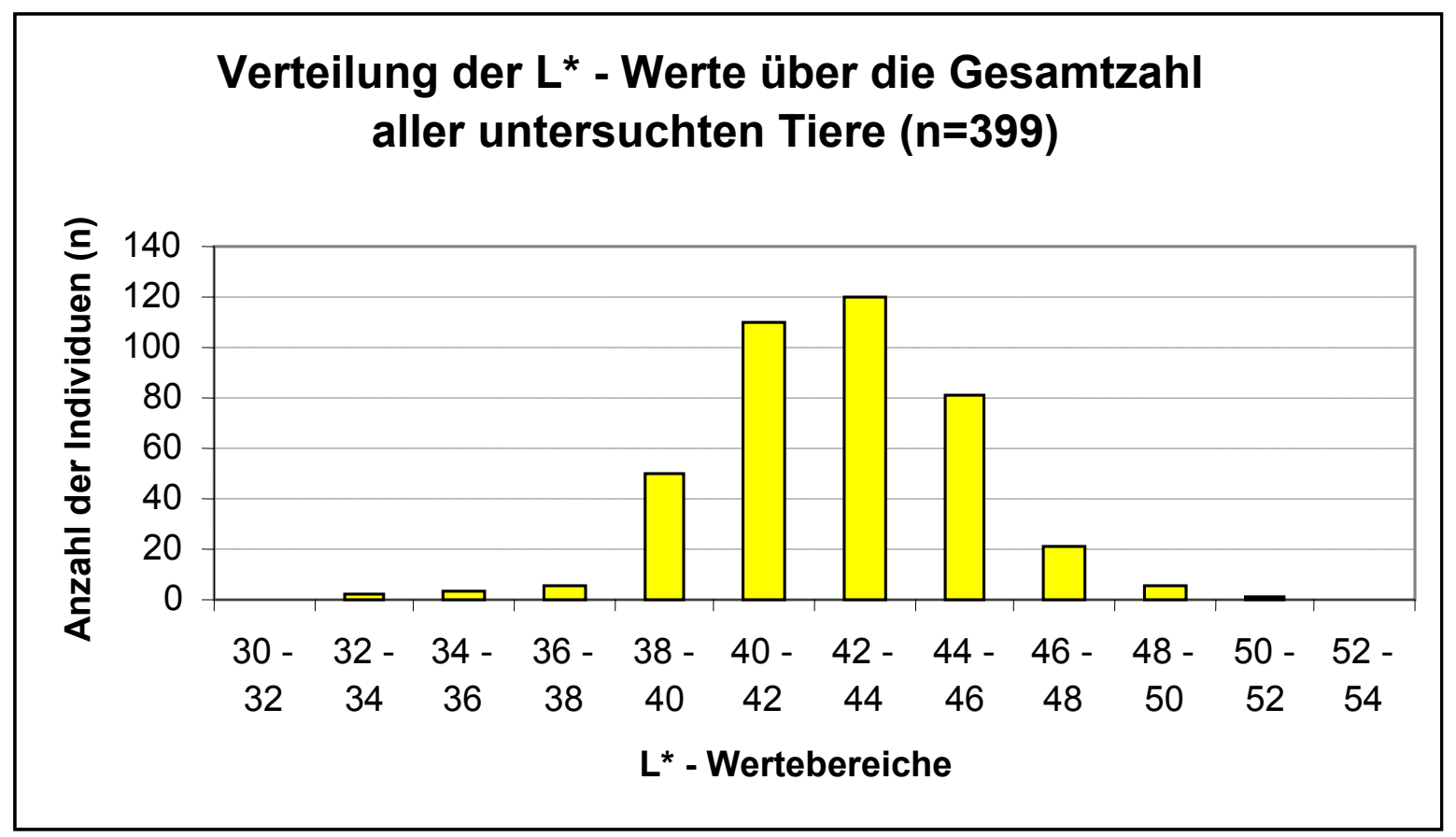

Abb. 21: Verteilung der $L^{*}$ - Werte der Gesamtheit aller untersuchten Mm. pect. superfic. von Puten ( $n=399)$

MOLETTE et al. (2005) beschrieben den pH - Wert 20 min. p.m. als geeigneten Parameter für die Identifikation von PSE - Fleisch. Genaue Grenzwerte wurden von den Autoren ebenfalls nicht genannt. Vielmehr unterteilten die Autoren die zu untersuchenden Puten anhand ihrer Werteverteilung in zwei Gruppen (schnell und langsam glycolysierend), anhand derer ein Zusammenhang zu schneller Glycolyse hergestellt wurde. Dies bedeutet aber nicht zwangsläufig, dass die Puten aus der schnell glycolysierenden Gruppe hinsichtlich der Brustfleischqualität auch PSE Ausprägungen zeigten. Würde an dieser Stelle auf die von ZHANG und BARBUT (2005) für Hühnerbrüste festgelegten frühpostmortalen $\mathrm{pH}$ - Werte zur Identifikation von PSE - Fleisch zurückgegriffen, würden alle $\mathrm{Mm}$.pect.superfic. mit einem $\mathrm{pH}-$ Wert 20 min. p.m. unter 5,7 als PSE - verdächtig eingestuft werden. In der vorliegenden Untersuchung beträfe dies lediglich drei Tiere (Abb. 22). Der direkte Vergleich von Hühnerbrustfleisch und Putenbrustfleisch ist zwar nicht zulässig, erlaubt aber zumindest eine grobe Einschätzung der vorliegenden Werte, da es sich hinsichtlich Anatomie und Physiologie um vergleichbare Muskulatur handelt und die Pute zudem zu den Hühnervögeln gehört.

Auch wenn aufgrund der vorhandenen Literaturnachweise keine genaue Aussage zur PSE - Häufigkeit bei den untersuchten Tieren getroffen werden kann, so lässt sich doch sagen, dass PSE bei den untersuchten Mm.pect.superfic. eine untergeordnete Rolle spielte. 


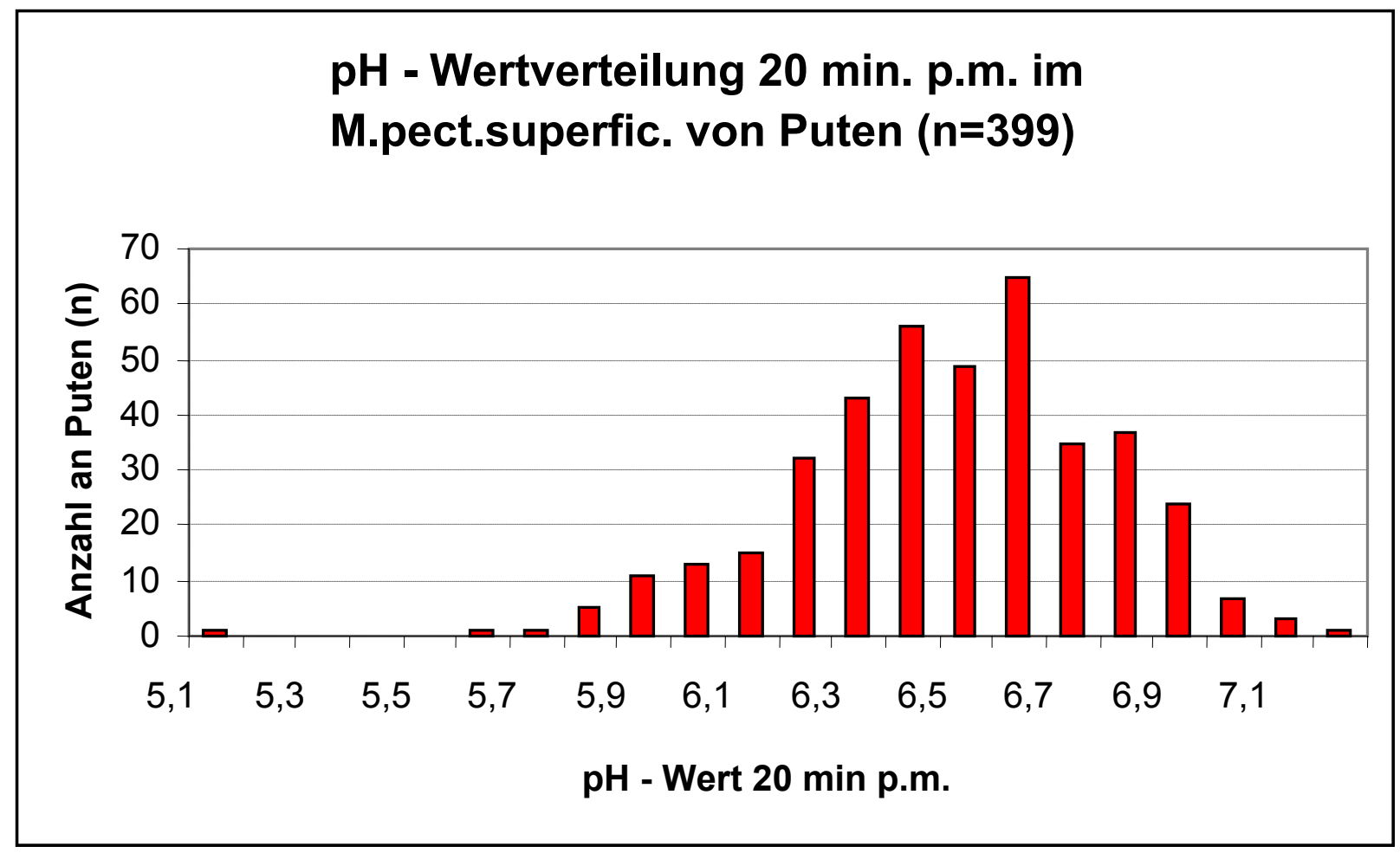

Abb. 22: pH - Wertverteilung 20 min. p.m. im M. pect. superfic. von Puten ( $n=399)$

\subsection{Fehlerbetrachtung}

Der Durchführung des Versuchs wurden Standard-Mastverfahren zu Grunde gelegt. Die Hochleistungsgenotypen BIG 6 (B.U.T.) und BBB (Kelly) sind hinsichtlich ihrer Haltungsanforderungen entsprechend züchterisch bearbeitet worden. Dies war bei den Linien Wrolstad und Super Mini nicht der Fall. Da aber die in Deutschland üblichen Mastverfahren hinsichtlich Haltung, Ernährung und Hygiene den Ansprüchen einer Pute sehr entgegenkommen dürfte der Einfluss der Haltungsbedingungen, welche bei allen Versuchsdurchführungen gleich waren, nicht ins Gewicht fallen.

Hinsichtlich der Versuchsdurchführung ist statt der Ermittlung des Grillverlustes bei zukünftigen Projekten der Parameter "Kochverlust“ aus zwei Gründen vorzuziehen. Zum einen kommt es bei der Grillverlustermittlung trotz Messung der Kerntemperatur des Probenstücks immer wieder zu Bereichen im Testgewebe, welche nicht vollständig durchgegart wurden. Zum anderen kommt es bei der Bearbeitung des Probenstücks mit dem Kontaktplattengrill zu Veränderungen der Probenoberfläche, welche kaum gleichmäßigen Denaturierungsvorgängen entsprechen und deshalb keine präzisen Aussagen zur Grillverlustbestimmung zulassen. Die KochsaftverlustErmittlung ist dagegen homogener und würde genauere Ergebnisse ermöglichen.

Bei der Bestimmung der Anzahl an Blutpunkten im Muskelgewebe gibt es verschiedene Herangehensweisen bei der Wahl der Schnittführung bzw. der ausgewählten Flächen, welche zum Auszählen von Blutpunkten herangezogen werden. Alle bekannten Modelle sind für diese Schätzung geeignet, sofern sie eine genügend große Anzahl an Schnittflächen berücksichtigen. Eine Orientierung an den großen Blutgefäßen des Brustmuskels, welche die Blutversorgung gewährleisten, ist nicht notwendig, da die Blutpunkte eine Folge von Kapillarschädigungen darstellen. Die Kapillaren sind weitgehend gleichmäßig im Gewebe verteilt, weshalb die 
Messpunkte (außerhalb der Randbereiche des Muskels) willkürlich gewählt werden können. Da die Kapillaren in der Regel parallel zur Faserrichtung verlaufen, versteht es sich, dass die Schnittführung quer zum Faserverlauf zu erfolgen hat.

In der Literatur wird die Aktivität der Creatinkinase im Stichblut häufig als Marker für Zellschädigungen bzw. Degenerationen beschrieben. Die vorliegenden Untersuchungen belegen, dass die CK - Aktivität extrem abhängig vom Gewicht der Versuchstiere ist. Deshalb ist dieser Parameter zum Vergleich von Genotypen mit unterschiedlichem Mastendgewicht nicht geeignet, um Zellschädigungen sicher zu bestätigen.

Die Gewichtsparameter, welche über eine Videobildauswertung ermittelt wurden, beinhalten zwar eine leichte Varianz zum realen Gewicht der Schlachtkörper bzw. der Teilstücke, der mögliche Fehler ist jedoch sehr gering, da sich die ermittelten Korrelationen immer in der gleichen Größenordnung zu denen bewegten, welche bei den durch Wiegung ermittelten Gewichtsparameter gefunden wurden. 


\section{Zusammenfassung und Schlussfolgerung}

In der Literatur sowie auf einschlägigen Fachtagungen häufen sich Berichte über Fleischqualitätsmängel bei Mastputen. Als Gründe dafür werden einseitige Selektion auf hohe Schlachtkörpergewichte, auf bessere Futterverwertung sowie auf einen höheren Ausschlachtungsgrad genannt. Neben den Fleischqualitätsmängeln treten ferner Myopathien und plötzlicher Transporttod auf. Diese Probleme sind bei Broiler und Pute unter dem Begriff "Aviäres Stress Syndrom“ zusammengefasst. Auch mindert das Auftreten von Blutpunkten im Putenbrustfleisch die Verbraucherakzeptanz erheblich. In der vorliegenden Abhandlung wurde untersucht, ob es Putenherkünfte gibt, auf welche gegebenenfalls zurückgegriffen werden kann, um Fleischqualitätsmängel bei Mastputen zu vermeiden.

Dazu wurde die in Deutschland am häufigsten verwendete Putenherkunft BIG 6 des Züchters B.U.T. im ersten Versuchsdurchgang mit einer gleichfalls schweren Linie BBB des Züchters Kelly und im zweiten Durchgang mit der mittelschweren Linie Wrolstad und mit der leichten Linie Super Mini, beide ebenfalls Produkte des Züchters Kelly, verglichen. Die Tiere wurden analog zu den in Deutschland üblichen Mastverfahren gehalten und gefüttert. Im Alter von 12 und von 22 Wochen wurde jeweils die Hälfte der Puten pro Herkunft und Durchgang in einem konventionellen Schlachthof geschlachtet. Am Schlachthof erfolgte die Bestimmung der $\mathrm{pH}$ - und Leitfähigkeitswerte 20 min. p.m. sowie der Schlachtkörper und Teilstückgewichte über Videobildbestimmung.

4 h p.m. wurden im Labor des Forschungs- und Studienzentrums für Veredelungswirtschaft Weser/Ems pH - und Leitfähigkeitswerte, Helligkeits- - und Farbwerte, weitere Gewichtsparameter sowie die Anzahlen an Blutpunkten ermittelt. Ferner wurden Probenstücke für die spätere Tropfsaft- und Grillverlustermittlung, für die Bestimmung der Rohnährstoffgehalte, für die Bestimmung für Scherwerte sowie für die histologische Weiterverarbeitung entnommen.

Die Ergebnisse der Untersuchungen lassen sich wie folgt zusammenfassen:

\section{Altersgruppenvergleich}

- Die Schlachtkörpergewichte der 22 Wochen alten Puten waren höher, der prozentuale Brustmuskelanteil dagegen geringer als bei den 12 Wochen alten Tieren.

- Die ältere Tiergruppe zeigte geringere Rohproteingehalte (\%) und höhere Rohfettgehalte im M. pectoralis superficialis, als die jüngere Gruppe.

- Die älteren Tiere zeigten höhere Werte bei den Parametern pH - Wert Differenz und Leitfähigkeit 4 h p.m., verglichen mit der

12 Wochen alten Versuchsgruppe.

- Die 22 Wochen alten Tiere zeigten zwar geringere Scherkraftwerte, dafür aber mehr Blutpunkte im M. pect. superfic. als die 12 Wochen alte Vergleichsgruppe.

- Die 22 Wochen alten Puten zeigten hinsichtlich der Helligkeits- und Farbwerte L* und $a^{*}$ höhere Werte, als die 12 Wochen alten Tiere.

- Die Querschnittsfläche der Muskelfasern des M. pect. superfic. war bei den älteren Tieren größer als bei den jüngeren.

- Der Anteil an degenerierten Muskelfasern zeigte zwischen den Altersstufen keinen signifikanten Unterschied. 


\section{Durchgang I}

- In beiden Altersstufen zeigten die Puten der Herkunft BIG 6 sowohl höhere Schlachtkörpergewichte, als auch Brustmuskelanteile als Kelly's BBB.

- Im schlachtrelevanten Alter von 22 Wochen zeigten die BBB-Puten die höchsten pH-Wertdifferenzen und Leitfähigkeitswerte (4h p.m.) im M. pect. superfic..

- Der M. pect. superfic. der 22 Wochen alten BBB - Puten war heller und weniger rot, als bei den BIG 6 - Puten.

- Die Probanden der Herkunft BIG 6 zeigten höhere Scherkraftwerte als die BBB Puten.

- Trotz vergleichbarem Zelldurchmesser zeigte der M. pect. superfic. der BBB Puten mehr degenerierte Muskelfasern als die BIG 6 - Puten.

\section{Durchgang II}

- In beiden Altersstufen zeigten die BIG 6 Puten die höchsten Schlachtkörpergewichte. Die Linien Wrolstad und Super Mini unterschieden sich dabei nicht signifikant.

- Der Brustmuskelanteil unterschied sich zwischen den Linien Wrolstad und Super Mini nicht signifikant, die Linie BIG 6 zeigte in beiden Altersstufen geringere Brustmuskelanteile.

- Im schlachtrelevanten Alter von 22 Wochen zeigten die Puten des Züchters Kelly die höchsten $\mathrm{pH}-$ Wertdifferenzen und Leitfähigkeitswerte (4h p.m.) im M. pect. superfic..

- Der M. pect. superfic. der 22 Wochen alten Probanden der Herkunft BIG 6 war dunkler als das der Linien Wrolstad und Super Mini, hinsichtlich der Rotfärbung war kein signifikanter Unterschied absicherbar.

- Im alter von 22 Wochen zeigten die BIG 6 - Puten fast doppelt so viele Blutpunkte, wie die Linien Wrolstad und Super Mini.

- Obwohl die Probanden der Herkunft BIG 6 die größten Muskelfaserdurchmesser im M. pect. superfic. zeigten, wiesen sie weniger degenerierte Muskelfasern auf, als die Linien Wrolstad und Super Mini.

Anhand der vorliegenden Untersuchung soll die Frage beantwortet werden, ob es zu der häufig in Deutschland verwendeten Mastpute BIG 6 des Züchters B.U.T. Alternativen gibt, auf welche zurückgegriffen werden kann, um Schlachtkörper- und Fleischbeschaffenheitsmerkmale zu verbessern. Problematisch ist eine positive oder negative Beurteilung bei Parametern, welche subjektiven Eindrücken unterliegen. So kann zwar exakt bestimmt werden, dass die Herkunft BIG 6 im Alter von 22 Wochen ein signifikant dunkleres Brustfleisch zeigte, als die Vergleichsherkunft BBB des Züchters Kelly, offen bleibt, ob dieser Unterschied hinsichtlich des Verbraucherverhaltens positiv oder negativ zu bewerten ist. Zu diesen nur subjektiv beurteilbaren Parametern gehören die Helligkeits- und Farbwerte sowie die Muskelinhaltstoffe. Da bei nahezu allen anderen Parametern im schlachtrelevanten Alter von 22 Wochen die Herkunft BIG 6 von B.U.T. entweder überlegen oder doch zumindest gleichwertig im Vergleich zu den Herkünften BBB, Wrolstad und Super Mini des Züchters Kelly war, stellen letztere im Hinblick auf eine Verbesserung der Schlachtkörper- und Fleischqualität keine nennenswerte Alternative dar. Zwar konnten die BBB - Puten geringere Scherkräfte aufweisen, was eine höhere Zartheit gegenüber den BIG 6 - Puten bedeutet, jedoch gilt die Zähigkeit von Brustfleisch bei Puten zur Zeit nicht zu den Problembereichen hinsichtlich der Fleischqualität. Die 
Zahl der Blutpunkte im M.pect.superfic. war bei den Probanden der Herkunft BIG 6 höher als bei den Vergleichsherkünften. Da sich dieser nachteilige Umstand aber dadurch relativieren lässt, in dem man die Zahl der Blutpunkte auf das Gewicht des M.pect.superfic. bezieht, ist auch bei diesem Parameter kein Vorteil der Vergleichsherkünfte gegenüber B.U.T.'s BIG 6 erkennbar.

Die vorliegende Untersuchung zeigt eine Vielzahl von Parametern auf, welche sich gegenseitig beeinflussen. So konnte u.a. festgestellt werden, dass mit zunehmendem Gewicht (Schlachtkörpergewicht, Brustmuskelgewicht, etc.) der End - pH - Wert signifikant absinkt. Durch eine enge Korrelation zwischen den Gewichtsparametern und den histologischen Parametern, welche die Zellgröße beschreiben, konnte belegt werden, dass das Wachstum der Muskeln über Zellvergrößerung realisiert wird. Unter Beachtung der Nachteile, die mit einem niedrigen End - pH - Wert und stark vergrößerten Muskelfasern einhergehen, wäre eine Selektion von Mastputen weg von den Gewichtsparametern in Richtung Zellvermehrung und kleinerer Muskelfasern sinnvoll, auch wenn dies möglicherweise mit höheren Scherkraftwerten einhergeht, denn die vorliegende Untersuchung hat ebenfalls eine negative Korrelation zwischen den Zelldurchmessern und den Scherkraftwerten belegt.

Außer für den Parameter „Anteil degenerierter Muskelfasern (\%)“ konnte für alle untersuchten Parameter ein Alterseinfluss nachgewiesen werden. 


\section{Summary and Results}

In literature as well as on relevant congresses, reports about faults in meat quality are increasing. For reasons, unbalanced selection on high carcass weights, better convertion of nutrients as well as higher grade of cut up are named. In addition to faults in meat quality, myopathies and sudden death during transport are encountered. These problems are summarized under the conception "Avian $\underline{\text { Stress }}$ Syndrome". The presence of Blood spots in turkey meat decreases the acceptance of the consumers, too.

In the present essay was investigated, if there are lines of turkeys existing, which can be used to avoid faults in meat quality. Therefore the mostly in Germany used turkey line BIG 6 from the breeder B.U.T. was compared in the first round of investigation with another heavy line BBB from the breeder Kelly, in the second round with the medium Line Wrolstad and the light line Super Mini from the breeder Kelly, too. The turkeys were reared and fed analogous to german mostly used fattening-procedure. In the age of 12 and 22 weeks both, half of the turkeys of every line and round were slaughtered in a conventional poultry slaughterhouse. At the slaughterhouse, the $\mathrm{pH}-$ and conductivity - values 20 min. p.m. were measured as well as carcass- and cut up - weights. 4 h p.m. the pH - and conductivity - values, brightness- and colour values, further parameters of weight as well as the number of blood spots were determined in the laboratory of the Research Centre for Animal Production and Technology in Vechta. Further on, probes for Drip loss- and grill - loss determination, for determination of the content of nutrients, for the determination of shearforce values and for histological treatment were taken.

The results can be summarized as follows:

\section{Comparison of both groups of age}

- The carcass weights of the 22 weeks old turkeys were higher, the percentage of the breast muscle was lower, then in the 12 weeks old animals.

- The older group of turkeys showed lower contents off proteine and higher fat contents in the M.pect.superfic., compared to the younger group.

- The older animals showed higher values by the values of $\mathrm{pH}$ - difference and conductivity 4 h p.m., compared to the 12 weeks old group.

- The 22 weeks old turkeys showed lower values in shear force B.U.T. more blood spots in M.pect.superfic., compared to the 12 weeks old group.

- The 22 weeks old group showed higher $L^{*}$ and $a^{*}$ - values, compared to the 12 weeks old turkeys.

- The cross-section-area of the muscle fibres of the M.pect.superfic. was bigger in the older turkeys, than in the younger group.

- There was no difference in the percentage of degenerated muscle fibres between both groups. 


\section{Round I}

- In both groups of age, the BIG 6 . turkeys higher carcass weights as well as higher percentages of breast muscle, compared to Kelly's BBB.

- In the slaughter-relevant age of 22 weeks, the BBB - turkeys showed higher differences between the $\mathrm{pH}$ - values $20 \mathrm{~min}$. p.m. and 4 h p.m. as well as higher conductivity values 4 h p.m. in M.pect.superfic., compared to the BIG 6 - turkeys.

- The M.pect.superfic. of the 22 weeks old BBB - turkeys were more bright and not so red than the BIG 6 - turkeys.

- The BIG 6 - turkeys showed higher shear force values than the BBB - turkeys.

- In spite of comparable cell diameters, the M.pect.superfic. of the BBB - turkeys showed a higher percentage of degenerated muscle fibres than the BIG 6 - turkeys.

\section{Round II}

- In both groups of age, the BIG 6 - turkeys shoed the highest carcass weights. There was no significant difference in carcass weights between the Lines Wrolstad and Super Mini.

- The percentage of the breast muscle showed no difference between the lines Wrolstad und Super Mini; in both groups of age, the BIG 6 - turkeys showed the lowest percentage of breast muscle.

- In the slaughter-relevant age of 22 weeks, the turkeys of the breeder Kelly showed the highest differences between the $\mathrm{pH}$ - values 20 min. p.m. and $4 \mathrm{~h}$ p.m. as well as the conductivity values $4 \mathrm{~h}$ p.m. in the M.pect.superfic.

- The M.pect.superfic. of the 22 weeks old BIG 6 - turkeys was darker than the one of the lines Wrolstad and Super Mini; there was no significant difference between the lines in the parameter $a^{*}$ (redness).

- In the age of 22 weeks, the BIG 6 - turkeys showed nearly the double number of blood spots, compared to the lines Wrolstad and Super Mini.

- Although the BIG 6 - turkeys showed the highest diameters in muscle fibres in M.pect.superfic., they showed a lower percentage of degenerated muscle fibres than the lines Wrolstad and Super Mini.

The present investigation shall answer the question, if there exist alternatives to the in Germany mostly used turkey line BIG 6 of the breeder B.U.T., which can be used to improve carcass- and meat quality traits. Problematic is a positive or negative judgement about parameters with a subjective character. So it can be exactly determined, that the line BIG 6 in the age of 22 weeks showed a significant darker breast meat, than the BBB - turkeys, B.U.T. this gives no answer, if the poultry industry and the consumers judge this fact positively or negatively. To these subjective parameters belong the brightness and colour values as well as the content 
of the muscle ingredients. Because in most of all parameters in slaughter-relevant age of 22 weeks the line BIG 6 of the breeder B.U.T. was either superior or at least equivalent in the comparison to the lines BBB, Wrolstad and Super Mini of the breeder Kelly, the Kelly products were no considerable alternative to better up the carcass- and meat quality traits. Indeed the BBB - turkeys showed lower shear force values, what means a higher tenderness in spite of the BIG 6 - turkeys, however, the toughness of breast meat is not a main problem in poultry meat production. The number of blood spots in M.pect.superfic. was higher in BIG 6 - turkeys, than in the comparative lines. Because this disadvantageous fact can be relativized by relating the number of blood spots onto the weight of the M.pect.superfic., there is no advantage in this parameter for the Kelly products.

The present investigation showed a lot of parameters, which influenced each other. So it could be determined, that higher weights (carcass, breast muscle, etc.) lowers the end-pH-value significantly. In cause of a high correlation-coefficient between the parameters of weight and the histological parameters of cell size it could be proved, that muscle growth was realized by cell-enlargement. Under consideration of the disadvantages, which go together with low end-pH-values and extreme enlarged muscle fibres, a selection of turkeys away from parameters of high weight and in direction to increasing numbers of muscle cells might be suggestive, even this goes together with higher shear force values, because the present investigation showed a negative correlation between the cell diameter and the shear force values.

Except the parameter \%percentage of degenerated muscle fibres" for all investigated parameters an influence of age could be proved. 


\section{Literaturverzeichnis}

AHN, D.U. ; OLSON, D.G. ; JO, C. ; CHEN, X. ; WU, C. ; LEE, J.I. ; 1998 :

Effect of muscle type, packaging and irradiation on lipid oxidation, volatile production and color in raw pork patties.

Meat Sci. 47, 27 - 39

ALVARADO, C.Z. ; SAMS, A.R. ; 2000 :

Rigor mortis development in turkey breast muscle and the effect of electrical stunning. Poultry Science 79, 1694 - 1698

ALVARADO, C.Z. ; SAMS, A.R. ; 2002 :

The role of carcass chilling rate in the development of pale, soft and exudative turkey pectoralis.

Poultry Sci. 81, 1365 - 1370

ALVARADO, C.Z. ; SAMS, A.R. ; 2004 :

Turkey carcass chilling and protein denaturation in the development of pale, soft and exudative meat. Poultry Sci. 83, 1039 - 1046

APPLE, J.K. ; DIKEMAN, M. E. ; MINTON, J.E. ; MCMURPHY, R.M. ; FEDDE, M.R. ; LEITH, D.E. ; UNRUH, J.A. ; 1995 :

Effects of restrain and isolation stress and epidural blockade on endocrine and blood metabolite status, muscle glycogen metabolism, and incidence of darkcutting longissimus dorsi of sheep.

J. Anim. Sci. 73, 2295 - 2307

ASHMORE, C.R. ; TOMPKINS, G. ; DOERR, L. ; 1972 :

Postnatal development of muscle fiber types in domestic animals.

J. Anim. Sci. 34, 37 - 41

BARBUT, S. ; 1993 :

Colour measurements for evaluating the pale, soft, exudative (PSE)

occurrence in turkey meat.

Food Res. Internat. 26, 39 - 43

BARBUT, S. ; 1997a :

Problem of pale exudative meat in broiler chickens.

Brit. Poultry Sci. 38, $355-358$

BARBUT, S. ; 1997b :

Occurrence of pale, soft, exudative meat in mature turkey hens.

Brit. Poultry Sci. 38, 74 - 77

BARBUT, S. ; 2002 :

Poultry products processing - an industry guide.

ISBN 1-58716-060-9 
BARBUT, S. ; ZHANG, L. ; MARCONE, M. ; 2005 :

Effects of pale, normal and dark chicken breast meat on microstructure, extractable proteins, and cooking of marinated fillets.

Poultry Science 84, 797 - 802

BARTON-GARDE, B.A.; BEJERHOLM, C.; 1985:

Eating quality of pork - what the Danes have found

Pig farming, 33 (12), 56-57

BATE-SMITH, E.C.; BENDALL, J.R.; 1947:

Rigor mortis and adenosine triphosphate, J. Physiol. 106, 177

BECHTEL, P.J.; 1986:

Muscle as Food. Orlando, San Diego, New York: Academic Press, Inc.

BECK, M.; 2002:

Exportpotential noch nicht ausgeschöpft

Deutsche Geflügel- und Schweinewirtschaft 40, 41 - 42

BENDALL, J.R.; 1973:

Postmortem changes in muscle. Structure and function of muscle. Bourne ed. Academic Press, New York 243 - 309.

BENDALL, J.R.; HALLUND, O.; WISMER-PEDERSEN, J.; 1963:

Postmortem changes in the muscle of landrace pigs. J.Food Sci. 28, 156

BENTLER, W.; 1972:

Über postmortale Vorgänge im Skelettmuskel, vor allem bei

Schlachtschweinen. Fleischwirtschaft 52, 1015

BENTLEY, J.S.; 1999

Meat characteristics of turkeys: A breeders perspective

$14^{\text {th }}$ European Symposium on the Quality of Poultry meat; Bologna, Italy 9 - 19

BERGMANN, M.; v. LENGERKEN, G.; SCHMIDT, S.; RICHTER, F.; 1989:

Fettsäurezusammensetzung des intramuskulären Fettes und Beziehungen zu anderen Merkmalen

Akad.Landwirtsch. Wiss. Tagung; Berlin 277, 37-42

BERK, J.; 1999:

Haltung und Management in der Putenzucht und -mast.

Arch. Geflügelk. 63, 52 - 58

BERRI, C.; WACRENIER, N.; MILLET, N.; LeBIHAN-DUVAL, E.; 2001:

Effect of selection for improved body composition on muscle and meat characteristics of broilers from experimental and commercial lines.

Poultry Sci. 80, $833-838$ 
BÖTTCHER, W.; SCHMIDT, U.; 2002:

Statistische Angaben zum Eier- und Geflügelmarkt

Jahrbuch der Geflügelwirtschaft , Verlag Eugen Ulmer, Stuttgart

BOJARSKA, U.; BATURA, J.; CIERACH, M.; 2003:

The Effect of measurement site on the evaluation of tom breast muscle colour.

Polish Jour. of Food and Nutrition Sciences. 12, 45 - 49

BOWKER, B.C.; GRANT, A.L.; SWARTZ, D.R.; GERRARD, D.E.; 2004:

Myosin heavy chain isoforms influence myofibrillar ATPase activity under simulated post-mortem $\mathrm{pH}$, calcium, and temperature conditions.

Meat Sci. 67, 139 - 147

BRANSCHEID, W.; HAHN, G.; WICKE, M.; 2004a:

Qualität von Putenfleisch - Probleme und Gegenmaßnahmen

Mitteilungsblatt BAFF 43 Nr. 163, 63 - 71

BRANSCHEID, W.; HAHN, G.; WICKE, M.; 2004b:

Qualität von Putenfleisch - Probleme und Gegenmaßnahmen

Fleischwirtschaft 11/2004, 109 - 112

BRISKEY, E.J.; KASTENSCHMIDT, L.L.; FORREST, J.C.; BEECHER, M.D.; JUGDE, M.D.; CASSENS, R.G.; HOEKSTRA, W.G.; 1966:

Biochemical aspects of post mortem changes. J.Agric. Food Chem.14, 201

BRISKEY, E.J., WISMER-PEDERSEN, J.; 1961a:

Biochemistry of pork muscle structure. 2. preliminary observations of biopsy samples versus ultimate muscle structure. J. Food Sci.26, 306

BURKE, W.H.; 1994:

Sex differences in weight on turkey embryos.

Poultry Sci. 73, $749-753$

BURKE, W.H.; SHARP, P.; 1989:

Sex differences in body weight of chicken embryos.

Poultry Sci. 68, 805 - 810

BUSCH, W.A.; STROMER, M.H.; GOLL, D.E.; SUZUKI, A.; 1972:

$\mathrm{Ca}^{2+}$-specific removal of Z-Lines from rabbit skeletal muscle.

Journal Cell. Biol. 52, 367

CASSENS, R.G.; COOPER, C.C.; BRISKEY, E.J.; 1969:

The occurrence and histochemical characterization of Giant fibres in the muscle of growing and adult animals.

Acta Neuropath. 12, $300-304$

CHANG, K.C.; COSTA, da, N.; BLACKLEY, R.; SOUTHWOOD, O.; EVANS, G.; PLASTOW, G.; WOOD, J.D.; RICHARDSON, R.I.; 2003:

Relationships of myosin heavy chain fibre types to meat quality traits in traditional and modern pigs.

Meat Sci. 64, 93 - 103 
CHIANG, W.; LINZ, J.; MAILE, M.; STRASBURG, G.; 2002:

Mutation in turkey alpha-RyR genomic DNA.

J. Anim. Sci. Vol. 80 1/J. Dairy Sci. 85 1, 129

CHIANG, W.; STRASBURG, G.M.; 2003:

Recentadvances in turkey ryanodine receptors.

$16^{\text {th }}$ European Symposium on the Quality of Poultry Meat and $10^{\text {th }}$ European

Symposium on the Quality of Eggs and Egg Products, St. Brieuc, France.

Proc. Vol. 2, 324 - 334

COOPER, C.C.; CASSENS, R.G.; BRISKEY, E.J.; 1969:

Capillary Distribution and Fiber Characteristics in Skeletal Muscle of StressSusceptible Animals.

Journal of Food Science 34, 299 - 302

DAYTON, W.R.; REVILLE, J.W.; GOLL, D.E.; STROMER, M.H.; 1976:

$\mathrm{Ca}^{2+}$-activated protease possibly involved in myofibrillar turnover. Partial characterization of the purified enzyme.

Biochemistry 15, 2159

DIP.BUNDESTAG.DE

Drucksache 16/2396 15.08.2006

DRANSFIELD, E.; SOSNICKI, A.A.; 1999:

Relationship between muscle growth and poultry meat quality.

Poultry Sci. 78, 743 - 746

DUTSON, T.R.; MERKEL, R.A.; PEARSON, A.M.;GANN, G.L.; 1978:

Structural characteristics of porcine skeletal muscle giant myofibers as observed by light and electron microscopy.

Journal of Animal Science 46, 1212 - 1220

EHINGER, F.: GSCHWINDT, B.; 1981:

Der Einfluss unterschiedlicher Transportzeiten auf die Fleischqualität und auf die physiologischen Merkmale bei Broilern verschiedener Herkunft

Arch. Geflügelk. 45, 260 - 265

ELMINOWSKA-WENDA, G.; SZPINDA, M.; KLOSOWSKA, D.; 2005:

Capillaries of pectoralis and biceps femoris muscles in turkeys.

Arch. Geflügelk. 69, 35 - 39.

FELDHAUS, L.; SIEVERDING, E.; 2001:

Putenmast

Verlag Eugen Ulmer, Stuttgart

FENNEMA, O.R.; 1990:

Comparative water holding properties of various muscle food.

J. of Muscle Food 1, $363-381$ 
FERKET, P.R.; FOEGEDING, E. A.; 1994:

How nutrition and management influence PSE in poultry meat.

Proceedings of BASF Technical Symposium, Poultry Feeding and nutrition conference, Indianapolis, 64 - 78

FERNANDEZ, X.; FORSLID, A.; TORNBERG, E.; 1994:

The effect of high post-mortem temperature on the development of pale, soft and exudative pork: Interaction with ultimate $\mathrm{pH}$.

Meat Science 37, 133 - 147

FERNANDEZ, X.; SANTE, V.; BAEZA, E.; LEBIHAN-DUVAL, E.; BERRI, C.;

REMIGNON, H.; BABILE, R.; LE POTTIER, G.; MILLET, N.;BERGE, P.;

ASTRUC, T.: 2001a:

Post mortem muscle metabolism and meat quality in three genetic types of turkey. Brit. Poultry Sci. 42, 462 - 469

FERNANDEZ, X.; SANTE, V.; BAEZA, E.; LEBIHAN-DUVAL, E.; BERRI, C.; REMIGNON, H.; BABILE, R.; LE POTTIER, G.; ASTRUC, T.: 2002:

Effects of the rate of muscle post mortem $\mathrm{pH}$ fall on the technological quality of turkey meat. Brit. Poultry Sci. 43, 245 - 252

FISCHER, C.; HONIKEL, K.O.; 1977: Ein einfacher Schnelltest zur Unterscheidung von normalem, PSE- und DFD-Fleisch beim Schwein.

Fleischwirtschaft 57, 1018

FLETCHER, D.L.; 1999:

Colour variation in commercial packaged, broiler breast fillets.

Jour. App. Poult. Res. 8, 67 - 69

FLETCHER, D.L.; 2002:

Poultry meat quality.

World's Poultry Science Journal 58, 131 - 145

FLETCHER, D.L.; QIAO, M.; SMITH, D.P.; 2000:

The relationship of raw broiler breast meat color and $\mathrm{pH}$ to cooked meat color and $\mathrm{pH}$. Poultry Sci. 79, 784 - 788

FRAQUEZA, M.J.; FERREIRA, M.F.; OUAKININ, J.S.; BARRETO, A.S.; 2001:

Evaluation of turkey meat quality at a commercial Portuguese slaughterhouse. $47^{\text {th }}$ ICoMST 2001, $168-169$

FRONING, G.W.; BABIJII, A.S.; MATHER, F.B.: 1978:

The effect of preslaughter temperature, stress, struggle and anesthetization on color and textural characteristics of turkey muscle.

Poult. Sci. 57, 630 - 633

GALOBART, J.; MORAN, E.T.; 2004:

Refrigeration and freeze-thaw effects on broiler fillets having extreme $L^{*}$-values. Poultry Sci. 83, 1433 - 1439 
GÖTZ, K.-U.; 2002:

Wie Züchter den Genusswert des Fleisches verbessern können.

Schweinezucht und Schweinemast, 4, 40 - 43

HAAS, J.S.; 2005:

Ischämische und pharmakologische Präkonditionierung von Schweineherzen im Working-Heart-Modell.

Diss. Eberhard-Karls-Universität Tübingen, 69 - 70

HAHN, G.; 2000:

Aktuelles aus der internationalen Fleischforschung - Qualität von

Geflügelfleisch.

Fleischwirtschaft 4/2000, 120 - 122

HAHN, G.; 2001:

Fleischqualität bei Puten: Einfluss der Primärqualität auf die Verarbeitung.

Lohmann Information 1/2001, 23 - 25

HAHN, G.; 2001b:

Aktuelles aus der internationalen Fleischforschung - Qualität von Geflügelfleisch.

Fleischwirtschaft 4/2001, 124 - 126

HAHN, G.; BRANSCHEID, W.; DOBROWOLSKI, A.; DÜNKEL, R.; 1998:

Handelswertbestimmung von Puten - Methoden und Anwendbarkeit

Fleischwirtschaft 78/3, $181-183$

HAHN, G.; MALENICA, M.; MÜLLER, W.-D.; TAUBERT, E.; 2001a:

Putenbrustfleisch: Postmortale Glycolyse und technologische Eigenschaften.

Mitteilungsblatt BAFF 152, 135 - 141

HAHN, G.; MALENICA, M.; MÜLLER, W.-D.; TAUBERT, E.; PETRAK, T.; 2001b:

Putenbrustfleisch: Postmortale Glycolyse und technologische Eigenschaften.

Fleischwirtschaft 10/2001, 120 - 122

HAHN, G.; MALENCIA, M.; BRANSCHEID, W.; 2002:

The relationship between $\mathrm{pH}$-decline post-mortem and biochemical and physico-chemical properties of turkey breast meat.

Arch. Geflügelkd. 66, 65

HAMM, R.; 1981:

Struktur und Funktion des Muskels.

Fleischwirtschaft 61, 1822

HAMM, R.; 1981:

Struktur und Funktion des Muskels. Beiträge zur Chemie und Physik des Fleisches. HRSG. BAFF Kulmbach. 57 
HAMM, R.; 1996:

Einfluss des $\mathrm{pH}$ - Wertes auf die Protein-Nettoladung im myofibrillären System.

Fleischwirtschaft 76(12), $1330-1335$

HONIKEL, K.O.; FISCHER, C.; 1977:

Eine Schnellmethode zur Bestimmung von PSE- und DFD-Fleisch beim

Schwein. Fleischwirtschaft 57, 1015

HONIKEL, K.O.; SCHWÄGELE, F.; 1998:

Biochemische Prozesse der Fleischbildung. Aus: Qualität von Fleisch und Fleischwaren. W. Branscheid, K.O. Honikel, G.v. Lengerken, K. Tröger.

Band 2 , Dt. Fachverlag, $593-615$

HOOF, J.V.; 1979:

Influence of ante- and peri-mortem factors on biochemical and physical characteristics of turkey breast muscle. Vet.Quart. 1, 29

HOPPELER, H.; MATHIEU, O.; KRAUER, R.; CLAASEN, H.; ARMSTRONG, R.B.; WEIBEL, E.R.; 1981:

Structure- function correlation in the respiratory system. Distribution of mitochondria and capillaries in various muscles.

Respir. Physiol. 44, 87 - 112 (aus ELMINOWSKA-WENDA et al.2005)

HOPPELER, H.; HUDLICKA, O.; 1984:

Capillary density with respect to oxidative potential of muscle fibers.

Microcirculation Clin. Exp. 3, 577 (aus ELMINOWSKA-WENDA et al.2005)

HORAK, V.; 1983:

A successive histochemical staining for succinate dehydrogenase and reversed ATPase in a single section for the skeletal muscle fiber typing. Histochemistry 78, $545-553$

HUDLICKA, O.; 1985:

Development and adaptability of microvasculature in skeletal muscle.

J. Exp. Biol. 115, 215 - 228

HUXLEY, H.E.; HANSON, J.; 1954:

Changes in the cross-striation of muscle during contraction and stretch and their structural interpretation. Nature 173, 973

IANSSEN, K.; SEHESTED, E.; 1989:

Intramuscular fat in the norwegian pig breeding program

$40^{\text {th }}$ Annual Meeting of the E. A.A.P., Dublin, 27-31

KATSARAS, K.; TETZLAFF, G.; BUDRAS, K.-D.; 1984:

Morphologische Veränderungen der Rindermuskulatur während der Reifung.

Fleischwirtschaft 64, 1252 
KETTNER, P.G.; 1976:

Zu den Begriffen Konsistenz und Textur bei Fleisch und Fleischerzeugnissen. Mitteilungsblatt der Bundesanstalt für Fleischforschung,

Kulmbach, Nr. 53, 2811-2814

KLOSOWSKA, D.; KLOSOWSKI, B.; FIEDLER, I.; WEGNER, J.; 1985:

Veränderungen in der Fasertypenverteilung und Muskelfasergröße im M. longissimus dorsi der Schweine während des Wachstums und Beziehungen zwischen histologischen Merkmalen und Schlachtkörperkriterien.

Arch. Tierz. 28, $171-180$

KLOSOWSKA, D.; PUCHAJDA, H.; ELMINOWSKA-WENDA, G.; WALASIK, K.; ROSINSKI, A.; MROCZKOWSKI, S.; 2000:

Microstructural parameters of the breast and tight muscles, carcass and meat quality in the heavy type of turkey female.

Proc. $46^{\text {th }}$ ICoMST 2000 Buenos Aires.

KRANEN, R.W.; LAMBOOY, E.; VEERKAMP, C.H.; KUPPEVELT, VAN T.H.; VEERKAMP, J.H.; 2000:

Histological characterization of haemorrhages of broiler chickens.

Poultry Sci. 79, 110 - 116

KRANEN, R.W.; VEERKAMP, C.H.; LAMBOOY, E.; KUPPEVELT, VAN T.H.; VEERKAMP, J.H.; 1998:

The Effect of thermal preslaughter stress on the susceptibility of broiler chickens differing with respect to growth rate, age at slaughter, blood parameters and ascites mortality to haemorrhages in muscles.

Poultry Sci. 77, 737 - 744

KROMPECHNER, S.; LACZKO, J.; LADANYI, P.; LASZLO, M.B.; LEVAI, G.; 1970:

Contribution to the comparative morphology, electron microscopy, enzymology and biochemistry of cardiac, red and white muscles of the hen (gallus domesticus).

Acta Biol. Acad. Sci. Hung. 21, 43 - 54

LAAK, VAN R.L.J.M.; LIU, C.-H; SMITH, M.O.; LOVEDAY, H.D.; 2000:

Characteristics of pale, soft exudative broiler breast meat.

Poultry Sci. 79, 1057 - 1061

LE BIHAN-DUVAL, E.; MILLET, N.; REMIGNON, H.; 1999:

Broiler meat quality: Effect of selection for increased carcass quality and estimates of genetic parameters.

Poultry Sci. 78, $822-826$

LEE, Y.J.; SCHÖN, L.: 1985:

Untersuchungen über die Abhängigkeit der Zartheit von Rindermuskeln. Definition, morphologische und chemische Grundlagen der Zartheit sowie Einflussfaktoren. Fleischwirtschaft 65, 1144 - 1149 
LEESON, S.; SUMMERS, J.D.; 1980:

Production and carcass characteristics of the broiler chicken.

Worlds Poultry Sci.J. 59, 786 - 798

LENGERKEN, v. G.; MAAK, S.; WICKE, M.; 2002:

Muscle metabolism and meat quality of pigs and poultry.

Veterinarija ir Zootechnika 20, 82 - 86

LIU, X.; NESTOR, K.E.; VELLEMAN, S.G.; 2004:

The influence of selection for increased Body weight and sex on pectoralis major muscle weight during the embryonic and posthatch periods.

Poultry Sci. 83, 1089 - 1092

MA, T-I.R.; ADDIS, P.B.; 1973:

The association of struggle during exsanguination to glycolysis, protein solubility and shear in turkey pectoralis muscle.

J. Food Sci. 38, 995 - 997

MAHON, M.; 1999:

Muscle abnormalities: Morphological aspects.

Poultry meat Sci. (Hrsg. Richardson/Mead), CABI Publishing Vol. 25

ISBN 0851992374; 19-64

MARTENS, H.; 1998:

Physiologie der Muskulatur und das MHS-Gen des Schweines:

Zur Diskussion um eine Eliminierung des mutierten Ryanodin-Rezeptors aus der deutschen Schweinezucht.

Arch. Tierz. Dummerstorf 41, 179 - 192

MAURO, A.;1961:

Satellite cell of skeletan muscle fibres.

Biophys. Biochem. Cytol. 9, 493 - 495

MC CURDY, M.C.; BARBUT, S.; QUINTON, M.; 1996:

Seasonal effects on PSE in young turkey breast meat.

Food Res. Int. 29, 363 - 366

MC KEE, S.R.; HARGIS, B.M.; SAMS, R.; 1998:

Pale, soft and exudative meat in turkeys treated with succinylcholine.

Poultry Sci. 77, 356 - 360

MC KEE, S.R.; SAMS, R.; 1997:

The Effect of seasonal heat stress on rigor development and incidence of pale, exudative turkey meat.

Poultry Sci. 76, 1616 - 1620

MC KEE, S.R.; SAMS, R.; 1998:

Rigor mortis development at elevated temperatures induces pale, soft and exudative turkey meat characteristics. Poultry Sci. 77, 169 - 174 
MC SHERRY, B.J.; FERGUSON, A.E.; BALLANTYNE, J.; 1945:

A dissenting aneurysm in internal haemorrhage in turkeys.

J. Americ. Vet. Med. Assoc. 124, 279 - 283

MEIERING, K.; 1995:

Prüfung der Eignung physikalisch-chemischer Meßmethoden zur Bestimmung der sensorischen Qualität von Putenbrustfleisch und Erkenntnisse über Zusammenhänge zwischen Glykolyseverlauf und Fleischqualitätsparametern. Diss.med.vet. Freie Universität Berlin

MEYER, H.; 1991:

Nicholas N88 - Eine Alternative zur B.U.T. Big 6

DGS 45, 1368 - 1370

MICHEL, G.; SALOMON, F.V.; 1977:

Quantitative Untersuchungen zum Einfluss motorischen Trainings auf die Muskelfasern und Kapillaren einiger Skelettmuskeln des Schweines.

Verh. Anat. Ges. 71, 269 - 273

MITCHELL, M.A.; SANDERCOOCK, D.A.; 1995:

Creatine kinase isoenzyme profiles in the plasma of domestic fowl (Gallus domesticus): effects of acute heat stress.

Res. Vet. Sci. 59, 30 - 34

MOLETTE, C.; RÉMIGNON, H.; BABILĖ, R.; 2002:

Differences in color are not sufficient to detect PSE turkey meat.

Arch. Geflügelk. 66, Sonderheft 2, 165

MOLETTE, C.; RÉMIGNON, H.; BABILĖ, R.; 2003a:

Early post-mortem $\mathrm{pH}$ and turkey breast meat quality.

Proc. $16^{\text {th }}$ Europ. Sympos. on Quality of Poultry Meat, St. brieuc, 48 - 53

MOLETTE, C.; RÉMIGNON, H.; BABILĖ, R.; 2003b:

Maintaining muscles at high post mortem temperature induces PSE - like meat in turkey.

Meat Sci. 63, 525 - 532

MOLETTE, C.; RÉMIGNON, H.; BABILĖ, R.; 2005:

Modification of glycolyzing Enzymes lowers meat quality of turkey.

Poultry Sci. 84, 119 - 127

MORITA, S.; CASSENS, R.G.; BRISKEY, E.J.; KAUFFMAN, R.G.; KASTENSCHMIDT, L.L.; 1970:

Localization of myoglobin in pig muscle.

Journal of Food Sci. 35, 111 - 112

MOSS, F.P.; LE BLOND, C.P.; 1971:

Satellite cells as the source of nuclei in muscles of growing rats.

Anat.Rec. 170, 421 - 462 
NANKE, K.E.; SEBRANEK, J.G.; OLSON, D.G.; 1998:

Color characteristics of irradiated vacuum-packed pork, beef and turkey. Journal of Food Sci. 63, 1001 - 1006

NAM, K.C.; AHN, D.U.; 2002:

Carbon monoxide-heme pigment is responsible fort he pink color in irradiated raw turkey breast meat.

Meat Sci. 60, 25 - 33

NIEWIAROWICZ, A.; PIKUL, J.; 1979:

$\mathrm{pH}$-Wert der Hautoberfläche vor der Schlachtung als Indikator für PSE- und DFD-Fleisch bei Broilern. Fleischwirtschaft 59, 406

OBANOR, F.; MORTON, J.D.; GEESINK, G.H.; BICKERSTAFFE, R.; 2005:

Effect of Processing on Turkey Meat Quality and Proteolysis.

Poultry Science 84, 1123 - 1128

OFFER, G.; 1991:

Modelling of the formation of pale, soft and exudative meat: Effects of chilling regime and rate and extent of glycolysis. Meat Sci. 30, 157 - 184

OFFER, G.; TRINICK, J.; 1983:

On the mechanism of water holding in meat: The swelling and shrinking of myofibrils. Meat Sci. 8, 245

OLSON, D.G.; PARRISH, F.C.; 1977:

Relationship of myofibril fragmentation index to measures of beefsteak tenderness. Jour. Food Sci. 42, 506

OLSON, D.G.; PARRISH, F.C.; DAYTON, W.R.; GOLL, D.E.; 1977:

Effect of post mortem storage and calcium activated factor on the myofibrillar proteins of bovine skeletal muscle.

Jour. Food Sci. 42117

OPALKA, J.R.; WICKE, M.; GELLERICH, F.N.; SCHMIDT, R.; ROSNER, F.; ZIERZ, S.; LENGERKEN, v.G.; 2004:

Mitochondrial function in turkey skeletal muscle-impact on meat quality.

Brit. Poultry Sci. 45, 367 - 379

OTTO, E.; WEGNER, J.; 1976:

Quantitativ-mikroskopische Untersuchungen der Muskelfaser und ihre Beziehung zum Fleischansatz beim Schwein.

Arch. Tierz. 19, $419-429$

OWENS, C.M.; HIRSCHLER, E.M.; MC KEE, S.R.; MARTINEZ-DAWSON, R.; SAMS, A.R.; 2000:

The characterization and incidence of pale, soft, exudative turkey meat in a commercial plant. Poultry Sci. 79, 553 - 558 
OWENS, C.M.; SAMS, A.R.; 1997:

Muscle metabolism and meat quality of pectoralis from turkeys treated with post mortem electrical stimulation. Poultry Sci. 76, 1047 - 1051

OWENS, C.M.; MATTHEWS, N.S.; SAMS, A.R.; 2000b:

The use of halothane gas to identify turkeys prone to developing pale, exudative meat when transported before slaughter.

Poultry Sci. 79, 789 - 795

OWENS, C.M.; SAMS, A.R.; 2000:

The Influence of transportation on turkey meat quality.

Poultry Sci. 79, 1204 - 1207

PAPINAHO, P.A.; FLETCHER, D.L.; 1995 :

Effect of stunning amperage on broiler breast muscle rigor development and meat quality. Poultry Sci. 74, 1527 . 1532

PENNY, J.F.; 1974:

The action of a muscle protease on the myofibrillar proteins of bovine muscle. Journal Sci. Food Agricult. 25, 1273

PENNY, J.F.; DRANSFIELD, E.; 1979:

Relationship between toughness and troponin-T in conditioned beef.

Meat Sci. 3, 135

PETER, J.B.; BARNARD, R.J.; EDGERTON, V.R.; GILLESPIE, C.A.;

STEMPLE, K.E.; 1972:

Metabolic profiles of three fiber types of skeletal muscle in guinea pigs and rabbits.

Biochemistry 11, $2627-2633$

PETRACCI, M.; BETTI, M.; BIANCHI, M.; CAVANI, C.; 2004:

Color variation and characterization of broiler breast meat during processing in italy. Poultry Sci. 83, 2086 - 2092

PIETRZAK, M.; GREASER, M.L.; SOSNICKI, A.A.; 1997:

Effect of rapid rigor mortis processes on protein functionality in pectoralis major muscle of domestic turkeys.

J. Anim. Sci. 75, 2106 - 2116

PINGEL, H.; JEROCH, H; 1980:

Biologische Grundlagen der industriellen Geflügelproduktion.

Gustav Fischer Verlag, Jena.

PINGEL, H.; WICKE, M.; v. LENGERKEN, G.; 1998:

Gewinnung und Qualität von Geflügelfleisch.

in: BRANSCHEID, W.; HONIKEL, K.-O.; LENGERKEN, G.v.; TROEGER, K.; (Hrsg) (1998): Qualität von Fleisch und Fleischwaren

Deutscher Fachverlag GmbH, Frankfurt a. Main, 301 - 338 
PRIESTLEY, R.I.; 1979:

Effects of heating on foodstuffs. London; App. Science publishers.

RAMMOUZ, EL, R.; BABILĖ, R.; FERNANDEZ, X.; 2004:

Effect of ultimate $\mathrm{pH}$ on the physicochemical and biochemical characteristics of turkey breast muscle showing normal rate of post-mortem $\mathrm{pH}$ fall.

Poultry Sci. 83, 1750 - 1757

RATHGEBER, B.M.; BOLES, J.A.; SHAND, P.J.; 1999:

Rapid post mortem decline and delayed chilling reduce quality of turkey breast meat. Poultry Sci. 78, 477 - 484

REDE, R.; PRIBISCH, V.; RAKELIC, S.; 1986:

Untersuchungen über die Beschaffenheit von Schlachttierkörpern und Fleisch primitiver und hochselektierter Scheinerassen.

Fleischwirtschaft 66 (5), 898 - 907

REMIGNON, H.; ZANUSSO, J.; ALBERT, G.; BABILE, R.; 2000:

Occurrence of giant myofibres according to muscle type, pre- or post-rigor state and genetic background in turkeys.

Meat Sci. 56, 337 - 343

RIEGEL, J.; ROSNER, F.; SCHMIDT, R.; SCHÜLER, L.; WICKE, M.; 2004:

Untersuchungen zur Fleischqualität am Musculus pectoralis superficialis männlicher und weiblicher Japanischer Wachteln (Coturnix Japonica).

Arch. Geflügelk. 68, 170 - 175

RISTIC, M.; 1978:

Einfluss der Transportbeschaffenheit auf die Fleischbeschaffenheit von Broilern.

Fleischwirtschaft 58, 1031- 1034

ROCK, E.; KOZAK-REISS, G.; 1987:

Effect of halothane on the $\mathrm{Ca}^{2+}$-transport system of surface membranes isolated from normal and malignant hyperthermia pig skeletal muscle.

Arch. Biochem. Biophys. 256, $703-707$

RUUSUNEN, M.; POULANNE, E.; 2004:

Histochemical properties of fibre types in muscles of wild and domestic pigs and the effect of growth rate on muscle fibre properties.

Meat Sci. 67, 533 - 539

SALOMON, F.V.; ANGER, T.; KRUG, H.; GILLE, U.; PINGEL, H.; 1990:

The growth $f$ the skeleton, body mass and muscle fiber diameter of the turkey (Meleagris gallopavo) from hatching to the 224th day.

Anatomia, histological, embryologica 19, 314 - 325

SAMS, A.R.; JANKY, D.M.; 1991:

Characterization of rigor mortis development in four broiler muscles.

Poultry Science 70, 1003 - 1009 
SANDRITTER, W.; 1971:

Histopathologie;

Schattauer Verlag Stuttgart, ISBN 3794501470, 201 - 203

SANTÉ, V.; BIELICKI, G.; RENERRE, M.; LACOURT, A.; 1991:

Post mortem evolution in the pectoralis superficialis muscle from two turkey breeds: Relationship between $\mathrm{pH}$ and colour changes.

Proc. Of $37^{\text {th }}$ int. congress of meat sci. and technol.

Kulmbach, Germany, 465 - 468

SANTE, V.; FERNANDEZ, X.F.; 2000:

The measurement of $\mathrm{pH}$ in raw and frozen turkey pectoralis superficialis muscle. Meat Sci. 55, 503 - 506

SANTÉ, V.; SOSNICKI, A.A.; GREASER, M.L.; PIETRZAK, M.; POSPIECH, E.; OUALI, O.; 1995:

Impact of turkey breeding and production on breast meat quality.

Proc. of XII European symposium on the quality of poultry meat. Zaragoza, Spain, $151-156$

SCHMIDT, R.F.; THEWS, G.; 1993:

Physiologie des Menschen; Springer Verlag 25. Auflage

ISBN 3-540-57104-3; 67-73

SCHWÖRER, J.F.; MOREL, P.; REBSAMEN, A.; 1987:

Selektion auf intramuskuläres Fett beim Schwein

Der Tierzüchter 39 (9), 392 - 394

SEBASTIÁN, I.; SANTÉ LHOUTELLIER, V.; MART'Y-MAHE, P.; LOISEL, P.; BROSSARD, D.; Le POTTIER, G.; MONIN, G.; 2003:

Characterization of turkey breast meat quality using colour image analysis. $16^{\text {th }}$ European Symposium on the quality of Poultry meat, St Brieuc

Proc. Vol. II, 341 - 346

SEVEN, A.; CIVELEK, S.; KOCAMAN, F.; KOLDAS, L.; CANDAN, G.; 1998:

Blood Laktate/pyruvate as a predictor of shock development in acute myocardial infarction.

Tr. J. of Med. Sci. 28, 67 - 69

SIELAFF, H.; 1996:

Fleischtechnologie

Behr's Verlag GmbH \& Co., Hamburg

ISBN 3-86022-188-4

SILBERNAGL, S.; DESPOPOULOS, A; 1991:

Taschenatlas der Physiologie, Thieme Verlag, 4. Auflage

ISBN 3-13-567704-0, 34 - 39 
SLOWINSKI, M.; STOLARSKI, M.; 1998:

Beurteilung der technologischen Qualität von Putenfleisch - Messung von elektrischer Leitfähigkeit und $\mathrm{pH}$ - Wert.

Fleischwirtschaft 78 (9), 1005 - 1007

SMITH, J.H.; 1963:

Relation of body size to muscle cell size and number in the chicken.

Poultry Sci. 42, 283 - 290

SOKOLOVA, L.A.; IVANOVA, T.V.; TOCHILOVA, I.I.; 1988:

Effect of overstunning on bleeding degree of broiler chicken meat.

Proc. $34^{\text {th }}$ Int. congr. of meat sci. and technol. Brisbane, Australia, $109-111$

SOLOMON, M.B.; VAN LAAK, R.L.J.M.; EASTRIDGE, J.S.; 1998:

Biophysical basis of pale, soft, exudative (PSE) pork and poultry muscle: A review. J. Muscle Foods 9, 1 - 11

SOSNICKI, A.A.; GREASER, M.L.; PIETRZAK, M.; POSPIECH; E.SANTE, V.; 1998:

PSE-like syndrome in breast muscle of domestic turkeys: A review.

J. Muscle Foods 9, 13 - 23

SOSNICKI, A.A.; WILSON, B.W.; 1991:

Pathology of turkey skeletal muscle: implications for the poultry industry.

Food Structure 10, 317 - 326

SZENIAK, A.S.; 1963:

Objective Measurements of Food Texture.

J. Food Sci. 28, $385-410$

VELLEMAN, S.G.; COY, C.S.; ANDERSON, J.W.; PATTERSON, R.A.;

NESTOR, K.E.; 2002: Effect of selection for growth rate on embryonic breast muscle development in turkeys.

Poultry Sci. 81, 1113 - 1121

VELLEMAN, S.G.; ANDERSON, J.W.; COY, C.S.; NESTOR, K.E.; 2003 a:

Effect of selection for growth rate on muscle damage during turkey breast muscle development.

Poultry Sci. 82, 1069 - 1074

VELLEMAN, S.G.; COY, C.S.; ANDERSON, J.W.; PATTERSON, R.A.;

NESTOR, K.E.; 2003 b:

Effect of selection for growth rate and inheritance on posthatch muscle development in turkeys.

Poultry Sci. 82, 1365 - 1372

VELLEMAN, S.G.; NESTOR, K.E.; 2003:

Effect of selection for growth rate on myosin heavy chain temporal and spatial localization during turkey breast muscle development.

Poultry Sci. 82, 1373 - 1377 
VELLEMAN, S.G.; NESTOR, K.E.; 2004:

Inheritance of breast muscle morphology in turkeys at sixteen weeks of age.

Poultry Sci 83, 1060 - 1066

VOET, D.; VOET, J.G.; 1992:

Biochemie, ISBN 3-527-28242-4,

WABECK, C.J.; 1974:

Pectoralis major differences for tenderness between male broilers reared in cages and in floor pens

Poultr Sci. 53, 1623 - 1624

WAKEFIELD, D.K.; DRANSFIELD, E.; DOWN, N.F.; TAYLOR, A.A.; 1989:

Influence of post mortem treatments on turkey and chicken meat texture.

Int. Journal of Food Sci. Technol. 24, 81 - 92

WERLEIN, H.-D.; WATKINSON, B.M.; 1998:

Standardisierte Texturmessung - Kompressions- und Scherkraftmessung an gegartem Schweine- und Putenfleisch.

Fleischwirtschaft 78 (10), 1085 - 1088

WHEELER, B.R.; MCKEE, S.R.; MATTHEWS, N.S.; MILLER, R.K.;

SAMS, A.R.; 1999:

A halothane test to detect turkeys prone to developing pale, soft and exudative meat. Poultry Sci. 78, 1634 - 1638

WICKE, M.; OPALKA, J.R.; GELLERICH, F.N.; ZIERZ, S.:

LENGERKEN, von G.; 2000a:

Influence of mitochondrial function on growth and meat quality in turkey.

Proc. $46^{\text {th }}$ ICOMST 1, $110-111$

WICKE, M.; HAHN, G.; MAAK, S.; LENGERKEN, G. von; 2000b:

Physiologische Grenzen des Wachstums bei Schweinen und Geflügel - auch ein Problem nachhaltiger Fleischerzeugung.

Kulmbacher Reihe 17, 70 - 88

WICKE, M.; HAHN, G.; MAAK, S.; LENGERKEN, G. von; 2001:

Nachhaltigkeit in der Fleischerzeugung - Der Aspekt physiologischer Wachstumsgrenzen bei Schweinen und Geflügel.

Fleischwirtschaft 9/2001, 125 - 128

WILSON, B.W.; NIEBERG, P.S.; BUHR, R.J.; KELLY, B.J.; SHULTZ, F.T.;1990:

Turkey muscle growth and focal myopathy.

Poultry Sci. 69, 1553 - 1562

WILKINS, L.J.; BROWN, S.N.; PHILLIPS, A.J.; WARRIS, P.D.; 2000:

Variation in the colour of broiler breast fillets in the UK.

Brit. Poultry Sci. 41, $308-312$ 
WINDHORST, H.-W.; 2001:

Putenproduktion - Sektorale und regionale Strukturen eines wachsenden Marktes.

Tier und Ernährung 2, Roché Vitamine GmbH, Grenzach - Wyhlen

WISKUS, K.J.; ADDIS, P.B.; MA, R.T-I.; 1976:

Distribution of $\beta \mathrm{R}, \alpha \mathrm{R}, \alpha \mathrm{W}$ fibers in turkey muscle.

Poultry Sci. 55, 562 - 572

WOELFEL, R.L.; SAMS, A.R.; 2001:

Marination performance of pale broiler breast meat

Poultry Sci. 80, 1519 - 1522

WOELFEL, R.L.; OWENS, C.M.; HIRSCHLER, E.M.; MARTINEZ-DAWSON, R.; SAMS, A.R.; 2002:

The characterization and incidence of pale, soft and exudative broiler meat in a commercial processing plant. Poultry Sci. 81, 579 - 584

WOJCIK, A.; SOWINSKA, J.; IWANCZUK-CZERNIK, K.; MITUNIEWICZ, T.; 2004: The effect of a housing system in slaughter turkeys on mechanical damage to carcass and meat quality.

Czech. J. Anim. Sci. 49, 80 - 85

WWW.KELLY-TURKEYS.COM

WYNVEEN, E.J.; BOWKER, B.C.; GRANT, A.L.; DEMOS, B.P.; GERRARD, D.E.; 1999:

Effects of muscle $\mathrm{pH}$ and chilling on development of PSE-like turkey breast meat. British Poultry Sci. 40, 253 - 256

YABLONKA-REUVENI, Z.; 1995:

Development and postnatal regulation of adult myoblasts.

Microsc. Res. Technol. 30, 366 - 380

YELLIN, H.; GUTH, L.; 1970:

The histochemical classification of muscle fibres.

Exp. Neurol. 26, 424 - 432

YOST, J.K.; KENNEY, P.B.; SLIDER, S.D.; RUSSEL, R.W. KILLEFER, J.; 2002: Influence of selection for breast muscle mass on myosin isoform composition and metabolism of deep pectoralis muscles of male and female turkeys.

Poultry Sci. 81, 911 - 917

ZHANG, L.; BARBUT, S.; 2005:

Effects of regular and modified starches on cooked pale, soft and exudative; normal; and dry, firm and dark breast meat batters.

Poultry Science 84, $789-796$ 
ZMP; 2002:

ZMP - Marktbilanz Eier und Geflügel 2002

Bonn: Zentrale Markt- und Preisberichtstelle ISBN-3-935898-07-X 


\section{Danksagung}

Mein herzlicher Dank gilt Herrn Prof. Dr. M. Wicke für die Überlassung des Themas und die Anregungen bei der Anfertigung der vorliegenden Arbeit sowie Herrn Prof. Dr. M. Gauly für die Übernahme des Korreferats.

Der Firma Heidemark und hier insbesondere Herrn Dr. P. Behr und allen Beteiligten des Schlachthofpersonals für die Hilfestellung bei der Gewinnung des Probenmaterials.

Der Familie Niemann in Emstek/Höltinghausen für die liebevolle Betreuung der Puten.

Weiterhin möchte ich mich ganz besonders bei den Mitarbeitern des Forschungsund Studienzentrums Weser/Ems in Vechta bedanken. Die Laborkräfte unter der Leitung von Herrn Vehlow, die wiss. Mitarbeiter sowie die in der Verwaltung arbeitenden Kräfte haben erheblich zum Gelingen der vorliegenden Arbeit sowie weiterer Veröffentlichungen beigetragen. 